\title{
Developmental changes in the pulmonary circulation: role of the nitric oxide/ soluble guanylate cyclase/cyclic GMP and the isoprostane pathways
}

Citation for published version (APA):

González-Luis, G. E. (2011). Developmental changes in the pulmonary circulation: role of the nitric oxide/ soluble guanylate cyclase/cyclic GMP and the isoprostane pathways. [Doctoral Thesis, Maastricht University]. Maastricht University. https://doi.org/10.26481/dis.20111021gg

Document status and date:

Published: 01/01/2011

DOI:

10.26481/dis.20111021gg

Document Version:

Publisher's PDF, also known as Version of record

Please check the document version of this publication:

- A submitted manuscript is the version of the article upon submission and before peer-review. There can be important differences between the submitted version and the official published version of record.

People interested in the research are advised to contact the author for the final version of the publication, or visit the DOI to the publisher's website.

- The final author version and the galley proof are versions of the publication after peer review.

- The final published version features the final layout of the paper including the volume, issue and page numbers.

Link to publication

\footnotetext{
General rights rights.

- You may freely distribute the URL identifying the publication in the public portal. please follow below link for the End User Agreement:

www.umlib.nl/taverne-license

Take down policy

If you believe that this document breaches copyright please contact us at:

repository@maastrichtuniversity.nl

providing details and we will investigate your claim.
}

Copyright and moral rights for the publications made accessible in the public portal are retained by the authors and/or other copyright owners and it is a condition of accessing publications that users recognise and abide by the legal requirements associated with these

- Users may download and print one copy of any publication from the public portal for the purpose of private study or research.

- You may not further distribute the material or use it for any profit-making activity or commercial gain

If the publication is distributed under the terms of Article $25 \mathrm{fa}$ of the Dutch Copyright Act, indicated by the "Taverne" license above, 


\section{Developmental changes in the pulmonary circulation: Role of the nitric oxide/ soluble guanylate cyclase/cyclic GMP and the isoprostane pathways}

Gema Esther González-Luis 
ISBN/EAN: 


\section{Developmental changes in the pulmonary circulation: Role of the nitric oxide/ soluble guanylate cyclase/cyclic GMP and the isoprostane pathways}

\section{PROEFSCHRIFT}

ter verkrijging van de graad van doctor aan de Universiteit Maastricht, op gezag van de Rector Magnificus prof. Mr. G.P.M.F. Mols volgens het besluit van het College van Decanen, in het openbaar te verdedigen op vrijdag 21 oktober 2011 om 12:00 uur

door

Gema Esther González-Luis

Geboren op 10 juli 1972

te Los Realejos (Santa Cruz de Tenerife), Spanje 


\section{Promotores}

Prof. dr. C.E. Blanco

Prof. dr. Francisco Perez-Vizcaino (Universidad Complutense de Madrid, Spain)

\section{Co-promotor}

Dr. E. Villamor

\section{Beoordelingscommissie}

Prof. dr. L. J. I. Zimmermann (voorzitter)

Prof. dr. S.H. Abman (University of Colorado)

Prof. dr. J. Vazquez-Jimenez (Universitätsklinikum Aachen)

Prof. dr H.A.J. Struijker-Boudier

Dr. E. Rubio-Gozalbo 


\section{Contents}

Justification, aim and outline of the Thesis........................................... 3

Part I

Chapter I: The NO/ sGC/cGMP/ pathway.

Chapter II: Soluble guanylyl cyclase during postnatal porcine pulmonary maturation. Am J Physiol Lung Cell Mol Physiol 2005; 288:L125-30

Chapter III: Relaxant effects of the soluble guanylate cyclase activator and NO sensitizer YC-1 in piglet pulmonary arteries. Biol Neonate 2006; 90:66-72......

Chapter IV: Nitric oxide-mediated nonadrenergic noncholinergic relaxation of piglet pulmonary arteries decreases with postnatal age.

$J$ Physiol Pharmacol 2007; 58:45-56.

Part II

Chapter V: Isoprostanes in fetal and neonatal health and disease. Free Radic Biol Med 2010;48:177-88.

Chapter VI: Age-related differences in vasoconstrictor responses to isoprostanes in piglet pulmonary and mesenteric vascular smooth muscle. Pediatr Res 2005; 57:84552

63

Chapter VII: Age-related changes in isoprostane-mediated relaxation of piglet vessels. Front Biosci 2010; E2:369-379.

\section{Appendixes}

1. Abbreviations

2. Samenvatting.

3. Acknowledgements

4. Curriculum vitae. 


\section{Justification, aim and outline of the Thesis}

The fetal circulation is characterized by high pulmonary vascular resistance (PVR), low systemic vascular resistance (SVR), presence of an additional low resistance vascular bed (i.e. the placental bed), and right-to-left shunting via the foramen ovale and ductus arteriosus (DA). Distribution of blood flow to the lungs, systemic organs and placenta is determined by local vascular resistance. The placental vascular bed receives about 40-50 per cent of the combined ventricular output whereas the lungs receive less than 10 per cent and the rest is diverted through the foramen ovale and the DA to the systemic circulation $(1,15,34,39,52)$. At birth, as the lung assumes the respiratory function, the pulmonary circulation undergoes a striking transition characterized by an immediate 8- to 10-fold rise in pulmonary blood flow and a sustained decrease in PVR $(1,6,11)$. Therefore, successful adaptation of the newborn to postnatal conditions requires a dramatic transition of the pulmonary circulation from a high resistance state in utero to a low-resistance state within minutes after birth.

Several mechanisms contribute to the normal fall in PVR at birth, including the establishment of a gas-liquid interface in the lung, increased oxygen tension, rhythmic distension of the lung and shear stress $(1,4,6,9,14,45)$. These physical stimuli lead to a cascade of events which facilitate the activation of vasodilator responses and reduce vasoconstrictor stimuli from the vascular endothelium that synthesizes and/or extracts many vasoactive mediators. These include nitric oxide (NO), prostacyclin $\left(\mathrm{PGI}_{2}\right)$, endothelin-1 (ET-1), catecholamines, angiotensin-1 or thromboxane $\mathrm{A}_{2}\left(\mathrm{TXA}_{2}\right)$ $(1,4,6,17,50,52)$. Normally, pulmonary arterial pressure falls to the half of the systemic pressure by $24 \mathrm{~h}$ and then progressively decreases to adult levels within 2-6 weeks $(19,50)$. This process is accompanied by a decrease in the pulmonary arterial wall thickness and a reorganization of the cytoskeleton of both the endothelial and the smooth muscle cells (19). Therefore, the process of pulmonary circulatory transition is not limited to the first hours of extrauterine life, but gradually matures during the following weeks (17-19).

Failure of the pulmonary circulation to undergo or to maintain a normal transition results in persistent pulmonary hypertension of the newborn (PPHN), a clinical syndrome of various neonatal cardiopulmonary disorders which are characterized by sustained elevation of PVR after birth, leading to right-to-left shunting of blood across the ductus arteriosus or foramen ovale and severe hypoxemia (25). Mechanisms that cause PPHN can include abnormalities of pulmonary vascular tone, reactivity, growth, and structure $(1,6,50,52)$ but the nature of the underlying defects is uncertain, not surprising when the mechanisms responsible for achieving a normal fall in PVR at birth are still poorly understood (50). 
Throughout fetal and neonatal life, the response to various vasoactive stimuli is probably dependent on the state of structural development of the pulmonary circulation and perhaps more specifically on the state of structural and functional maturation of specific receptors. In addition, different vasoactive mechanisms mature at different rates and have different vulnerabilities to insults, such as hypoxia (50). Over the past several years, numerous studies focussed on developmental changes in pulmonary vascular reactivity from several mammalian species by comparing fetal, neonatal and adult vessels. Maturational differences in vasoconstriction and endothelium-dependent and -independent relaxation have been described several species including lambs $(4,6,24,46)$, pigs $(9,26,36,48,49)$, rabbits $(31,32)$ and guinea pigs $(7,44)$. These, and numerous other investigations, profusely studied the role in the perinatal period of several vasoactive regulators including $\mathrm{NO}(3,4,24,32$, $36,41,42,47-49)$, eicosanoids $(5,12,22,40)$, endothelin-1 $(13,46)$, atrial natriuretic peptide $(28,37)$, $\mathrm{K}^{+}$-channels $(38)$, purines $(29,30)$, myogenic response (7) , carbon monoxide $(16,49)$, 5-hydrotryptamine (31), bradykinin (10), phosphodiesterases (33, $35)$, adrenomedullin $(27,43)$ calcitonin gene-related peptide (20), Platelet-activating factor $(21,23,51)$, vasoactive intestinal peptide $(20)$, protein kinase $\mathrm{C}(8,12)$ and phosphatases (8). However, despite the relevance of these investigations, our understanding of normal adaptation to extrauterine life and early postnatal development is still so deficient that it is difficult to identify the early crucial factors which instigate the cascade of abnormal structural and functional changes which manifest themselves clinically as pulmonary hypertension.

The control of pulmonary circulation tone involves a large number of factors acting through a wide variety of signalling pathways and it is not possible to cover all of them in one investigation. Therefore, the main purpose of this Thesis is to provide insight into two pathways (NO/cGMP/sGC and isoprostane pathways) and to analyze the developmental changes that they undergo during the first days of postnatal life in pulmonary and systemic vessels. These changes were analyzed in blood vessels from newborn and 2-week-old piglets. 


\section{Outline of the Thesis}

\section{PART I: the NO/cyclic GMP (cGMP)/soluble guanylate cyclase (sGC) pathway}

Chapter I is a brief review of the mechanisms underlying NO/sGC/cGMP-mediated relaxation.

In chapter II (Am J Physiol Lung Cell Mol Physiol. 2005; 288:L125-30), the changes in function and expression of $\mathrm{sGC}$ in pulmonary arteries during early postnatal maturation are investigated.

In chapter III (Biol Neonate. 2006; 90:66-72), the effects of the NO-independent and heme-dependent sGC activator and NO sensitizer YC-1 in neonatal pulmonary arteries are analyzed.

In chapter IV ( $J$ Physiol Pharmacol. 2007; 58:45-56), the postnatal changes that undergoes NO-mediated nonadrenergic noncholinergic relaxation in pulmonary and systemic arteries are investigated.

\section{PART II. The isoprostane pathway}

-In chapter V (Free Radic Biol Med. 2010; 48:177-88), the biochemical pathways involved in isoprostane formation, the biological function of isoprostanes and their pathogenetic relevance in disease states are reviewed. We specifically focus on isoprostanes (IsoPs) as markers of oxidative stress during gestation and the perinatal period. In addition, the limited available data relative to the involvement of isoprostanes on the developmental-dependent regulation of pulmonary and systemic vascular resistance and their associated clinical implications are reviewed.

Chapter VI (Pediatr Res. 2005; 57:845-52) is a study of the effects of several E-ring (8-iso-PGE ${ }_{1}$ and 8-iso-PGE ${ }_{2}$ ) and F-ring (8-iso-PGF $1 \alpha, 8$-iso-PGF - $_{1 \beta}, 8$-iso-PGF ${ }_{2 \alpha}, 8$-iso$\mathrm{PGF}_{2 \beta}$ ) isoprostanes on contractile activity in isolated pulmonary arteries, pulmonary veins and mesenteric arteries during the first days of postnatal life.

Chapter VII (Front Biosci. 2010; E2:369-379) focus on the putative relaxant effects of several isoprostanes (8-iso-PGE ${ }_{1}$, and 8-iso-PGE 2 , 8-iso- $\mathrm{PGF}_{1 \mathrm{a}}, 8$-iso-PGF ${ }_{1 \beta}$, 8-iso$\mathrm{PGF}_{2}$ a, and 8-iso-PGF $\mathrm{PG}_{2 \beta}$ ) in pulmonary, mesenteric, coronary arteries and pulmonary veins during the first days of postnatal life. 
Finally, in Part III, a general discussion of the Thesis is outlined.

\section{References}

1. Abman SH. Abnormal vasoreactivity in the pathophysiology of persistent pulmonary hypertension of the newborn. Pediatr Rev 20: e103-109, 1999.

2. Abman SH. Recent advances in the pathogenesis and treatment of persistent pulmonary hypertension of the newborn. Neonatology 91: 283-290, 2007.

3. Abman SH, Chatfield BA, Hall SL, and McMurtry IF. Role of endothelium-derived relaxing factor during transition of pulmonary circulation at birth. Am J Physiol 259: H19211927, 1990.

4. Abman SH, Chatfield BA, Rodman DM, Hall SL, and McMurtry IF. Maturational changes in endothelium-derived relaxing factor activity of ovine pulmonary arteries in vitro. $A m$ $J$ Physiol 260: L280-285, 1991.

5. Abman SH and Stenmark KR. Changes in lung eicosanoid content during normal and abnormal transition in perinatal lambs. Am J Physiol 262: L214-222, 1992.

6. Abman SH and Stevens T. Perinatal pulmonary vasoregulation: implications for the pathophysiology and treatment of neonatal pulmonary hypertension. In: Tissue Oxygen Deprivation: Developmental, Molecular and Integrative Function, edited by Haddad G and Lister G. New York: Marcel Dekker, 1996, p. 367-432.

7. Belik J. Myogenic response in large pulmonary arteries and its ontogenesis. Pediatr Res 36: 34-40, 1994.

8. Berkenbosch JW, Baribeau J, Ferretti E, and Perreault T. Role of protein kinase C and phosphatases in the pulmonary vasculature of neonatal piglets. Crit Care Med 29: 12291233, 2001.

9. Blanco CE, Martin CB, Rankin J, Landauer M, and Phernetton T. Changes in fetal organ flow during intrauterine mechanical ventilation with or without oxygen. J Dev Physiol 10: 53-62, 1988.

10. Boels PJ, Deutsch J, Gao B, and Haworth SG. Maturation of the response to bradykinin in resistance and conduit pulmonary arteries. Cardiovasc Res 44: 416-428, 1999.

11. Cassin S, Dawes GS, Mott JC, Ross BB, and Strang LB. The Vascular Resistance of the Foetal and Newly Ventilated Lung of the Lamb. J Physiol 171: 61-79, 1964.

12. Cogolludo A, Moreno L, Lodi F, Tamargo J, and Perez-Vizcaino F. Postnatal maturational shift from PKCzeta and voltage-gated $\mathrm{K}^{+}$channels to RhoA/Rho kinase in pulmonary vasoconstriction. Cardiovasc Res 66: 84-93, 2005.

13. Docherty $\mathbf{C}$ and MacLean MR. Development of endothelin receptors in perinatal rabbit pulmonary resistance arteries. Brit $J$ Pharmacol 124: 1165-1174, 1998.

14. Enhorning G, Adams FH, and Norman A. Effect of lung expansion on the fetal lamb circulation. Acta Paediatr Scand 55: 441-451, 1966.

15. Fineman JR, Soifer SJ, and Heymann MA. Regulation of pulmonary vascular tone in the perinatal period. Annu Rev Physiol 57: 115-134, 1995.

16. Grover TR, Rairigh RL, Zenge JP, Abman SH, and Kinsella JP. Inhaled carbon monoxide does not cause pulmonary vasodilation in the late-gestation fetal lamb. Am J Physiol Lung Cell Mol Physiol 278: L779-784, 2000.

17. Haworth SG. Pulmonary endothelium in the perinatal period. Pharmacol Rep 58 Suppl: 153-164, 2006.

18. Haworth SG and Hislop AA. Adaptation of the pulmonary circulation to extra-uterine life in the pig and its relevance to the human infant. Cardiovasc Res 15: 108-119, 1981.

19. Haworth SG and Hislop AA. Lung development-the effects of chronic hypoxia. Semin Neonatol 8: 1-8, 2003.

20. Hislop AA, Boels PJ, Deutsch J, Polak JM, and Haworth SG. Developmental changes in binding sites and reactivity for CGRP and VIP in porcine pulmonary arteries. Peptides 19: 703-714, 1998.

21. Ibe BO, Ameer A, Portugal AM, Renteria L, and Raj JU. Platelet-activating factor modulates activity of cyclic nucleotides in fetal ovine pulmonary vascular smooth muscle. $J$ Pharmacol Exp Ther 320: 728-737, 2007.

22. Ibe BO, Anderson JM, and Raj JU. Leukotriene synthesis by isolated perinatal ovine intrapulmonary vessels correlates with age-related changes in 5-lipoxygenase protein. Biochem Mol Med 61: 63-71, 1997.

23. Ibe BO, Hibler S, and Raj JU. Platelet-activating factor modulates pulmonary vasomotor tone in the perinatal lamb. J Appl Physiol 85: 1079-1085, 1998.

24. Kolber KA, Gao Y, and Raj JU. Maturational changes in endothelium-derived nitric oxide-mediated relaxation of ovine pulmonary arteries. Biol Neonate 77: 123-130, 2000. 
25. Levin DL, Heymann MA, Kitterman JA, Gregory GA, Phibbs RH, and Rudolph AM. Persistent pulmonary hypertension of the newborn infant. J Pediatr 89: 626-630, 1976.

26. Levy M, Tulloh RM, Komai H, Stuart-Smith K, and Haworth SG. Maturation of the contractile response and its endothelial modulation in newborn porcine intrapulmonary arteries. Pediatr Res 38: 25-29, 1995.

27. Marinoni E, Di Iorio $\mathbf{R}$, Alo $\mathbf{P}$, Villaccio $\mathbf{B}$, Alberini A, and Cosmi EV. Immunohistochemical localization of adrenomedullin in fetal and neonatal lung. Pediatr Res 45: 282-285, 1999.

28. Matsushita T, Hislop AA, Boels PJ, Deutsch J, and Haworth SG. Changes in ANP responsiveness of normal and hypertensive porcine intrapulmonary arteries during maturation. Pediatr Res 46: 411-418, 1999.

29. McMillan MR, Burnstock G, and Haworth SG. Vasoconstriction of intrapulmonary arteries to P2-receptor nucleotides in normal and pulmonary hypertensive newborn piglets. Brit J Pharmacol 128: 549-555, 1999.

30. McMillan MR, Burnstock G, and Haworth SG. Vasodilatation of intrapulmonary arteries to P2-receptor nucleotides in normal and pulmonary hypertensive newborn piglets. Brit $J$ Pharmacol 128: 543-548, 1999.

31. Morecroft I and MacLean MR. 5-hydroxytryptamine receptors mediating vasoconstriction and vasodilation in perinatal and adult rabbit small pulmonary arteries. Brit $J$ Pharmacol 125: 69-78, 1998.

32. Morecroft I and MacLean MR. Developmental changes in endothelium-dependent vasodilation and the influence of superoxide anions in perinatal rabbit pulmonary arteries. Brit J Pharmacol 125: 1585-1593, 1998.

33. Moreno L, Losada B, Cogolludo A, Lodi F, Lugnier C, Villamor E, Moro M, Tamargo $\mathbf{J}$, and Perez-Vizcaino F. Postnatal maturation of phosphodiesterase 5 (PDE5) in piglet pulmonary arteries: activity, expression, effects of PDE5 inhibitors, and role of the nitric oxide/cyclic GMP pathway. Pediatr Res 56: 563-570, 2004.

34. Noori S, Friedlich PS, and Seri I. Pathophysiology of Shock in the Fetus and Neonate. In: Fetal and Neonatal Physiology, edited by Polin RA, Fox WW and Abman SH. Philadelphia: Saunders, 2004, p. 772-781.

35. Okogbule-Wonodi AC, Ibe BO, Yue BW, Hsu S, and Raj JU. Phosphodiesterase activity in intrapulmonary arteries and veins of perinatal lambs. Mol Genet Metab 65: 229-237, 1998.

36. Perez-Vizcaino F, Lopez-Lopez JG, Santiago R, Cogolludo A, Zaragoza-Arnaez F, Moreno L, Alonso MJ, Salaices $\mathbf{M}$, and Tamargo J. Postnatal maturation in nitric oxideinduced pulmonary artery relaxation involving cyclooxygenase-1 activity. Am J Physiol Lung Cell Mol Physiol 283: L839-848, 2002.

37. Perreault T, Baribeau J, and Gutkowska J. ANF system in the newborn piglet pulmonary vessels. J Cardiovasc Pharmacol 29: 740-746, 1997.

38. Reeve HL, Weir EK, Archer SL, and Cornfield DN. A maturational shift in pulmonary $\mathrm{K}+$ channels, from Ca2+ sensitive to voltage dependent. Am J Physiol 275: L1019-1025, 1998.

39. Reuss ML and Rudolph AM. Distribution and recirculation of umbilical and systemic venous blood flow in fetal lambs during hypoxia. J Dev Physiol 2: 71-84, 1980.

40. Shaul PW, Farrar MA, and Magness RR. Oxygen modulation of pulmonary arterial prostacyclin synthesis is developmentally regulated. Am J Physiol 265: H621-628, 1993.

41. Shaul PW, Farrar MA, and Magness RR. Pulmonary endothelial nitric oxide production is developmentally regulated in the fetus and newborn. Am J Physiol 265: H1056-1063, 1993.

42. Steinhorn RH, Morin FC, 3rd, Gugino SF, Giese EC, and Russell JA. Developmental differences in endothelium-dependent responses in isolated ovine pulmonary arteries and veins. Am J Physiol 264: H2162-2167, 1993.

43. Takahashi Y, de Vroomen M, Gournay V, Roman C, Rudolph AM, and Heymann MA. Mechanisms of adrenomedullin-induced increase of pulmonary blood flow in fetal sheep. Pediatr Res 45: 276-281, 1999.

44. Thompson $\mathbf{L P}$ and Weiner CP. Endothelium-derived relaxing factor inhibits norepinephrine contraction of fetal guinea pig arteries. Am J Physiol 264: H1139-1145, 1993.

45. Tiktinsky MH and Morin FC, 3rd. Increasing oxygen tension dilates fetal pulmonary circulation via endothelium-derived relaxing factor. Am J Physiol 265: H376-380, 1993.

46. Toga H, Ibe BO, and Raj JU. In vitro responses of ovine intrapulmonary arteries and veins to endothelin-1. Am J Physiol 263: L15-21, 1992.

47. Villamor E, Degraeuwe PL, De Mey JG, and Blanco CE. Vascular reactivity of pulmonary arteries from premature lambs subjected to liquid ventilation. Biol Neonate 84: 172$178,2003$.

48. Villamor E, Kessels CG, Fischer MA, Bast A, de Mey JG, and Blanco CE. Role of superoxide anion on basal and stimulated nitric oxide activity in neonatal piglet pulmonary vessels. Pediatr Res 54: 372-381, 2003. 
49. Villamor E, Perez-Vizcaino F, Cogolludo AL, Conde-Oviedo J, Zaragoza-Arnaez F, Lopez-Lopez JG, and Tamargo J. Relaxant effects of carbon monoxide compared with nitric oxide in pulmonary and systemic vessels of newborn piglets. Pediatr Res 48: 546-553, 2000.

50. Wojciak-Stothard B and Haworth SG. Perinatal changes in pulmonary vascular endothelial function. Pharmacol Therapeut 109: 78-91, 2006.

51. Zhou W, Ibe BO, and Raj JU. Platelet-activating factor induces ovine fetal pulmonary venous smooth muscle cell proliferation: role of epidermal growth factor receptor transactivation. Am J Physiol 292: H2773-2781, 2007.

52. Ziegler JW, Ivy DD, Kinsella JP, and Abman SH. The role of nitric oxide, endothelin, and prostaglandins in the transition of the pulmonary circulation. Clin Perinatol 22: 387-403, 1995. 


\section{Chapter I: The NO/ sGC/ cGMP/ pathway}

\section{Nitric oxide}

Possibly, the most momentous change that has occurred in the field of vascular biology in the past 50 years has been the discovery and elucidation of the endocrine/paracrine roles of the endothelium (5). In simple, but elegant experiments, Furchgott and Zawadzki (17) found that relaxation with muscarinic agonists in precontracted vessels was only possible if endothelial cells were present. Several endothelium-derived relaxing and contracting factors have been found, including NO, PGs, TXA 2 , ET-1, CO and endothelium-derived hyperpolarizing factors (EHDF) $(8,11)$. Therefore, it is now widely recognized that the endothelium is not merely a passive, blood-compatible surface but plays a primary role in the local modulation of vascular function and structure.

NO is endogenously synthesized from L-arginine by a family of enzymes called NO synthases (NOS). Three NOS isoforms have been identified sharing a 50-60\% homology: two constitutive, the neuronal (nNOS, type I) and endothelial (eNOS, type III) enzymes, and one inducible (iNOS, type II) $(29,30)$. Now it is appreciated that eNOS is found in other cells and tissues besides the endothelium, iNOS is found constitutively in some tissues, and there are inducible forms of both eNOS and nNOS. The three NOS isoforms have an amino-terminal heme- and arginine-binding domain, a central calmodulin-binding region, and a carboxyl-terminal reductase domain, with an NADPH-binding site (15). Under physiological conditions, NO produced by eNOS is released from endothelial cells in response to shear stress and vasoactive factors (acetylcholine, bradykinin, catecholamines, angiotensin-II and ET-1) and diffuses into adjacent vascular smooth muscle cells (VSMC) to induce relaxation $(15,29,30)$ In addition, a large body of evidence indicates that NO generated by nNOS is involved in nonadrenergic and noncholinergic (NANC) vascular relaxation $(18,26,27,33,34)$. 


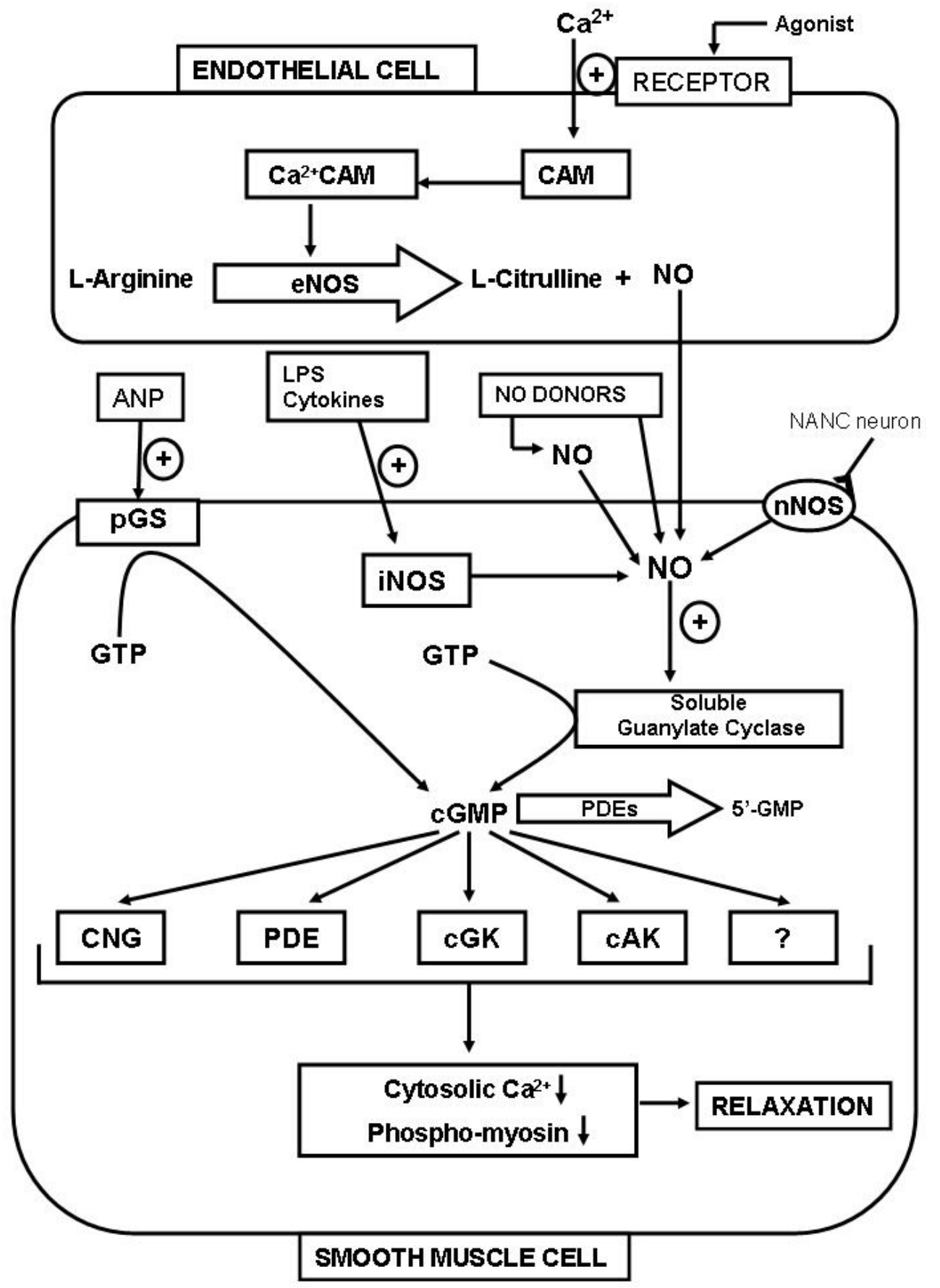

Figure 1. Diagram illustrating the mechanisms of production and action of NO in blood vessels. 
The functional eNOS protein is a dimer that is localized to the Golgi apparatus and plasma membrane caveolae $(15,16,25)$. In the inactive or basal state, the protein in caveolae is coupled to Cav-1, which decreases its activity. Moreover, eNOS is constitutively phosphorylated by PKC on Thr495 which prevents its association with calmodulin $(15,16)$. In response to cell stimulation eNOS and Cav-1 disassociate (probably assisted by dynamin), Thr495 is dephosphorylated allowing calmodulin to bind to and activate the enzyme and activating serine sites (e.g., Ser1177) are phosphorylated $(15,16)$. The interaction between the heat shock protein 90 (HSP90) and eNOS also enhances the activation of the enzyme $(9,15,16,28)$. This complex process controls the NADPH-dependent electron flux from the reductase to the oxygenase domain, where NO synthesis occurs. Reduced availability of the substrate L-arginine, or the cofactor tetrahydrobiopterin $\left(\mathrm{BH}_{4}\right)$, as well as changes in the regulatory proteins, can uncouple the electron transfer reactions and result in the production of superoxide instead of NO. The eNOS is then said to be uncoupled $(9,15$, $22,23,32,41)$.

\section{Soluble guanylate cyclase}

Guanine nucleotidyl (guanylyl; guanylate) cyclases (GC) are widely distributed signaltransduction enzymes that, in response to various cellular stimuli, convert GTP into the second messenger cyclic GMP (14). In contrast to the transmembrane particulate GC, which serves as a receptor for atrial, B-type and C-type natriuretic peptides, sGCs are receptors for gaseous ligands, namely NO and carbon monoxide (CO).

Soluble GC is typically found as a heterodimer, consisting of a larger a-subunit and a smaller haem-binding $\beta$-subunit. The prosthetic haem moiety of sGC can exist in a reduced (ferrous; $\mathrm{Fe}^{2+}$ ) or an oxidized (ferric; $\mathrm{Fe}^{3+}$ ) state. Removal of the haem or its oxidation abolishes any NO-induced enzyme activation (14). NO binds to the iron in the haem group of the enzyme forming a hexacoordinate complex which then converts to a pentacoordinate nitrosyl-haem complex by one of two routes. For approximately $25 \%$ of the haem, this conversion occurs rapidly, whereas for the remaining 
hexacoordinate nitrosyl complex this process is considerably slower and appears dependent upon the interaction of NO with an unidentified, non-haem site on the protein $(13,15,21)$. CO also forms a complex with the haem moiety of sGC, but unlike NO, only the six-coordinate complex is formed (36), resulting in a low activation of purified sGC when compared with that attained by NO $(13,21)$.

NO-mediated activation of SGC can be compromised either by reducing the bioavailability of NO or by altering the redox state of sGC itself, making it unresponsive to NO $(2,14)$. Two novel drug classes seem to be able to overcome these obstacles: sGC stimulators and sGC activators $(2,14,35)$. NO-independent but haemdependent stimulators of sGC (such as YC-1 and BAY 41-2272) stimulate sGC directly and enhance the sensitivity of the reduced enzyme to low levels of bio-available NO. Conversely, NO- and haem-independent sGC activators (such as BAY 58-2667) do not modulate NO signalling at all, but activate the NO-unresponsive, haem-oxidized or haem-free enzyme $(10,14,35)$.

\section{Cyclic GMP}

The activation of sGC leads to the formation of the second messenger cyclic guanosine-3', 5'-monophosphate (cGMP). The biological effects of cGMP are mediated by three major types of intracellular effectors: cGMP-dependent protein kinases I and II, cGMP-gated ion channels and cGMP-regulated phosphodiesterases (PDEs) (2, 12, 14) (Figure 1). Degradation of cGMP is catalysed by several differentially expressed PDE families (PDE1, 2, 3, 5, 6, 9, 10 and 11). In the pulmonary vasculature, PDE5 represents the major metabolic pathway for $\operatorname{cGMP}(12,31)$.

\section{The NO/sGC/cGMP pathway and the perinatal lung}

Experimental studies have clearly demonstrated the critical roles of endogenous NOcGMP signalling in the regulation of the pulmonary circulation during development and at birth and that impaired NO-cGMP signalling contributes to PPHN (2, 4, 38-40). However, although NO appears to play a crucial role in regulating the vasoreactivity of 
the transitional circulation it is not essential since endothelial eNOS deficient mice survive and there is no evidence that either iNOS or nNOS compensates for the absence of eNOS (20).

NO participates in the modulation of basal PVR in the fetus, mediates the vasodilator response to specific physiological and pharmacological stimuli, and opposes the strong myogenic tone in the normal fetal lung $(1,2)$. In addition, NO may potentially contribute to angiogenesis during early lung development and recent laboratory studies have provided ample evidence that reduced NO-cGMP activity impairs lung vascular growth and subsequent alveolarization during development, especially in response to neonatal lung injury $(2,6,7,19,24,37)$. At birth, ventilation, increased oxygen tension and shear stress are independently capable of stimulating NO production and NOS inhibitors impair the birth-related fall in PVR (1-4). Finally, during the first days of postnatal life an increased responsiveness of the pulmonary circulation to the NO/sGC/cGMP has been demonstrated in numerous species (20). The mechanisms involved in these postnatal changes are one of the subjects of the present Thesis.

\section{References}

1. Abman SH. Abnormal vasoreactivity in the pathophysiology of persistent pulmonary hypertension of the newborn. Pediatr Rev 20: e103-109, 1999.

2. Abman SH. Recent advances in the pathogenesis and treatment of persistent pulmonary hypertension of the newborn. Neonatology 91: 283-290, 2007.

3. Abman SH, Chatfield BA, Hall SL, and McMurtry IF. Role of endothelium-derived relaxing factor during transition of pulmonary circulation at birth. Am J Physiol 259: H19211927, 1990.

4. Abman SH and Stevens T. Perinatal pulmonary vasoregulation: implications for the pathophysiology and treatment of neonatal pulmonary hypertension. In: Tissue Oxygen Deprivation: Developmental, Molecular and Integrative Function, edited by Haddad G and Lister G. New York: Marcel Dekker, 1996, p. 367-432.

5. Alexander RW and Dzau VJ. Vascular biology: the past 50 years. Circulation 102: IV112-116, 2000.

6. Balasubramaniam V, Maxey A, and Abman S. Inhaled nitric oxide reverses hypoxia induced lung hypoplasia in endothelial nitric oxide synthase-deficient mice. Chest 128: 613S614S, 2005.

7. Balasubramaniam V, Maxey AM, Fouty BW, and Abman SH. Nitric oxide augments fetal pulmonary artery endothelial cell angiogenesis in vitro. Am J Physiol Lung Cell Mol Physiol 290: L1111-1116, 2006

8. Baragatti BB, F., Barogi S, Laubach VE, Sodini D, Sheseli EG, Regan RF, and Coceani F. Interactions between NO, $\mathrm{CO}$ and an endothelium-derived hyperpolarizing factor $(\mathrm{EDHF})$ in maintaining patency of the ductus arteriosus in the mouse. Br J Pharmacol 151: 5462, 2007.

9. Belik J, Jerkic M, McIntyre BA, Pan J, Leen J, Yu LX, Henkelman RM, Toporsian M, and Letarte M. Age-dependent endothelial nitric oxide synthase uncoupling in pulmonary 
arteries of endoglin heterozygous mice. Am J Physiol Lung Cell Mol Physiol 297: L1170-1178, 2009.

10. Bryan NS, Bian K, and Murad F. Discovery of the nitric oxide signaling pathway and targets for drug development. Front Biosci 14: 1-18, 2009.

11. Busse R, Edwards G, Feletou M, Fleming I, Vanhoutte PM, and Weston AH. EDHF: bringing the concepts together. Trends Pharmacol Sci 23: 374-380, 2002.

12. Cogolludo A, Moreno L, and Villamor E. Mechanisms controlling vascular tone in pulmonary arterial hypertension: implications for vasodilator therapy. Pharmacology 79: 65-75, 2007.

13. Deinum G, Stone JR, Babcock GT, and Marletta MA. Binding of nitric oxide and carbon monoxide to soluble guanylate cyclase as observed with Resonance raman spectroscopy. Biochemistry 35: 1540-1547, 1996.

14. Evgenov OV, Pacher P, Schmidt PM, Hasko G, Schmidt HH, and Stasch JP. NOindependent stimulators and activators of soluble guanylate cyclase: discovery and therapeutic potential. Nat Rev Drug Discov 5: 755-768, 2006.

15. Fleming I. Molecular mechanisms underlying the activation of eNOS. Pflügers Arch, 2009.

16. Fleming I and Busse R. Molecular mechanisms involved in the regulation of the endothelial nitric oxide synthase. Am J Physiol Regul Integr Comp Physiol 284: R1-12, 2003.

17. Furchgott RF and Zawadzki Jv. The obligatory role of endothelial cells in the relaxation of arterial smooth muscle by acetylcholine. Nature 288: 373-376, 1980.

18. Gumusel B, Orhan $\mathbf{D}$, Tolunay $\mathbf{O}$, and Uma $\mathbf{S}$. The role of nitric oxide in mediating nonadrenergic, noncholinergic relaxation in rat pulmonary artery. Nitric Oxide 5: 296-301, 2001.

19. Halbower AC, Tuder RM, Franklin WA, Pollock JS, Forstermann U, and Abman SH. Maturation-related changes in endothelial nitric oxide synthase immunolocalization in developing ovine lung. Am J Physiol 267: L585-591, 1994.

20. Haworth SG. Pulmonary endothelium in the perinatal period. Pharmacol Rep 58 Suppl: 153-164, 2006.

21. Hobbs AJ. Soluble guanylate cyclase: the forgotten sibling. Trends Pharmacol Sci 18: 484-491, 1997.

22. Kalinowski $\mathbf{L}$ and Malinski T. Endothelial NADH/NADPH-dependent enzymatic sources of superoxide production: relationship to endothelial dysfunction. Acta Biochim Pol 51: 459-469, 2004.

23. Li H, Wallerath T, Munzel T, and Forstermann U. Regulation of endothelial-type NO synthase expression in pathophysiology and in response to drugs. Nitric Oxide 7: 149-164, 2002.

24. Lin YJ, Markham NE, Balasubramaniam V, Tang JR, Maxey A, Kinsella JP, and Abman SH. Inhaled nitric oxide enhances distal lung growth after exposure to hyperoxia in neonatal rats. Pediatr Res 58: 22-29, 2005.

25. Liu J, Hughes TE, and Sessa WC. The first 35 amino acids and fatty acylation sites determine the molecular targeting of endothelial nitric oxide synthase into the Golgi region of cells: a green fluorescent protein study. J Cell Biol 137: 1525-1535, 1997.

26. Liu SF, Crawley DE, Evans TW, and Barnes PJ. Endothelium-dependent nonadrenergic, noncholinergic neural relaxation in guinea pig pulmonary artery. $J$ Pharmacol Exp Ther 260: 541-548, 1992.

27. Liu SF, Crawley DE, Rohde JA, Evans TW, and Barnes PJ. Role of nitric oxide and guanosine 3',5'-cyclic monophosphate in mediating nonadrenergic, noncholinergic relaxation in guinea-pig pulmonary arteries. Br J Pharmacol 107: 861-866, 1992.

28. Mata-Greenwood E, Jenkins C, Farrow KN, Konduri GG, Russell JA, Lakshminrusimha S, Black SM, and Steinhorn RH. eNOS function is developmentally regulated: uncoupling of eNOS occurs postnatally. Am J Physiol Lung Cell Mol Physiol 290: L232-241, 2006.

29. Moncada S and Higgs EA. The discovery of nitric oxide and its role in vascular biology. Br J Pharmacol 147 Suppl 1: S193-201, 2006.

30. Moncada S, Palmer RM, and Higgs EA. Nitric oxide: physiology, pathophysiology, and pharmacology. Pharmacol Rev 43: 109-142, 1991.

31. Moreno L, Losada B, Cogolludo A, Lodi F, Lugnier C, Villamor E, Moro M, Tamargo J, and Perez-Vizcaino F. Postnatal maturation of phosphodiesterase 5 (PDE5) in piglet pulmonary arteries: activity, expression, effects of PDE5 inhibitors, and role of the nitric oxide/cyclic GMP pathway. Pediatr Res 56: 563-570, 2004.

32. Rabelink TJ and Luscher TF. Endothelial nitric oxide synthase: host defense enzyme of the endothelium? Arterioscl Throm Vas 26: 267-271, 2006.

33. Scott JA, Craig I, and McCormack DG. Nonadrenergic noncholinergic relaxation of human pulmonary arteries is partially mediated by nitric oxide. Am J Resp Crit Care 154: 629632, 1996. 
34. Scott JA and McCormack DG. Nonadrenergic noncholinergic vasodilation of guinea pig pulmonary arteries is mediated by nitric oxide. Can J Physiol Pharm 77: 89-95, 1999.

35. Stasch JP and Hobbs AJ. NO-independent, haem-dependent soluble guanylate cyclase stimulators. Handb Exp Pharmacol: 277-308, 2009.

36. Stone JR and Marletta MA. The ferrous heme of soluble guanylate cyclase: formation of hexacoordinate complexes with carbon monoxide and nitrosomethane. Biochemistry 34: 16397-16403, 1995.

37. Tang JR, Seedorf G, Balasubramaniam V, Maxey A, Markham N, and Abman SH. Early inhaled nitric oxide treatment decreases apoptosis of endothelial cells in neonatal rat lungs after vascular endothelial growth factor inhibition. Am J Physiol Lung Cell Mol Physiol 293: L1271-1280, 2007.

38. Tiktinsky MH and Morin FC, 3rd. Increasing oxygen tension dilates fetal pulmonary circulation via endothelium-derived relaxing factor. Am J Physiol 265: H376-380, 1993.

39. Villamor E, Le Cras TD, Horan MP, Halbower AC, Tuder RM, and Abman SH. Chronic intrauterine pulmonary hypertension impairs endothelial nitric oxide synthase in the ovine fetus. Am J Physiol 272: L1013-1020, 1997.

40. Ziegler JW, Ivy DD, Kinsella JP, and Abman SH. The role of nitric oxide, endothelin, and prostaglandins in the transition of the pulmonary circulation. Clin Perinatol 22: 387-403, 1995.

41. Zou MH, Cohen R, and Ullrich V. Peroxynitrite and vascular endothelial dysfunction in diabetes mellitus. Endothelium 11: 89-97, 2004. 


\section{Chapter II:}

Soluble guanylyl cyclase during postnatal porcine pulmonary maturation.

Am J Physiol Lung Cell Mol Physiol 2005; 288:L125-30 


\title{
Soluble guanylyl cyclase during postnatal porcine pulmonary maturation
}

\author{
Laura Moreno, ${ }^{1}$ Gema Gonzalez-Luis, ${ }^{2}$ Angel Cogolludo, ${ }^{1}$ Federica Lodi, ${ }^{1}$ Antonio Lopez-Farre, ${ }^{3}$ \\ Juan Tamargo, ${ }^{1}$ Eduardo Villamor, ${ }^{2}$ and Francisco Perez-Vizcaino ${ }^{1}$ \\ ${ }^{1}$ Department of Pharmacology, Institute of Pharmacology and Toxicology, School of Medicine, Universidad Complutense \\ and ${ }^{3}$ Instituto de Cardiología, Hospital Universitario San Carlos, Madrid, Spain; and ${ }^{2}$ Department of Pediatrics, \\ University Hospital Maastricht, Research Institute Growth and Development, Maastricht, The Netherlands
}

Submitted 29 June 2004; accepted in final form 15 September 2004

Moreno, Laura, Gema Gonzalez-Luis, Angel Cogolludo, Federica Lodi, Antonio Lopez-Farre, Juan Tamargo, Eduardo Villamor, and Francisco Perez-Vizcaino. Soluble guanylyl cyclase during postnatal porcine pulmonary maturation. Am J Physiol Lung Cell Mol Physiol 288: L125-L130, 2005. First published September 24, 2004; doi:10.1152/ajplung.00244.2004.-The nitric oxide (NO)/ cGMP pathway plays a key role in the regulation of pulmonary vascular tone during the transition from the fetal to the neonatal circulation, and it is impaired in pathophysiological conditions such as pulmonary hypertension. In the present study, we have analyzed the changes in the function and expression of soluble guanylyl cyclase (sGC) in pulmonary arteries during early postnatal maturation in isolated third-branch pulmonary arteries from newborn $(3-18 \mathrm{~h}$ of age) and 2-wk-old piglets. The expression of sGC $\beta_{1}$-subunit in pulmonary arteries increased with postnatal age both at the level of mRNA and protein. The catalytic region of porcine sGC $\beta_{1}$ was sequenced, showing a $92 \%$ homology with the human sequence. This age-dependent increase in sGC expression correlated with increased vasorelaxant responses to the physiological sGC activator $\mathrm{NO}$ and to the exogenous SGC activator YC-1, but not to the membrane-permeable cGMP analog 8-bromoguanosine $3^{\prime}, 5^{\prime}$-cyclic monophosphate. In conclusion, an increased expression of $\mathrm{sGC}$ in pulmonary conduit arteries from 2-wk-old compared with newborn piglets explains, at least partly, the age-dependent increase in the vasorelaxant response of $\mathrm{NO}$ and other activators of $\mathrm{sGC}$.

newborn; YC-1; vascular smooth muscle

NITRIC OXIDE (NO) is a key mediator in the regulation of pulmonary vascular tone $(2,6)$. Most of the physiological effects of NO occur through the activation of soluble guanylyl cyclase (sGC) $(4,36)$ leading to a 200 -fold increase in activity, i.e., the conversion of GTP to cGMP. sGC is a heterodimer consisting of $\alpha$ - and $\beta$-subunits (73 and $70 \mathrm{kDa}$, respectively) and a heme group that serves as the NO-binding site (16).

Changes in the expression of sGC during rat postnatal development have been reported. In the rat heart and kidney, sGC increased postnatally $(7,9)$. In contrast, sGC expression in carotid and cerebral arteries was higher in 3- to 7-day-old lambs compared with adult sheep (37). In the pulmonary arterial system, an increase in the responsiveness to NO with postnatal age, which plays a key role in the reduction of pulmonary vascular resistance during early extrauterine life, has been reported in most $(3,21,25,28,31,38)$, but not all (27), studies on rabbits, lambs, and piglets. In rats, where functional changes in the NO/cGMP pathway in pulmonary arterial postnatal maturation have not been analyzed, lung sGC mRNA, protein, and activity were higher at 1 or 8 days than in

Address for reprint requests and other correspondence: F. Pérez-Vizcaíno, Dept. Pharmacology, School of Medicine, Universidad Complutense, 28040 Madrid, Spain (E-mail: fperez@med.ucm.es). adults $(8,12)$. Immunostaining in pulmonary vascular smooth cells was estimated to be higher in newborns than in adult animals (8).

Impaired vasodilator responses to the NO/cGMP pathway have been involved in several pathological conditions. In fact, reduced NO synthesis, bioavailability, and/or activity have been involved in the pathogenesis of primary and secondary pulmonary hypertension, including the persistent pulmonary hypertension of the newborn $(1,17,34)$. Desensitization of sGC describes a reduced response to a given NO challenge that may be caused by a change in enzyme reactivity or an alteration of the amount of the enzyme present (16). In fact, changes in the lung expression of sGC have been demonstrated in several animal models of lung injury and pulmonary hypertension $(10,11,20)$.

Therefore, the aim of the present study was to analyze the changes in function and expression of sGC in pulmonary arteries during early postnatal maturation. We hypothesized that sGC expression and the responses to $\mathrm{YC}-1$ could increase with age in parallel with the increased responsiveness to NO.

\section{METHODS}

All the procedures conform to the Guide for the Care and Use of Laboratory Animals (NIH publication No. 85-23, revised 1996) and are approved by our Institutional Review Board.

Tissue preparation. Male piglets of $3-18 \mathrm{~h}$ (newborn, $n=12$ ) or 15-20 days ( $2 \mathrm{wk}, n=17$ ) from a local farm were killed by exsanguination after being anesthetized with pentobarbital sodium $(100 \mathrm{mg} / \mathrm{kg})$. The lungs were rapidly immersed in cold $\left(4^{\circ} \mathrm{C}\right) \mathrm{Krebs}$ solution (composition in mM: $118 \mathrm{NaCl}, 4.75 \mathrm{KCl}, 25 \mathrm{NaHCO}_{3}, 1.2$ $\mathrm{MgSO}_{4}, 2.0 \mathrm{CaCl}_{2}, 1.2 \mathrm{KH}_{2} \mathrm{PO}_{4}$, and 11 glucose). Third-branch pulmonary arteries (external diameter of $\sim 1-2 \mathrm{~mm}$ ) were carefully dissected free of surrounding tissue and cut into rings under a microscope (28). The endothelium was removed by gently rubbing the intimal surface of the rings with a metal rod. The endothelium removal procedure was verified by the inability of acetylcholine (1 $\mu \mathrm{M})$ to relax arteries precontracted with norepinephrine $(1 \mu \mathrm{M})$.

Contractile tension recording. Third-branch pulmonary arteries were mounted between two hooks in a 5-ml organ bath filled with Krebs solution and stretched to their optimal resting tension $(0.5$ and $0.7 \mathrm{~g}$ for newborn and 2-wk pulmonary arteries, respectively), at which the rings produced the maximal contractile response to $\mathrm{KCl}$ in previous experiments. The contraction was measured by an isometric force transducer using data acquisition software and hardware (28). Krebs solution was maintained at $37^{\circ} \mathrm{C}$ and gassed with a $95 \% \mathrm{O}_{2}-5 \%$ $\mathrm{CO}_{2}$ gas mixture. In previous experiments, the relaxant response to $\mathrm{NO}$ was not modified by the concentration of oxygen in the bubbling mixture (35).

The costs of publication of this article were defrayed in part by the payment of page charges. The article must therefore be hereby marked "advertisement" in accordance with 18 U.S.C. Section 1734 solely to indicate this fact. 
Rings were stimulated with the thromboxane $\mathrm{A}_{2}$ mimetic 9,11dideoxy- $11 \alpha, 9 \alpha$-epoxymethano-prostaglandin $\quad F_{2 \alpha} \quad(U-46619, \quad 0.1$ $\mu \mathrm{M})$, which induced a contractile response $(628 \pm 64 \mathrm{mg}, n=12$ and $986 \pm 89 \mathrm{mg}, n=12$, in third-branch newborn and 2-wk-old piglets, respectively) of $70-75 \%$ of the maximal response to U-46619 in both age groups. In previous experiments, these contractions were equieffective in the two age groups when expressed as a percentage of the responses induced by $40 \mathrm{mM} \mathrm{KCl} \mathrm{(28).} \mathrm{Then,} \mathrm{concentration-response}$ curves to YC-1, and to the cGMP analog 8-bromoguanosine $3^{\prime}, 5^{\prime}$ cyclic monophosphate (8-BrcGMP), were carried out by cumulative addition of the drugs. Because of the rapid disappearance of NO gas in the bath, the curves to NO were performed in a noncumulative fashion by addition of increasing volumes of Krebs solution saturated with NO.

Western blot analysis of $s G C$. Third-branch pulmonary arteries were isolated, frozen in liquid nitrogen, and stored at $-80^{\circ} \mathrm{C}$. Frozen tissues were homogenized and separated into cytosolic and particulate fractions as described (14). The protein concentration was determined using the Bradford assay (reagents from Bio-Rad). Western blotting was performed with $20 \mu \mathrm{g}$ of protein from the cytosolic fraction per lane. SDS-PAGE (7.5\% acrylamide) was performed using the method of Laemmli in a mini-gel system (Bio-Rad). Samples from newborns and 2-wk-old animals were run in parallel. The proteins were transferred to polyvinylidene difluoride membranes overnight and incubated with a rabbit anti- $\beta_{1}$ subunit of sGC polyclonal antibody $(1: 2,500$, Alexis Biochemicals) and then with an anti-rabbit secondary horseradish peroxidase-conjugated antibody. The bands were visualized by chemiluminescence (ECL, Amersham). The membranes were then stripped and incubated with a mouse antibody against smooth muscle $\alpha$-actin $(1: 10,000$, Sigma) and then with an anti-mouse secondary horseradish peroxidase-conjugated antibody. Bands were quantified using image analysis software (TotalLab, Nonlinear Dynamics). The results were expressed as a percentage of the data of newborn animals.

$R T-P C R$. Pulmonary arteries were isolated and frozen in liquid nitrogen. Frozen arteries were homogenized in a glass potter with $1 \mathrm{ml}$ of Tri Reagent (Sigma), and total RNA was extracted with the guanidinium thiocyanate-phenol-chloroform method (13). The RNA was dissolved in RNA storage solution (Ambion) and stored at $-70^{\circ} \mathrm{C}$. The integrity of the purified RNA was determined by $1 \%$ agarose gel electrophoresis, and its concentration was determined spectrophotometrically at $260 \mathrm{~nm}$. One microgram of total RNA was converted into complementary DNA by reverse transcription following the protocol of the manufacturer (AMV reverse transcriptase; Promega, Southampton, UK). The mRNA sequence of porcine sGC $\beta_{1}$ has not been previously reported. Therefore, primers for the PCR were selected from the regions of the catalytic domain of the rat $\beta_{1}$-subunit of sGC (NM012769, GenBank), which were highly conserved in human (BC047620) and mouse (NM017469). All sequences were compared with GenBank using the Blast software (National Center for Biotechnology Information website). The following primers, synthesized on request by Metabion (Martinsried, Germany), were used for the amplification of sGC $\beta_{1}$ sense: 5'-AGATACGACAATGTGACCATCCTC-3' and antisense: 5'-GATAGAAACCAGACTTGCATTGGC-3' resulting in a product of $569 \mathrm{bp}$; and for $\beta$-actin, sense: 5'-GGACCTGACCGACTACCTCA-3' and antisense: 5'-CATGATCGAGTTGAAGGTGG-3', which yielded a product of $301 \mathrm{bp}$. In preliminary experiments, we tested a number of cycles ranging from 24 to 35 , with cDNA diluted over a range of three magnitudes, to establish the linearity of the reaction (24). PCR of sGC $\beta_{1}$ was performed using a MyCycler Thermal cycler (Bio-Rad) by using Taq DNA polymerase (Biotools, B\&M Labs) for 27 cycles $\left(92^{\circ} \mathrm{C}\right.$ for $1 \mathrm{~min}, 59^{\circ} \mathrm{C}$ for $1.5 \mathrm{~min}$, and $72^{\circ} \mathrm{C}$ for $3 \mathrm{~min}$ ) followed by a final extension step at $72^{\circ} \mathrm{C}$ for $10 \mathrm{~min}$. The same protocol was used for $\beta$-actin except for the annealing temperature, which was $56.5^{\circ} \mathrm{C}$. The products of the PCR were separated in $1.5 \%$ agarose gels stained with ethidium bromide, and bands were quantified using image analysis software (Quantity One, Bio-Rad). Results were normalized to the bands of $\beta$-actin from the same samples and expressed as a percentage of the data of newborn animals. The nucleotide sequence of amplified products was determined in Unidad de Genómica y Proteómica (Universidad Complutense de Madrid) by automated sequencing using an ABI PRISM BigDye Terminator V3.0 Ready Reaction Cycle sequencing kit in a 3730 DNA analyzer (Applied Biosystems). The sequencing was performed using both upstream and downstream primers to check its accuracy.

Drugs. YC-1 was from Cayman Chemical, 1H-[1,2,4]oxadiazolo[4,3-a]quinoxalin-1-one (ODQ) was from Tocris Cookson (Bristol, UK), and all other drugs were from Sigma Chemical (Alcobendas, Spain). NO solutions were prepared by bubbling Krebs solution with NO (450 ppm) as described (23). Drugs were initially dissolved in distilled deionized water (except for $\mathrm{YC}-1$ in DMSO) to prepare a $0.01 \mathrm{M}$ stock solution, and further dilutions were made in Krebs solution. The vehicle DMSO at the maximal concentration used $(0.1 \%)$ had no significant effect on U-46619-induced tone or NOinduced vasorelaxation.

Statistical analysis. Results are expressed as means $\pm \mathrm{SE}$, and $n$ reflects the number of animals. Individual cumulative concentrationresponse curves were fitted to a logistic equation. The drug concentrations producing $30 \%$ relaxation were calculated from the fitted concentration-response curves for each ring and expressed as negative $\log$ molar $\left(-\log \left[\mathrm{IC}_{30}\right]\right)$. Statistically significant differences between groups were calculated by Student's $t$-test for unpaired observations. $P<0.05$ was considered statistically significant.

\section{RESULTS}

Maturational changes in NO-, YC-1-, and 8-BrcGMP-induced pulmonary vasorelaxation. To avoid the possible interference of endothelial-derived NO, the age-dependent changes on the relaxation induced by sGC activators and 8-BrcGMP were analyzed in endothelium-denuded arteries. The vasorelaxant responses induced by exogenously added NO in endothelium-denuded pulmonary arteries (third branch) increased significantly with postnatal age (Fig. $1 A$ ). As Fig. $1 B$ shows, YC-1 also produced a significantly higher relaxant response in 2-wk-old animals compared with newborns. However, the relaxant responses of 8-BrcGMP, a membrane-permeable analog of cGMP, were not significantly different in the two age groups, even when a trend for increased response with age was also observed (Fig 1C). The age-dependent change in the potency of these drugs was calculated from the ratios of the $\mathrm{IC}_{30}$ values in the two age groups, i.e., the distance between the two curves at the level of $30 \%$ relaxation. These ratios were 5.6, 4.0, and 1.9 for NO, YC-1, and 8-BrcGMP, respectively.

Expression of $s G C$ protein and $m R N A$. In blots of the cytosolic fraction of homogenates from piglet pulmonary arteries (third branch) using an antibody recognizing the $\beta_{1^{-}}$ subunit of sGC, a single band of $\sim 70 \mathrm{kDa}$ was detected (Fig. $2 A$ ). The expression of sGC increased significantly with postnatal age (Fig. 2, $A$ and $B$ ). In spite of a trend for increased expression of smooth muscle $\alpha$-actin in the cytosolic fraction with age, the change in sGC expression in 2-wk-old animals remained significantly elevated after normalization of the densitometric values with those of actin $(212 \pm 28 \%, P<0.05)$. In contrast, the sGC protein content was negligible in the particulate fraction (not shown).

The expression of the $\beta_{1}$-subunit of sGC was also analyzed at the level of mRNA. The amplified porcine cDNA corresponds with nucleotides 1328 to 1896 in the human BC047620 sequence (i.e., amino acids 416 to 604 located in the catalytic 


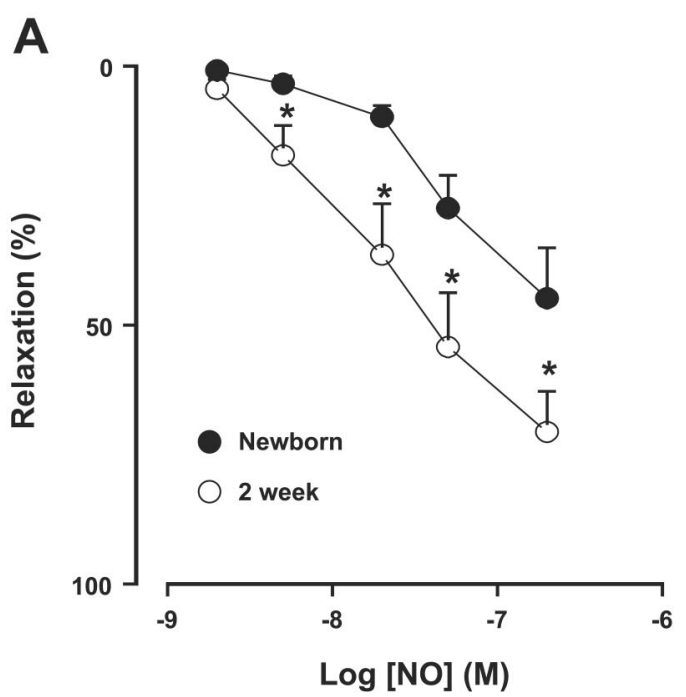

B

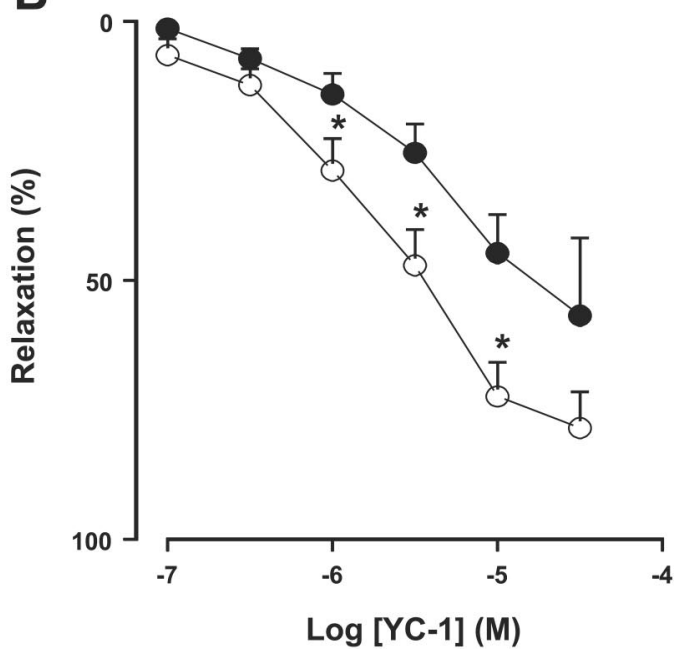

C

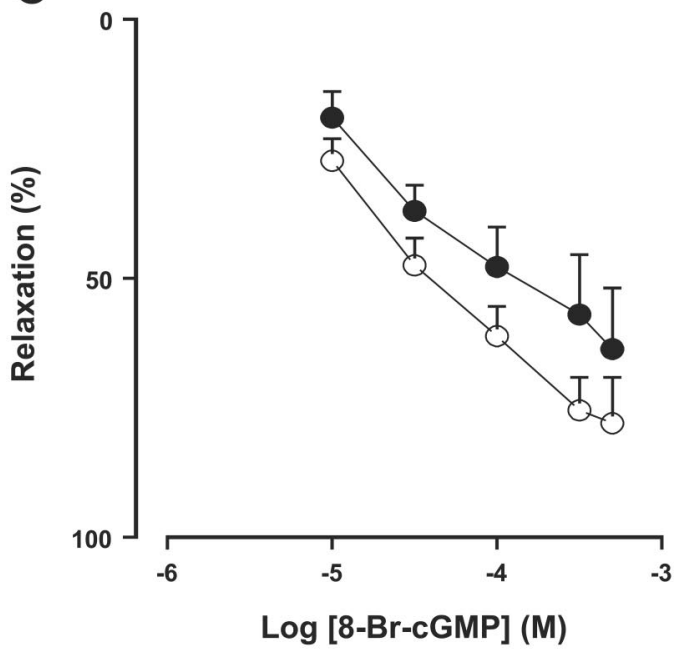

Fig. 1. Changes in the pulmonary relaxant effects of nitric oxide (NO), YC-1, and 8-bromoguanosine 3',5'-cyclic monophosphate (8-BrcGMP) during postnatal maturation. Isolated third-branch endothelium-denuded pulmonary artery rings from newborn and 2-wk-old piglets were constricted with $0.1 \mu \mathrm{M}$ U-46619, and concentration-response curves to NO $(A)$, YC-1 $(B)$, and 8-BrcGMP $(C)$ were carried out. Results are means \pm SE $(n=6-12)$. $* P<$ 0.05 vs. newborn.

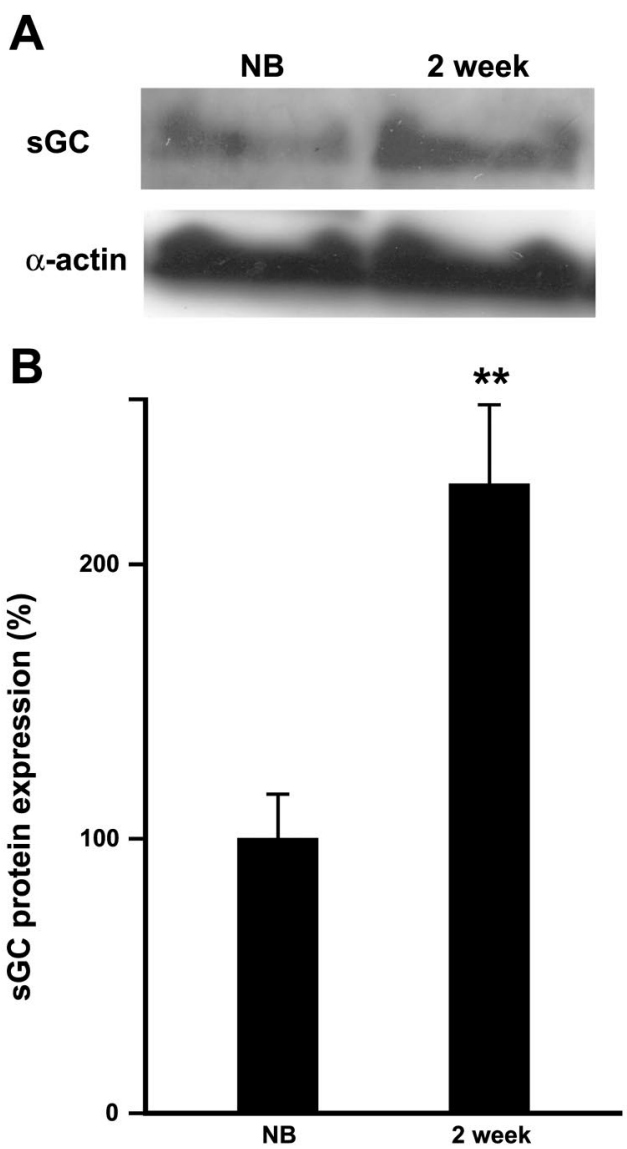

Fig. 2. Soluble guanylyl cyclase (sGC) protein expression in cytosolic fractions during maturation. $A$ : representative Western blots of sGC $\beta_{1}$ and $\alpha$-actin in pulmonary arteries from newborn $(\mathrm{NB})$ and 2-wk-old old animals. $B$ : densitometric data analysis of sGC $\beta_{1}$ protein in pulmonary arteries as a percentage of newborn (means \pm SE, $n=4-5, * * P<0.01$ ). Bands of sGC $\beta_{1}$ had a molecular weight of $\sim 70 \mathrm{kDa}$, and all lanes were loaded with $20 \mu \mathrm{g}$ of protein.

region). This cDNA was sequenced and submitted to the GenBank database (accession no. AY661709) and showed a 92,89 , and $88 \%$ homology with sGC $\beta_{1}$ human, rat, and mouse sequences, respectively. However, the 47 differences found between the human and porcine nucleotide sequences (Fig. 3C) resulted in only three changes in the translated amino acid sequences (A432T, S574T, P575S), i.e., 98.5\% homology at the protein level. Consistent with the increased protein $\beta_{1^{-}}$ subunit levels, an increase in mRNA for the $\beta_{1}$-subunit was also observed in the older animals (Fig. 3, $A$ and $B$ ). This increase remained significant after normalization of the densitometric values with those of $\beta$-actin $(155 \pm 27 \%, P<0.05)$.

\section{DISCUSSION}

The aim of the present study was to analyze the changes in the function and expression of sGC in pulmonary arteries during early postnatal life. The main finding of this study is that the expression of sGC in homogenates from pulmonary arteries increased with postnatal age at both the level of mRNA and protein. This increased expression correlated with increased responsiveness to the physiological sGC activator NO and to the exogenous sGC activator YC-1. 


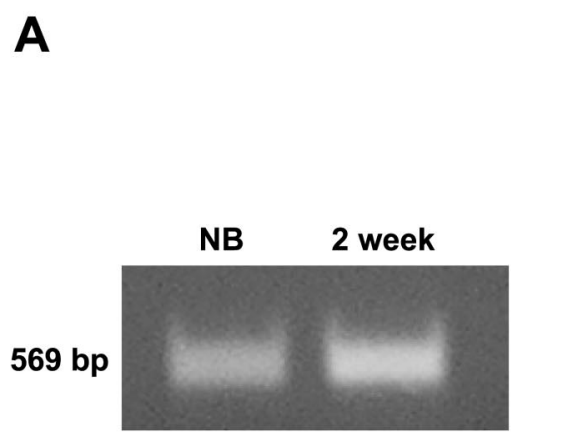

B

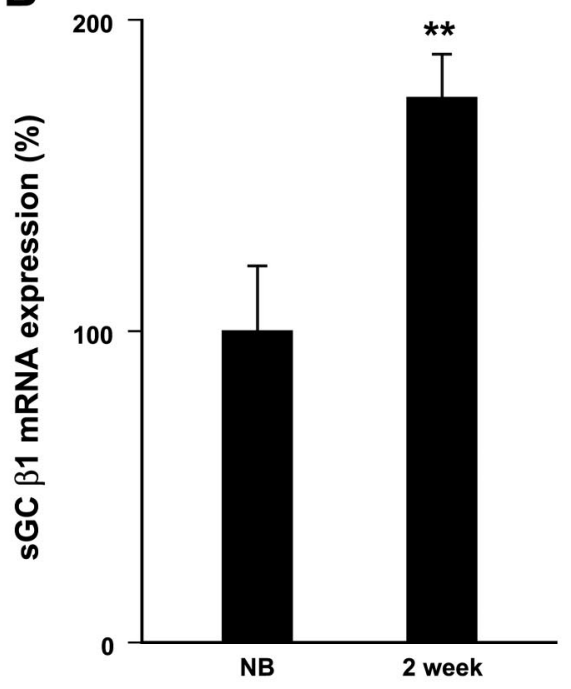

Fig. 3. sGC mRNA expression during maturation. RTPCR analysis of mRNA isolated from newborn and 2-wk-old piglet pulmonary arteries. A: ethidium bromide-stained agarose gels containing RT-PCR products of the sGC $\beta_{1}$. B: densitometric analysis of the sGC $\beta_{1}$ mRNA intensity analyzed by RT-PCR (means \pm SE from 3 animals). $* * P<0.01$ vs. newborns. $C$ : oligonucleotide sequence of the catalytic region of the human sGC $\beta_{1}$ (nucleotides 1328-1898) aligned with the sequence of the amplified RT-PCR porcine sGC $\beta_{1}$ product. Differences in the 2 sequences are highlighted.

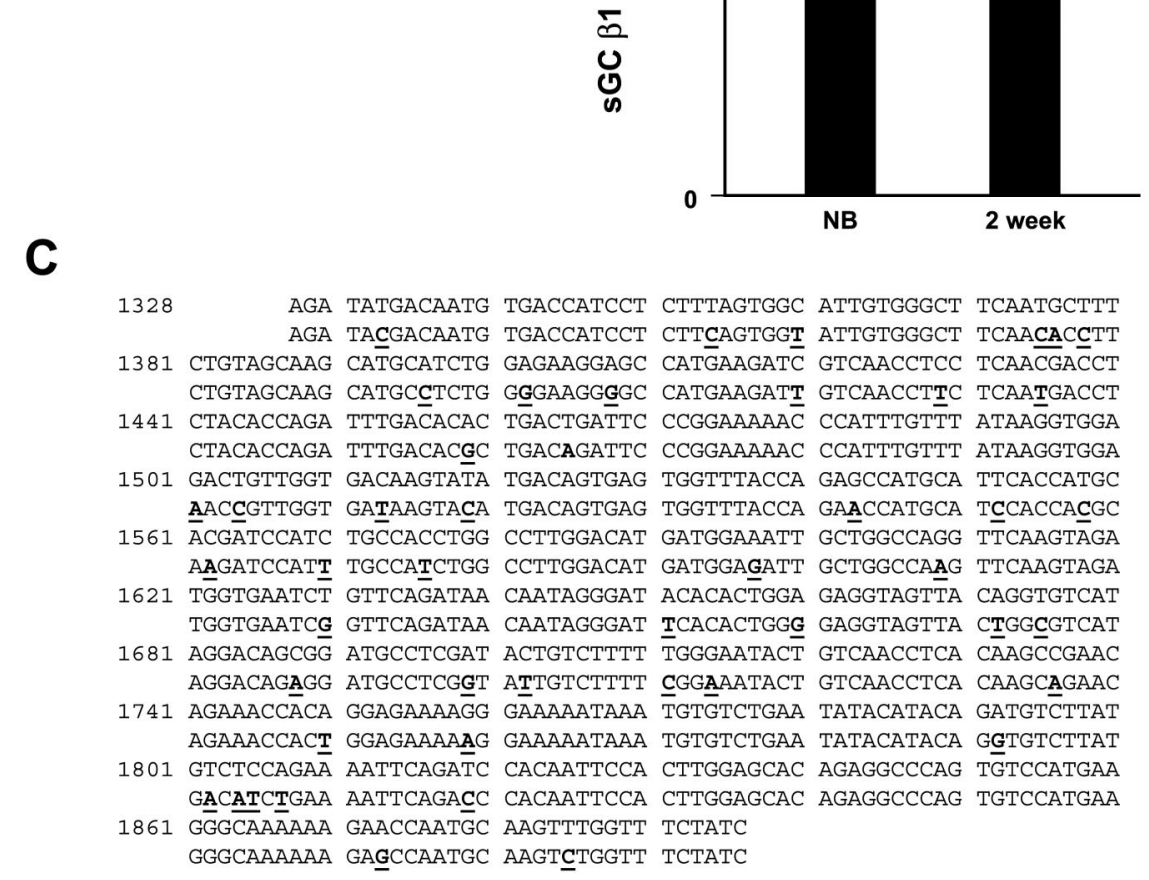
AGA TACGACAATG TGACCATCCT CTTCAGTGGT ATTGTGGGCT TCAACACCTT CTACACCAGA TTTGACACAC TĞACTGATTC CCGGAAAAĀ CCATTTGTTT ATAAGGGTGGA CTACACCAGA TTTGACACGC TGACAGATTC CCGGAAAAAC CCATTTGTTT ATAAGGTGGA

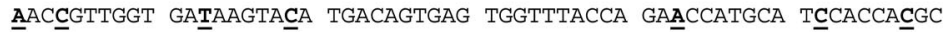
61 ÄCGÄTCCATC TGCCACCTGG CCTTGGACAT GATGGAAATT GCT̈GGCCAGG TTCAAGTĀGA AAGATCCATT TGCCATCTGG CCTTGGACAT GATGGAGATT GCTGGCCAAG TTCAAGTAGA TGGTGAATCG GTTCAGATA CAATAGGGAT ACACACTGGA GAGGTAGTTA CAGGTGTCAT 81 AGGACAGCGG ATGCCTCGAT ACTGTCTTTT TGGGAATACT GTCAACCTCA CÄAGCCGAAC AGGACAGAGG ATGCCTCGGT ATTGTCTTTT CGGAAATACT GTCAACCTCA CAAGCAGAAC 1 AGAAACCĀCA GGAGAAAAGG GAAAAATAAA TGTGTCTGAA TATACATACA GATGTCTTAT AGAAACCACT GGAGAAAAAG GAAAAATAAA TGTGTCTGAA TATACATACA GGTGTCTTAT GACATCTGAA AATTCAGACC CACAATTCCA CTTGGAGCAC AGAGGCCCAG TGTCCATGAA GGGCAAAAAA GAGCCAATGC AAGTCTTGTT TCTATC
At birth, as the lung becomes responsible for blood oxygenation, there is an 8- to 10-fold increase in pulmonary blood flow, and pulmonary arterial pressure falls from suprasystemic levels in the fetus to about one-half of systemic values. NO is critically involved in these changes (30). A second gradual phase of reduction in pulmonary vascular resistance occurs over the first days and weeks of postnatal life to reach the low pulmonary arterial pressure characteristic of the adult (18). An increased responsiveness to the $\mathrm{NO} / \mathrm{cGMP}$ pathway during this period is thought to be a key event in this maturational process and has been demonstrated in isolated pulmonary arteries from numerous species $(3,21,28,32,35,38)$.

The mechanisms responsible for the increased response to NO with postnatal maturation have been analyzed with pharmacological tools stimulating the NO/cGMP signaling pathway at different levels. The responses induced by acetylcholine increased with age $(3,21,32,35,38)$. In these arteries, $N^{\mathrm{G}}$-nitro-L-arginine methyl ester almost abolished the relaxant response to acetylcholine, indicating the prominent role of $\mathrm{NO}$ in this relaxation (35). Furthermore, exogenous NO gas also induced greater relaxant responses in pulmonary arteries from 2-wk-old animals than from newborn animals $(28,35,38$, present results). These relaxant responses were almost abol- ished by the sGC inhibitor ODQ in both age groups (28), ruling out possible sGC-independent mechanisms. In addition, we demonstrated that the responses to the sGC activator YC-1, analyzed in the absence of endothelium to avoid interferences with endogenous NO, increased with postnatal age. However, the responses to 8-BrcGMP, the membrane-permeable analog of cGMP, were unchanged even when we found a nonsignificant trend for increased responses in piglets in the present and in a previous study (35). Finally, a trend for increased vasorelaxant responses to three different inhibitors of phosphodiesterase type 5 (PDE5), the major metabolic pathway for cGMP in pulmonary arteries, was also observed (26).

The expression and activity of key proteins involved in the NO/cGMP pathway during the first days of extrauterine life have also been analyzed. The endothelial NO synthase expression and activity did not change after birth $(5,19$, unpublished observations), whereas the cytosolic superoxide dismutase (SOD-1) expression and activity decreased $(28,33)$ and PDE5 activity and expression increased with postnatal age (26). Herein, we found an age-dependent increase in the sGC $\beta_{1}$ subunit protein expression that correlates with an increased vasorelaxant response to the sGC activators $\mathrm{NO}$ and $\mathrm{YC}-1$. Therefore, we also analyzed by RT-PCR whether the age- 
dependent changes were also observed at the level of the ${ }_{s G C} \beta_{1}$ mRNA in pulmonary arteries. The mRNA or protein sequences of porcine $s \mathrm{GC} \beta_{1}$ have not been previously reported. Thus we amplified and sequenced the catalytic region of porcine sGC $\beta_{1}$. The amplified cDNA from porcine pulmonary arteries showed a 92,89 , and $88 \%$ homology with the human, rat, and mouse sequences, respectively. The $\mathrm{sGC} \beta_{1}$ increase was also observed at the level of mRNA, indicating that the age-dependent change does not require posttransductional mechanisms. The mammalian $\alpha_{1}$ - and $\beta_{1}$-sGC genes are separated by $43 \mathrm{~kb}$ in human and $60 \mathrm{~kb}$ in mouse, and independent transcription of the two subunits in mammals is possible. However, the expression of the two subunits is synchronized due to the multiple shared putative binding sites for transcription factors (29). Thus even when we did not analyze the expression of the $\alpha_{1}$-sGC, we speculate that the changes in its expression in piglet pulmonary arteries parallel those of the $\beta_{1}$-subunit. The data of increased sGC expression is also consistent with increased accumulation of cGMP stimulated by either acetylcholine or NO at 6 and 17 days of age compared with newborns (32). Changes in the expression of sGC can account for a reduced relaxant response of the NO/cGMP pathway (22). However, sGC can also be downregulated as a counterregulatory mechanism when NO levels are increased (15). Our present results suggest that the lower neonatal sGC expression is not originated as a counterbalance mechanism but rather it seems to be causative of the reduced NO/cGMP activity in newborn arteries.

Together, all these results suggest that the maturational changes in the efficacy of NO/cGMP to induce pulmonary relaxation are due to alterations in multiple steps in the signaling pathway. First, the bioavailability of NO during the first hours of life may be reduced due to an enhanced metabolism of NO involving SOD or cyclooxygenase $(25,28)$. Second, a reduced expression of $\mathrm{sGC}$ in newborns as described herein is consistent with a lower response to endogenous and exogenous NO and YC-1. Third, a reduced expression and activity of PDE5, and thus reduced cGMP degradation, in newborn piglets may partly counteract the above mechanisms (26). Finally, increased vascular smooth muscle cell responsiveness to cGMP cannot be excluded. In conclusion, an increased expression of sGC in pulmonary arteries from 2-wk-old compared with newborn piglets explains, at least partly, the age-dependent increase in the vasorelaxant response of NO and other activators of sGC. However, in the present study, we have used medium-sized pulmonary arteries, and thus the results may not exactly reflect the situation of resistance arteries and pulmonary vascular resistance.

\section{ACKNOWLEDGMENTS}

The authors are grateful to Cristina Rivas for excellent technical assistance.

Present address of G. Gonzalez-Luis: Division of Neonatology, Department of Pediatrics, Hospital Universitario Materno-Infantil de Canarias Las Palmas de Gran Canaria, Spain.

\section{GRANTS}

This work was supported by Comunidad Autónoma de Madrid (08.4/ 0036.2001) and Comisión Interministerial de Ciencia y Tecnología (SAF 2002/02304) grants. A. Cogolludo, L. Moreno, F. Lodi, and G. Gonzalez-Luis were supported by grants from Red Temática de Investigación Cardiovascular (FIS), Ministerio de Educación y Ciencia (FPU), CSIC (I3P), and Fundación Canaria de Investigación y Salud (FUNCIS-2/2002), respectively.

\section{REFERENCES}

1. Abman SH. Abnormal vasoreactivity in the pathophysiology of persistent pulmonary hypertension of the newborn. Pediatr Rev 20: E103-E109, 1999.

2. Abman SH, Chatfield B, Hall SL, and McMurtry IF. Role of endothelium-derived relaxing factor during the transition of the pulmonary circulation at birth. Am J Physiol Heart Circ Physiol 259: H1921-H1927, 1990.

3. Abman SH, Chatfield BA, Rodman DM, Hall SL, and McMurtry IF. Maturational changes in endothelium-derived relaxing factor activity in ovine pulmonary arteries in vitro. Am J Physiol Lung Cell Mol Physiol 260: L280-L285, 1991.

4. Arnold WP, Mittal CK, Katsuki S, and Murad F. Nitric oxide activates guanylate cyclase and increases guanosine 3',5'-cyclic monophosphate levels in various tissue preparations. Proc Natl Acad Sci USA 74: 32033207, 1977.

5. Arrigoni FI, Hislop AA, Pollock JS, Haworth SG, and Mitchell JA. Birth upregulates nitric oxide synthase activity in the porcine lung. Life Sci 70: 1609-1620, 2002.

6. Barnes PJ and Liu SF. Regulation of pulmonary vascular tone. Pharmacol Rev 47: 87-131, 1995.

7. Behrends S, Budaeus L, Kempfert J, Scholz H, Starbatty J, and Vehse K. The $\beta_{2}$ subunit of nitric oxide-sensitive guanylyl cyclase is developmentally regulated in rat kidney. Naunyn Schmiedebergs Arch Pharmacol 364: 573-576, 2001

8. Behrends S, Kempfert J, Mietens A, Koglin M, Scholz H, and Middendorff $\mathbf{R}$. Developmental changes of nitric oxide-sensitive guanylyl cyclase expression in pulmonary arteries. Biochem Biophys Res Commun 283: 883-887, 2001.

9. Behrends S, Mietens A, Kempfert J, Koglin M, Scholz H, and Middendorff $\mathbf{R}$. The expression pattern of nitric oxide-sensitive guanylyl cyclase in the rat heart changes during postnatal development. J Histochem Cytochem 50: 1325-1332, 2002.

10. Black SM, Sanchez LS, Mata-Greenwood E, Bekker JM, Steinhorn RH, and Fineman JR. sGC and PDE5 are elevated in lambs with increased pulmonary blood flow and pulmonary hypertension. Am J Physiol Lung Cell Mol Physiol 281: L1051-L1057, 2001.

11. Bland RD, Ling CY, Albertine KH, Carlton DP, MacRitchie AJ, Day RW, and Dahl MJ. Pulmonary vascular dysfunction in preterm lambs with chronic lung disease. Am J Physiol Lung Cell Mol Physiol 285: L76-L85, 2003.

12. Bloch KD, Filippov G, Sanchez LS, Nakane M, and De La Monte SM. Pulmonary soluble guanylate cyclase, a nitric oxide receptor, is increased during the perinatal period. Am J Physiol Lung Cell Mol Physiol 272: L400-L406, 1997.

13. Chomczynski P and Mackey K. Short technical reports. Modification of the TRI reagent procedure for isolation of RNA from polysaccharide- and proteoglycan-rich sources. Biotechniques 19: 942-945, 1995.

14. Cogolludo A, Moreno L, Bosca L, Tamargo J, and Perez-Vizcaino F. Thromboxane $\mathrm{A}_{2}$-induced inhibition of voltage-gated $\mathrm{K}^{+}$channels and pulmonary vasoconstriction: role of protein kinase $\mathrm{C} \zeta$. Circ Res 93: 656-663, 2003.

15. Filippov G, Bloch DB, and Bloch KD. Nitric oxide decreases stability of mRNAs encoding soluble guanylate cyclase subunits in rat pulmonary artery smooth muscle cells. J Clin Invest 100: 942-948, 1997.

16. Friebe A and Koesling D. Regulation of nitric oxide-sensitive guanylyl cyclase. Circ Res 93: 96-105, 2003.

17. Hampl V and Herget J. Role of nitric oxide in the pathogenesis of chronic pulmonary hypertension. Physiol Rev 80: 1337-1372, 2000.

18. Haworth SG and Hislop AA. Adaptation of the pulmonary circulation to extra-uterine life in the pig and its relevance to the human infant. Cardiovasc Res 15: 108-119, 1981.

19. Hislop AA, Springal DR, Buttery LDK, Pollock JS, and Haworth SG. Abundance of endothelial nitric oxide synthase in newborn intrapulmonary arteries. Arch Dis Child 12: F17-F21, 1995.

20. Li D, Laubach VE, and Johns RA. Upregulation of lung soluble guanylate cyclase during chronic hypoxia is prevented by deletion of eNOS. Am J Physiol Lung Cell Mol Physiol 281: L369-L376, 2001.

21. Liu SF, Hislop AA, Haworth SG, and Barnes PJ. Developmental changes in endothelium-dependent pulmonary vasodilatation in pigs. $\mathrm{BrJ}$ Pharmacol 106: 324-330, 1992.

22. Lopez-Farre A, Rodriguez-Feo JA, Garcia-Colis E, Gomez J, LopezBlaya A, Fortes J, de Andres R, Rico L, and Casado S. Reduction of the soluble cyclic GMP vasorelaxing system in the vascular wall of stroke- 
prone spontaneously hypertensive rats: effect of the $\alpha_{1}$-receptor blocker doxazosin. J Hypertens 20: 463-470, 2002.

23. López-López JG, Pérez-Vizcaíno F, Cogolludo AL, Ibarra M, Zaragozá-Arnáez $\mathbf{F}$, and Tamargo J. Nitric oxide and nitric oxide donors induced relaxation and its modulation by oxidative stress in piglet pulmonary arteries. Br J Pharmacol 133: 615-624, 2001.

24. Marone M, Mozzetti S, De Ritis D, Pierelli L, and Scambia G. Semiquantitative RT-PCR analysis to assess the expression levels of multiple transcripts from the same sample. Biol Proc Online 3: 19-25, 2001.

25. Morecroft I and MacLean MR. Developmental changes in endotheliumdependent vasodilation and the influence of superoxide anions in perinatal rabbit pulmonary arteries. Br J Pharmacol 125: 1585-1593, 1998.

26. Moreno L, Losada L, Cogolludo A, Lodi F, Lugnier C, Villamor E, Moro M, Tamargo J, and Pérez-Vizcaíno F. Postnatal maturation of phosphodiesterase 5 (PDE5) in piglet pulmonary arteries: activity, expression, effects of pde5 inhibitors and role on the NO/cyclic GMP pathway. Pediatr Res 56: 563-570, 2004.

27. O'Donnell DC, Tod ML, and Gordon JB. Developmental changes in endothelium-dependent relaxation of pulmonary arteries: role of EDNO and prostanoids. J Appl Physiol 81: 2013-2019, 1996.

28. Pérez-Vizcaíno F, López-López JG, Santiago R, Cogolludo A, Zaragozá-Arnáez F, Moreno L, Alonso MJ, Salaíces M, and Tamargo J. Postnatal maturation in nitric oxide-induced pulmonary artery relaxation involving cyclooxygenase-1 activity. Am J Physiol Lung Cell Mol Physiol 283: L839-L848, 2002.

29. Sharina IG, Martin E, Thomas A, Uray KL, and Murad F. CCAATbinding factor regulates expression of the $\beta 1$ subunit of soluble guanylyl cyclase gene in the BE2 human neuroblastoma cell line. Proc Natl Acad Sci USA 100: 11523-11528, 2003.
30. Shaul PW. Regulation of vasodilator synthesis during lung development. Early Hum Dev 54: 271-294, 1999.

31. Steinhorn RH, Morin FC III, Gugino SF, Giese E, and Russell JA. Developmental differences in endothelium-dependent responses in isolated ovine pulmonary arteries and veins. Am J Physiol Heart Circ Physiol 264: H2162-H2167, 1993.

32. Tulloh RMR, Hislop AA, Boels PJ, Deutch J, and Haworth SG. Chronic hypoxia inhibits postnatal maturation of porcine intrapulmonary artery relaxation. Am J Physiol Heart Circ Physiol 272: H2436-H2445, 1997.

33. Villamor E, Kessels CG, Fischer MA, Bast A, de Mey JG, and Blanco CE. Role of superoxide anion on basal and stimulated nitric oxide activity in neonatal piglet pulmonary vessels. Pediatr Res 54: 372-381, 2003.

34. Villamor E, Le Cras TD, Horan MP, Halbower AC, Tuder RM, and Abman SH. Chronic intrauterine pulmonary hypertension impairs endothelial nitric oxide synthase in the ovine fetus. Am J Physiol Lung Cell Mol Physiol 272: L1013-L1020, 1997.

35. Villamor E, Perez-Vizcaino F, Cogolludo AL, Conde-Oviedo J, Zaragoza-Arnaez F, Lopez-Lopez JG, and Tamargo J. Relaxant effects of carbon monoxide compared with nitric oxide in pulmonary and systemic vessels of newborn piglets. Pediatr Res 48: 546-553, 2000.

36. Warner TD, Mitchell JA, Sheng H, and Murad F. Effects of cyclic GMP on smooth muscle relaxation. Adv Pharmacol 26: 171-194, 1994.

37. White CR, Hao X, and Pearce WJ. Maturational differences in soluble guanylate cyclase activity in ovine carotid and cerebral arteries. Pediatr Res 47: 369-375, 2000.

38. Zellers TM and Vanhoutte PM. Endothelium-dependent relaxations of piglet pulmonary arteries augment with maturation. Pediatr Res 30: 176-180, 1991.

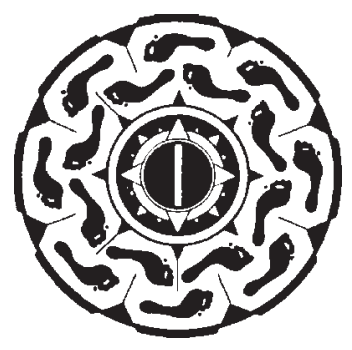




\section{Chapter III:}

Relaxant effects of the soluble guanylate cyclase activator and NO sensitizer YC- 1 in piglet pulmonary arteries.

Biol Neonate 2006; 90:66-72 


\title{
Relaxant Effects of the Soluble Guanylate Cyclase Activator and NO Sensitizer YC-1 in Piglet Pulmonary Arteries
}

\author{
Gema González-Luis $^{a, b}$ Angel Cogolludo $^{c}$ Laura Moreno $^{c}$ Federica Lodi $^{c}$ \\ Juan Tamargo ${ }^{c}$ Francisco Pérez-Vizcaíno ${ }^{c}$ Eduardo Villamor ${ }^{a}$ \\ ${ }^{a}$ Department of Pediatrics, University Hospital Maastricht, Research Institute Growth and Development, \\ Maastricht, The Netherlands; ${ }^{b}$ Division of Neonatology, Department of Pediatrics, Hospital Universitario \\ Materno-Infantil de Canarias, Las Palmas de Gran Canaria, ' Department of Pharmacology, Institute of \\ Pharmacology and Toxicology, School of Medicine, Universidad Complutense, Madrid, Spain
}

\section{Key Words}

Nitric oxide $\cdot$ YC-1 Soluble guanylate cyclase $\cdot$

Pulmonary artery

\begin{abstract}
Background: The indazole derivative $\mathrm{YC}-1$ has been characterized as a nitric oxide (NO)-independent and heme dependent soluble guanylate cyclase (sGC) activator, which also sensitizes SGC to NO. Objective: To examine the effects of YC-1 on vascular relaxation in newborn and 2-week-old piglet pulmonary arteries. The effect of YC-1 on the relaxation induced by exogenous NO was also analyzed. Methods: Isolated rings from third branch pulmonary arteries and fifth-seventh-generation intrapulmonary arterioles were mounted in organ chambers for isometric tension recording. Arteries were precontracted with the thromboxane $A_{2}$ mimetic U46619. Results: YC-1 induced relaxation was greater in 2-week-old pulmonary arteries and was abolished by the SGC inhibitor ODQ $(10 \mu M)$. YC-1 induced relaxation was similar in conduit pulmonary arteries and arterioles. In the 2-week-old conduit pulmonary arteries, the response to $\mathrm{YC}-1$ was sig-
\end{abstract}

nificantly reduced when the endothelium was removed or after incubation with the NO synthase inhibitor LNAME $(0.1 \mathrm{mM})$. YC-1 augmented NO-induced relaxation in 2-week-old but not in neonatal conduit pulmonary arteries. Conclusions: Our results indicate that YC-1 induced pulmonary vascular relaxation in conduit and resistance pulmonary arteries and these effects increased with postnatal age. In the 2-week-old conduit pulmonary arteries and besides being a direct activator of sGC, YC-1 produced endothelium-dependent relaxation and synergized with exogenous NO.

Copyright (c) 2006 S. Karger AG, Basel

\section{Introduction}

Nitric oxide (NO) is a key mediator in the regulation of pulmonary vascular tone in the adult life and during the transition from the fetal to the postnatal pulmonary circulation [1]. Soluble guanylyl cyclase (sGC) is the predominant intracellular NO receptor in vascular smooth muscle cells. Most of the physiological effects of NO occur through sGC activation [2] leading to a 200-fold in-

\section{KARGER \\ Fax +41613061234 E-Mail karger@karger.ch} www.karger.com
(C) 2006 S. Karger AG, Basel

$0006-3126 / 06 / 0901-0066 \$ 23.50 / 0$

Accessible online at:

www.karger.com/bon
E. Villamor

Department of Pediatrics, University Hospital Maastricht

P. Debyelaan 25, PO Box 5800

NL-6202 AZ Maastricht (The Netherlands)

Tel. +31 433877246 , Fax +31 43387 5246, E-Mail eiv@paed.azm.nl 
crease in activity, i.e., the conversion of GTP to cyclic guanosine monophosphate (cGMP). During the last years, new substances have been identified which also activate sGC. YC-1 (3-(5'-hydroxymethyl-2'-furyl)-1benzylindazole) was the first compound of this series to be identified [3-5]. YC-1 causes a 10-fold activation of purified sGC independent of NO [6]. In vascular smooth muscle cells, YC-1 was reported to increase cGMP levels and to induce relaxation of rat and rabbit aortic rings [6-8]. It has been suggested that the mechanism of action of YC-1 is to stabilize the active configuration of sGC [6]. Interestingly, $\mathrm{YC}-1$ has been shown to decrease the dissociation rates of NO from the activated enzyme [9], sensitizing sGC towards $\mathrm{NO}$ and increasing the potency of NO by one order of magnitude [4].

Sensitization/desensitization of sGC describe an alteration of its response toward a given NO challenge due to a change in enzyme reactivity or an alteration of the amount of the enzyme present [4]. Desensitization of sGC has been involved in several pathological conditions such as primary and secondary pulmonary hypertension, including the persistent pulmonary hypertension of the newborn (PPHN) [1, 10]. Changes in sGC expression in pulmonary arteries have been also reported during postnatal development [11]. The ability of YC-1 to directly activate sGC and to its NO sensitizing effects makes this drug a potentially attractive therapeutic agent $[4,12]$. A pathological condition for which NO sensitization has proved to be a valuable therapeutic strategy is pulmonary hypertension. In fact, phosphodiesterase 5 inhibitors, which sensitize the cGMP pathway by inhibiting the breakdown of cGMP and increase the responsiveness to NO, have been reported to be selective pulmonary vasodilators, useful for the treatment of this condition [13, 14]. We have recently reported that YC-1 induced relaxation in endothelium-denuded third branch piglet pulmonary arteries and this effect augmented with postnatal age [11]. However, there are no reports about the effects of YC-1 in pulmonary resistance arteries or analyzing the sensitizing effects of YC-1-like drugs on endothelium-derived or exogenous NO in the pulmonary circulation.

We hypothesized that YC-1 induced sensitization towards endogenous or exogenous $\mathrm{NO}$ in the pulmonary arteries during the postnatal period and that this effect was developmentally regulated. Therefore, the aim of the present work was to study the effects of YC-1 in third branch and resistance arteries and to analyze the role of $\mathrm{NO}$ on YC-1-induced relaxation in piglet pulmonary arteries.

\section{Methods}

All the procedures conform to the guide for the Care and Use of Laboratory Animals (NIH publication No. 85-23, revised 1996) and approved by our Institutional Review Board.

\section{Tissue Preparation}

Male piglets of 3-18 h (newborn, $\mathrm{n}=16$ ) or 15-20 days old (2-week-old, $n=16$ ) from a local farm were used in this study. Animals were killed by exsanguination after having been anesthetized with sodium pentobarbitone $\left(100 \mathrm{mg} \mathrm{kg}^{-1}\right)$. The lungs were rapidly immersed in cold $\left(4^{\circ} \mathrm{C}\right) \mathrm{Krebs}$ solution (composition in $\mathrm{m} M: \mathrm{NaCl} 118, \mathrm{KCl} 4.75, \mathrm{NaHCO}_{3} 25, \mathrm{MgSO}_{4} 1.2, \mathrm{CaCl}_{2} 2.0$, $\mathrm{KH}_{2} \mathrm{PO}_{4} 1.2$ and glucose 11$)$. Third branch pulmonary arteries (external diameter of about 1-2 mm) and fifth-seventh-generation intrapulmonary arterioles (external diameter of 150-200 $\mu \mathrm{m}$ ) were carefully dissected free of surrounding tissue and cut into rings under a microscope. In some experiments, the endothelium was removed by rubbing gently the intimal surface of the rings with a metal rod. The endothelium removal procedure was verified by the inability of acetylcholine $(1 \mu M)$ to relax arteries precontracted with noradrenaline $(1 \mu M)$ or U46619 $(0.1 \mu M)$.

\section{Contractile Tension Recording}

Third branch pulmonary rings were mounted between two hooks in a 5-ml organ bath filled with Krebs solution and stretched to their optimal resting tension $(0.5$ and $0.7 \mathrm{~g}$ for newborn and 2week-old, respectively), at which the rings produced the maximal contractile response to $\mathrm{KCl}$ in previous experiments. As previously described, the contraction was measured by an isometric force transducer using data acquisition software and hardware [15]. Arterioles were mounted between an isometric force transducer (Kistler Morce DSC 6, Seattle, Wash., USA) and a displacement device in a myograph (model 610M, Danish Myo Technology, Aarhus, Denmark) using two stainless steel wires (diameter $40 \mu \mathrm{m}$ ). Each arteriole was stretched to its individual optimal lumen diameter, i.e., the diameter at which it developed the strongest contractile response to $125 \mathrm{mM} \mathrm{K}^{+}$, using a diameter-tension protocol as previously described [16]. During mounting and experimentation, Krebs solution was maintained at $37^{\circ} \mathrm{C}$ and gassed with a $95 \%$ $\mathrm{O}_{2}-5 \% \mathrm{CO}_{2}$ gas mixture. In previous experiments, the relaxant response to NO was not modified by the concentration of oxygen in the bubbling mixture [17].

Endothelium-intact rings were precontracted with the thromboxane $\mathrm{A}_{2}$ mimetic 9,11-dideoxy- $11 \alpha, 9 \alpha$-epoxymethano-prostaglandin $\mathrm{F}_{2 \alpha}(\mathrm{U} 46619,0.1 \mu M)$ which induced a submaximal contractile response [15]. In previous experiments, these contractions were equieffective in the two age groups when expressed as a percent of the responses induced by $62.5 \mathrm{mM} \mathrm{KCl} \mathrm{[15].} \mathrm{Then,} \mathrm{concen-}$ tration-response curves to YC-1 (by cumulative addition of the drug) and NO (in a non-cumulative fashion) were carried out. In some experiments, rings were stimulated with U46619 $(0.1 \mu M)$, after washing, rings were treated for $20 \mathrm{~min}$ with the $\mathrm{sGC}$ inhibitor ODQ $(10 \mu M)$ or the non-selective inhibitor of NO synthase (NOS) L-NAME $(0.1 \mathrm{mM})$ and again stimulated with U46619 at the concentration $(0.03-0.1 \mu M)$ required to reach a contractile response similar to the initial control one and finally cumulative concentration-response curves to YC-1 were performed. In another set of experiments, after contracting with U46619 $(0.1 \mu M)$, endothelium-denuded rings were exposed to YC-1 $(3 \mu M)$ for 20 min which 
induced a $20-35 \%$ relaxation, then further U46619 was added as needed (final concentration of $0.2-0.3 \mu M$ ) in order to reverse YC-1-induced vasorelaxation and finally a concentration-response curve to NO was performed. To disclose whether the relaxant effects of $\mathrm{YC}-1$ were affected by the different concentrations of U46619 (0.03-0.3 $\mu M)$ used to precontract the arteries. Experiments evaluating YC-1-induced relaxation after stimulation with the above mentioned concentrations of U46619 were also performed.

Drugs

YC-1 was from Cayman Chemical(USA), ODQ (1H-[1,2,4] oxadiazolo[4,3-a]quinoxalin-1-one) from Tocris Cookson Ltd. (Bristol, UK), and all other drugs from Sigma Chemical Co. (Alcobendas, Spain). NO solutions were prepared by bubbling Krebs solution with NO (450 ppm) as described [17]. Drugs were dissolved initially in distilled deionized water (except for YC-1, forskolin and ODQ, in dimethylsulfoxide) to prepare a $0.01 \mathrm{M}$ stock solution and further dilutions were made in Krebs solution. The vehicle dimethylsulfoxide used at the maximal concentration $(0.1 \%)$ had no significant effect on U46619-induced tone or NO-induced vasorelaxation.

\section{Statistical Analysis}

Results are expressed as means \pm SEM and $n$ reflects the number of animals. Individual cumulative concentration-response curves were fitted to a logistic equation. The drug concentrations producing $50 \%$ relaxation were calculated from the fitted concentration-response curves for each ring and expressed as negative $\log$ molar (-Log $\left.\left[\mathrm{IC}_{50}\right]\right)$. Statistically significant differences between groups were calculated by Student's t test for unpaired observation or for multiple comparisons by an ANOVA followed by a Newman Keuls test. $\mathrm{p}<0.05$ was considered statistically significant.

\section{Results}

\section{YC-1-Induced Pulmonary Vasorelaxation}

YC-1 induced a concentration-dependent relaxation in endothelium-intact third branch pulmonary arteries (fig. $1 \mathrm{~A},-\log \left[\mathrm{IC}_{50}\right]=5.74 \pm 0.15$ and $5.23 \pm 0.18$ for newborn and 2-week-old, respectively) and in fifth- to seventh-generation intrapulmonary arterioles (fig. 1B, $-\log \left[\mathrm{IC}_{50}\right]=5.53 \pm 0.15$ and $5.28 \pm 0.2$ for newborn and 2-week-old, respectively). The guanylyl cyclase inhibitor ODQ $(10 \mu M)$ almost abolished the effects of YC-1 either in third branch pulmonary arteries or arterioles from both age groups (fig. 1A, B). The vasorelaxant responses induced by YC-1 increased significantly with postnatal age in both types of arteries. No significant differences were observed between third branch pulmonary arteries and fifth- to seventh-generation intrapulmonary arterioles of the same age group. Precontraction of third branch pulmonary arteries with differ-

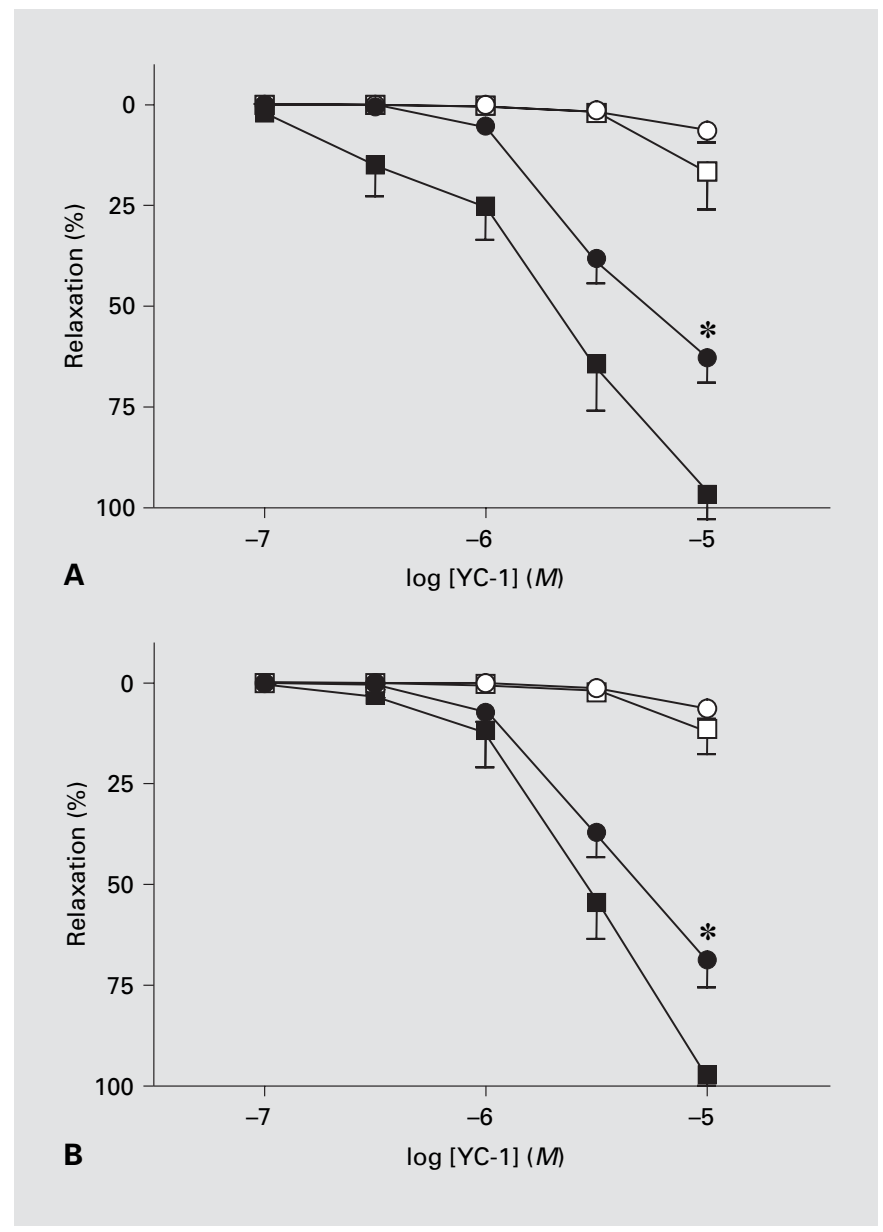

Fig. 1. Concentration-dependent relaxant effects of $\mathrm{YC}-1$ in endothelium-intact isolated third branch intrapulmonary arteries (A) and fifth-seventh-generation intrapulmonary arterioles (B) from newborn $(\bigcirc, \bigcirc)$ and 2-week-old $(\boldsymbol{\square}, \square)$ piglets. The effects of pretreatment with the soluble guanylyl cyclase inhibitor ODQ (10 $\mu M$, $\bigcirc, \square)$ are also shown. Vessels were constricted with U46619. The results are means $\pm \mathrm{SE}(\mathrm{n}=6-7) .{ }^{*} \mathrm{p}<0.05$ newborn vs. 2-weekold. Only levels of statistical significance for the highest difference are shown.

ent concentrations of U46619 $(0.03-0.3 \mu M)$ did not significantly affect the relaxant effects of YC-1 (fig. 2A and $\mathrm{B})$. Contractions $(\mathrm{n}=6-12)$ induced by $0.03,0.1$ and $0.3 \mu M \mathrm{U} 46619$ in third branch pulmonary arteries were $3.57 \pm 0.5,4.03 \pm 0.6$, and $4.7 \pm 0.6 \mathrm{mN}$, respectively in newborn, and $6.52 \pm 0.7,8.01 \pm 0.8$, and $8.6 \pm 0.9 \mathrm{mN}$, respectively in 2-week-old. In arterioles the responses were $0.43 \pm 0.1,0.51 \pm 0.14$, and $0.57 \pm$ $0.12 \mathrm{mN}$, respectively in newborn and $0.62 \pm 0.15$, $0.87 \pm 0.16$, and $0.94 \pm 0.16$, respectively in 2 -weekold animals. 


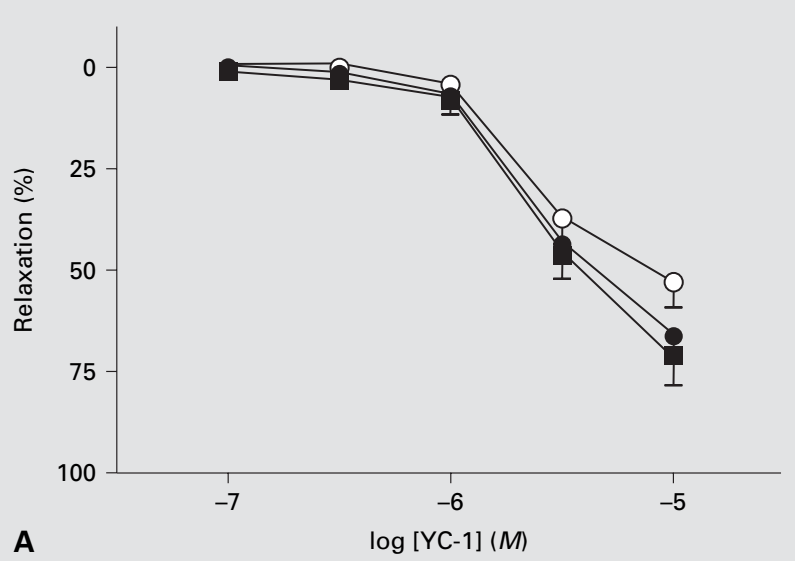

A

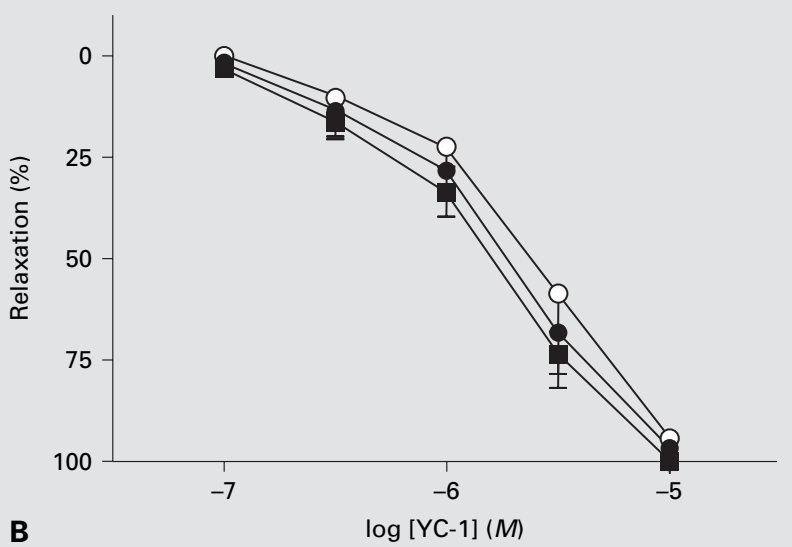

B

Fig. 2. Concentration-dependent relaxant effects of YC-1 in endothelium-intact isolated third branch intrapulmonary arteries from newborn (A) and 2-week-old (B) piglets. Vessels were constricted with $\mathrm{U} 466190.03 \mu M(\bigcirc), 0.1 \mu M(\mathbf{O})$, or $0.3 \mu M(\boldsymbol{\square})$. The results are means $\pm \operatorname{SE}(\mathrm{n}=4)$.

Dependence on Endothelium and Endogenous NO of the Relaxant Effects of YC-1

The contribution of endothelium and endogenous NO to the relaxant effects of YC-1 was analyzed in the third branch pulmonary arteries stimulated with U46619. In 2-week-old third branch pulmonary arteries, the relaxant response induced by YC-1 was inhibited by endothelium removal (fig. 3B). In this age group, the NOS inhibitor L-NAME $(100 \mu M)$ produced an inhibitory effect on YC-1-induced relaxation similar to that produced by endothelium removal (fig. 3B). However, in neonatal third
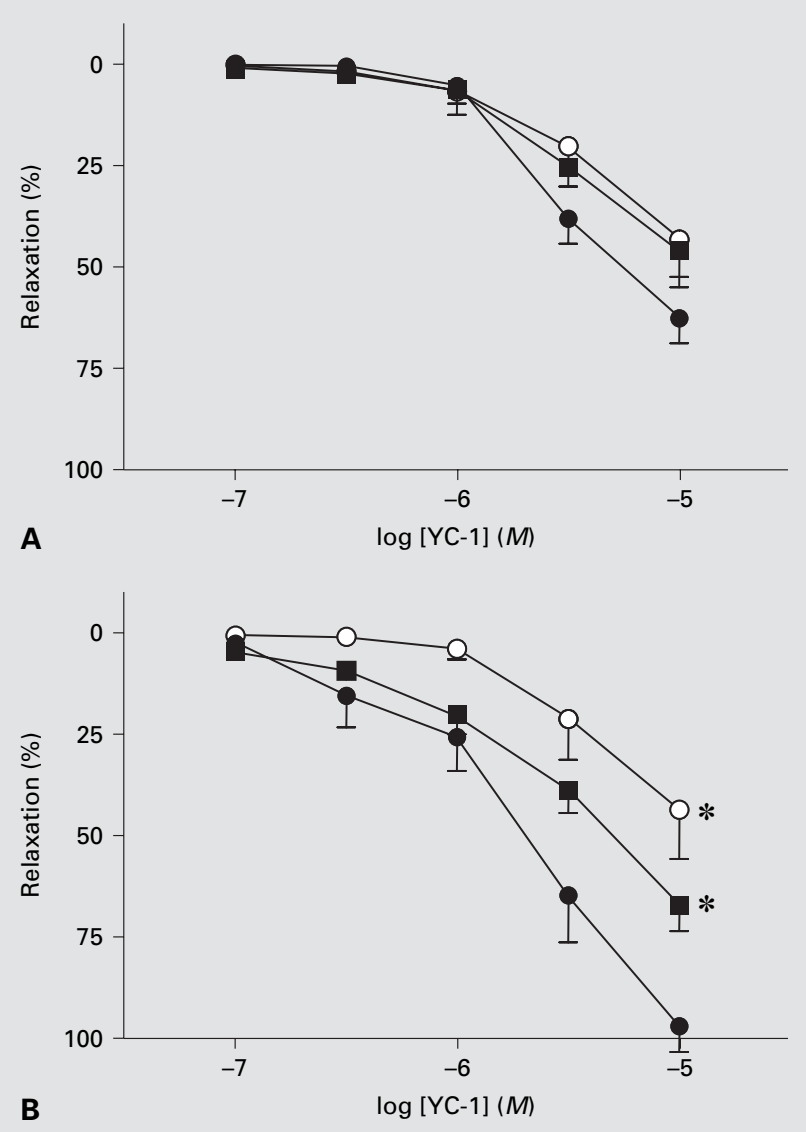

Fig. 3. Role of endothelium and NOS on the relaxant effects of YC-1. Experiments were performed in isolated third branch endothelium intact (control, $\mathbf{O}$ ) or endothelium denuded ( $\mathbf{\square}$ ) pulmonary arteries from newborn $\mathbf{A}$ and 2-week-old (B) piglets stimulated with U46619. The effects of pretreatment with the NOS inhibitor L-NAME $(0.1 \mathrm{~m} M, \bigcirc)$ in endothelium intact pulmonary arteries are also shown. The results are means $\pm \mathrm{SE}(\mathrm{n}=6-11){ }^{*} \mathrm{p}<0.05$ vs. control. Only levels of statistical significance for the highest difference are shown.

branch pulmonary arteries, endothelium removal or L-NAME produced only a weak and statistically non significant reduction of the response to YC-1 (fig. 3A).

\section{Sensitization of Exogenous NO-Induced Pulmonary \\ Vasorelaxation by $Y C-1$}

In order to analyze whether YC-1 sensitized the responses to exogenous $\mathrm{NO}$, a concentration-response curve to NO was constructed in endothelium-denuded third branch pulmonary arteries from newborn and 2-week-old piglets stimulated with U46619 in the absence or pres- 


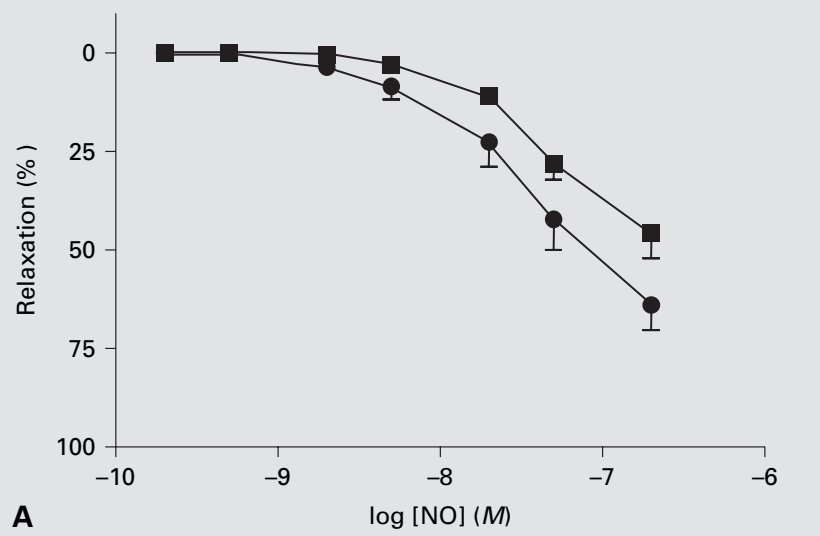

A

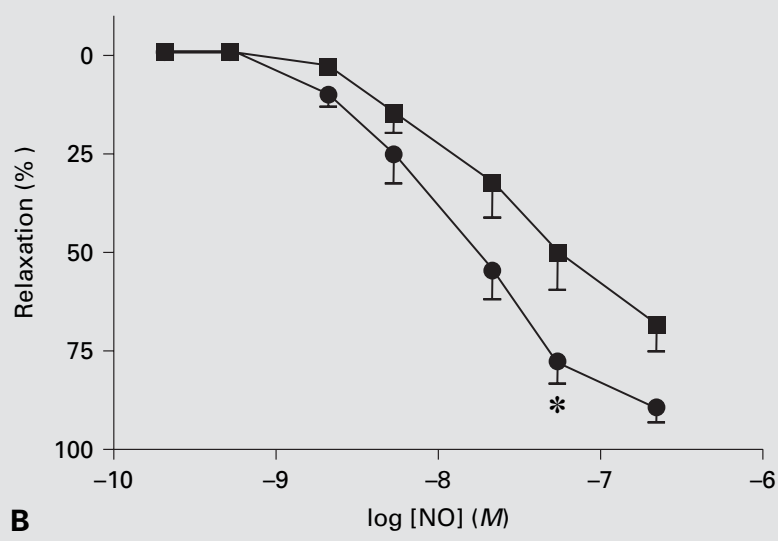

Fig. 4. $\mathrm{NO}$ sensitizing effects of $\mathrm{YC}-1$. Isolated third branch endothelium-denuded pulmonary artery rings from newborn $(\mathbf{A})$ and 2-week-old (B) piglets were constricted with U46619 in the absence (control, $\mathbf{\square})$ or presence of YC-1 $(3 \mu M, \mathbf{O})$ and concentration-response curves to $\mathrm{NO}$ were carried out. The results are means $\pm \mathrm{SE}$ $(\mathrm{n}=7-12) . * \mathrm{p}<0.05$ vs. control. Only levels of statistical significance for the highest difference are shown.

ence of $3 \mu M$ of YC-1. The effect of YC-1 on NO-induced relaxation was not studied in arterioles. As figure 4 shows, NO induced a concentration-dependent relaxation, being more potent in the 2-week-old than in newborn animals $\left(-\log \left[\mathrm{IC}_{50}\right]=7.36 \pm 0.24\right.$ and $6.62 \pm 0.32$, respectively). In the 2 -week-old animals, YC-1 produced a significant increase in the vasorelaxant potency of $\mathrm{NO}$ (fig. $4 \mathrm{~B},-\log \left[\mathrm{IC}_{50}\right]=7.79 \pm 0.13, \mathrm{p}<0.05$ ). However, YC-1 produced a weaker $\left(-\log \left[\mathrm{IC}_{50}\right]=7.07 \pm 0.14\right)$ and non-significant potentiation of the response to $\mathrm{NO}$ of the neonatal vessels (fig. 4A).

\section{Discussion}

The compound YC-1 belongs to a novel class of drugs regarded as NO-independent activators and sensitizers of sGC, which are potential therapeutic agents in the treatment of several pathologies in which the NO-cGMP pathway is impaired such as pulmonary hypertension [4]. In the present study we describe that: (1) YC-1 induced a sGC-mediated relaxation of isolated fifth- to seventhgeneration intrapulmonary arterioles with a similar potency like in larger pulmonary arteries, (2) In the 2-weekold piglet, but not in newborn animals, YC-1-induced pulmonary artery relaxation was impaired by endothelium removal and NOS inhibition, (3) Finally, YC-1 ameliorated the response to exogenous NO in the 2-week-old but not in the neonatal pulmonary arteries.

Successful adaptation of the newborn to postnatal conditions requires a dramatic transition of the pulmonary circulation from a high-resistance state in utero to a lowresistance state within minutes after birth. NO is critically involved in these changes [1]. A second gradual phase of reduction in pulmonary vascular resistance occurs over the first days and weeks of postnatal life in order to reach the low pulmonary arterial pressure characteristic of the adult [18]. An increased responsiveness to the NO/cGMP pathway during this period is thought to be a key event in this maturational process and has been demonstrated in isolated pulmonary arteries from numerous species [17, 19-24]. To understand this phenomenon, developmental changes in the expression and activity of numerous proteins involved in the NO/cGMP pathway have been analyzed. The endothelial NO synthase (eNOS) expression and activity did not change after birth [25, 26; authors unpublished data], cytosolic superoxide dismutase (SOD-1) expression and activity decreased [23, 24], the expression of sGC in homogenates from pulmonary arteries increased with postnatal age both at the level of mRNA and protein [11] and PDE5 activity and expression increased with postnatal age [27].

In the present work, we have observed that the response to YC-1 augmented with postnatal age in endothelium-intact piglet pulmonary arteries, confirming our previous results in endothelium-denuded arteries [11]. Different parts of the pulmonary circulation can react differently to vasoconstrictor and dilator stimuli, a phenomenon further influenced by age [28]. However, YC-1 showed similar vasorelaxant potency and a similar pattern of age-related changes was observed in third branch and fifth-seventh-generation intrapulmonary arterioles. These results are consistent with the age-dependent 
changes in the expression of sGC in the pulmonary resistance arteries as described in third branch pulmonary arteries [11]. The pharmacology of YC-1 in piglet pulmonary arteries appears to be different from that of other sGC activators (e.g., NO and the NO donor nitroprusside) and PDE5 inhibitors (e.g., sildenafil). They all share their dependence on sGC activity because their effects are strongly inhibited by the SGC inhibitor ODQ. However, in contrast to NO [17, 24] and sildenafil [27], the effects of YC-1 were, in the 2-week-old pulmonary arteries, partially dependent on endothelium-derived $\mathrm{NO}$ as indicated by the inhibitory effect of L-NAME and endothelium removal. Thus, our data suggest that YC-1 stimulated vascular relaxation might be attenuated when the endothelium loses its integrity and/or ability to synthesize $\mathrm{NO}$ and suggest a synergistic action of basal endotheliumderived $\mathrm{NO}$ and $\mathrm{YC}-1$ on sGC. Alternatively, YC-1 might induce direct release of endothelium-derived $\mathrm{NO}$ as demonstrated in bovine aortic endothelial cells [8]. Even when our results cannot rule out a possible effect of YC-1 on endothelial cells, YC-1 showed sinergistic effects with exogenous NO in endothelium denuded arteries consistent with the view that $\mathrm{YC}-1$ sensitized sGC to NO.

Some infants fail to achieve normal postnatal decrease in pulmonary vascular resistance, which leads to severe respiratory distress and hypoxemia, referred to as PPHN [1]. Reduced NO synthesis, bioavailability and/or activity have been involved in the pathogenesis of PPHN [1, 29]. In addition, multicenter, randomized trials have shown that inhaled NO improves the clinical condition of infants with PPHN [30]. However, therapy with inhaled NO fails in $40-50 \%$ of the patients [30]. Sensitization to NO that can be achieved by either increasing cGMP synthesis (i.e., increasing sGC activity) or reducing cGMP metabolism (i.e., reducing PDE5 activity) appears as a novel potential strategy to treat PPHN. The PDE5 inhibitor sildenafil has been shown to be a relatively selective pulmonary vasodilator with minor systemic effects and can be used either alone or in combination with inhaled NO [31]. It has been recently introduced in the treatment of adult pulmonary hypertension and it is also potentially useful in the treatment of PPHN [30]. However, deleterious effects on arterial oxygenation have been reported in animal models of neonatal pulmonary hypertension [32].

Apart form its putative effects as PDE inhibitor [4], YC-1 and similar compounds, which produce NO independent activation and sensitization towards NO, might have important pharmacological implications for the therapy of PPHN. The pyrazolopyridine derivative BAY
41-2272, a compound structurally related to YC-1 [33], augmented and prolonged the pulmonary vasodilator response to inhaled NO in lambs with U46619-induced pulmonary hypertension [34]. In the present work, we have observed that YC-1 increased the peak relaxation in response to an exogenous NO challenge in endotheliumdenuded 2-week-old conduit pulmonary arteries. This effect is consistent with the previously reported YC-1-induced increase in the potency of $\mathrm{NO}$ on purified sGC activity [35]. Remarkably, YC-1 mediated NO sensitization was weak and non-significant in the neonatal arteries. In fact, and as previously described the vasorelaxant responses induced by exogenously added NO in endothelium-denuded pulmonary arteries increased with maturation $[17,27]$, and this age-related differences in NO-induced relaxation were exacerbated in the presence of YC-1. As mentioned above, maturational changes in the efficacy of NO/cGMP to induce pulmonary vascular relaxation are due to alterations in multiple steps in the signaling pathway [11]. Due to the important segmental differences in vascular contractility that are present in the pulmonary circulation, informations obtained in conduit pulmonary arteries should be cautiously extrapolated to resistance vessels and to in vivo situation. However, the present results indicate that YC-1 is also less effective as a vasodilator and $\mathrm{NO}$ sensitizer in the neonatal period and suggest a possible disadvantage of this drug for the treatment of PPHN.

In conclusion, the ability of $\mathrm{YC}-1$ to induce pulmonary vascular relaxation and to augment the relaxant effects of $\mathrm{NO}$ increased with postnatal age. Either alone or in combination with exogenous NO, YC-1 and YC-1-like compounds could be an excellent therapeutic tool for the management of PPHN. However, one of the points of concern would be a reduced sensitivity of neonatal vessels to the pulmonary vascular actions of these compounds.

\section{Acknowledgements}

This work was supported by CAM (08.4/0036.2001) and CICYT (SAF 2002/02304) Grants. A.C., L.M., F.L., and G. G.-L. were supported by FISS, by Ministerio de Educación y Ciencia, by CSIC and by Fundación Canaria de Investigación y Salud (FUNCIS-2/2002), respectively.

Biol Neonate 2006;90:66-72 71 


\section{References}

1 Abman SH: Abnormal vasoreactivity in the pathophysiology of persistent pulmonary hypertension of the newborn. Pediatr Rev 1999; 20:e103-e109.

-2 Warner TD, Mitchell JA, Sheng H, Murad F: Effects of cyclic GMP on smooth muscle relaxation. Adv Pharmacol 1994;26:171-194.

$\checkmark 3$ Ko FN, Wu CC, Kuo SC, Lee FY, Teng CM: YC-1, a novel activator of platelet guanylate cyclase. Blood 1994;84:4226-4233.

$\checkmark 4$ Friebe A, Koesling D: Regulation of nitric oxide-sensitive guanylyl cyclase. Circ Res 2003; 93:96-105.

$\checkmark 5$ Wu CC, Ko FN, Kuo SC, Lee FY, Teng CM: $\mathrm{YC}-1$ inhibited human platelet aggregation through NO-independent activation of soluble guanylate cyclase. Br J Pharmacol 1995; 116: 1973-1978.

6 Mülsch A, Bauersachs J, Schäfer A, Stasch JP, Kast R, Busse R: Effect of YC-1, an NO-independent, superoxide-sensitive stimulator of soluble guanylyl cyclase, on smooth muscle responsiveness to nitrovasodilators. Br J Pharmacol 1997; 120:681-689.

7 Galle J, Zabel U, Hubner U, Hatzelmann A, Wagner B, Wanner C, Schmidt HH: Effects of the soluble guanylyl cyclase activator, YC-1, on vascular tone, cyclic GMP levels and phosphodiesterase activity. Br J Pharmacol 1999;127: 195-203.

-8 Wohlfart P, Malinski T, Ruetten H, Schindler $\mathrm{U}$, Linz W, Schoenafinger $\mathrm{K}$, Strobel $\mathrm{H}$, Wiemer G: Release of nitric oxide from endothelial cells stimulated by $\mathrm{YC}-1$, an activator of soluble guanylyl cyclase. Br J Pharmacol 1999; 128:1316-1322.

-9 Friebe A, Schultz G, Koesling D: Sensitizing soluble guanylyl cyclase to become a highly CO-sensitive enzyme. EMBO J 1996; 15:68636868.

10 Hampl V, Herget J: Role of nitric oxide in the pathogenesis of chronic pulmonary hypertension. Physiol Rev 2000;80:1337-1372.

$\checkmark 11$ Moreno L, Gonzalez-Luis G, Cogolludo A, Lodi F, Lopez-Farre A, Tamargo J, Villamor E, Perez-Vizcaino F: Soluble guanylyl cyclase during postnatal porcine pulmonary maturation. Am J Physiol Lung Cell Mol Physiol 2005;288:L125-L130.

-12 Tulis DA, Durante W, Peyton KJ, Chapman GB, Evans AJ, Schafer AI: YC-1, a benzyl indazole derivative, stimulates vascular cGMP and inhibits neointima formation. Biochem Biophys Res Commun 2000;279:646-652.
13 Ghofrani HA, Wiedemann R, Rose F, Schermuly RT, Olschewski H, Weissmann N, Gunther A, Walmrath D, Seeger W, Grimminger F: Sildenafil for treatment of lung fibrosis and pulmonary hypertension: a randomised controlled trial. Lancet 2002;360:895-900.

14 Kanthapillai P, Lasserson TJ, Walters EH: Sildenafil for pulmonary hypertension. Cochrane Database Syst Rev 2004;4:CD003562.

15 Gonzalez-Luis G, Perez-Vizcaino F, GarciaMuñoz F, de Mey JG, Blanco CE, Villamor E: Age-related differences in vasoconstrictor responses to isoprostanes in piglet pulmonary and mesenteric vascular smooth muscle. Pediatr Res 2005;57:845-852.

16 Villamor E, Ruijtenbeek K, Pulgar V, De Mey JG, Blanco CE: Vascular reactivity in intrapulmonary arteries of chicken embryos during transition to ex ovo life. Am J Physiol Regul Integr Comp Physiol 2002;282:R917-R927.

17 Villamor E, Perez-Vizcaino F, Cogolludo AL, Conde-Oviedo J, Zaragoza-Arnaez F, LopezLopez JG, Tamargo J: Relaxant effects of carbon monoxide compared with nitric oxide in pulmonary and systemic vessels of new born piglets. Pediatr Res 2000;48:546-553.

18 Haworth SG, Hislop AA: Adaptation of the pulmonary circulation to extra-uterine life in the pig and its relevance to the human infant. Cardiovasc Res 1981;15:108-119.

19 Abman SH, Chatefield BA, Rodman DM, Hall SL, McMurtry IF: Maturational changes in endothelium-derived relaxing factor activity in ovine pulmonary arteries in vitro. Am J Physiol 1991;260:L280-L285.

20 Zellers TM, Vanhoutte PM: Endothelium-dependent relaxations of piglet pulmonary arteries augment with maturation. Pediatr Res 1991;30:176-180.

21 Liu SF, Hislop AA, Haworth SG, Barnes PJ: Developmental changes in endothelium-dependent pulmonary vasodilatation in pigs. $\mathrm{Br}$ J Pharmacol 1992;106:324-330.

22 Tulloh RMR, Hislop AA, Boels PJ, Deutch J, Haworth SG: Chronic hypoxia inhibits postnatal maturation of porcine intrapulmonary artery relaxation. Am J Physiol 1997;272: H2436-H2445.

23 Villamor E, Kessels CG, Fischer MA, Bast A, de Mey JG, Blanco CE: Role of superoxide anion on basal and stimulated nitric oxide activity in neonatal piglet pulmonary vessels. Pediatr Res 2003;54:372-381.

24 Pérez-Vizcaíno F, López-López JG, Santiago R, Cogolludo A, Zaragozá-Arnáez F, Moreno L, Alonso MJ, Salaíces M, Tamargo J: Postnatal maturation in nitric oxide-induced pulmonary artery relaxation involving cyclooxygenase-1 activity. Am J Physiol Lung Cell Mol Physiol 2002;283:L839-L848.
25 Hislop AA, Springal DR, Buttery LDK, Pollock JS, Haworth SG: Abundance of endothelial nitric oxide synthase in newborn intrapulmonary arteries. Arch Dis Child 1995;12: F17-F21.

26 Arrigoni FI, Hislop AA, Pollock JS, Haworth SG, Mitchell JA: Birth upregulates nitric oxide synthase activity in the porcine lung. Life Sci 2002;70:1609-1620.

27 Moreno L, Losada L, Cogolludo A, Lodi F, Lugnier C, Villamor E, Moro M, Tamargo J, Pérez-Vizcaíno F: Postnatal maturation of phosphodiesterase 5 (PDE5) in piglet pulmonary arteries: activity, expression, effects of PDE5 inhibitors and role on the $\mathrm{NO} /$ cyclic GMP pathway. Pediatr Res 2004;56:563570

28 Boels PJ, Deutsch J, Gao B, Haworth SG: Maturation of the response to bradykinin in resistance and conduit pulmonary arteries. Cardiovasc Res 1999;44:416-428.

29 Villamor E, Le Cras TD, Horan MP, Halbower AC, Tuder RM, Abman SH: Chronic intrauterine pulmonary hypertension impairs endothelial nitric oxide synthase in the ovine fetus. Am J Physiol 1997;272:L1013-L1020.

30 Finer NN, Barrington KJ: Nitric oxide for respiratory failure in infants born at or near term. Cochrane Database Syst Rev 2001;4: CD000399.

31 Travadi JN, Patole SK: Phosphodiesterase inhibitors for persistent pulmonary hypertension of the newborn: a review. Pediatr Pulmonol 2003; 36:529-535.

32 Shekerdemian LS, Ravn HB, Penny DJ: Interaction between inhaled nitric oxide and intravenous sildenafil in a porcine model of meconium aspiration syndrome. Pediatr Res 2004; 55:413-418.

-33 Stasch JP, Becker EM, Alonso-Alija C, Apeler H, Dembowsky K, Feurer A, Gerzer R, Minuth T, Perzborn E, Pleiss U, Schroder H, Schroeder W, Stahl E, Steinke W, Straub A, Schramm M: NO-independent regulatory site on soluble guanylate cyclase. Nature 2001;410: 212-215.

34 Evgenov OV, Ichinose F, Evgenov NV, Gnoth MJ, Falkowski GE, Chang Y, Bloch KD, Zapol WM: Soluble guanylate cyclase activator reverses acute pulmonary hypertension and augments the pulmonary vasodilator response to inhaled nitric oxide in awake lambs. Circulation 2004; 110:2253-2259.

35 Friebe A, Koesling D: Mechanism of YC-1-induced activation of soluble guanylyl cyclase. Mol Pharmacol 1998;53:123-127. 


\section{Chapter IV:}

Nitric oxide-mediated nonadrenergic noncholinergic relaxation of piglet pulmonary arteries decreases with postnatal age.

J Physiol Pharmacol 2007; 58:45-56 
G. GONZÁLEZ-LUIS ${ }^{1,2}$, A.J.W. FLETCHER ${ }^{3}$, L. MORENO ${ }^{4}$, F. PÉREZ-VIZCAÍNO ${ }^{4}$, C.E. BLANCO ${ }^{1}$, E. VILLAMOR ${ }^{1}$.

\section{NITRIC OXIDE-MEDIATED NONADRENERGIC NONCHOLINERGIC RELAXATION OF PIGLET PULMONARY ARTERIES DECREASES WITH POSTNATAL AGE}

${ }^{1}$ Department of Pediatrics, University Hospital Maastricht, Research Institute Growth and Development (GROW), Maastricht, The Netherlands. ${ }^{2}$ Division of Neonatology, Department of Pediatrics, Hospital Universitario Materno-Infantil de Canarias, Las Palmas de Gran Canaria, Spain. ${ }^{3}$ Department of Physiology, University of Cambridge, United Kingdom. ${ }^{4}$ Department of Pharmacology. Institute of Pharmacology and Toxicology. School of Medicine. Universidad Complutense, Madrid, Spain.

Nonadrenergic noncholinergic (NANC) vasodilator mechanisms may contribute to the maintenance of adult pulmonary and systemic vascular tone. However, their actions in the neonatal circulation have not been studied. We aimed to investigate NANC vasorelaxation in neonatal and 2-week-old piglet pulmonary and mesenteric arteries and to examine the potential role of nitric oxide (NO) in this phenomenon. Responses to electric field stimulation (EFS, $50 \mathrm{~V}, 0.25-32 \mathrm{~Hz}$ ) were investigated in pulmonary and mesenteric artery rings (external diameter 150-200 $\mu \mathrm{m}$ ) precontracted with the thromboxane $\mathrm{A}_{2}$ mimetic $\mathrm{U} 46619$, in the presence of guanethidine $(10 \mu \mathrm{M})$ and atropine $(10 \mu \mathrm{M})$. Under these conditions, EFS resulted in a frequency dependent relaxation of newborn pulmonary (maximal relaxation of $53 \pm 9.1 \%)$, mesenteric $(68.8 .2 \pm 7.1 \%)$ and 2 -wk-old mesenteric $(466.3 \%)$ arteries but this relaxation was significantly reduced $(4.5 \pm 2.2 \%)$ in 2-week-old pulmonary arteries. In neonatal pulmonary arteries, the neurotoxin tetrodotoxin $(0.3 \mu \mathrm{M})$, the NO synthase inhibitor L-NAME $(0.1 \mathrm{mM})$, and the guanylyl cyclase inhibitor ODQ $(10 \mu \mathrm{M})$ abolished EFS-induced relaxations, suggesting that NANC relaxation of porcine neonatal pulmonary arteries is mediated by NO, which is probably neuronal in origin. However, The expression in pulmonary arteries of the neuronal NO synthase (nNOS), as determined by Western-blot analysis, increased with postnatal age whereas the expression of the endothelial NOS (eNOS) did not change. In conclusion, NANC relaxation is present in neonatal pulmonary and mesenteric arteries and it is, at least partially, mediated through NO. NANC relaxation of porcine pulmonary and mesenteric arteries decreases with postnatal maturation.

Key words: nonadrenergic noncholinergic, nitric oxide, pulmonary artery, newborn 


\section{INTRODUCTION}

During the transition from fetal to postnatal life, dramatic changes in the pulmonary circulation take place, characterized by a marked decrease in pulmonary vascular resistance within minutes from birth (1). A second postnatal phase of pulmonary vascular resistance reduction takes place over the first weeks of extra-uterine life (2). Many factors regulate pulmonary blood flow in these critical periods, including mechanical influences and the release of a variety of vasoactive substances (1). Over the past several years, numerous studies have focussed on developmental changes in pulmonary vascular reactivity and have shown that responses to a variety of agonists mature at different rates and have different vulnerabilities to insults, such as hypoxia (2).

The autonomic nervous system may modify pulmonary blood flow under physiological conditions and may be involved in the pathophysiology of pulmonary vascular diseases (3). The pulmonary vasculature expresses both adrenergic and cholinergic nerves, which help to regulate pulmonary vascular tone and also contribute significantly to the structural development of the vasculature during lung growth (3). In addition, nonadrenergic noncholinergic (NANC) autonomic control has been demonstrated in many organ systems to mediate various functions, including relaxation of pulmonary arteries (4-8). Depending on species and vascular beds, there are many putative neurotransmitters mediating NANC relaxation including substance $\mathrm{P}$, calcitonin gene related peptide, adenosine and nitric oxide (NO) (4-8).

To the present date, NANC relaxation in neonatal pulmonary arteries has not been evaluated and consequently its possible role in the control of pulmonary circulation in the newborn remains unknown. In the present study, we hypothesized that NANC relaxation in early postnatal life is developmentally regulated. Therefore, our purpose was to determine whether NANC exists and undergoes postnatal changes in porcine pulmonary and mesenteric arteries, and to examine the role of NO in this phenomenon.

\section{MATERIAL AND METHODS}

All the procedures conform to the guide for the Care and Use of Laboratory Animals (NIH publication No 85-23, revised 1996) and approved by our Institutional Review Board.

\section{Tissue preparation and recording of arterial reactivity}

Piglets of 12-23 h (newborn, $n=12$ ) or 15-20 d of age ( 2 week-old, $n=12$ ) from a local farm were used in this study. Animals were killed by exsanguination after being anesthetized with sodium pentobarbitone $\left(100 \mathrm{mg} \mathrm{kg}^{-1}\right)$. The lungs and intestines were rapidly immersed in cold $\left(4^{\circ} \mathrm{C}\right)$ Krebs solution (composition in $\mathrm{mM}: \mathrm{NaCl} 118, \mathrm{KCl} 4.75, \mathrm{NaHCO}_{3} 25, \mathrm{MgSO}_{4} 1.2, \mathrm{CaCl}_{2} 2.0$, $\mathrm{KH}_{2} \mathrm{PO}_{4} 1.2$ and glucose 11). Fifth- through seventh-generation intrapulmonary arterioles (in situ external diameter of $150-200 \mu \mathrm{m}$ ) were carefully dissected free of surrounding tissue. Small 
mesenteric arteries (in situ external diameter 200-300 $\mu \mathrm{m}$ ) were removed from the mesentery of the distal jejunum and proximal ileum. These arteries were the distal-most portion of the mesenteric arterial arcade in swine and run, unbranched, from their origin in a dense arterial plexus to pierce the intestinal wall (9). Vessels were cut into rings of 1.7-2 mm of length under a dissection microscope.

Vessels were mounted between an isometric force transducer (Kistler Morce DSC 6, Seattle, USA) and a displacement device in a myograph (model 610M, Danish Myo Technology, Aarhus, Denmark) using two stainless steel wires (diameter $40 \mu \mathrm{m}$ ). Each vessel was stretched to its individual optimal lumen diameter, i.e., the diameter at which it developed the strongest contractile response to $62.5 \mathrm{mM} \mathrm{K}^{+}$, using a diameter-tension protocol as previously described (10). During mounting and experimentation, Krebs solution was maintained at $37^{\circ} \mathrm{C}$ and gassed with a $95 \% \mathrm{O}_{2}$ $5 \% \mathrm{CO}_{2}$ gas mixture. The endothelium of some vessels was removed by rubbing the inside of the mounted vessel with a human hair as previously described (10). The endothelium removal procedure was verified by the inability of acetylcholine $(1 \mu \mathrm{M})$ to relax arteries precontracted with the thromboxane $\mathrm{A}_{2}$ mimetic $\mathrm{U} 46619(0.1 \mu \mathrm{M})$. For studying adrenergic contraction, concentrationresponse curves to noradrenaline (NA) $(10 \mathrm{nM}-0.1 \mathrm{mM})$ were constructed. For studying cholinergic relaxation, vessels were precontracted with $\mathrm{U} 46619$ at a concentration $(0.1 \mu \mathrm{M})$ causing $60-80 \%$ of the maximum response to the drug $(11,12)$ and concentration-response curves to acetylcholine (ACh) $(10 \mathrm{nM}-0.1 \mathrm{mM})$ were constructed.

\section{Electrical field stimulation (EFS)}

For studying NANC relaxation, the arterial rings were preincubated with atropine $(10 \mu \mathrm{M})$ and guanethidine $(10 \mu \mathrm{M})$ to inhibit cholinergic and adrenergic components of the relaxation (8), respectively, and were precontracted with U46619 $(0.1 \mu \mathrm{M})$. After a stable contraction was obtained, EFS was applied via two platinum electrodes that were placed in the axial direction of the blood vessel and connected to an stimulator (Technical Services, Universiteit Maastricht, The Netherlands). An initial frequency-response curve was constructed utilizing the following stimulus parameters: $50 \mathrm{~V}$; train length $20 \mathrm{~s}$; pulse duration $2 \mathrm{~ms}$; frequency 0.25 to $32 \mathrm{~Hz}$. In other experiments, the U-46619-precontracted rings were stimulated with fixed EFS stimuli $(16 \mathrm{~Hz}$ for the pulmonary arteries and $8 \mathrm{~Hz}$ for the mesenteric arteries) in the presence of vehicle, the nonselective inhibitor of NO synthase (NOS) L-NAME $(0.1 \mathrm{mM})$, the soluble guanylyl cyclase inhibitor ODQ $(10 \mu \mathrm{M})$, or the neurotoxin tetrodotoxin $(0.3 \mu \mathrm{M})$.

\section{Western blot analysis}

Pulmonary arteries were frozen in liquid nitrogen and stored at $-80^{\circ} \mathrm{C}$, homogenized in a glass potter in $300 \mathrm{ml}$ of a buffer of the following composition: $10 \mathrm{mM}$ HEPES (pH 8), $10 \mathrm{mM} \mathrm{KCl}, 1 \mathrm{mM}$ EDTA, $1 \mathrm{mM}$ EGTA, $1 \mathrm{mM}$ dithiothreitol, $40 \mathrm{mg} / \mathrm{ml}$ aprotinin, $4 \mathrm{mg} / \mathrm{ml}$ leupeptin, $4 \mathrm{mg} / \mathrm{ml} \mathrm{N \alpha}$-ptosyl-1-lysine chloromethyl ketone, $5 \mathrm{mM} \mathrm{NaF}, 10 \mathrm{mM} \mathrm{Na} 2 \mathrm{MoO} 4,1 \mathrm{mM} \mathrm{NaVO} 4$ and $0.5 \mathrm{mM}$ phenylmethanesulfonyl fluoride. The homogenate was centrifuged at $100.000 \mathrm{~g}$ for $30 \mathrm{~min}$. The supernatant (cytosolic fraction) was collected and the pellet was resuspended in $200 \mathrm{~mL}$ of the same buffer containing nonidet P-40 1\% and gently shaken for 30 minutes at $4{ }^{\circ} \mathrm{C}$ and again centrifuged at $100000 \mathrm{~g}$ for 30 minutes. The pellet was discarded, and the supernatant was collected (particulate enriched fraction). The protein content was determined using the Bradford assay (reagents from Bio$\mathrm{Rad}$ ). Western blotting was performed with $20 \mathrm{mg}$ of protein from the cytosolic (for neuronal NOS, nNOS) or particulate (for endothelial NOS, eNOS) fractions. SDS-PAGE (7.5\% acrylamide) electrophoresis was performed using the method of Laemli in a mini-gel system (Bio-Rad, CA, USA). The proteins were transferred to PVDF membranes overnight, incubated with mouse anti-nNOS 
(1:2500) or anti-eNOS (1:2000) antibodies (BD Transduction Laboratories) and then with anti-mouse secondary horseradish peroxidase conjugated antibody. The bands were visualized by chemiluminiscence (ECL, Amersham, UK) and quantified using image analysis software (TotalLab, Nonlinear dynamics, UK). The results were expressed as a percentage of the data of newborn animals.

\section{Drugs}

U46619 (9,11-dideoxy-11 $\alpha, 9 \alpha$-epoxymethano-prostaglandin $\mathrm{F}_{2 \alpha}$ methyl acetate solution) was from Cayman Chemical, ODQ (1H-[1,2,4]oxadiazolo[4,3-a]quinoxalin-1-one) from Tocris Cookson Ltd (Bristol, UK), and all other drugs from Sigma Chemical Co. (St. Louis, USA). Drugs were dissolved initially in distilled deionized water (except for ODQ, in dimethylsulfoxide) to prepare a $0.01 \mathrm{M}$ stock solution and further dilutions were made in Krebs solution.

\section{Statistical analysis}

Results are expressed as means $\pm \mathrm{SE}$, and $n$ reflects the number of animals. Relaxations are expressed as the percentage of reduction of U46619-induced tone. Individual cumulative concentration-response curves were analyzed by fitting the experimental data to a nonlinear sigmoidal regression curve (GraphPad Software, San Diego, USA). Maximal effect $\left(\mathrm{E}_{\max }\right)$ and $\mathrm{EC}_{50}$ were calculated from the fitted concentration-response curves for each ring. Statistically significant differences between means were calculated by Student's ${ }^{\circ}$-test for unpaired observations. $P<0.05$ was considered statistically significant.

\section{RESULTS}

The contractions induced by $62.5 \mathrm{mM} \mathrm{KCl}$ and $0.1 \mu \mathrm{M} \mathrm{U} 46619$ in intrapulmonary arteries were not significantly different between the newborn and the 2-wk-old group (Fig. 1). These vessels did not respond to NA (Fig 1).

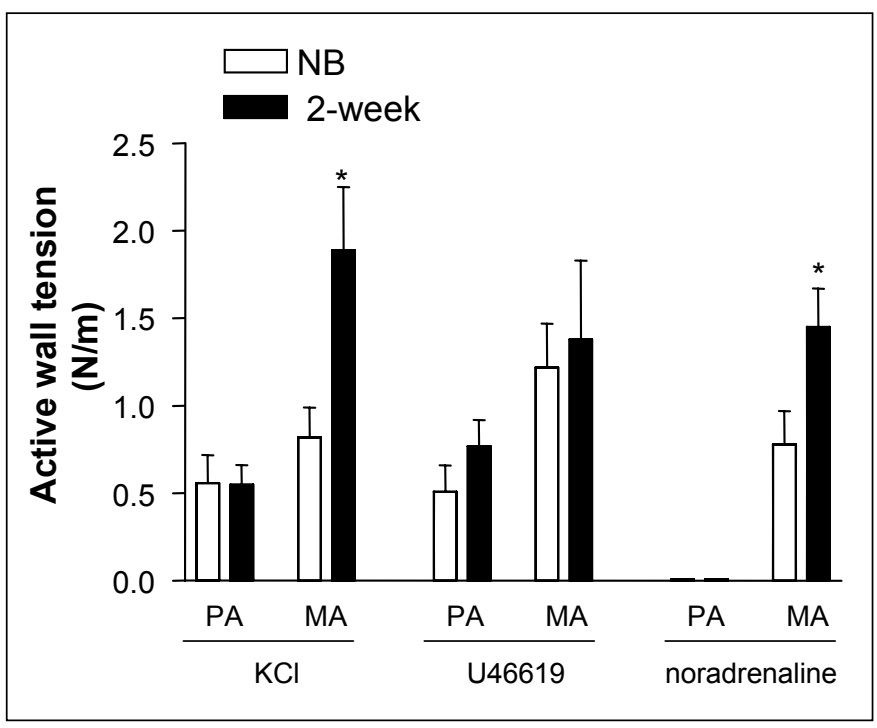

Fig. 1. Contractions of pulmonary and mesenteric arteries and small mesenteric arteries arteries of newborn (NB) and 2-wk-old piglets induced by $\mathrm{KCl}(62.5 \mathrm{mM})$, the thromboxane $\mathrm{A}_{2}$ mimetic U46619 $(0.1 \quad \mu \mathrm{M})$ and noradrenaline $(30 \mu \mathrm{M})$. Data are shown as means $+\mathrm{SE} ; n$ $=6-10$ for each group. *Significant difference between newborn and 2week-old $(P<0.05)$. 


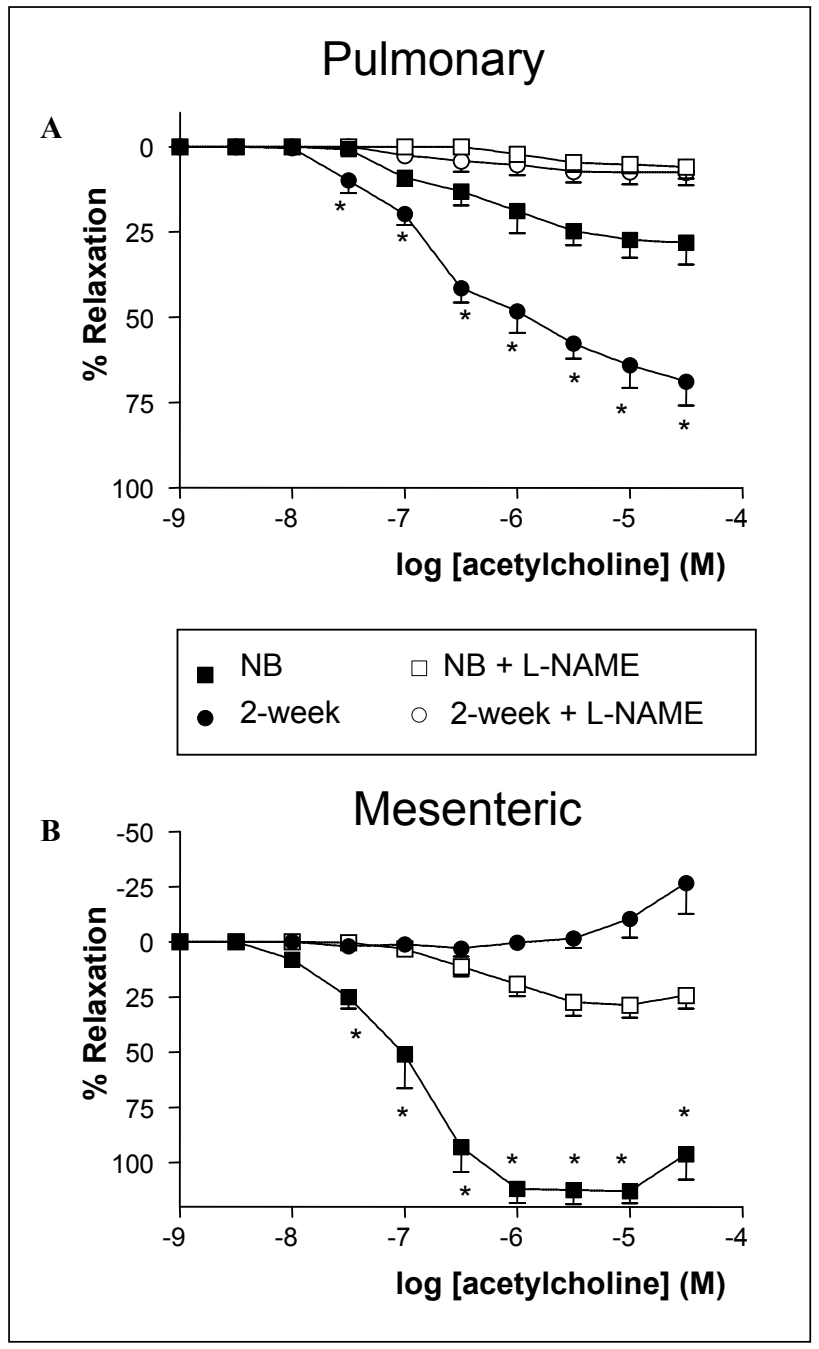

Fig 2. Relaxations of pulmonary (A) and mesenteric (B) arteries of newborn (NB) and 2-wk-old piglets induced by acetylcholine. Vessels were constricted with U46619 $(0.1 \mu \mathrm{M})$. The effects of pretreatment with the NO synthase inhibitor L-NAME $(100 \mu \mathrm{M})$ are also shown. Data are shown as means $+\mathrm{SE} ; n=6$ 10 for each group. *Significant difference between newborn and 2-week-old $(P<0.05)$.

Acetylcholine produced a concentration-dependent relaxation of U46619contracted pulmonary arteries that was significantly more marked in the 2 -wk-old piglets (Fig. 2). The maximal relaxations induced by ACh were $28.2 \pm 6.3 \%$ and $68.35 \pm 6.9 \%$ of U46619-generated tone for newborn and 2-wk-old pulmonary arteries respectively $(\mathrm{P}<0.01)$. However, sensitivity to $\mathrm{ACh}$ was not significantly different for newborn (-Log $\left.\mathrm{EC}_{50}: 6.44 \pm 0.14\right)$ and 2-wk-old (-Log $\mathrm{EC}_{50}: 6.63 \pm$ $0.15)$ pulmonary arteries. Pre-treatment of the vessels with the NOS inhibitor LNAME abolished ACh-induced relaxation in both groups of age (Fig 2).

In the mesenteric arteries, $\mathrm{KCl}$-induced contraction was significantly higher in the 2-wk-old animals, whereas U46619-evoked contraction did not change with postnatal age (Fig 1). Noradrenaline evoked a concentration-dependent 


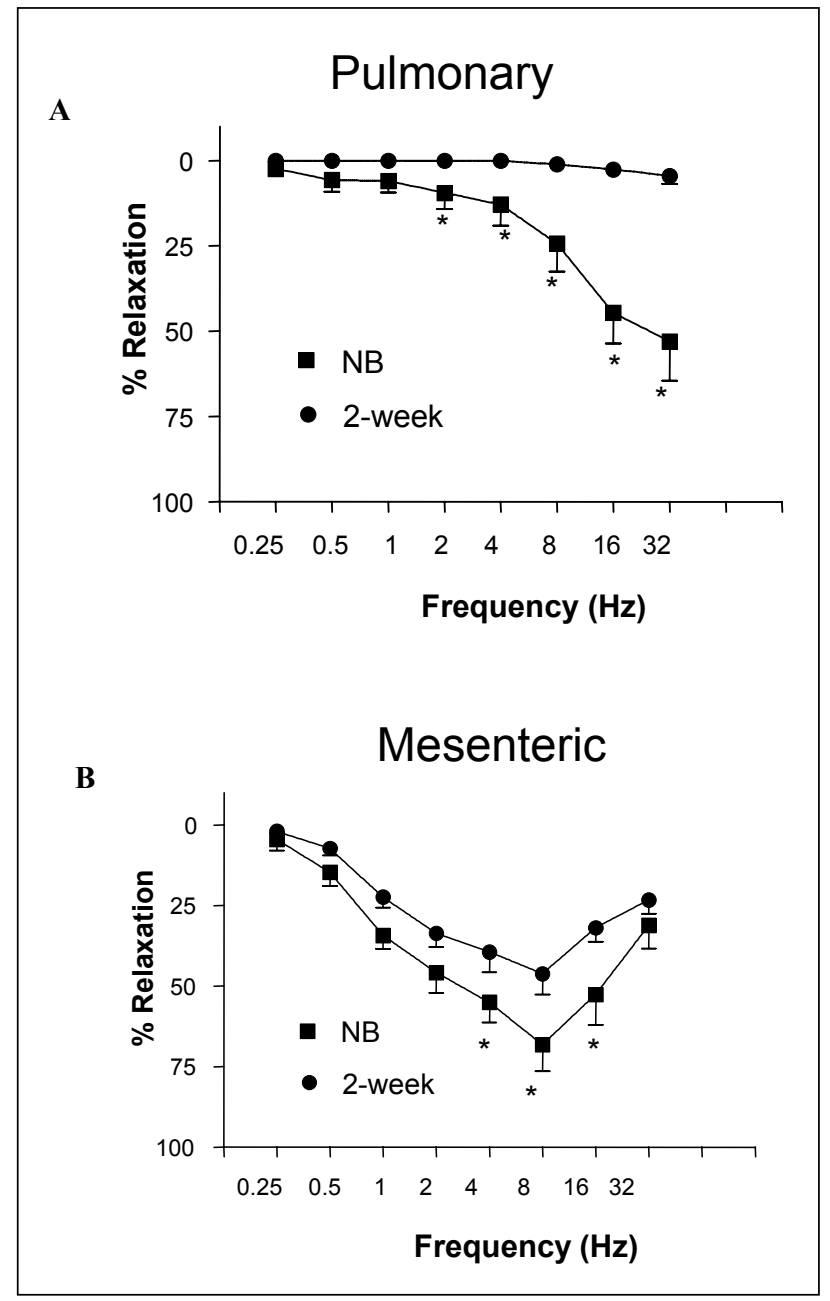

Fig 3. Frequency-dependent relaxations produced by electrical field stimulation of isolated pulmonary (A) and mesenteric (B) arteries of newborn (NB) and 2-wk-old piglets in the presence of cholinergic and adrenergic blockade with atropine $(10 \mu \mathrm{M})$ and guanethidine $(10 \mu \mathrm{M})$, respectively. Vessels were constricted with U46619 (0.1 $\mu \mathrm{M})$. Data are shown as means + SE; $n=6-10$ for each group.*Significant difference between newborn and 2-weekold $(P<0.05)$. Only levels of statistical significance for the highest difference are shown.

contraction that was significantly higher in the 2-wk-old $\left(\mathrm{E}_{\max }: 1.45 \pm 0.21 \mathrm{~N} / \mathrm{m}\right)$ than in the newborn piglets $\left(\mathrm{E}_{\max } 0.83 \pm 0.18 \mathrm{~N} / \mathrm{m}, \mathrm{P}<0.05\right)$ but showed a similar potency in both vessels $\left(-\log \mathrm{EC}_{50}: 6.39 \pm 0.17\right.$ and $6.11 \pm 0.16$ for NB and 2wk-old respectively) (Fig. 1). Acetylcholine produced a concentration-dependent relaxation of U6619 contracted neonatal mesenteric arteries (maximal relaxation $109.3 \pm 6.7 \%,-\log \mathrm{EC}_{50}: 7.07 \pm 0.1$ ), but did not relax 2-wk-old mesenteric arteries (Fig. 2). The NOS inhibitor L-NAME abolished ACh-mediated relaxation of neonatal mesenteric arteries (Fig. 2).

In the presence of atropine $(10 \mu \mathrm{M})$ and guanethidine $(10 \mu \mathrm{M}), \mathrm{U} 46619(0.1$ $\mu \mathrm{M})$ produced a stable long-lasting contraction of pulmonary and mesenteric arteries and EFS induced a transient, frequency-dependent relaxation of the 


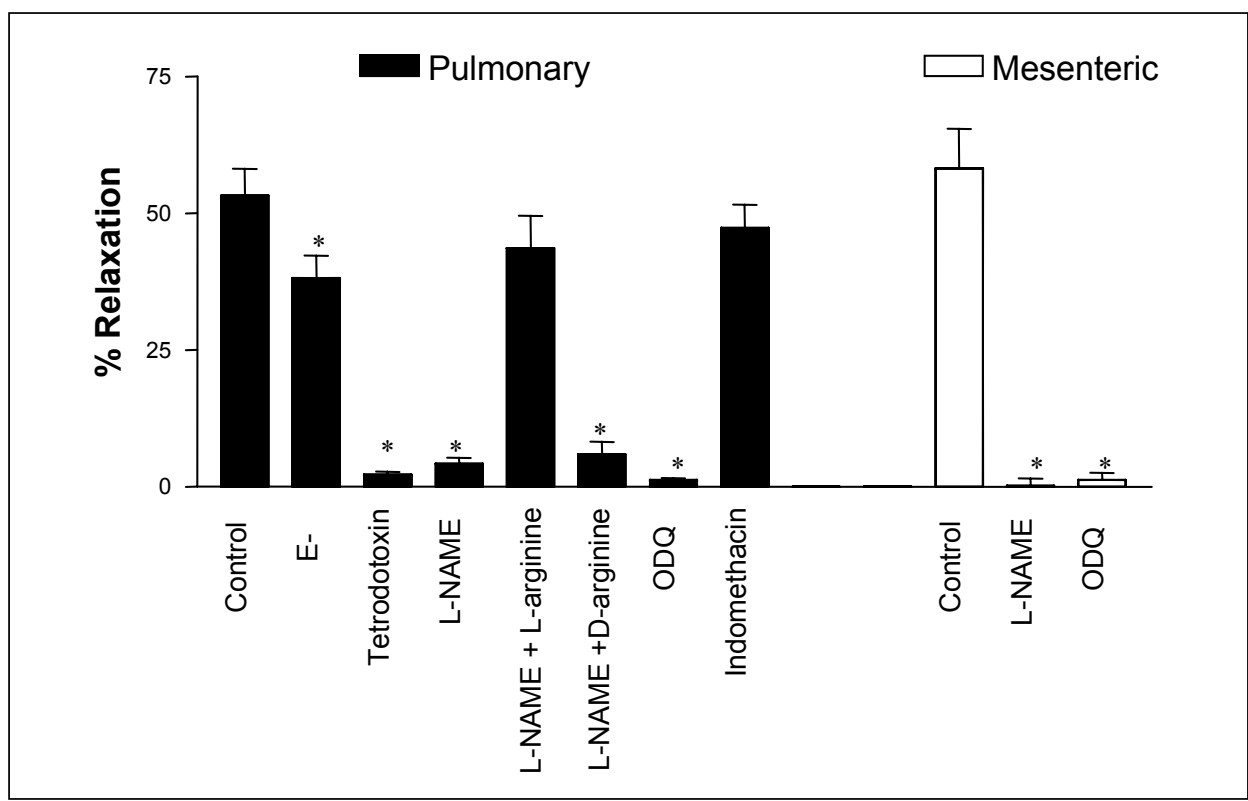

Fig 4. Effects of endothelium removal (E-), the neurotoxin tetrodotoxin $(0.3 \mu \mathrm{M})$, the non selective inhibitor of NO synthase L-NAME $(0.1 \mathrm{mM})$, the soluble guanylyl cyclase inhibitor ODQ $(10 \mu \mathrm{M})$, and the cyclooxygenase inhibitor indomethacin $(10 \mu \mathrm{M})$ on the vasorelaxant response to electrical field stimulation (EFS) of isolated pulmonary arteries (EFS: $50 \mathrm{~V}, 0.2 \mathrm{~ms}, 16 \mathrm{~Hz}$, for $20 \mathrm{~s}$ ) and mesenteric arteries (EFS: $50 \mathrm{~V}, 0.2 \mathrm{~ms}, 8 \mathrm{~Hz}$, for $20 \mathrm{~s}$ ) of newborn piglets in the presence of cholinergic and adrenergic blockade with atropine and guanethidine, respectively. Vessels were constricted with U46619 $(0.1 \mu \mathrm{M})$. Reversal by L-arginine $(1 \mathrm{mM})$, but not by D-arginine $(1 \mathrm{mM})$, of the inhibitory effect of L-NAME $(0.1 \mathrm{mM})$ on NANC relaxation is also shown. Relaxations are expressed as percentage of vessel tension before EFS was started. Data are shown as means $\pm \mathrm{SE}$; $n=6-10$ for each group. $*$ Significantly different from controls $(P<0.05)$.

U46619-induced contractions. This relaxation decreased significantly with age, particularly in the pulmonary arteries (Fig. 3A). As shown in Fig. 4, endothelium removal reduced NANC relaxation of neonatal pulmonary arteries whereas pretreatment of the vessels with the NOS inhibitor L-NAME, the soluble guanylyl cyclase inhibitor ODQ, or the neurotoxin tetrodotoxin abolished NANC relaxation. NANC relaxation of mesenteric arteries was also abolished by ODQ and L-NAME (Fig. 4). The inhibitory effect of L-NAME on the NANC relaxation was completely reversed by L-arginine $(1 \mathrm{mM})$ but not by D-arginine (Fig. 4). The presence of the cyclooxygenase inhibitor indomethacin did not significantly reduce NANC relaxation of the pulmonary arteries.

\section{Expression of nNOS and eNOS}

Both nNOS and eNOS proteins were detected by Western blot in pulmonary arteries from piglets of both groups of age. An increased expression of nNOS was 


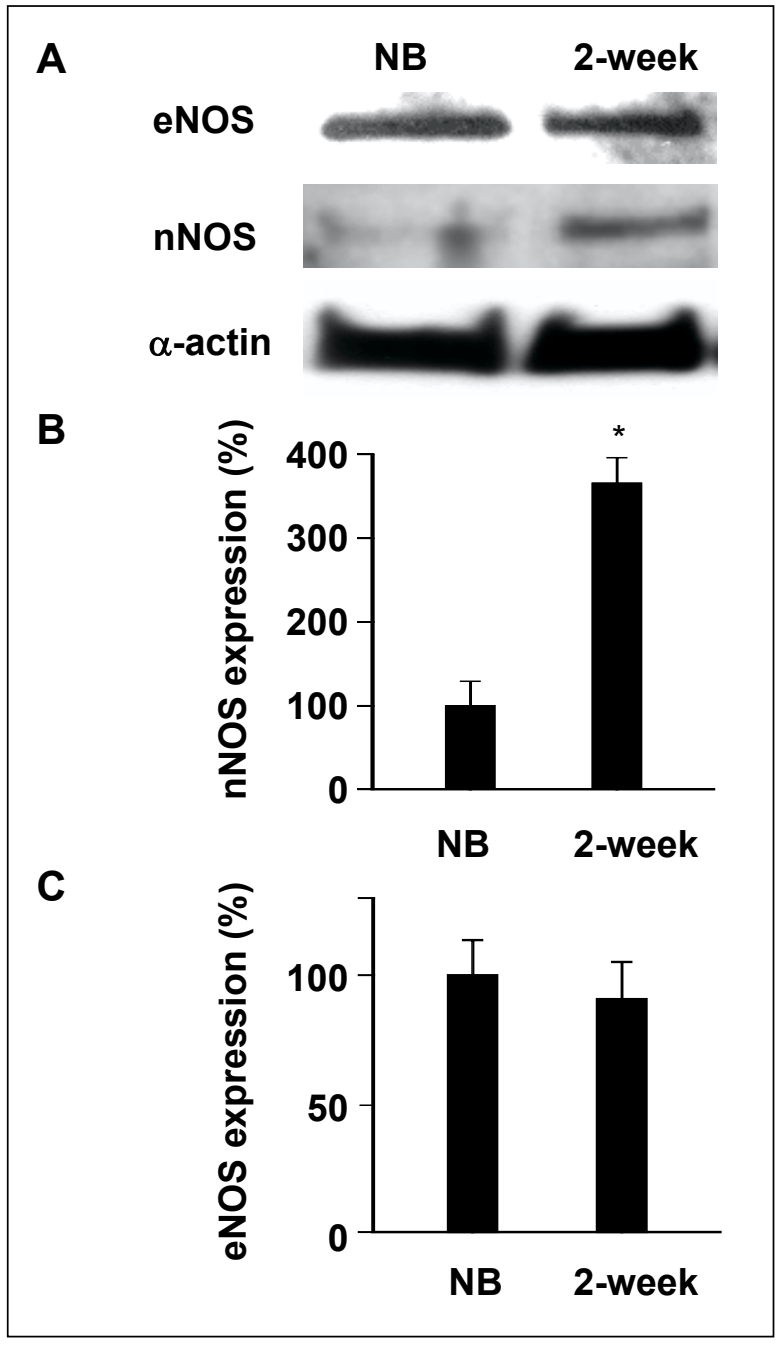

Fig 5. Expression of $\mathrm{nNOS}$ and eNOS in homogenates of pulmonary arteries from newborn (NB) and 2-week old piglets. A: typical Western blots. B and C: densitometric analysis of nNOS and eNOS protein, respectively. The results are expressed as a percentage of the data of newborn animals, means \pm SEM $(\mathrm{n}=4-6)$, *Significant difference between newborn and 2-week-old $(P<0.05)$.

observed in 2-week old animals when compared with newborns (Fig. 5) and this difference remained significant $(3.0 \pm 0.6$ fold increase, $\mathrm{P}<0.05)$ when the data were normalized to the expression of a-actin, used as an internal loading control. In contrast, eNOS expression in pulmonary arteries did not change with age (Fig. 5).

\section{DISCUSSION}

It has been widely recognized that both perivascular nerves and endothelial cells control the tone of the vascular smooth muscles and hence regulate the local blood flow. The NANC pathway plays a particularly important role in producing 
relaxation of smooth muscle in the cerebral circulation and the gastrointestinal, urogenital and respiratory tracts (13). This study is the first to demonstrate NANC relaxation in neonatal pulmonary arteries. NANC relaxation of porcine pulmonary arteries decreased with postnatal age and was abolished by the NOS inhibitor L-NAME, the soluble guanylate cyclase inhibitor ODQ, and by the neurotoxin tetrodotoxin. In contrast, endothelial denudation reduced but did not abolish NANC relaxation. Although the use of a non-specific NOS inhibitor (i.e. L-NAME) instead of a specific inhibitor of the nNOS is a limitation of our study, our data support the hypothesis that the NANC relaxation of porcine neonatal pulmonary arteries is mediated by NO, which is probably neuronal in origin.

Previous reports have demonstrated the presence of endothelium-dependent and-independent NO-mediated NANC relaxation in human, rat, guinea pig and cat pulmonary arteries $(3,5-8)$. In the present work, we observed an important endothelium-independent component of NANC relaxation of neonatal pulmonary arteries. A large body of evidence indicates that NO generated by nNOS is involved in NANC relaxation of pulmonary arteries $(3,6-8)$. Investigators have used immunohistochemical staining to demonstrate localization of nNOS in the perivascular nerves and pulmonary vascular smooth muscle of several species, including the pig $(14,15)$. Accordingly, we also observed that nNOS was expressed in piglet pulmonary arteries. However, the specific role of nNOS in both the developing and the mature lung is unclear. Neuronal NOS has been identified in fetal lung neuronal, epithelial, and vascular smooth muscle cells, and its expression increases with advancing gestational age $(16,17)$. In addition, there is evidence from multiple studies that nNOS is upregulated by estrogen, which normally rises markedly in the fetal circulation during the third trimester due to increasing production by the placenta (18). Moreover, a selective nNOS antagonist increased pulmonary vascular resistance in the late-gestation ovine fetus (16), supporting the hypothesis that nNOS contributes to the basal production of NO and modulation of basal vascular tone in the normal fetal pulmonary circulation. However, whether stimulation of nNOS located in the pulmonary vasculature contributes to the release of $\mathrm{NO}$ and the marked decrease in pulmonary vascular resistance at birth remains unknown. Right ventricular systolic pressure was not altered in nNOS-deficient mice compared with wildtype controls, suggesting an absent role of nNOS in the control of postnatal vascular tone, at least in this species (19).

An increased responsiveness of pulmonary circulation to the NO/cGMP pathway during the first days of postnatal life has been demonstrated in numerous species $(12,20-24)$. Thus when comparing pulmonary arteries from newborn and 2 -week-old piglets, it is observed a marked age-related increase in the responsiveness to NO-mediated/endothelium-dependent relaxation and NOmediated/endothelium-independent relaxation as well as to NO-independent activation of soluble guanylate cyclase (sGC) $(12,20-24)$. To understand this phenomenon, developmental changes in the expression and activity of several 
proteins involved in the NO/cGMP pathway have been analyzed. The endothelial NO synthase (eNOS) expression and activity did not change after birth $(24,25$ and present study). The expression of sGC in homogenates from pulmonary arteries increased with postnatal age both at the level of mRNA and protein (26). However, the activity and expression of the cGMP-degrading enzyme phosphodiesterase 5 also increased with postnatal age (27). Finally, an increased responsiveness of the older pulmonary arteries to cGMP cannot be excluded.

In the present work, we also demonstrated postnatal changes in NO-mediated NANC pulmonary vascular relaxation. However, in contrast to relaxations induced by $\mathrm{ACh}, \mathrm{NO}$ gas or the NO donor sodium nitroprusside (20-22), NOmediated NANC of piglet pulmonary arteries decreased with postnatal age and is almost absent in the 2-week-old pulmonary arteries. Paradoxically, whereas NANC relaxation decreased with advancing age, a marked increase in nNOS expression was observed. These data reflect how during the early stages of life, where marked physiological changes take place, changes in the expression of a single protein often do not correlate with a complex functional response which involves the integrated activity of large number of proteins. In addition to changes in protein expression, other potential mechanism which might account for changes in NANC relaxation include developmental changes in other vasoactive mediators released by NANC stimulation, alterations in nNOS cellular localization, differences in nNOS substrate and cofactor availability, and structural or metabolic factors which might interfere with the NO diffusion from the nerve terminal to the smooth muscle cell and its oxidative breakdown within the adventitial layer of the vessel $(20,22,28,29)$. Interestingly, Afshar et al. (18) demonstrated in a fetal baboon model that nNOS protein expression was increased with normal fetal development from 125 to $140 \mathrm{~d}$ of gestation (term $=$ $185 \mathrm{~d}$ ), but it was dramatically decreased when the baboons were delivered and maintained with mechanical ventilation over the same maturational period. In contrast, postnatal exposure to 3-4 days of hypoxia did not alter the pulmonary vascular expression of nNOS in the piglet (14). These effects of a perinatal adverse environment on nNOS maturation warrant further investigation that will also address whether the reduced NANC relaxation of the porcine 2-week pulmonary arteries is permanent or transitory, reappearing later in life, as is suggested by the presence of NO-mediated NANC relaxation in pulmonary arteries from adults of other species (4-8).

In addition to our findings in pulmonary arteries, we have also observed NOmediated NANC relaxation of small mesenteric arteries. Interestingly, this relaxation also decreased with postnatal age, whereas noradrenaline-evoked contraction augmented. Moreover, and in contrast to pulmonary arteries, NOmediated, acetylcholine-induced relaxation of small mesenteric arteries also decreased with age. The newborn intestine is the site of intense growth and dramatic vascular changes during early postnatal life as it transitions from relative dormancy in utero to become the sole means of water and nutrient assimilation after birth 
$(9,30)$. Thus, in 1-d old piglets, mesenteric vascular tone is determined by endothelial production of $\mathrm{NO}$ and endothelin, and the inherent myogenic response. In contrast, in older subjects mesenteric circulation is primarily passive in nature and fail to demonstrate significant changes in response to blockade of endogenous NO production or endothelin receptors, or applied perturbations of pressure or flow rate $(9,30)$. These mechanisms of maturation of the intestinal vasculature may play important roles in gut development during early postnatal life $(9,30)$.

In summary, our results indicate that in neonatal pulmonary arteries, EFS induces a NANC vasodilator response. This neural relaxation is mediated predominantly by $\mathrm{NO}$ and decreases with postnatal age, suggesting a role for NANC mechanisms in the perinatal transitional circulation.

\section{REFERENCES}

1. Abman S. Abnormal vasoreactivity in the pathophysiology of persistent pulmonary hypertension of the newborn. Pediatr Rev 1999; 20:103-109.

2. Haworth SG, Hislop AA. Lung development-the effects of chronic hypoxia. Semin Neonatol 2003;8:1-8.

3. Barnes PJ, Liu SF. Regulation of pulmonary vascular tone. Pharmacol Rev 1995; 47:87-131.

4. Liu SF, Crawley DE, Evans TW, Barnes PJ. Endothelium-dependent nonadrenergic, noncholinergic neural relaxation in guinea pig pulmonary artery. J Pharmacol Exp Ther 1992; 260:541-548.

5. Liu SF, Crawley DE, Rohde JA, Evans TW, Barnes PJ. Role of nitric oxide and guanosine 3',5'cyclic monophosphate in mediating nonadrenergic, noncholinergic relaxation in guinea-pig pulmonary arteries. Br J Pharmacol 1992;107: 861-866.

6. Scott JA, Craig I, McCormack DG. Nonadrenergic noncholinergic relaxation of human pulmonary arteries is partially mediated by nitric oxide. Am J Respir Crit Care Med 1996;154: 629-632.

7. Scott JA, McCormack DG. Nonadrenergic noncholinergic vasodilation of guinea pig pulmonary arteries is mediated by nitric oxide. Can J Physiol Pharmacol 1999;77: 89-95.

8. Gumusel B, Orhan D, Tolunay O, Uma S. The role of nitric oxide in mediating nonadrenergic, noncholinergic relaxation in rat pulmonary artery. Nitric Oxide 2001;5:296-301.

9. Nankervis CA, Dunaway DJ, Nowicki PT. Determinants of terminal mesenteric artery resistance during the first postnatal month. Am J Physiol Gastrointest Liver Physiol 2001;280:678-686.

10. Villamor E, Ruijtenbeek K, Pulgar V, De Mey JG, Blanco CE. Vascular reactivity in intrapulmonary arteries of chicken embryos during transition to ex ovo life. Am J Physiol Regul Integr Comp Physiol 2002;282:917-927.

11. González-Luis G, Pérez-Vizcaino F, García-Munoz F., de Mey JG., Blanco CE, Villamor E. Age-related differences in vasoconstrictor responses to isoprostanes in piglet pulmonary and mesenteric vascular smooth muscle. Pediatr Res 2005;57:845-852.

12. González-Luis G, Cogolludo A, Moreno L, Lodi F, Tamargo J, Pérez-Vizcaíno F, Villamor E. Relaxant Effects of the Soluble Guanylate Cyclase Activator and NO Sensitizer YC-1 in Piglet Pulmonary Arteries. Biol Neonate 2006;90:66-72.

13. Ignarro LJ. Nitric oxide as a unique signaling molecule in the vascular system: a historical overview. J Physiol Pharmacol. 2002; 53:503-514. 
14. Turley JE, Nelin LD, Kaplowitz MR, Zhang Y, Fike CD. Exhaled NO is reduced at an early stage of hypoxia-induced pulmonary hypertension in newborn piglets. Am J Physiol Lung Cell Mol Physiol 2003;284:489-500.

15. Sherman TS., Chen Z, Yuhanna IS, Lau KS, Margraf LR, Shaul PW. Nitric oxide synthase isoform expression in the developing lung epithelium. Am J Physiol 1999;276:383-390.

16. Rairigh RL, Storme L, Parker TA, et al. Role of neuronal nitric oxide synthase in regulation of vascular and ductus arteriosus tone in the ovine fetus. Am J Physiol Lung Cell Mol Physiol 2000;278:105-110.

17. Shaul PW. Ontogeny of nitric oxide in the pulmonary vasculature. Semin Perinatol 1997;21:381-392.

18. Afshar S, Gibson LL, Yuhanna IS, et al. Pulmonary NO synthase expression is attenuated in a fetal baboon model of chronic lung disease. Am J Physiol Lung Cell Mol Physiol 2003;284:749-758.

19. Fagan KA., Tyler RC, Sato K, et al. Relative contributions of endothelial, inducible, and neuronal NOS to tone in the murine pulmonary circulation. Am J Physiol 1999;277:472-478.

20. Lopez-Lopez JG, Perez-Vizcaino F, Cogolludo AL, Ibarra M, Zaragoza-Arnaez F, Tamargo J. Nitric oxide- and nitric oxide donors-induced relaxation and its modulation by oxidative stress in piglet pulmonary arteries. Br J Pharmacol. 2001;133:615-624.

21. Villamor E, Pérez-Vizcaíno F, Cogolludo AL, et al. Relaxant effects of carbon monoxide compared with nitric oxide in pulmonary and systemic vessels of new born piglets. Pediatr Res 2000;48:546-553.

22. Villamor E, Kessels CG, Fischer MA, Bast A, de Mey JG, Blanco CE. Role of superoxide anion on basal and stimulated nitric oxide activity in neonatal piglet pulmonary vessels. Pediatr Res 2003;54:372-381.

23. Abman SH, Chatefield BA, Rodman DM, Hall SL, McMurtry IF. Maturational changes in endothelium-derived relaxing factor activity in ovine pulmonary arteries in vitro. Am J Physiol 1991;260:280-285.

24. Hislop AA, Springal DR, Buttery LDK, Pollock JS, Haworth SG. Abundance of endothelial nitric oxide synthase in newborn intrapulmonary arteries. Arch Dis Child 1995;12:17-21.

25. Arrigoni FI, Hislop AA, Pollock JS, Haworth SG, Mitchell JA. Birth upregulates nitric oxide synthase activity in the porcine lung. Life Sci 2002;70:1609-1620.

26. Moreno L, González-Luis G, Cogolludo A, et al. Soluble guanylyl cyclase during postnatal porcine pulmonary maturation. Am J Physiol Lung Cell Mol Physiol 2005;288:125-130.

27. Moreno L, Losada L, Cogolludo A, Lodi F, Lugnier C, Villamor E, Moro M, Tamargo J, PérezVizcaíno F. Postnatal maturation of phosphodiesterase 5 (PDE5) in piglet pulmonary arteries: activity, expression, effects of PDE5 inhibitors and role on the NO/cyclic GMP pathway. Pediatr Res 2004;56:563-570.

28. Kamada Y, Jenkins GJ, Lau M, Dunbar AY, Lowe ER, Osawa Y. Tetrahydrobiopterin depletion and ubiquitylation of neuronal nitric oxide synthase. Brain Res Mol Brain Res 2005;142:19-27.

29. McCormack DG, Salonen RO, Barnes PJ. Effect of sensory neuropeptides on canine bronchial and pulmonary vessels in vitro. Life Sci. 1989;45:2405-2412.

30. Nankervis CA, Reber KM, Nowicki PT. Age-dependent changes in the postnatal intestinal microcirculation. Microcirculation. 2001;8:377-387.

Received: July 6, 2006

Accepted: XXX

Author's address: E. Villamor. Dept of Pediatrics, University Hospital Maastricht. P. Debyelaan 25. P.O. Box 5800. 6202 AZ Maastricht. The Netherlands. Phone +31 43-3877246, fax +31 43-3875246; e-mail: eiv@paed.azm.nl 


\section{Part II}

\section{Chapter V:}

Isoprostanes in fetal and neonatal health and disease.

Free Radic Biol Med 2010;48:177-88 


\title{
Review Article
}

\section{Isoprostanes in fetal and neonatal health and disease}

\author{
Jaques Belik ${ }^{\mathrm{a}, *}$, Gema E. González-Luis ${ }^{\mathrm{b}}$, Francisco Perez-Vizcaino ${ }^{\mathrm{c}}$, Eduardo Villamor ${ }^{\mathrm{d}}$ \\ a Departments of Pediatrics and Physiology University of Toronto and Physiology and Experimental Medicine Program of the Research Institute, The Hospital for Sick Children, \\ Toronto, Canada \\ ${ }^{\mathrm{b}}$ Division of Neonatology, Department of Pediatrics, Hospital Universitario Materno-Infantil de Canarias, Las Palmas de Gran Canaria, Spain \\ ' Department of Pharmacology, School of Medicine, Complutense University, CIBER Enfermedades Respiratorias (CiberRes), Madrid Spain \\ d Department of Pediatrics, Maastricht University Medical Center (MUMC+), School for Oncology and Developmental Biology (GROW), Maastricht, The Netherlands
}

\section{A R T I C L E I N F O}

\section{Article history:}

Received 26 May 2009

Revised 28 September 2009

Accepted 18 October 2009

Available online 23 October 2009

\section{Keywords:}

Prostaglandins

Lung

Cardiovascular System

Pregnancy

\begin{abstract}
A B S T R A C T
Isoprostanes are prostaglandin-like bioactive molecules generated via nonenzymatic peroxidation of lipid membrane-derived arachidonic acid by free radicals and reactive oxygen species. Their cognate receptors, biological actions, and signaling pathways are poorly understood. Aside from being sensitive and specific biomarkers of oxidative stress, E- and F-ring isoprostanes have important biological functions and likely mediate many of the disease-related pathological changes for which they are used as indicators. The biochemical pathways involved in isoprostane formation, their pathogenetic relevance to adult disease states, and their biological function are addressed. Developmentally, plasma and tissue content data show that isoprostane levels are highest during fetal and early neonatal life, when compared with adults. As such, the available data suggesting that isoprostanes play an important biological role, as well as possibly actively participate in the regulation of pulmonary vascular tone and the transition from fetal to postnatal life, are here reviewed. Lastly, the association between isoprostanes and certain neonatal clinical conditions is addressed. Although its existence has been recognized for almost 20 years, little is known about the critical importance of isoprostanes during fetal life and immediate neonatal period. This review is an attempt to bridge this knowledge gap.
\end{abstract}

(c) 2009 Elsevier Inc. All rights reserved.

\section{Contents}

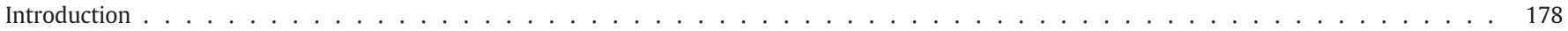

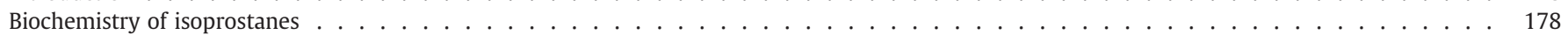

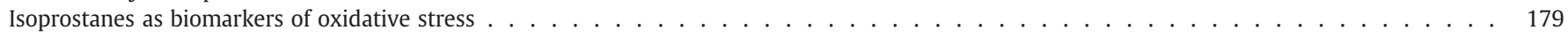

Isoprostanes as mediators of biological activity . . . . . . . . . . . . . . . . . . . . . . . . . . . 180

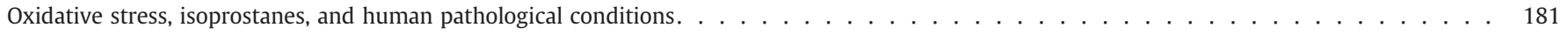

Isoprostanes and the fetus . . . . . . . . . . . . . . . . . . . . . . . . . . . . . . . . . 182

Isoprostanes and the control of umbilical vasculature . . . . . . . . . . . . . . . . . . . . . . . . . . . . 182

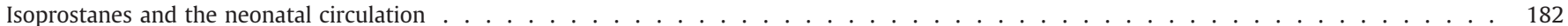

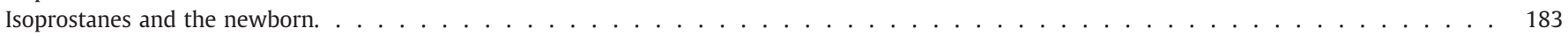

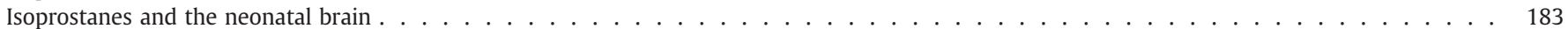

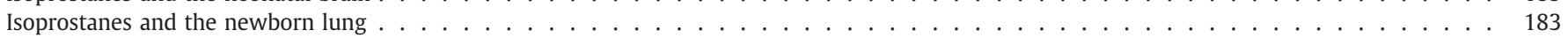

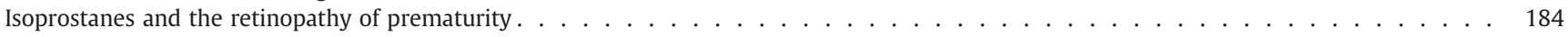

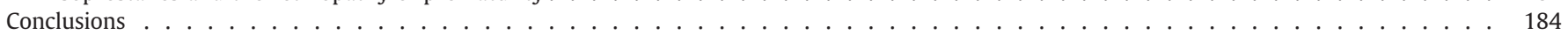

Acknowledgments . . . . . . . . . . . . . . . . . . . . . . . . . . . . . . . . . . . . . . . . . . . . . . . . . .

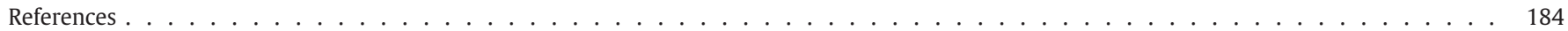

Abbreviations: BPD, bronchopulmonary dysplasia; COX, cyclooxygenase; EETs, epoxyeicosatrienoic acids; ET-1, endothelin-1; GM-CSF, granulocyte/macrophage colonystimulating factor; G-CSF, granulocyte colony-stimulating factor; HETEs, hydroxyeicosatetraenoic acids; IsoP, isoprostane; MAPK, mitogen-activated protein kinase; MLC phos, myosin light chain phosphorylation; NB, newborn; PG, prostaglandin; ROCK, Rho kinase; ROS, reactive oxygen species; RNS, reactive nitrogen species; TK, tyrosine kinase; TP, TXA ${ }_{2}^{-}$ $\mathrm{PGH}_{2}$ receptor; TX, thromboxane.

* Corresponding author. The Hospital for Sick Children, 555 University Avenue, Toronto, Ontario, Canada M5G 1X8. Fax: +1 4168135245.

E-mail address: Jaques.Belik@SickKids.ca (J. Belik). 


\section{Introduction}

The long-standing paradigm that only enzymatically formed compounds have important biological functions changed when Morrow et al. discovered that racemic prostaglandin (PG) diastereoisomers, later named isoprostanes (IsoPs), were produced in large amounts in vivo [1-3]. IsoPs are nonenzymatic, free radical-catalyzed isomers of cyclooxygenase (COX)-derived enzymatic products of arachidonic acid $[1,2,4]$.

Under physiological conditions, IsoPs are present at nanomolar concentrations in biological fluids [2]. The development of reproducible and highly sensitive techniques, such as gas chromatography coupled to tandem mass spectrometry, to accurately measure IsoP levels [5] led to its acceptance as one of the most reliable indicators of in vivo free radical-induced oxidative stress.

IsoP body fluid levels have been extensively used as clinical markers of oxidative stress in many disease states such as atherosclerosis, diabetes, systemic hypertension, and cystic fibrosis [6-8]. Yet, members of the IsoP family are also biologically active and likely contribute to the pathogenesis of oxidant-induced injury and may mediate clinical features of diseases for which they are used as indicators.

Oxidative stress, a term originally coined by Helmut Sies [9], results from an imbalance between production of reactive oxygen and nitrogen species (ROS and RNS) and endogenous antioxidant defense mechanisms. Superoxide anion, hydrogen peroxide, and hydroxyl radicals are the main ROS involved in oxidative stress-mediated damage. Peroxynitrite, formed when nitric oxide interacts with superoxide, is one of the most important RNS compounds and their generation associated with vascular changes and tissue damage [10].
The transition from fetal to postnatal life imposes a significant stress on the newborn by virtue of a 3- to 4-fold increase in arterial oxygen tension. This "physiologic" oxidative stress activates specific metabolic pathways enabling an adequate adaptation to the extrauterine environment [11-15]. Although possibly better suited than adults to withstand the rapid increase in blood oxygen tension occurring at birth, the newborn IsoP levels are significantly higher than later in life $[16,17]$. Increased IsoP body fluid levels have also been reported in preeclampsia, intrauterine growth retardation, asphyxia, intraventricular hemorrhage, periventricular leukomalacia, bronchopulmonary dysplasia [18], pulmonary hypertension, and retinopathy of prematurity [19-22]. Common to all these fetal and/ or neonatal conditions is the presence of ROS-induced oxidative stress.

In this review we will address the biochemical pathways involved in IsoP formation, their pathogenetic relevance in disease states and biological function. We will specifically focus on IsoPs as markers of oxidative stress during gestation and the perinatal period. In addition we will review the limited available data relative to the involvement of IsoPs on the developmental-dependent regulation of pulmonary and systemic vascular resistance and their associated clinical implications. A better understanding of the factors accounting for IsoP generation and their biological effects may open new therapeutic and preventive avenues in dealing with disease states from fetal to adult life.

\section{Biochemistry of isoprostanes}

The isolation of PG diastereomer compounds from human plasma and urine $[1,2]$ led to the recognition that PGs and IsoPs are generated

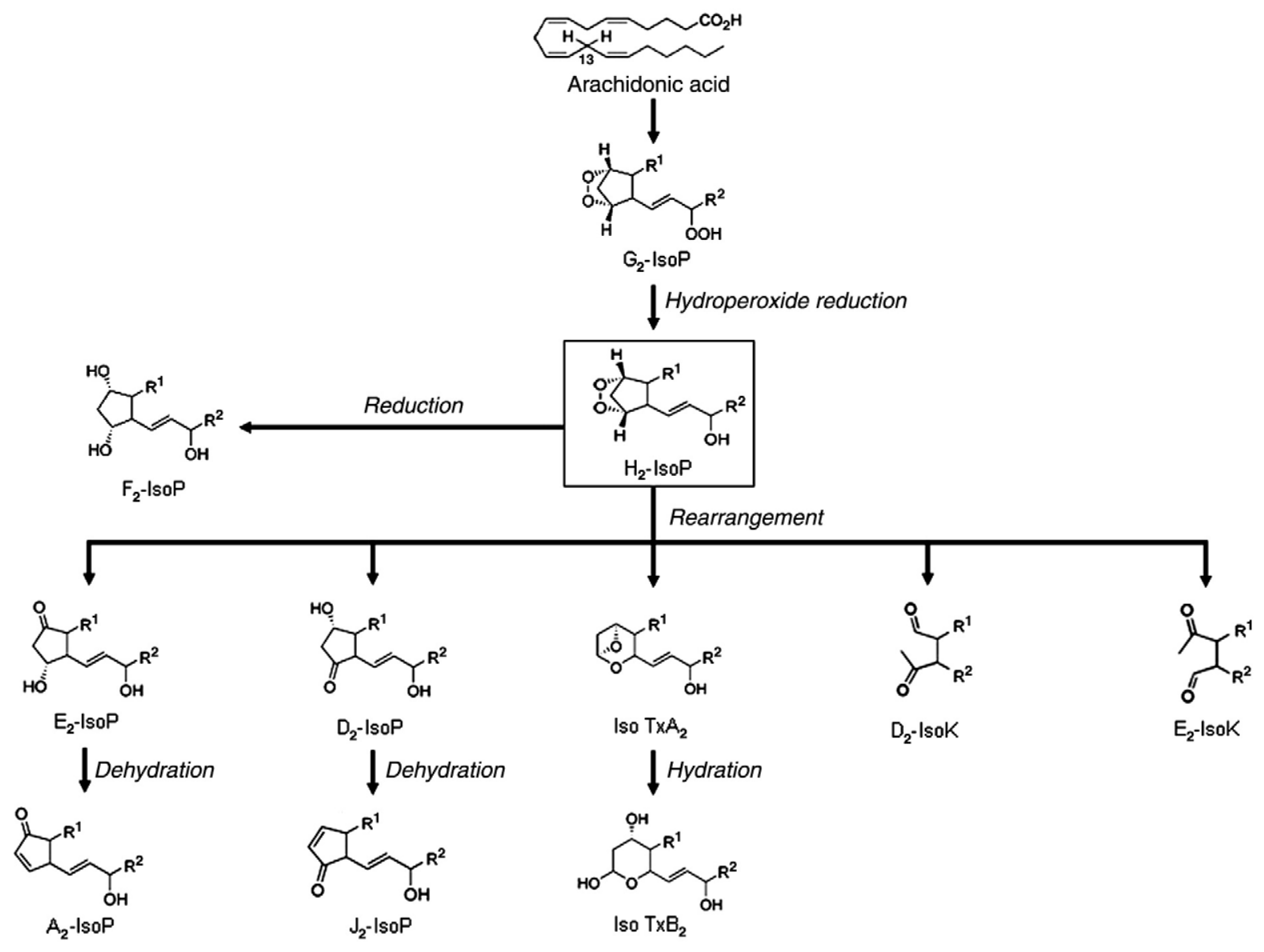

Fig. 1. Generation and structure of isoPs, isothromboxanes, and isoketals. 
via very similar pathways [3]. The nonenzymatic formation of IsoPs requires arachidonic acid, molecular oxygen, and free radicals (Fig. 1). Unlike COX-derived PGs, IsoPs are formed primarily in situ from esterified arachidonate present in tissue phospholipids. Following tissue formation, esterified IsoPs are enzymatically hydrolyzed in situ to form bioactive compounds that are released into the circulation $[23,24]$.

The pathway of IsoP biosynthesis has been extensively described in several recent reviews [3,4,6,25-27], and thus will be only summarized here. Following abstraction of a bisallylic hydrogen atom and the addition of a molecule of oxygen to arachidonic acid to form a peroxyl radical, exo-cyclization occurs and an additional molecule of oxygen is added to form $\mathrm{PGG}_{2}$-like compounds $\left(\mathrm{G}_{2}\right.$-IsoPs) [3,4,6,25-27]. The process can be triggered by several ROS and RNS, including superoxide and peroxynitrite. Reduction of $\mathrm{G}_{2}-$ to $\mathrm{H}_{2}$-IsoPs follows in a process that mirrors PG biosynthesis. Once formed, $\mathrm{H}_{2}$-IsoPs are fully reduced to form one of four prostaglandin $\mathrm{F}_{2 \mathrm{a}}$ isomers (F-ring or $\mathrm{F}_{2}$ IsoPs), which are denoted as 5-, 12-, 8-, or 15 -series isomers depending on the carbon atom to which the side chain hydroxyl is attached. Platelet-activating factor acetylhydrolases play an important role in the hydrolysis of $\mathrm{F}_{2}$ IsoPs [24].

The $\mathrm{H}_{2}$-IsoP intermediate can also undergo rearrangement to form compounds that are isomeric to $\mathrm{PGE}_{2}$ (E-ring or $\mathrm{E}_{2}$ IsoPs), $\mathrm{PGD}_{2}$ (Dring or $\mathrm{D}_{2}$ IsoPs), or thromboxane (TX)A $\mathrm{A}_{2}$ (isothromboxanes) (Fig. 1) [6,28]. Dehydration of $\mathrm{E}_{2^{-}}$and $\mathrm{D}_{2}$-IsoPs, under physiological conditions generates cyclopentenone $\mathrm{A}_{2}$ - and $\mathrm{J}_{2}$-IsoPs, respectively. These cyclopentenone IsoPs, unlike other classes of IsoPs, contain highly reactive unsaturated carbonyl moieties on the prostane ring analogous to COX-derived $\mathrm{PGA}_{2}$ and $\mathrm{PGJ}_{2}$ that readily undergo Michael addition to thiols [29].

An important structural distinction between IsoPs and COXderived PGs is that the former contain side chains predominantly oriented cis to the prostane ring $[2,26]$. Because the first IsoPs described differed from COX-derived PGs, they were originally named 8 -iso-PGF $2 \alpha$, or 8-epi-PGF $2 \alpha$. However, such a nomenclature does not allow for the clear differentiation of the numerous isomeric structures and alternative nomenclatures [30,31] have been proposed. One of these newer nomenclatures is the one by Taber et al. that will be used in this review. However, as the original former nomenclature is still frequently used, the "classical" names of the compounds more frequently addressed in this review are described (together with the Taber's suggested terminology) in Fig. 2 and tables legends.

Arachidonic acid is not the only polyunsaturated fatty acid that can be oxidized to generate IsoPs [32-34,26]. F-ring IsoPs have been shown to be generated from the peroxidation of linolenic acid $\left(\mathrm{F}_{1}\right.$ IsoPs), eicosapentaenoic acid ( $\mathrm{F}_{3}$-IsoPs), and docosahexaenoic acid ( $\mathrm{F}_{4}$-neuroprostanes). In addition, E-, D-, A- and J-ring isoP-like compounds are generated from the oxidation of docosahexaenoic and presumably eicosapentaenoic acid [33-34,26]. The biological relevance of these new compounds is currently under scrutiny. However, it should be noted that, when compared to arachidonic acid, the cell contents of linolenic and eicosapentaenoic acids are very low. Docosahexaenoic acid is mostly present in brain gray matter [3]. Nevertheless, it has been hypothesized that eicosapentaenoic and docosahexaenoic acid-derived IsoPs contribute to the beneficial biological effects of fish oil supplementation [26].

A series of highly reactive isomeric acyclic compounds termed isoketals (or isolevuglandins) (Fig. 1) are generated from IsoPs and can be present in biological systems [35-38]. These compounds can form covalent protein adducts at a very fast rate, exceeding what is commonly observed for other lipid peroxidation compounds [39]. Isoketals are possibly involved in the arrhythmia-related myocardial ischemia-induced changes in cardiac ion channel function [40]. Isoketals also appear to play a role in platelet aggregation and may contribute to the pathogenesis of atherosclerosis and thrombosis [37]. The role of isoketals has not been investigated in the fetus and
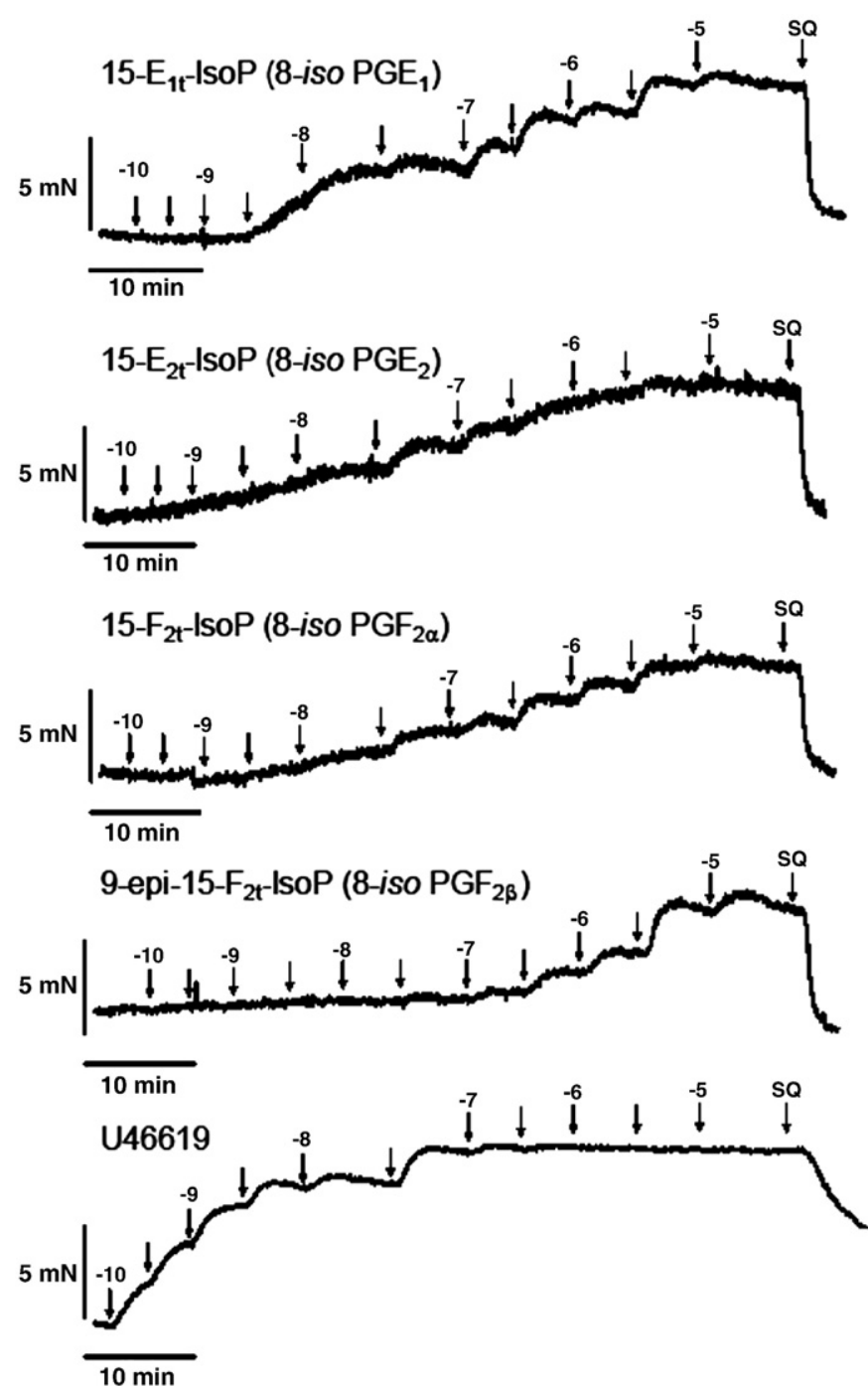

Fig. 2. Contractile effects of cumulative half-logarithmic concentrations of isoPs in pulmonary arteries of newborn $(<24$-h-old) piglets. Note that both E- and F-ring isoprostanes induce concentration-dependent contractions that are reversed by addition of the TP-receptor antagonist SQ 29,548 (SQ, $10 \mu \mathrm{M}$ ). The thromboxane $\mathrm{A}_{2}$ mimetic U46619 shows a higher contractile potency and efficacy than the isoPs.

newborn, but these compounds likely also play a role in oxidative stress-related disorders during this stage of development.

Recently, another family of isomers termed isofurans has been discovered [41]. Isofurans derive from the peroxidation of arachidonic acid and are characterized by a substituted tetrahydrofuran ring structure and are the result of molecular $\mathrm{O}_{2}$-induced attack in the carbon-centered radical intermediate of the IsoP pathway. A rise in arterial blood $\mathrm{O}_{2}$ tension secondary to hyperoxia exposure promotes isofuran generation, consequently limiting the formation of IsoPs [42].

\section{Isoprostanes as biomarkers of oxidative stress}

ROS are unstable and have a complex chemistry and most biochemical methods to measure oxidative status lack specificity and/or sensitivity. IsoPs rapidly diffuse to the extracellular space and remain stable in body fluids such as blood and urine. This, together with the well-proven direct relationship between their blood and urine levels, has heralded IsoPs as reliable, reproducible, and sensitive markers of oxidative stress [43]. IsoP levels can be measured in plasma, urine, cerebral spinal fluid, bile, and bronchoalveolar lavage fluid [44]. Normal $15-\mathrm{F}_{2 \mathrm{t}}$-IsoP urine values for healthy adults have 
been determined [45]. As compared with other biomarkers of oxidative stress, quantification of plasma or urinary IsoPs is the best approach to evaluate oxidant stress status in vivo [43].

Most commonly the $\mathrm{F}_{2}$-IsoPs are the chosen ones to quantify oxidative stress both in vitro and in vivo. Gas chromatography/mass spectrometry (GC/MS) is currently the most sensitive and reliable method to measure $F_{2}$-IsoPs in biological fluids and tissues [44]. Other methods employing either gas or liquid chromatographic/mass spectrometry (LC/MS) are also available, but concerns about the sensitivity of this method have been raised [44]. A number of other, commercially available, immunological methods exist to measure IsoPs in vivo or in vitro. Yet, the sensitivity and specificity of these available ELISA kits remain questionable [44].

As noted above, under high $\mathrm{O}_{2}$ tension, the formation of IsoP is reduced while isofuran generation increases. As such, it has been recently proposed that isofurans may be more reliable biomarkers of oxidative stress under these conditions [42]. For example, a marked increase in isofurans during hyperoxia-induced lung injury in mice has been observed, whereas IsoPs remained unchanged [41]. Moreover, resuscitation of preterm babies with high $\mathrm{O}_{2}$ concentrations (90\%) has been shown to be associated with increased bronchopulmonary dysplasia (BPD) prevalence, as well higher urine isofurans, but not IsoP levels [11]. Together these data suggest that when studying body fluids of subjects exposed to high inspired $\mathrm{O}_{2}$ concentrations in addition to IsoPs, isofuran concentrations should also be measured.

In body fluids, $\mathrm{F}_{2}$-IsoPs and isofurans can be purified and quantified simultaneously in a single GC/MS assay. Currently, no immunological methods are commercially available to measure isofurans. Yet, in the commonly utilized immunoassays for IsoPs cross-reactivity with isofurans has not been properly evaluated. Thus, it is possible that IsoP immunoassayed measurements may reflect, at least partially, changes in isofuran levels.

Lastly, the extent to which urine IsoP levels are influenced by the renal tissue production of these molecules is unclear. The primary urinary metabolite of $15-\mathrm{F}_{2 \mathrm{t}}$-IsoP is the 2,3-dinor-5,6-dihydro-8-isoprostaglandin $F_{2 \alpha}$ [46]. More recently developed methodologies capable of separating this urine-specific metabolite from the total IsoP pool may allow for more accurate determination of extrarenal oxidative stress in vivo [47].

\section{Isoprostanes as mediators of biological activity}

IsoPs exhibit vasoactive, inflammatory, and mitogenic properties $[6,48,49]$ and thus may mediate and/or be directly responsible for a number of physiological and/or pathological processes. The current knowledge on the biological effects of IsoPs is mostly derived from the $\mathrm{F}_{2}$ series (of which $15-\mathrm{F}_{2 \mathrm{t}}$-IsoP is the most studied) and $15-\mathrm{E}_{2}$-IsoP.

Most of the available data identify $15-\mathrm{F}_{2 \mathrm{t}}$-IsoP as a vasoconstrictor in most species and vascular systems [50]. Yet the $15-\mathrm{F}_{2 \mathrm{t}}$-IsoPdependent smooth muscle contractile response is not restricted to blood vessels. A similar response has also been reported in lymphatic [51,52], bronchial [53], intestinal [54], and uterine smooth muscle [55]. Other 15-F IsoPs, such as 9-epi-15- F $_{2 t}$-IsoP, 15-epi-15- F $_{2 t}$-IsoP, ent-15$\mathrm{F}_{2 \mathrm{t}}$-IsoP, and ent-15-epi-15- $\mathrm{F}_{2 \mathrm{t}}$-IsoP are also vasoactive, although for the most part less potent than $15-\mathrm{F}_{2 \mathrm{t}}$-IsoP (Tables 1 and 2 ). $\mathrm{TXA}_{2}-\mathrm{PGH}_{2}$ receptors (TP) are believed to mediate the effect of these ligands [49]. In endothelial cells, $15-\mathrm{F}_{2 \mathrm{t}}$-IsoP modulates the release of vasodilators such as nitric oxide and prostacyclin, as well as vasoconstrictors such as TXA $_{2}$ and endothelin-1 (ET-1) (Tables 1 and 2).

In humans, two major metabolites of $15-\mathrm{F}_{2 \mathrm{t}}$-IsoP are produced: 2,3-dinor-15- $\mathrm{F}_{2 \mathrm{t}}$-IsoP and 2,3-dinor-5,6-dihydro-15- $\mathrm{F}_{2 \mathrm{t}}$-IsoP $[46,48]$. The 2,3-dinor-5,6-dihydro-15- $\mathrm{F}_{2 \mathrm{t}}$-IsoP-induced porcine brain microvessel constriction is comparable to that of $15-\mathrm{F}_{2 \mathrm{t}}$-IsoP [56].

The vasoactive properties of several 5 - and 12 -series $F_{2}$ IsoP isomers have been also studied in pig retinal and brain microvasculature. The 12 -series isomers tested, $12-\mathrm{F}_{2 \mathrm{t}^{-}}$-IsoP and $12-\mathrm{epi}-12-\mathrm{F}_{2 \mathrm{t}^{-}}$ IsoP, caused marked vasoconstriction. Of the 5-series isomers tested, 5- $\mathrm{F}_{2 \mathrm{t}}$-IsoP and 5-epi-5- $\mathrm{F}_{2 \mathrm{t}}$-IsoP possessed no vasomotor properties, whereas ent-5- $\mathrm{F}_{2 \mathrm{t}}$-IsoP caused modest vasoconstriction [57].

E-ring IsoPs, and more particularly $15-E_{2}$-IsoP, can also induce vasoconstriction via TP receptors (Tables 1 and 2). In certain vascular tissues, $15-\mathrm{E}_{2}$-IsoP is a more potent vasoconstrictor than $15-\mathrm{F}_{2 \mathrm{t}}$-IsoP [58]. Interestingly, a contractile response was found to be exerted through EP receptors (likely of the EP3 subtype) in porcine pulmonary vein $[49,59]$. However, $15-E_{2}$-IsoP may also induce smooth muscle relaxation through EP receptors $[49,60]$.

Relaxant actions of F- and E-ring IsoPs have been described in many other vascular tissues [61-63]. These actions were frequently masked by the vasoconstrictive effects of IsoPs via TP receptors, and only were observed when these receptors were blocked by

Table 1

Isoprostane reported effects in distinct adult animal species and vascular beds

\begin{tabular}{|c|c|c|c|}
\hline Species/vascular bed & Compound & Effect (pathway) & References \\
\hline Rat/renal & $F_{2 \alpha}$ & Constriction (TP) & {$[2,163]$} \\
\hline Rat/pulmonary & $F_{2 \alpha}$ & Constriction (TP, COX, PKC)/ relaxation (NO) & {$[61,164-166]$} \\
\hline Rat/aorta & $\mathrm{F}_{2 \alpha}$ & Constriction (TP,) & {$[166,167]$} \\
\hline Rat/cerebral arterioles & $\mathrm{F}_{2 \alpha}, \mathrm{E}_{2}$ & Constriction (TP) & [168] \\
\hline Rat/portal vein & $\mathrm{F}_{2 \alpha}$ & Constriction (TP) & [169] \\
\hline Rat/whole animal & $\mathrm{F}_{2 \alpha}, \mathrm{E}_{2}$ & Hypertension (TP) & {$[170]$} \\
\hline Mouse/renal & $\mathrm{E}_{2}$ & Relaxation (cAMP, $\mathrm{K}_{\mathrm{Ca}}$ ) & [62] \\
\hline Rabbit/pulmonary & $\mathrm{F}_{2 \alpha}$ & Constriction (TP) & [171] \\
\hline Rabbit/ear & $\mathrm{F}_{2 \alpha}$ & Constriction (TP) & {$[172]$} \\
\hline Guinea pig/coronary & $\mathrm{F}_{2 \alpha}, \mathrm{E}_{2}$ & Constriction (TP) & [173] \\
\hline Guinea pig/cochlear vessels & $\mathrm{F}_{2 \alpha}$ & Constriction (TP) & [174] \\
\hline Pig, cow, sheep / coronary & $F_{2 \alpha}$ & Constriction, not in sheep (TP) & [175] \\
\hline Pig/carotid & $F_{2 \alpha}$ & Constriction (TP, MAPK, MLC phos) & [176] \\
\hline Pig/retinal vessels & $F_{2 \alpha}$ & Constriction $\left(\mathrm{TXA}_{2}, \mathrm{ET}-1\right)$ & [161] \\
\hline Pig/coronary & $\mathrm{F}_{2 \alpha}$ & Constriction ( $\uparrow$ in hypercholesterolemia) & [177] \\
\hline Pig/pulmonary & $\mathrm{E}_{1}, \mathrm{E}_{2}, \mathrm{~F}_{1 \alpha}, \mathrm{F}_{2 \alpha}, \mathrm{F}_{2 \beta}$ & Constriction & [59] \\
\hline Pig/coronary & $\mathrm{E}_{1}, \mathrm{E}_{2}, \mathrm{~F}_{2 \beta}$ & Relaxation (hyperpolarization) & [63] \\
\hline Dog/pulmonary & $\mathrm{E}_{1}, \mathrm{E}_{2}, \mathrm{~F}_{1 \alpha}, \mathrm{F}_{2 \alpha}, \mathrm{F}_{2 \beta}, \mathrm{F}_{3 \beta}$ & Constriction (TP, EP, TK, ROCK)/ relaxation $\left(\mathrm{E}_{1}\right)$ & [178] \\
\hline Human/saphenous vein & $\mathrm{F}_{2 \alpha}$ & Constriction (TP) & [179] \\
\hline Human/internal mammary & $\mathrm{F}_{2 \alpha}$ & Constriction (TP, $\left.\mathrm{TXA}_{2}\right)$ & [180] \\
\hline Human/pulmonary & $\mathrm{E}_{1}, \mathrm{E}_{2}, \mathrm{~F}_{1 \alpha}, \mathrm{F}_{2 \alpha}, \mathrm{F}_{2 \beta}, \mathrm{F}_{3 \beta}$ & Constriction (TP, EP, TK, ROCK)/ relaxation ( $\mathrm{E}_{1}$ in veins) & [178] \\
\hline Human/radial artery & $\mathrm{E}_{1}, \mathrm{E}_{2}, \mathrm{~F}_{2 \beta}$ & Constriction (TP, $\mathrm{Ca}^{2+}$ stores, $\left.\mathrm{ROCK}\right)$ & [181] \\
\hline
\end{tabular}

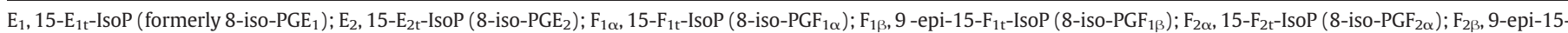

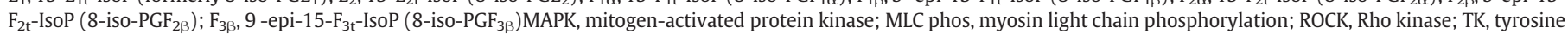
kinase; $\mathrm{TP} / \mathrm{EP}$, prostanoid receptors. 
Table 2

Isoprostane reported effects in distinct fetal and newborn animal species and vascular beds

\begin{tabular}{|c|c|c|c|}
\hline Species/vascular bed & Compound & Effect (pathway) & References \\
\hline Rat(NB)/pulmonary & $F_{2 \alpha}$ & Constriction (TP,TXA ${ }_{2}$ )/Relaxation (NO) & [131] \\
\hline Pig (18-d)/pulmonary & $F_{2 \alpha}$ & Constriction (TP) & [134] \\
\hline Pig (fetal, NB)/cerebral & $\mathrm{F}_{2 \alpha}$ & Constriction $\left(\mathrm{TXA}_{2}\right)$ & [141] \\
\hline Pig (NB)/pulmonary, mesenteric & $E_{1}, E_{2}, F_{1 \alpha}, F_{2 \alpha}, F_{1 \beta}, F_{2 \beta}$ & Constriction (TP, TK, ROCK)/Relaxation (NO) & [132] \\
\hline Human/umbilical artery & $\mathrm{F}_{2 \alpha}, \mathrm{E}_{2}$ & Constriction (TP, ROCK) & {$[123,124]$} \\
\hline Human/umbilical vein & $E_{1}, E_{2}, F_{1 \alpha}, F_{2 \alpha}, F_{2 \beta}$ & Constriction (TP, $\mathrm{TXA}_{2}$ ) & {$[121,122]$} \\
\hline Human/placental, myometrial arteries & $\mathrm{F}_{2 \alpha}, \mathrm{E}_{2}$ & Constriction (ROCK, placental arteries) & [182] \\
\hline
\end{tabular}

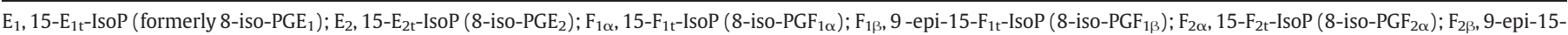

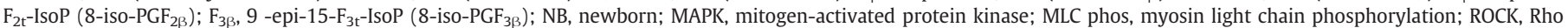
kinase; TK, tyrosine kinase; TP/EP, prostanoid receptors.

antagonists (such as SQ 29,548 or ICI 192605), or saturated by an agonist (such as U46619) [61-63].

Aside from its effect on smooth muscle tone, IsoPs participate in a number of other cell-specific functions. There have been a number of different E-ring and F-ring IsoPs tested for their function on platelets and they have collectively been found to be antiaggregatory [48]. The mechanism of the effects of $15-\mathrm{F}_{2 \mathrm{t}}$-IsoP on platelets and the receptors involved has been explored in detail. It was found to bind to two independent sites on platelets. One of these sites is the TP receptor, which is stimulatory. The other platelet-binding site results in increased cAMP levels and thus has an antiaggregatory effect. E-, but not F-ring, IsoPs promote the release of granulocyte/macrophage colony-stimulating factor (GM-CSF) and granulocyte colony-stimulating factor (G-CSF) from human airway smooth muscle cells stimulated with interleukin-1 $\beta$ [64]. The GM-CSF and G-CSF response is cAMP and PKA mediated and involves $\mathrm{EP}_{2}, \mathrm{EP}_{3}$, and $\mathrm{EP}_{4}$ receptors [64]. In addition, there is evidence that IsoPs may have an antiinflammatory effect. $15-\mathrm{F}_{2 \mathrm{t}}$-IsoP suppresses the adhesion of monocytes to microvascular endothelial cells in vitro via a TP-dependent and -independent signaling cascade [65]. No data concerning the biological effects of isothromboxanes are currently published, likely because the TXA 2 ring is very unstable and longer lasting isothromboxane analogues are required for these measurements.

Recent studies on cyclopentenone IsoPs, such as $15-\mathrm{A}_{2}$-IsoP and $15-\mathrm{J}_{2}$-IsoP, were rendered possible by their recent successful chemical synthesis $[66,67]$. It has been suggested that cyclopentenone IsoPs serve as negative feedback regulators of inflammation and may mediate the oxidative stress-induced inflammatory response $[3,68]$. Very recently, Musiek et al. proposed that cyclopentenone IsoPs represent a novel class of neurotoxic lipid peroxidation products that contribute to ischemic and excitotoxic injury in the central nervous system [69].

\section{Oxidative stress, isoprostanes, and human pathological conditions}

Oxidative stress is postulated to be involved in a number of pathological conditions involving the cardiovascular, pulmonary, renal, gastrointestinal, hepatic, and neurologic systems, as well as metabolic and inflammatory diseases [6]. Most of the data relative to the pathogenetic role of IsoPs in human disease were obtained from older children and adults. The relevant adult available data will be here reviewed with an exclusive focus on cardiovascular and pulmonary pathological conditions. The reader should be reminded, however, that the IsoP role in human diseases is likely equally operative under similar pathological conditions during fetal and neonatal life, as we further discuss in the next section.

Oxidative stress is known to induce endothelial dysfunction and vascular remodeling in a number of vasculopathies. Systemic hypertension associated with renovascular disease has an increased urinary $15-\mathrm{F}_{2 \mathrm{t}}$-IsoP excretion, suggesting that the elevated blood pressure is secondary to oxidative stress-induced activation of the renin-angiotensin system [70].
Diabetes, a condition involving alterations of the retinal, renal, and peripheral vasculature, is associated with evidence of oxidative stress. $15-\mathrm{F}_{2 \mathrm{t}}$-IsoP levels correlate with insulin requirements in early type 1 diabetes and are significantly higher in the poorly controlled, insulindependent diabetic when compared with patients under good glycemic control [71]. A cross-sectional study performed in children with recently diagnosed type 1 diabetes, and compared with age- and gender-matched subjects with onset of the disease longer than 1 year, showed significantly higher levels of $15-\mathrm{F}_{2 \mathrm{t}}$-IsoP in the former [72]. In fact, another large and well-controlled study of children less than 7 years of age documented a direct correlation between $15-\mathrm{F}_{2 \mathrm{t}}$-IsoP levels in early infancy and the risk of type 1 diabetes [73]. A connection among xanthine oxidase activity, ROS generation, and diabetic control in children has been shown and allopurinol, an inhibitor of this enzyme, improved glycosylated hemoglobin [74]. These results demonstrate that enhanced lipid peroxidation represents an early event in type 1 diabetes that is clearly present even prior to the disease onset, and possibly plays a pathogenic role in the disease development.

Hypercholesterolemia, a condition manifested early in life and resulting in premature arteriosclerosis in children, has recently been shown to be associated with oxidative stress [75]. This association is likely of a causative nature, since children with gp91(phox) hereditary deficiency showed downregulation of platelet gp91 (phox) and reduced urinary excretion of $\mathrm{F}_{2}$-IsoPs [75]. In adults with coronary artery calcification, a manifestation of coronary artery atherosclerosis, high $\mathrm{F}_{2}$-IsoPs have been reported in both sexes [76], suggesting that oxidative stress is also involved in these pathologies.

In the lung, oxidative stress with elevated levels of $15-\mathrm{F}_{2 \mathrm{t}}$-IsoP has been documented in adults with idiopathic pulmonary hypertension. In these patients, IsoP levels are inversely correlated with the magnitude of the decrease of pulmonary vascular resistance on treatment with inhaled nitric oxide [77] or epoprostenol [78]. This observation is supportive of a role for free radical generation in the pathogenesis of pulmonary hypertension. Increased IsoP levels are also present in a number of airway clinical conditions. These include cystic fibrosis [79-83] and asthma in children [84-87], as well as adults [88-90]. The extent to which oxidative stress is a biomarker of the disease, as suggested by many, or reflective of the IsoP direct biological activity [91] is currently unclear, but under intense scrutiny [49].

The vascular dysfunction observed in autoimmune diseases also appears to be related to oxidative stress. Adult patients with systemic lupus erythematosus, and a disease duration greater than 1 year, showed a higher $15-\mathrm{F}_{2 \mathrm{t}}$-IsoP serum concentrations, when compared with age- and sex-matched controls [92]. Another study addressing the atherosclerotic risk factors and endothelial function in pediatric-onset systemic lupus erythematosus reported no evidence of increased IsoP levels in these patients [93]. Yet, this could be related to duration of the disease state. In patients with multiple sclerosis, cerebrospinal fluid $15-\mathrm{F}_{2 \mathrm{t}}$-IsoP is elevated, and the levels correlate with the degree of disability and are reduced in 
subjects under steroid therapy [94]. Increased IsoP levels have been also been reported in Crohn's disease [95], and antiphospholipid syndrome [96]. Possibly because of its autoimmune etiology, hyperthyroidism, but not hypothyroidism, is also associated with higher $15-\mathrm{F}_{2 \mathrm{t}}$-IsoP levels [97].

Lastly elevated IsoP levels in biological fluids are present in a number of other conditions possibly associated with oxidative stress. Children with Duchene muscular dystrophy and Becker muscular dystrophy have elevated $15-\mathrm{F}_{2 \mathrm{t}}$-IsoP levels [98]. Adolescents with sickle cell anemia have elevated urine 2,3-dinor-5,6-dihydro- $15-\mathrm{F}_{2 \mathrm{t}^{-}}$ IsoP and inflammatory markers [99]. IsoPs have also been implicated in acute, trauma-related cerebral vascular changes in children. On the first day after a traumatic brain injury, $15-\mathrm{F}_{2 \mathrm{t}}$-IsoP levels in the cerebrospinal fluid are elevated, when compared with control subjects, and decrease with clinical improvement [100].

\section{Isoprostanes and the fetus}

As compared with adults, the plasma $15-\mathrm{F}_{2 \mathrm{t}}$-IsoP levels of newborns are significantly higher and an inverse relationship between the IsoP levels and the gestational age was reported $[16,17]$. The source of IsoP generation during gestation is unclear, but mounting evidence points to the placenta as an important contributor. $15-\mathrm{F}_{2 \mathrm{t}}$-IsoP concentration in plasma from the umbilical vein was reported to be much higher than the arterial counterpart, suggesting that the placenta is a major source of IsoP generation during fetal life [101]. Experiments with human umbilical vein endothelial cells demonstrated that estradiol decreased and progesterone reversed the estradiol-induced effect on $15-\mathrm{F}_{2 \mathrm{t}}$-IsoP formation in vitro [102], suggesting that IsoP generation during gestation may be under hormonal regulation.

Pregnancy-related placental abnormalities are associated and possibly caused by oxidative stress. In pregnancies complicated by preeclampsia, decidual placental layer-derived $15-\mathrm{F}_{2 \mathrm{t}}$-IsoP generation is increased [103,104], and maternal plasma levels of of this metabolite are significantly higher in women with preeclampsia, when compared with normal pregnancies $[8,105]$.

IsoPs, possibly by inducing placental vasoconstriction, may indeed modulate many of the clinical manifestations of preeclampsia [106]. In rats, chemical inhibition of angiogenesis early in pregnancy results in changes similar to preeclampsia and are associated with an increased placental $15-\mathrm{F}_{2 \mathrm{t}}-$ IsoP formation [107]. These findings strongly suggest that oxidative stress plays an important role in the pathogenesis of this disease.

A number of well-known maternal clinical conditions manifesting during pregnancy show evidence of oxidative stress, with diabetes being the most well-studied disease. In rats with chemically induced diabetes, the urinary excretion of $15-\mathrm{F}_{2 \mathrm{t}}$-IsoP is significantly increased during pregnancy, as compared with nondiabetic pregnant controls $[108,109]$. The association between oxidative stress and diabetic embryopathy has been suggested on the basis of experiments conducted with transgenic and knockout mice for the antioxidant CuZnSOD [110]. Knocking out of the gene responsible for CuZnSOD protein expression led to universal fetal demise. Yet, in mice made diabetic during pregnancy, the prevalence of fetal teratogenicity was more related to the increase in maternal blood glucose levels, than the fetal antioxidative capacity [110].

Increased IsoP levels were reported in small for gestational age neonates [111], and the risk of intrauterine fetal growth retardation is directly proportional to their amniotic fluid concentration [112]. Maternal smoking during pregnancy, a known cause of fetal growth retardation, is associated with increased umbilical arterial IsoP levels [113]. A ninefold increase in $15-\mathrm{F}_{2 \mathrm{t}}$-IsoP levels was found in amniotic fluid of pregnancies with Down's syndrome, a condition commonly associated with fetal growth restriction [114]. Interestingly, fetal alcohol exposure, another known cause of intrauterine growth retardation and embryopathies, is not associated with abnormal IsoP levels at birth [47].

Premature and prolong rupture of the membranes is also associated with higher IsoP levels in the amniotic fluid [115]. When the umbilical cord arterial and venous plasma levels were measured and correlated with the status of term infants at birth, significantly higher arterial concentrations were demonstrated in the presence of fetal distress [116]. In a study tracking the outcome of infants born prematurely a direct correlation between evidence of oxidative stress and neonatal morbidity was documented. The venous but not arterial umbilical cord-derived plasma $15-\mathrm{F}_{2 \mathrm{t}}$-IsoP levels are associated with a significant increase in the prevalence of one or more clinical conditions believed to be associated with, and possibly caused by, oxidative stress injury [19]. These include chronic lung disease, intracranial hemorrhage, necrotizing enterocolitis, and retinopathy of prematurity. Together these studies suggest that oxidative stress during gestation is associated with maternal and neonatal ill effects on the fetus and placenta possibly mediated via IsoP-induced vasoconstriction, thrombosis, and/or inflammation.

The extent to which maternal-fetal oxidative stress can be reduced during pregnancy is unknown. A reduction in the level of biomarkers of oxidative stress in neonates has been anecdotally reported following the use of antioxidants during pregnancy [117-120]. These included melatonin and fish oil, substances of questionable antioxidant effect when orally ingested. Until further evidence of their clinical benefit is available, the oral administration of such antioxidants during pregnancy ought to be considered as experimental therapy.

\section{Isoprostanes and the control of umbilical vasculature}

The IsoP-induced vasomotor effects on human umbilical vessels have been widely studied out of the belief that the in vitro responses offer further insight on the potential role of these prostanoids on the in vivo regulation of umbilical-placental vascular resistance. Although not necessarily so, given the unique nature of the umbilical vasculature, the reported data further substantiate results obtained from animal studies. When compared with the $\mathrm{TXA}_{2}$ analogue U46619, E- and F-ring IsoPs vasoconstrict human umbilical veins to a lesser extent [121,122]. E-ring IsoPs elicit a greater endotheliumdependent vasoconstrictive response, when compared with the F-ring compounds, an effect likely mediated via $\mathrm{TXA}_{2}$ [122].

Similar studies on the human umbilical artery also demonstrated that the E- and F-ring IsoPs have a vasoconstrictive effect mediated via TP receptors [123]. Yet, the $15-\mathrm{E}_{2 \mathrm{t}}$-IsoP-induced vasoconstriction was antagonized by the Rho kinase inhibitor Y-27632, suggesting that the response is RhoA/Rho kinase dependent [124]. Interestingly, in the same study, RhoA and Rho kinase mRNA expression levels were measured in umbilical arteries from neonates born to normotensive and preeclamptic women. Preeclampsia was associated with a reduction in mRNA expression of these compounds, which the authors speculated was a protective response to enhance placental blood flow in this disease [124].

\section{Isoprostanes and the neonatal circulation}

During the transition from fetal to postnatal life, dramatic changes in the pulmonary circulation take place, mostly characterized by a marked decrease in pulmonary vascular resistance within minutes from birth [125]. A second phase of pulmonary vascular resistance reduction takes place over the first weeks of extrauterine life. Many developmentally dependent factors are thought to regulate the pulmonary blood flow changes during, and immediately following, birth $[58,125-130]$. The pulmonary vascular responses to IsoPs have been studied in the newborn rat [131] and pig [58,132] and the available data suggest that these compounds play an important role in the transitional circulation. 
Belik et al. analyzed the effects of $15-\mathrm{F}_{2 \mathrm{t}}$-IsoP in intralobar pulmonary arteries of 1 - and 2-week-old rats, as compared with adults [131]. 15- $\mathrm{F}_{2 \mathrm{t}}$-IsoP evoked a TP-receptor-mediated contraction that increased with postnatal age in a similar pattern as previously reported with the $\mathrm{TXA}_{2}$ mimetic and TP-receptor agonist U46619 [133]. In U46619-precontracted pulmonary arterial muscle, $15-\mathrm{F}_{2 \mathrm{t}^{-}}$ IsoP induced a relaxant effect in the adult and further contraction in the newborn rat. This pulmonary vasoconstrictor effect of $15-\mathrm{F}_{2 \mathrm{t}}$-IsoP was abolished by endothelium removal and NO synthase inhibition, and was markedly attenuated by COX blockade [131].

Truog et al. [134] observed that $15-\mathrm{F}_{2 \mathrm{t}}$-IsoP induced marked pulmonary vasoconstriction in 2-week-old piglets. Gonzalez-Luis et al. [58] evaluated the response to several F- and E-ring IsoPs in pulmonary arteries and veins from newborn and 2-week-old piglets (Table 2). A postnatal age-dependent reduction in the contractile responses to $15-\mathrm{F}_{1 \mathrm{t}}$-IsoP, 9-epi-15- $\mathrm{F}_{1 \mathrm{t}}$-IsoP, $15-\mathrm{F}_{2 \mathrm{t}}$-IsoP, and $15-\mathrm{E}_{2 \mathrm{t}}{ }^{-}$ IsoP was documented in these vessels (Fig. 1). IsoP contraction was mediated through the TP receptor and the signaling pathways involved tyrosine kinases(s) and Rho kinase [58]. Interestingly, no developmental changes on the pulmonary vascular responsiveness to the TP-receptor agonist U46619 were observed. Therefore, agerelated decreases in pulmonary vascular sensitivity appear to be unique for IsoPs. In the presence of a TP-receptor antagonist (SQ 29,548), 15- $\mathrm{E}_{2 \mathrm{t}}$-IsoP induced an endothelium-derived NO-dependent relaxation in pulmonary arteries that increased with postnatal age [132]. The E- and the F-ring IsoPs also induced TP-mediated contraction of neonatal and 2-week-old piglet mesenteric arteries that decreased with postnatal age [58].

\section{Isoprostanes and the newborn}

Judged by the plasma and urine IsoP levels, newborns are subjected to a greater oxidative challenge, when compared with adults, and the more immature the infant at birth the higher the plasma $15-\mathrm{F}_{2 \mathrm{t}}$-IsoP content $[16,135]$. Interestingly, and further suggesting that the source of IsoP generation during gestation is the fetus and/or placenta, the maternal $15-\mathrm{F}_{2 \mathrm{t}}$-IsoP levels during pregnancy and post delivery are not different than levels in nonpregnant women [16]. The fact that the higher IsoP levels at birth are associated with oxidative stress is further supported by the evidence that markers of oxidation-damaged erythrocyte removal from the blood are present in $74 \%$ of preterm and $21 \%$ of term newborns, as compared with only in $10 \%$ of adults [136]. The plasma $15-\mathrm{F}_{2 \mathrm{t}}$-IsoP levels gradually decrease, and by 6 months of age are reduced to $25 \%$ of the birth value [17].

As noted earlier, IsoPs may be involved in the pathogenesis of several neonatal clinical conditions including asphyxia, intraventricular hemorrhage, periventricular leukomalacia, bronchopulmonary dysplasia pulmonary hypertension, and retinopathy of prematurity [19-22]. The following is an organ-specific review of the most relevant and recent reports suggesting a putative role for IsoPs in neonatal disease states.

\section{Isoprostanes and the neonatal brain}

Periventricular white matter injury is one of the most severe sequelae observed in premature and term infants. It is associated and likely causative of cerebral palsy and long-term neurological dysfunction in survivors of prematurity. The pathogenesis of this condition remains unclear, yet commonly ascribed to hypoxicischemic tissue injury [137]. Because ROS formation is seen following a decrease in cell oxygen availability, the prevalence of oxidative stress in this condition has been investigated. Oxidative tissue damage was documented in the periventricular white matter of premature neonates, as well as the cerebral cortex of term infants succumbing from severe hypoxic-ischemic insults [138]. In a small sample of premature infants with white matter injury, the cerebrospinal fluid $15-\mathrm{F}_{2 \mathrm{t}-\mathrm{IsoP}}$ levels were significantly increased in one-third of the subjects [139].

In the newborn rat, global perinatal asphyxia increases the brain tissue $15-\mathrm{F}_{2 \mathrm{t}}$-IsoP and the levels are predictive of behavioral disturbance sequelae [140]. In the fetal and neonatal pig cerebral circulation, $15-\mathrm{F}_{2 \mathrm{t}}$-IsoP causes periventricular vasoconstriction, the magnitude of which decreases postnatally, and appears to be mediated via $\mathrm{TXA}_{2}$ generation [141].

The nature of the cells involved in oxidative stress-associated brain injury is currently unknown. In postmortem examination of premature infants, the brain oxidative damage particularly targeted the oligodendrocyte lineage, suggesting that these cells are most vulnerable to this type of injury [138]. Experiments conducted in vitro documented that $15 \mathrm{E}_{2 \mathrm{t}}-\mathrm{IsoP}$, but not $15-\mathrm{F}_{2 \mathrm{t}}-\mathrm{IsoP}$, elicited a concentration-dependent death of progenitor oligodendrocytes by oncosis [142]. In another study, where different brain cells from newborn pigs were exposed in vitro to $15-\mathrm{F}_{2 \mathrm{t}}$-IsoP, oncotic death was only observed in the microvascular endothelial cells [143]. Cell death, in this study, was associated with increased endothelial $\mathrm{TXA}_{2}$ formation and was prevented by thromboxane synthase inhibitors of this compound, suggesting that IsoP-induced cell damage is mediated by TXA $_{2}$ [143].

Which specific lipid peroxidation product is responsible for the oxidative stress-induced brain damage is currently unclear. Aside from F- and E-ring IsoP-associated oxidative damage [141-143], a new class of free radical-mediated peroxidation products potentially involved in this process has been described. Neuroprostanes originate from peroxidation of docosahexaenoic acid, a polyunsaturated fatty acid particularly abundant in neurons [144]. The mechanism by which neuroprostanes induce neurological damage is unclear. However, molecular modeling of a neuroprostane esterified in phospholipids indicates that it is a very distorted molecule which would be expected to disrupt normal membrane integrity [145].

\section{Isoprostanes and the newborn lung}

In preterm infants, immaturity in combination with oxidative stress, volutrauma, and inflammatory processes can lead to chronic lung injury or BPD [18,146,147]. Oxidative damage is found very early in life in infants subsequently developing chronic lung disease, suggesting that ROS trigger cellular and molecular changes that may impair normal pulmonary growth and development [146,147]. Whether IsoP generation plays a significant role in the BPD pathogenesis remains a hotly debated issue.

In part the apparently discrepant data relate to the methodological approach employed in the distinct BPD studies. Urinary excretion of $15-\mathrm{F}_{2 \mathrm{t}}$-IsoP in early postnatal life was reported in one study not to correlate with the development of BPD in preterm infants [148]. Yet, a comparison of tracheal aspirate and urinary $15-\mathrm{F}_{2 \mathrm{t}}-\mathrm{IsoP}$ levels during the first 2 days of life in premature infants raised concerns about the urinary measurement of this IsoP metabolite. Tracheal aspirate $15-\mathrm{F}_{2 \mathrm{t}^{-}}$ IsoP alpha levels correlated with respiratory disease severity, whereas the urinary concentrations did not discriminate between sick and well infants [149]. An increase in plasma IsoPs was observed in preterm infants who developed either BPD or periventricular leukomalacia was reported utilizing an immunoassay test; however this methodology, as previously discussed, is less than optimal raising concerns about the results [21]. Very recent studies have shown a correlation between oxygen used during resuscitation of extremely premature babies and levels of IsoPs and isofurans in urine as measured by GC/ MS/MS, and the development of chronic conditions especially BPD [150].

The available animal experimental data clearly indicate that F-ring IsoPs are increased following exposure to hyperoxia. In premature lambs chronically exposed to $100 \% \mathrm{O}_{2}$ after birth, a significant increase 
in lung tissue $15-\mathrm{F}_{2 \mathrm{t}}$-IsoP was documented, when compared with airtreated animals [151]. A similar increase in plasma levels of this IsoP were documented in newborn rabbits exposed to $80-100 \% \mathrm{O}_{2}$ for 4 days [152]. That inflammation modulates the IsoP-induced chronic lung changes is highlighted by the decrease in $15-\mathrm{F}_{2 \mathrm{t}}$-IsoP levels following dexamethasone treatment of chronically hyperoxia-exposed newborn rabbits [152].

Newborn rats chronically subjected to $60 \% \mathrm{O}_{2}$ for 14 days develop lung parenchymal and pulmonary vascular changes compatible with BPD and persistent pulmonary hypertension syndrome [153]. Chronic oxygen supplementation is detrimental to the lung alveolar epithelial cells by inducing the release of free radicals. Which of the specific ROS is responsible for the $\mathrm{O}_{2}$-induced alveolar epithelial cell necrosis remains unclear, but there is evidence that hydrogen peroxide, as opposed to products of lipid peroxidation, is involved [154].

IsoPs have been directly implicated in the newborn rat chronic $\mathrm{O}_{2}$ exposure-induced pulmonary hypertension. The mechanism by which this occurs involves lipid peroxidation-dependent IsoP release that induces pulmonary hypertension via endothelin-1 generation [155]. Chronic $\mathrm{O}_{2}$ exposure in the presence of a ROS scavenger abrogates the pulmonary hypertension, but not the BPD-like lung parenchymal changes in this experimental newborn rat model [155]. Inhibition of lung macrophage influx in newborn rats chronically $\mathrm{O}_{2}$ exposed suppresses the tissue IsoP content increase and pulmonary hypertension features, but did not prevent the development of BPD in this experimental model [156]. Taken together, these results suggest that the mechanism involved in oxidative stress-induced pulmonary hypertension is distinct, when compared with the process leading to chronic parenchymal lung disease changes in the newborn rat.

The chronic hyperoxia-induced pulmonary hypertension in the newborn rat is mediated via TP receptors, but not $\mathrm{TXA}_{2}$ regulated [157]. This suggests that IsoP activation of TP receptors might be involved in this process. The in vitro newborn rat pulmonary arteries response to $15-\mathrm{F}_{2 \mathrm{t}}$-IsoP is altered following chronic $\mathrm{O}_{2}$ exposure. A significant increase in pulmonary arterial muscle force generation and a reduced endothelium-dependent relaxation were documented in the $60 \% \mathrm{O}_{2}$ chronically exposed newborn rat [158]. Thus, not only a hyperoxia regimen, similar to that used clinically, induces IsoP release, but it also potentiates the pulmonary vasoconstrictive capacity of these metabolites. These findings strongly corroborate the speculation that IsoPs play an important role in the pathogenesis of pulmonary hypertension. Recently other factors such as increased pulmonary arterial smooth muscle calcium sensitivity, mediated via RhoA/Rho kinase pathways, have been also signaled to contribute to the pathogenesis of this condition [22].

As previously discussed, as arterial blood oxygen tension increases, the formation of IsoPs becomes highly disfavored leading to an increase in isofurans [41]. Thus measuring IsoP changes secondary to hyperoxia exposure may lead to misleading results. Most of the available experimental data obtained in hyperoxia-exposed animals utilized an immunoassay to measure IsoP levels. When used for this purpose, immunoassay quantification of IsoPs is likely an unreliable indicator of oxidative stress.

Isofurans, like IsoPs, have a ring structure and contain 20 carbons. This possibly allows for a cross-reaction between IsoPs and isofurans. A recent clinical study assessing the effect of neonatal resuscitation with a high and low oxygen supplementation regime clearly showed changes in urine isofurans, but not IsoPs [11].

Lastly, exposure of newborn rats for 2 weeks to $13 \% \mathrm{O}_{2}$ induces pulmonary hypertension of a greater severity than observed following chronic hyperoxia [159]. Rho kinase activation is also involved in this process, and inhibitors of this enzyme abrogate the pulmonary hypertension severity in the chronically hypoxic newborn rat [159]. ROS formation is involved in the chronic hypoxia-induced pulmonary hypertension [160]. The extent to which IsoPs participate in this process warrants further investigation.

\section{Isoprostanes and the retinopathy of prematurity}

Retinopathy of prematurity is considered one of the most important tissue damage induced by oxidative stress in preterm infants [20]. As noted elsewhere, $15-\mathrm{F}_{2 \mathrm{t}}$-IsoP and its metabolite (2,3dinor-5,6-dihydro-15- $\mathrm{F}_{2 \mathrm{t}}$-IsoP) evoke vasoconstriction in the piglet retina by stimulating $\mathrm{TXA}_{2}$ formation from neurovascular cells [161]. In addition, a potential role for $15-\mathrm{F}_{2 \mathrm{t}}$-IsoP in retinal microvascular cell death has also been proposed [162]. The mechanism of this cell death seems largely mediated by TXA $\mathrm{T}_{2}$. However, further studies addressing the newborn retina are necessary to properly evaluate the possible role of IsoPs in the retinopathy of prematurity.

\section{Conclusions}

IsoPs are free radicals and ROS-generated bioactive molecules, via nonenzymatic peroxidation of lipid membrane-derived arachidonic acid. The knowledge about their cognate receptors, biological actions, and signaling pathways has increased considerably in recent years. Aside from being sensitive and specific biomarkers of oxidative stress, their generation is likely of critical physiological significance. E- and Fring IsoPs have important biological functions that mediate diseaseinduced vascular, lymphatic, and airway smooth muscle changes.

The potential physiological effect of IsoPs might be of particular importance during the fetal and neonatal period, given that their contents in body fluids during these stages are many fold higher than later in life. The IsoP isomer PGs play a major role in the control of fetal vascular tone and in the circulatory changes that take place following birth. However, the IsoP-dependent regulatory role of vascular resistance is poorly understood, but possibly of great importance early in life. Such is the case for the ductus arteriosus, a vessel only functional during fetal life under the control of COX-derived PGs. Further investigation of the role of IsoPs in the regulation of ductus arteriosus patency during fetal life, and its closure immediately after birth is warranted.

Given the potential role of IsoPs in multiple diseases, the development of tools directed to inhibit their synthesis or their biological effects is an appealing therapeutic strategy. Part of their biological effects can be prevented by TP-receptor antagonists. However, the nonenzymatic nature of their synthetic process is a challenge to achieve synthesis inhibition in a targeted manner. In addition, the biological significance of compounds such as isoketals, isofurans, neuroprostanes, or non-arachidonic acid-derived IsoPs requires further investigation. The broken paradigm that only enzymatically formed compounds have important biological functions now poses new challenges for drug development.

\section{Acknowledgments}

The authors research was supported by an grant-in-aid from the Heart and Stroke Foundation of Canada No. NA6127 (J. Belik) and an operating grant from the Canadian Institutes of Health and Research No. MOP 93710 (J. Belik) and Ministerio de Ciencia y Tecnología of Spain No. SAF 2008-03948 (F. Perez-Vizcaino).

\section{References}

[1] Morrow, J. D.; Harris, T. M.; Roberts, L. J. Noncyclooxygenase oxidative formation of a series of novel prostaglandins: analytical ramifications for measurement of eicosanoids. Anal. Biochem. 184:1-10; 1990.

[2] Morrow, J. D.; Hill, K. E.; Burk, R. F.; Nammour, T. M.; Badr, K. F.; Roberts, L. J. A series of prostaglandin F2-like compounds are produced in vivo in humans by a non-cyclooxygenase, free radical-catalyzed mechanism. Proc. Natl. Acad. Sci. USA 87:9383-9387; 1990.

[3] Jahn, U.; Galano, J. M.; Durand, T. Beyond prostaglandins-chemistry and biology of cyclic oxygenated metabolites formed by free-radical pathways from polyunsaturated fatty acids. Angew. Chem. Int. Ed. 47:5894-5955; 2008.

[4] Morrow, J. D. The isoprostanes-unique products of arachidonate peroxidation their role as mediators of oxidant stress. Curr. Pharm. Des. 12:895-902; 2006. 
[5] Taylor, A. W.; Bruno, R. S.; Frei, B.; Traber, M. G. Benefits of prolonged gradient separation for high-performance liquid chromatography-tandem mass spectrometry quantitation of plasma total 15 -series F-isoprostanes. Anal. Biochem. 350:41-51; 2006

[6] Basu, S. F2-isoprostanes in human health and diseases: from molecular mechanisms to clinical implications. Antioxid. Redox Signal. 10:1405-1434; 2008.

[7] Khasawneh, F. T.; Huang, J. S.; Mir, F.; Srinivasan, S.; Tiruppathi, C.; Le Breton, G. C. Characterization of isoprostane signaling: evidence for a unique coordination profile of 8-iso-PGF(2alpha) with the thromboxane $\mathrm{A}(2)$ receptor, and activation of a separate cAMP-dependent inhibitory pathway in human platelets. Biochem. Pharmacol. 75:2301-2315; 2008.

[8] Peter, S. T.; Scholl, T. O.; Schluter, M. D.; Leskiw, M. J.; Chen, X.; Spur, B. W., et al. Oxidative stress early in pregnancy and pregnancy outcome. Free Radic. Res. 42: $841-848 ; 2008$.

[9] Sies, H.; Cadenas, E. Oxidative stress: damage to intact cells and organs. Philos. Trans. R. Soc. Lond., B Biol. Sci. 311:617-631; 1985.

[10] Belik, J.; Jankov, R. P.; Pan, J.; Tanswell, A. K. Peroxynitrite inhibits relaxation and induces pulmonary artery muscle contraction in the newborn rat. Free Radic. Biol. Med. 37:1384-1392; 2004.

[11] Vento, M.; Moro, M.; Escrig, R.; Arruza, L.; Villar, G.; Izquierdo, I., et al. Preterm resuscitation with low oxygen causes less Q3 oxidative stress, inflammation, and chronic lung disease. Pediatrics 124:e439-e449; 2009.

[12] Vento, M.; Aguar, M.; Leone, T. A.; Finer, N. N.; Gimeno, A.; Rich, W., et al. Using intensive care technology in the delivery room: a new concept for the resuscitation of extremely preterm neonates. Pediatrics 122:1113-1116; 2008.

[13] Martin, R. J.; Bookatz, G. B.; Gelfand, S. L.; Sastre, J.; Arduini, A.; Aguar, M., et al. Consequences of neonatal resuscitation with supplemental oxygen. Semin. Perinatol. 32:355-366; 2008.

[14] Pallardo, F. V.; Sastre, J.; Asensi, M.; Rodrigo, F.; Estrela, J. M.; Vina, J. Physiological changes in glutathione metabolism in foetal and newborn rat liver. Biochem. J. 274 (Pt. 3):891-893; 1991.

[15] Martin, J. A.; Pereda, J.; Martinez-Lopez, I.; Escrig, R.; Miralles, V.; Pallardo, F. V. et al. Oxidative stress as a signal to up-regulate gamma-cystathionase in the fetal-to-neonatal transition in rats. Cell. Mol. Biol. (Noisy -le-grand) 53 (Suppl.): OL1010-OL1017; 2007.

[16] Comporti, M.; Signorini, C; Leoncini, S; Buonocore, G; Rossi, V; Ciccoli, Plasma F2-isoprostanes are elevated in newborns and inversely correlated to gestational age. Free Radic. Biol. Med. 37:724-732; 2004

[17] Friel, J. K.; Friesen, R. W.; Harding, S. V.; Roberts, L. J. Evidence of oxidative stress in full-term healthy infants. Pediatr. Res. 56:878-882; 2004

[18] Saugstad, O. D. Bronchopulmonary dysplasia and oxidative stress: are we closer to an understanding of the pathogenesis of BPD? Acta Paediatr. 86:1277-1282; 1997.

[19] Weinberger, B.; Nisar, S.; Anwar, M.; Ostfeld, B.; Hegyi, T. Lipid peroxidation in cord blood and neonatal outcome. Pediatr. Int. 48:479-483; 2006.

[20] Hardy, P.; Dumont, I.; Bhattacharya, M.; Hou, X.; Lachapelle, P.; Varma, D. R., et al. Oxidants, nitric oxide and prostanoids in the developing ocular vasculature: a basis for ischemic retinopathy. Cardiovasc. Res. 47:489-509; 2000.

[21] Ahola, T.; Fellman, V.; Kjellmer, I.; Raivio, K. O.; Lapatto, R. Plasma 8-isoprostane is increased in preterm infants who develop bronchopulmonary dysplasia or periventricular leukomalacia. Pediatr. Res. 56:88-93; 2004.

[22] Yi, S. L.; Kantores, C.; Belcastro, R.; Cabacungan, J.; Tanswell, A. K.; Jankov, R. P. 8Isoprostane-induced endothelin-1 production by infant rat pulmonary artery smooth muscle cells is mediated by Rho-kinase. Free Radic. Biol. Med. 41: 942-949; 2006

[23] Morrow, J. D.; Awad, J. A.; Boss, H. J.; Blair, I. A.; Roberts, L. J. Noncyclooxygenase-derived prostanoids (F2-isoprostanes) are formed in situ on phospholipids. Proc. Natl. Acad. Sci. USA 89:10721-10725; 1992.

[24] Stafforini, D. M.; Sheller, J. R.; Blackwell, T. S.; Sapirstein, A.; Yull, F. E.; McIntyre, T. M., et al. Release of free F2-isoprostanes from esterified phospholipids is catalyzed by intracellular and plasma platelet-activating factor acetylhydrolases. J. Biol. Chem. 281:4616-4623; 2006.

[25] Milne, G. L.; Morrow, J. D. Isoprostanes and related compounds: update 2006. Antioxid. Redox Signal. 8:1379-1384; 2006

[26] Milne, G. L.; Yin, H.; Morrow, J. D. Human biochemistry of the isoprostane pathway. J. Biol. Chem. 283:15533-15537; 2008.

[27] Musiek, E. S.; Yin, H.; Milne, G. L.; Morrow, J. D. Recent advances in the biochemistry and clinical relevance of the isoprostane pathway. Lipids 40: 987-994; 2005

[28] Chen, W.; Pawelek, T. R.; Kulmacz, R. J. Hydroperoxide dependence and cooperative cyclooxygenase kinetics in prostaglandin $\mathrm{H}$ synthase- 1 and -2 . J. Biol. Chem. 274:20301-20306; 1999.

[29] Chen, Y.; Morrow, J. D.; Roberts, L. J. Formation of reactive cyclopentenone compounds in vivo as products of the isoprostane pathway. J. Biol. Chem. 274: 10863-10868; 1999.

[30] Taber, D. F.; Morrow, J. D.; Roberts, L. J. A nomenclature system for the isoprostanes. Prostaglandins 53:63-67; 1997.

[31] Rokach, J.; Khanapure, S. P.; Hwang, S. W.; Adiyaman, M.; Lawson, J. A FitzGerald, G. A. Nomenclature of isoprostanes: a proposal. Prostaglandins 54: 853-873; 1997

[32] Yin, H.; Brooks, J. D.; Gao, L.; Porter, N. A.; Morrow, J. D. Identification of novel autoxidation products of the omega-3 fatty acid eicosapentaenoic acid in vitro and in vivo. J. Biol. Chem. 282:29890-29901; 2007.

[33] Gao, L.; Yin, H.; Milne, G. L.; Porter, N. A.; Morrow, J. D. Formation of F-ring isoprostane-like compounds (F3-isoprostanes) in vivo from eicosapentaenoic acid. J. Biol. Chem. 281:14092-14099; 2006.
[34] Brooks, J. D.; Milne, G. L.; Yin, H.; Sanchez, S. C.; Porter, N. A.; Morrow, J. D. Formation of highly reactive cyclopentenone isoprostane compounds (A3/J3isoprostanes) in vivo from eicosapentaenoic acid. J. Biol. Chem. 283: 12043-12055; 2008

[35] Brame, C. J.; Boutaud, O.; Davies, S. S.; Yang, T.; Oates, J. A.; Roden, D., et al. Modification of proteins by isoketal-containing oxidized phospholipids. J. Biol. Chem. 279:13447-13451; 2004.

[36] Brame, C. J.; Salomon, R. G.; Morrow, J. D.; Roberts, L. J. Identification of extremely reactive gamma-ketoaldehydes (isolevuglandins) as products of the isoprostane pathway and characterization of their lysyl protein adducts. J. Biol. Chem. 274:13139-13146; 1999.

[37] Bernoud-Hubac, N.; Alam, D. A.; Lefils, J.; Davies, S. S.; Amarnath, V.; Guichardant, M., et al. Low concentrations of reactive gamma-ketoaldehydes prime thromboxane-dependent human platelet aggregation via p38-MAPK activation. Biochim. Biophys. Acta 1791:307-313; 2009.

[38] Davies, S. S.; Amarnath, V.; Montine, K. S.; Bernoud-Hubac, N.; Boutaud, O.; Montine, T. J., et al. Effects of reactive gamma-ketoaldehydes formed by the isoprostane pathway (isoketals) and cyclooxygenase pathway (levuglandins) on proteasome function. FASEB J. 16:715-717; 2002.

[39] Roberts, L. J.; Salomon, R. G.; Morrow, J. D.; Brame, C. J. New developments in the isoprostane pathway: identification of novel highly reactive gamma-ketoaldehydes (isolevuglandins) and characterization of their protein adducts. FASEB J. 13:1157-1168; 1999.

[40] Boyden, P. A.; Davies, S. S.; Viswanathan, P. C.; Amarnath, V.; Balser, J. R.; Roberts, L. J. Potential role of isoketals formed via the isoprostane pathway of lipid peroxidation in ischemic arrhythmias. J. Cardiovasc. Pharmacol. 50:480-486; 2007.

[41] Fessel, J. P.; Porter, N. A.; Moore, K. P.; Sheller, J. R.; Roberts, L. J. Discovery of lipid peroxidation products formed in vivo with a substituted tetrahydrofuran ring (isofurans) that are favored by increased oxygen tension. Proc. Natl. Acad. Sci. USA 99:16713-16718; 2002.

[42] Fessel, J. P.; Jackson, R. L. Isofurans: novel products of lipid peroxidation that define the occurrence of oxidant injury in settings of elevated oxygen tension. Antioxid. Redox Signal. 7:202-209; 2005.

[43] Kadiiska, M. B.; Gladen, B. C.; Baird, D. D.; Germolec, D.; Graham, L. B.; Parker, C. E., et al. Biomarkers of oxidative stress study II: are oxidation products of lipids, proteins, and DNA markers of $\mathrm{CCl} 4$ poisoning? Free Radic. Biol. Med. 38: 698-710; 2005.

[44] Milne, G. L.; Yin, H.; Brooks, J. D.; Sanchez, S.; Jackson, R. L.; Morrow, J. D. Quantification of F2-isoprostanes in biological fluids and tissues as a measure of oxidant stress. Methods Enzymol. 433:113-126; 2007.

[45] Schweer, H.; Watzer, B.; Seyberth, H. W.; Nusing, R. M. Improved quantification of 8-epi-prostaglandin F2 alpha and F2-isoprostanes by gas chromatography/ triple-stage quadrupole mass spectrometry: partial cyclooxygenase-dependent formation of 8-epi-prostaglandin F2 alpha in humans. J. Mass Spectrom. 32: 1362-1370; 1997.

[46] Roberts, L. J.; Moore, K. P.; Zackert, W. E.; Oates, J. A.; Morrow, J. D. Identification of the major urinary metabolite of the F2-isoprostane 8-iso-prostaglandin F2alpha in humans. J. Biol. Chem. 271:20617-20620; 1996.

[47] Signore, C.; Aros, S.; Morrow, J. D.; Troendle, J.; Conley, M. R.; Flanigan, E. Y., et al. Markers of oxidative stress and systemic vasoconstriction in pregnant women drinking $>$ or $=48 \mathrm{~g}$ of alcohol per day. Alcohol. Clin. Exp. Res. 32:1893-1898; 2008.

[48] Cracowski, J. L.; Durand, T. Cardiovascular pharmacology and physiology of the isoprostanes. Fundam. Clin. Pharmacol. 20:417-427; 2006.

[49] Janssen, L. J. Isoprostanes and lung vascular pathology. Am. J. Respir. Cell Mol. Biol 39:383-389; 2008

[50] Morrow, J. D.; Zackert, W. E.; Yang, J. P.; Kurhts, E. H.; Callewaert, D.; Dworski, R, et al. Quantification of the major urinary metabolite of 15-F2t-isoprostane (8iso-PGF2alpha) by a stable isotope dilution mass spectrometric assay. Anal. Biochem. 269:326-331; 1999.

[51] Sinzinger, H.; Oguogho, A.; Kaliman, J. Isoprostane 8-epi-prostaglandin F2 alpha is a potent contractor of human peripheral lymphatics. Lymphology 30:155-159; 1997.

[52] Oguogho, A.; Kaliman, J.; Sinzinger, H. Levels of eicosanoids (6-oxo-PGF1 alpha and 8-epi-PGF2 alpha) in human and porcine lymphatics and lymph. Lymphology 31:186-189; 1998.

[53] Janssen, L. J.; Premji, M.; Netherton, S.; Catalli, A.; Cox, G.; Keshavjee, S., et al. Excitatory and inhibitory actions of isoprostanes in human and canine airway smooth muscle. J. Pharmacol. Exp. Ther. 295:506-511; 2000.

[54] Sametz, W.; Hummer, K.; Butter, M.; Wintersteiger, R.; Juan, H. Formation of 8iso-PGF(2alpha) and thromboxane $\mathrm{A}(2)$ by stimulation with several activators of phospholipase $\mathrm{A}(2)$ in the isolated human umbilical vein. Br. J. Pharmacol. 131: $145-151 ; 2000$.

[55] Crankshaw, D. Effects of the isoprostane, 8-epi-prostaglandin F2 alpha, on the contractility of the human myometrium in vitro. Eur. J. Pharmacol. 285:151-158; 1995.

[56] Hou, X.; Roberts, L. J.; Taber, D. F.; Morrow, J. D.; Kanai, K.; Gobeil Jr., F., et al. 2,3Dinor-5,6-dihydro-15-F(2t)-isoprostane: a bioactive prostanoid metabolite. Am. J. Physiol., Regul. Integr. Comp. Physiol. 281:R391-R400; 2001.

[57] Hou, X.; Roberts, L. J.; Gobeil Jr., F.; Taber, D.; Kanai, K.; Abran, D., et al. Isomerspecific contractile effects of a series of synthetic f2-isoprostanes on retinal and cerebral microvasculature. Free Radic. Biol. Med. 6:163-172; 2004

[58] Gonzalez-Luis, G.; Perez-Vizcaino, F.; Garcia-Munoz, F.; de Mey, J. G.; Blanco, C. E.; Villamor, E. Age-related differences in vasoconstrictor responses to isoprostanes in piglet pulmonary and mesenteric vascular smooth muscle. Pediatr. Res. 57: $845-852 ; 2005$. 
[59] Janssen, L. J.; Tazzeo, T. Involvement of TP and EP3 receptors in vasoconstrictor responses to isoprostanes in pulmonary vasculature. J. Pharmacol. Exp. Ther. 301: 1060-1066; 2002.

[60] Janssen, L. J. Isoprostanes: an overview and putative roles in pulmonary pathophysiology. Am. J. Physiol., Lung Cell Mol. Physiol. 280:L1067-L1082; 2001.

[61] Jourdan, K. B.; Evans, T. W.; Curzen, N. P.; Mitchell, J. A. Evidence for a dilator function of 8-iso prostaglandin F2 alpha in rat pulmonary artery. Br. J. Pharmacol. 120:1280-1285; 1997.

[62] Zhang, Y.; Pertens, E.; Janssen, L. J. 8-isoprostaglandin E(2) activates $\mathrm{Ca}(2+)$ dependent $\mathrm{K}(+)$ current via cyclic AMP signaling pathway in murine renal artery. Eur. J. Pharmacol. 520:22-28; 2005.

[63] Zhang, Y.; Tazzeo, T.; Hirota, S.; Janssen, L. J. Vasodilatory and electrophysiological actions of 8-iso-prostaglandin E2 in porcine coronary artery. J. Pharmacol. Exp. Ther. 305:1054-1060; 2003.

[64] Clarke, D. L.; Belvisi, M. G.; Hardaker, E.; Newton, R.; Giembycz, M. A. E-ring 8-isoprostanes are agonists at EP2- and EP4-prostanoid receptors on human airway smooth muscle cells and regulate the release of colony-stimulating factors by activating cAMP-dependent protein kinase. Mol. Pharmacol. 67:383-393; 2005.

[65] Kumar, A.; Kingdon, E.; Norman, J. The isoprostane 8-iso-PGF2alpha suppresses monocyte adhesion to human microvascular endothelial cells via two independent mechanisms. FASEB J. 19:443-445; 2005.

[66] Zanoni, G.; Porta, A.; Castronovo, F.; Vidari, G. First total synthesis of JS isoprostane. J. Org. Chem 68:6005-6010; 2003.

[67] Zanoni, G.; Porta, A.; Vidari, G. First total synthesis of A(2) isoprostane. J. Org. Chem. 67:4346-4351; 2002.

[68] Milne, G. L.; Musiek, E. S.; Morrow, J. D. The cyclopentenone (A2/J2) isoprostanes -unique, highly reactive products of arachidonate peroxidation. Antioxid. Redox Signal. 7:210-220; 2005.

[69] Musiek, E. S.; Breeding, R. S.; Milne, G. L.; Zanoni, G.; Morrow, J. D.; McLaughlin, B. Cyclopentenone isoprostanes are novel bioactive products of lipid oxidation which enhance neurodegeneration. J. Neurochem. 97:1301-1313; 2006.

[70] Minuz, P.; Patrignani, P.; Gaino, S.; Degan, M.; Menapace, L.; Tommasoli, R., et al. Increased oxidative stress and platelet activation in patients with hypertension and renovascular disease. Circulation 106:2800-2805; 2002.

[71] Hoeldtke, R. D.; Bryner, K. D.; McNeill, D. R.; Warehime, S. S.; Van, D. K.; Hobbs, G. Oxidative stress and insulin requirements in patients with recent-onset type 1 diabetes. J. Clin. Endocrinol. Metab. 88:1624-1628; 2003.

[72] Davi, G.; Chiarelli, F.; Santilli, F.; Pomilio, M.; Vigneri, S.; Falco, A., et al. Enhanced lipid peroxidation and platelet activation in the early phase of type 1 diabetes mellitus: role of interleukin-6 and disease duration. Circulation 107:3199-3203; 2003.

[73] Kauffman, L. D.; Sokol, R. J.; Jones, R. H.; Awad, J. A.; Rewers, M. J.; Norris, J. M. Urinary F2-isoprostanes in young healthy children at risk for type 1 diabetes mellitus. Free Radic. Biol. Med. 35:551-557; 2003.

[74] Desco, M. C.; Asensi, M.; Marquez, R.; Martinez-Valls, J.; Vento, M.; Pallardo, F. V., et al. Xanthine oxidase is involved in free radical production in type 1 diabetes: protection by allopurinol. Diabetes 51:1118-1124; 2002.

[75] Martino, F.; Loffredo, L.; Carnevale, R.; Sanguigni, V.; Martino, E.; Catasca, E., et al. Oxidative stress is associated with arterial dysfunction and enhanced intima-media thickness in children with hypercholesterolemia: the potential role of nicotinamide-adenine dinucleotide phosphate oxidase. Pediatrics 122:e648-e655; 2008.

[76] Gross, M.; Steffes, M.; Jacobs Jr., D. R.; Yu, X.; Lewis, L.; Lewis, C. E., et al. Plasma F2-isoprostanes and coronary artery calcification: the CARDIA Study. Clin. Chem. 51:125-131; 2005.

[77] Cracowski, J. L.; Cracowski, C.; Bessard, G.; Pepin, J. L.; Bessard, J.; Schwebel, C., et al. Increased lipid peroxidation in patients with pulmonary hypertension. $\mathrm{Am}$. J. Respir. Crit. Care Med. 164:1038-1042; 2001.

[78] Robbins, I. M.; Morrow, J. D.; Christman, B. W. Oxidant stress but not thromboxane decreases with epoprostenol therapy. Free Radic. Biol. Med. 38:568-574; 2005.

[79] Back, E. I.; Frindt, C.; Nohr, D.; Frank, J.; Ziebach, R.; Stern, M., et al. Antioxidant deficiency in cystic fibrosis: when is the right time to take action? Am. J. Clin. Nutr. 80:374-384; 2004.

[80] Wood, L. G.; Fitzgerald, D. A.; Gibson, P. G.; Cooper, D. M.; Garg, M. L. Increased plasma fatty acid concentrations after respiratory exacerbations are associated with elevated oxidative stress in cystic fibrosis patients. Am. J. Clin. Nutr. 75: $668-675 ; 2002$.

[81] Wood, L. G.; Fitzgerald, D. A.; Gibson, P. G.; Cooper, D. M.; Collins, C. E.; Garg, M. L. Oxidative stress in cystic fibrosis: dietary and metabolic factor. J. Am. Coll. Nutr. 20:157-165; 2001.

[82] Collins, C. E.; Quaggiotto, P.; Wood, L.; O'Loughlin, E. V.; Henry, R. L.; Garg, M. L. Elevated plasma levels of F2 alpha isoprostane in cystic fibrosis. Lipids 34: 551-556; 1999

[83] Ciabattoni, G.; Davi, G.; Collura, M.; Iapichino, L.; Pardo, F.; Ganci, A., et al. In vivo lipid peroxidation and platelet activation in cystic fibrosis. Am. J. Respir. Crit. Care Med. 162:1195-1201; 2000.

[84] Zanconato, S.; Carraro, S.; Corradi, M.; Alinovi, R.; Pasquale, M. F.; Piacentini, G., et al. Leukotrienes and 8-isoprostane in exhaled breath condensate of children with stable and unstable asthma. J. Allergy Clin. Immunol. 113:257-263; 2004.

[85] Baraldi, E.; Ghiro, L.; Piovan, V.; Carraro, S.; Ciabattoni, G.; Barnes, P. J., et al. Increased exhaled 8-isoprostane in childhood asthma. Chest 124:25-31; 2003.

[86] Baraldi, E.; Carraro, S.; Alinovi, R.; Pesci, A.; Ghiro, L.; Bodini, A., et al. Cysteinyl leukotrienes and 8-isoprostane in exhaled breath condensate of children with asthma exacerbations. Thorax 58:505-509; 2003.

[87] Bodini, A.; Peroni, D.; Vicentini, L.; Loiacono, A.; Baraldi, E.; Ghiro, L., et al. Exhaled breath condensate eicosanoids and sputum eosinophils in asthmatic children: a pilot study. Pediatr. Allergy Immunol. 15:26-31; 2004.
[88] Wood, L. G.; Fitzgerald, D. A.; Gibson, P. G.; Cooper, D. M.; Garg, M. L. Lipid peroxidation as determined by plasma isoprostanes is related to disease severity in mild asthma. Lipids 35:967-974; 2000.

[89] Dworski, R.; Murray, J. J.; Roberts, L. J.; Oates, J. A.; Morrow, J. D.; Fisher, L., et al. Allergen-induced synthesis of $\mathrm{F}(2)$-isoprostanes in atopic asthmatics. Evidence for oxidant stress. Am. J. Respir. Crit. Care Med. 160:1947-1951; 1999.

[90] Dworski, R.; Roberts, L. J.; Murray, J. J.; Morrow, J. D.; Hartert, T. V.; Sheller, J. R. Assessment of oxidant stress in allergic asthma by measurement of the major urinary metabolite of F2-isoprostane, 15-F2t-IsoP (8-iso-PGF2alpha). Clin. Exp. Allergy 31:387-390; 2001.

[91] Kawikova, I.; Barnes, P. J.; Takahashi, T.; Tadjkarimi, S.; Yacoub, M. H.; Belvisi, M. G. 8-Epi-PGF2 alpha, a novel noncyclooxygenase-derived prostaglandin, constricts airways in vitro. Am. J. Respir. Crit. Care Med. 153:590-596; 1996.

[92] bou-Raya, A.; el-Hallous, D.; Fayed, H. 8-Isoprostaglandin F2 alpha: a potential index of lipid peroxidation in systemic lupus erythematosus. Clin. Invest. Med. 27:306-311; 2004.

[93] Soep, J. B.; Mietus-Snyder, M.; Malloy, M. J.; Witztum, J. L.; von, S. E. Assessment of atherosclerotic risk factors and endothelial function in children and young adults with pediatric-onset systemic lupus erythematosus. Arthritis Rheum. 51: 451-457; 2004

[94] Greco, A.; Minghetti, L.; Puopolo, M.; Cannoni, S.; Romano, S.; Pozzilli, C., et al Cerebrospinal fluid isoprostanes are not related to inflammatory activity in relapsing-remitting multiple sclerosis. J. Neurol. Sci. 224:23-27; 2004.

[95] Cracowski, J. L.; Bonaz, B.; Bessard, G.; Bessard, J.; Anglade, C.; Fournet, J Increased urinary F2-isoprostanes in patients with Crohn's disease. Am. J. Gastroenterol. 97:99-103; 2002.

[96] Martinuzzo, M. E.; Forastiero, R. R.; Kordich, L.; Carreras, L. O. Increased lipid peroxidation correlates with platelet activation but not with markers of endothelial cell and blood coagulation activation in patients with antiphospholipid antibodies. Br. J. Haematol. 114:845-851; 2001.

[97] Kim, K. M.; Paeng, K. J.; Hahm, J. R.; Kim, D. R.; Chung, B. C. Elevated urinary 8-isoprostaglandin F(2alpha) in females with Graves' hyperthyroidism. Prostaglandins Leukot. Essent. Fatty Acids 71:143-147; 2004.

[98] Grosso, S.; Perrone, S.; Longini, M.; Bruno, C.; Minetti, C.; Gazzolo, D., et al Isoprostanes in dystrophinopathy: Evidence of increased oxidative stress. Brain Dev. 30:391-395; 2008.

[99] Akohoue, S. A.; Shankar, S.; Milne, G. L.; Morrow, J.; Chen, K. Y.; Ajayi, W. U., et al Energy expenditure, inflammation, and oxidative stress in steady-state adolescents with sickle cell anemia. Pediatr. Res. 61:233-238; 2007.

[100] Bayir, H.; Kagan, V. E.; Tyurina, Y. Y.; Tyurin, V.; Ruppel, R. A.; Adelson, P. D., et al Assessment of antioxidant reserves and oxidative stress in cerebrospinal fluid after severe traumatic brain injury in infants and children. Pediatr. Res. 51: 571-578; 2002.

[101] Braekke, K.; Harsem, N. K.; Staff, A. C. Oxidative stress and antioxidant status in fetal circulation in preeclampsia. Pediatr. Res. 60:560-564; 2006.

[102] Hermenegildo, C.; Garcia-Martinez, M. C.; Tarin, J. J.; Cano, A. Estradiol reduces F2alpha-isoprostane production in cultured human endothelial cells. Am. I. Physiol., Heart Circ. Physiol. 283:H2644-H2649; 2002.

[103] Walsh, S. W.; Vaughan, J. E.; Wang, Y.; Roberts, L. J. Placental isoprostane is significantly increased in preeclampsia. FASEB J. 14:1289-1296; 2000.

[104] Staff, A. C.; Halvorsen, B.; Ranheim, T.; Henriksen, T. Elevated level of free 8-isoprostaglandin F2alpha in the decidua basalis of women with preeclampsia. Am. J. Obstet. Gynecol. 181:1211-1215; 1999.

[105] Mandang, S.; Manuelpillai, U.; Wallace, E. M. Oxidative stress increases placental and endothelial cell activin A secretion. J. Endocrinol. 192:485-493; 2007.

[106] Davidge, S. T. Oxidative stress and altered endothelial cell function in preeclampsia. Semin. Reprod. Endocrinol. 16:65-73; 1998.

[107] Nash, P.; Wentzel, P.; Lindeberg, S.; Naessen, T.; Jansson, L.; Olovsson, M., et al. Placental dysfunction in Suramin-treated rats-a new model for pre-eclampsia. Placenta 26:410-418; 2005

[108] Cederberg, J.; Basu, S.; Eriksson, U. J. Increased rate of lipid peroxidation and protein carbonylation in experimental diabetic pregnancy. Diabetologia 44: 766-774; 2001.

[109] Gerber, R. T.; Holemans, K.; O'Brien-Coker, I.; Mallet, A. I.; van, B. R.; Van Assche, F. A., et al. Increase of the isoprostane 8-isoprostaglandin f2alpha in materna and fetal blood of rats with streptozotocin-induced diabetes: evidence of lipid peroxidation. Am. J. Obstet. Gynecol. 183:1035-1040; 2000.

[110] Zabihi, S.; Wentzel, P.; Eriksson, U. J. Maternal blood glucose levels determine the severity of diabetic embryopathy in mice with different expression of copperzinc superoxide dismutase (CuZnSOD). Toxicol. Sci. 105:166-172; 2008.

[111] Franco, M. C.; Kawamoto, E. M.; Gorjao, R.; Rastelli, V. M.; Curi, R.; Scavone, C., et al. Biomarkers of oxidative stress and antioxidant status in children born small for gestational age: evidence of lipid peroxidation. Pediatr. Res. 62:204-208; 2007.

[112] Longini, M.; Perrone, S.; Kenanidis, A.; Vezzosi, P.; Marzocchi, B.; Petraglia, F, et al. Isoprostanes in amniotic fluid: a predictive marker for fetal growth restriction in pregnancy. Free Radic. Biol. Med. 38:1537-1541; 2005.

[113] Obwegeser, R.; Oguogho, A.; Ulm, M.; Berghammer, P.; Sinzinger, H. Maternal cigarette smoking increases F2-isoprostanes and reduces prostacyclin and nitric oxide in umbilical vessels. Prostaglandins Other Lipid Mediat. 57:269-279; 1999.

[114] Perrone, S.; Longini, M.; Bellieni, C. V.; Centini, G.; Kenanidis, A.; De, M. L., et al. Early oxidative stress in amniotic fluid of pregnancies with Down syndrome. Clin. Biochem. 40:177-180; 2007.

[115] Longini, M.; Perrone, S.; Vezzosi, P.; Marzocchi, B.; Kenanidis, A.; Centini, G., et al Association between oxidative stress in pregnancy and preterm premature rupture of membranes. Clin. Biochem. 40:793-797; 2007. 
[116] Qin, Y.; Wang, C. C.; Kuhn, H.; Rathmann, J.; Pang, C. P.; Rogers, M. S. Determinants of umbilical cord arterial 8-iso-prostaglandin F2alpha concentrations. BJOG 107:973-981; 2000

117] Barden, A. E.; Mori, T. A.; Dunstan, J. A.; Taylor, A. L.; Thornton, C. A.; Croft, K. D. et al. Fish oil supplementation in pregnancy lowers F2-isoprostanes in neonates at high risk of atopy. Free Radic. Res. 38:233-239; 2004.

[118] Rietjens, S. J.; Beelen, M.; Koopman, R.; VAN Loon, L. J.; Bast, A.; Haenen, G. R. A single session of resistance exercise induces oxidative damage in untrained men. Med. Sci. Sports Exerc. 39:2145-2151; 2007.

[119] Rodriguez, M. C.; MacDonald, J. R.; Mahoney, D. J.; Parise, G.; Beal, M. F.; Tarnopolsky, M. A. Beneficial effects of creatine, CoQ10, and lipoic acid in mitochondrial disorders. Muscle Nerve 35:235-242; 2007.

[120] Welin, A. K.; Svedin, P.; Lapatto, R.; Sultan, B.; Hagberg, H.; Gressens, P., et al. Melatonin reduces inflammation and cell death in white matter in the midgestation fetal sheep following umbilical cord occlusion. Pediatr. Res. 61: 153-158; 2007.

[121] Daray, F. M.; Minvielle, A. I.; Puppo, S.; Rothlin, R. P. Vasoconstrictor effects of 8iso-prostaglandin E2 and 8-iso-prostaglandin $\mathrm{F}$ (2alpha) on human umbilical vein. Eur. J. Pharmacol. 499:189-195; 2004.

[122] Daray, F. M.; Colombo, J. R.; Kibrik, J. R.; Errasti, A. E.; Pelorosso, F. G.; Nowak, W. et al. Involvement of endothelial thromboxane A2 in the vasoconstrictor response induced by 15-E2t-isoprostane in isolated human umbilical vein. Naunyn Schmiedebergs Arch. Pharmacol. 373:367-375; 2006

[123] Oliveira, L.; Stallwood, N. A.; Crankshaw, D. J. Effects of some isoprostanes on the human umbilical artery in vitro. Br. J. Pharmacol. 129:509-514; 2000.

[124] Friel, A. M.; Sexton, D. J.; O'reilly, M. W.; Smith, T. J.; Morrison, J. J. Rho A/Rho kinase: human umbilical artery mRNA expression in normal and pre eclamptic pregnancies and functional role in isoprostane-induced vasoconstriction. Reproduction 132:169-176; 2006

[125] Abman, S. H. Recent advances in the pathogenesis and treatment of persistent pulmonary hypertension of the newborn. Neonatology 91:283-290; 2007.

[126] Gonzalez-Luis, G.; Cogolludo, A.; Moreno, L.; Lodi, F.; Tamargo, J.; PerezVizcaino, F., et al. Relaxant effects of the soluble guanylate cyclase activator and NO sensitizer YC-1 in piglet pulmonary arteries. Biol. Neonate 90:66-72; 2006.

[127] Moreno, L.; Losada, B.; Cogolludo, A.; Lodi, F.; Lugnier, C.; Villamor, E., et al. Postnatal maturation of phosphodiesterase 5 (PDE5) in piglet pulmonary arteries: activity, expression, effects of PDE5 inhibitors, and role of the nitric oxide/cyclic GMP pathway. Pediatr. Res. 56:563-570; 2004

[128] Moreno, L.; Gonzalez-Luis, G.; Cogolludo, A.; Lodi, F.; Lopez-Farre, A.; Tamargo, J., et al. Soluble guanylyl cyclase during postnatal porcine pulmonary maturation. Am. J. Physiol., Lung Cell Mol. Physiol. 288:L125-L130; 2005.

[129] Villamor, E.; Perez-Vizcaino, F.; Cogolludo, A. L.; Conde-Oviedo, J.; ZaragozaArnaez, F.; Lopez-Lopez, J. G., et al. Relaxant effects of carbon monoxide compared with nitric oxide in pulmonary and systemic vessels of newborn piglets. Pediatr. Res. 48:546-553; 2000.

[130] Villamor, E.; Degraeuwe, P. L.; de Mey, J. G.; Blanco, C. E. Vascular reactivity of pulmonary arteries from premature lambs subjected to liquid ventilation. Biol. Neonate 84:172-178; 2003.

[131] Belik, J.: Jankov, R. P.; Pan, J.; Yi, M.; Pace-Asciak, C. R.; Tanswell, A. K. Effect of 8isoprostaglandin F2alpha on the newborn rat pulmonary arterial muscle and endothelium. J. Appl. Physiol. 95:1979-1985; 2003.

[132] Gonzalez-Luis, G.; Perez-Vizcaino, F.; Blanco, C. E.; Villamor, E. Age-related changes in isoprostane-mediated relaxation of piglet blood vessels. Front. Biosci. E2:369-379; 2010

[133] Belik, J.; Kerc, E.; Pato, M. D. Rat pulmonary arterial smooth muscle myosin light chain kinase and phosphatase activities decrease with age. Am. J. Physiol., Lung Cell Mol. Physiol 290:L509-L516; 2006.

[134] Truog, W. E.; Norberg, M.; Thibeault, D. W. Effects of 8-epi-prostaglandin F2 alpha and U46,619 on pulmonary hemodynamics in piglets. Biol. Neonate 71: 306-316; 1997.

[135] Signorini, C.; Perrone, S.; Sgherri, C.; Ciccoli, L.; Buonocore, G.; Leoncini, S., et al. Plasma esterified F2-isoprostanes and oxidative stress in newborns: role of nonprotein-bound iron. Pediatr. Res. 63:287-291; 2008.

[136] Rossi, V.; Leoncini, S.; Signorini, C.; Buonocore, G.; Paffetti, P.; Tanganelli, D., et al. Oxidative stress and autologous immunoglobulin $\mathrm{G}$ binding to band 3 dimers in newborn erythrocytes. Free Radic. Biol. Med. 40:907-915; 2006.

[137] Back, S. A.; Riddle, A.; McClure, M. M. Maturation-dependent vulnerability of perinatal white matter in premature birth. Stroke 38:724-730; 2007.

[138] Back, S. A.; Luo, N. L.; Mallinson, R. A.; O'Malley, J. P.; Wallen, L. D.; Frei, B., et al. Selective vulnerability of preterm white matter to oxidative damage defined by F2-isoprostanes. Ann. Neurol. 58:108-120; 2005.

[139] Inder, T.; Mocatta, T.; Darlow, B.; Spencer, C.; Volpe, J. J.; Winterbourn, C. Elevated free radical products in the cerebrospinal fluid of VLBW infants with cerebral white matter injury. Pediatr. Res. 52:213-218; 2002.

[140] Calamandrei, G.; Venerosi, A. P.; Valanzano, A.; de Berardinis, M. A.; Greco, A.; Puopolo, M., et al. Increased brain levels of F2-isoprostane are an early marker of behavioral sequels in a rat model of global perinatal asphyxia. Pediatr. Res. 55: 85-92; 2004.

[141] Hou, X.; Gobeil Jr., F.; Peri, K.; Speranza, G.; Marrache, A. M.; Lachapelle, P., et al. Augmented vasoconstriction and thromboxane formation by $15-\mathrm{F}(2 \mathrm{t})$-isoprostane (8-iso-prostaglandin $\mathrm{F}$ (2alpha)) in immature pig periventricular brain microvessels. Stroke 31:516-524; 2000

[142] Brault, S.; Martinez-Bermudez, A. K.; Roberts, J.; Cui, Q. L.; Fragoso, G.; Hemdan, S., et al. Cytotoxicity of the E(2)-isoprostane 15-E(2t)-IsoP on oligodendrocyte progenitors. Free Radic. Biol. Med. 37:358-366; 2004.
[143] Brault, S.; Martinez-Bermudez, A. K.; Marrache, A. M.; Gobeil Jr., F.; Hou, X.; Beauchamp, M., et al. Selective neuromicrovascular endothelial cell death by 8Iso-prostaglandin F2alpha: possible role in ischemic brain injury. Stroke $\mathbf{3 4}$ : 776-782; 2003.

[144] Greco, A.; Minghetti, L. Isoprostanes as biomarkers and mediators of oxidative injury in infant and adult central nervous system diseases. Curr. Neurovasc. Res. 1:341-354; 2004.

[145] Roberts, L. J.; Montine, T. J.; Markesbery, W. R.; Tapper, A. R.; Hardy, P.; Chemtob, S., et al. Formation of isoprostane-like compounds (neuroprostanes) in vivo from docosahexaenoic acid. J. Biol. Chem. 273:13605-13612; 1998.

[146] Bland, R. D. Neonatal chronic lung disease in the post-surfactant era. Biol. Neonate 88:181-191; 2005.

[147] Saugstad, O. D. Bronchopulmonary dysplasia-oxidative stress and antioxidants. Semin. Neonatol. 8:39-49; 2003

[148] Reuter, S. D.; O'Donovan, D. J.; Hegemier, S. E.; Smith, E. O.; Heird, W. C.; Fernandes, C. J. Urinary F2-isoprostanes are poor prognostic indicators for the development of bronchopulmonary dysplasia. J. Perinatol. 27:303-306; 2007.

[149] Goil, S.; Truog, W. E.; Barnes, C.; Norberg, M.; Rezaiekhaligh, M.; Thibeault, D. Eight-epi-PGF2alpha: a possible marker of lipid peroxidation in term infants with severe pulmonary disease. J. Pediatr. 132:349-351; 1998.

[150] Vento, M.; Roberts, J. L.; Izquierdo, I.; Arruza, A.; Escrig, R.; Villar, G., et al. Monitorization of hypo-or-hyperoxia derived oxidative stress in extremely low birthweight (ELBW) infants using urinary F2-isoprostanes and isofuranes. E-PAS20085851; 2009

[151] Lakshminrusimha, S.; Russell, J. A.; Wedgwood, S.; Gugino, S. F.; Kazzaz, J. A.; Davis, J. M., et al. Superoxide dismutase improves oxygenation and reduces oxidation in neonatal pulmonary hypertension. Am. J. Respir. Crit. Care Med. 174: 1370-1377; 2006.

[152] Ozaki, N.; Beharry, K.; Nishihara, K. C.; Akmal, Y.; Ang, J. G.; Modanlou, H. D. Differential regulation of prostacyclin and thromboxane by dexamethasone and celecoxib during oxidative stress in newborn rabbits. Prostaglandins Other Lipid Mediat. 70:61-78; 2002.

[153] Tanswell, A. K.; Jankov, R. P. Bronchopulmonary dysplasia: one disease or two? Am. J. Respir. Crit. Care Med. 167:1-2; 2003.

[154] Luo, X.; Christie, N. A.; McLaughlin, M. A.; Belcastro, R.; Sedlackova, L.; Cabacungan, J., et al. $\mathrm{H}_{2} \mathrm{O}_{2}$ mediates $\mathrm{O}_{2}$ toxicity in cultured fetal rat distal lung epithelial cells. Free Radic. Biol. Med. 26:1357-1368; 1999.

[155] Jankov, R. P.; Luo, X.; Cabacungan, J.; Belcastro, R.; Frndova, H.; Lye, S. J., et al. Endothelin-1 and 02-mediated pulmonary hypertension in neonatal rats: a role for products of lipid peroxidation. Pediatr. Res. 48:289-298; 2000.

[156] Jankov, R. P.; Luo, X.; Belcastro, R.; Copland, I.; Frndova, H.; Lye, S. J., et al. Gadolinium chloride inhibits pulmonary macrophage influx and prevents $\mathrm{O}(2)$ induced pulmonary hypertension in the neonatal rat. Pediatr. Res. 50:172-183; 2001.

[157] Jankov, R. P.; Belcastro, R.; Ovcina, E.; Lee, J.; Massaeli, H.; Lye, S. J., et al. Thromboxane $\mathrm{A}(2)$ receptors mediate pulmonary hypertension in $60 \%$ oxygenexposed newborn rats by a cyclooxygenase-independent mechanism. Am. J. Respir. Crit. Care Med. 166:208-214; 2002.

[158] Belik, J.; Jankov, R. P.; Pan, J.; Yi, M.; Chaudhry, I.; Tanswell, A. K. Chronic O2 exposure in the newborn rat results in decreased pulmonary arterial nitric oxide release and altered smooth muscle response to isoprostane. J. Appl. Physiol. 96: 725-730; 2004.

[159] McNamara, P. J.; Murthy, P.; Kantores, C.; Teixeira, L.; Engelberts, D.; van, V. T., et al. Acute vasodilator effects of Rho-kinase inhibitors in neonatal rats with pulmonary hypertension unresponsive to nitric oxide. Am. J. Physiol. 294: L205-L213; 2008.

[160] Jankov, R. P.; Kantores, C.; Pan, J.; Belik, J. Contribution of xanthine oxidasederived superoxide to chronic hypoxic pulmonary hypertension in neonatal rats. Am. J. Physiol., Lung Cell Mol. Physiol 294:L233-L245; 2008.

[161] Lahaie, I.; Hardy, P.; Hou, X.; Hassessian, H.; Asselin, P.; Lachapelle, P., et al. A novel mechanism for vasoconstrictor action of 8-isoprostaglandin F2 alpha on retinal vessels. Am. J. Physiol. 274:R1406-R1416; 1998.

[162] Beauchamp, M. H. Martinez-Bermudez, A. K · Gobeil Jr. F. Marrache, A. M. Hou, X.; Speranza, G., et al. Role of thromboxane in retinal microvascular degeneration in oxygen-induced retinopathy. J. Appl. Physiol. 90:2279-2288; 2001.

[163] Takahashi, K.; Nammour, T. M.; Fukunaga, M.; Ebert, J.; Morrow, J. D.; Roberts, L. J., et al. Glomerular actions of a free radical-generated novel prostaglandin, 8epi-prostaglandin F2 alpha, in the rat. Evidence for interaction with thromboxane A2 receptors. J. Clin. Invest. 90:136-141; 1992.

[164] John, G. W.; Valentin, J. P. Analysis of the pulmonary hypertensive effects of the isoprostane derivative, 8-iso-PGF2alpha, in the rat. Br. J. Pharmacol. 122: 899-905; 1997.

[165] Kang, K. H.; Morrow, J. D.; Roberts, L. J.; Newman, J. H.; Banerjee, M. Airway and vascular effects of 8-epi-prostaglandin F2 alpha in isolated perfused rat lung. J. Appl. Physiol. 74:460-465; 1993.

[166] Wagner, R. S.; Weare, C.; Jin, N.; Mohler, E. R.; Rhoades, R. A. Characterization of signal transduction events stimulated by 8 -epi-prostaglandin(PG)F2 alpha in rat aortic rings. Prostaglandins 54:581-599; 1997.

[167] Sametz, W.; Hennerbichler, S.; Glaser, S.; Wintersteiger, R.; Juan, H. Characterization of prostanoid receptors mediating actions of the isoprostanes, 8-iso-PGE (2) and 8-iso-PGF(2alpha), in some isolated smooth muscle preparations. Br. J. Pharmacol. 130:1903-1910; 2000 .

[168] Hoffman, S. W.; Moore, S.; Ellis, E. F. Isoprostanes: free radical-generated prostaglandins with constrictor effects on cerebral arterioles. Stroke 28: 844-849; 1997. 
[169] Marley, R.; Harry, D.; Anand, R.; Fernando, B.; Davies, S.; Moore, K. 8Isoprostaglandin F2 alpha, a product of lipid peroxidation, increases portal pressure in normal and cirrhotic rats. Gastroenterology 112:208-213; 1997.

[170] Audoly, L. P.; Rocca, B.; Fabre, J. E.; Koller, B. H.; Thomas, D.; Loeb, A. L., et al. Cardiovascular responses to the isoprostanes iPF(2alpha)-III and iPE(2)-III are mediated via the thromboxane $\mathrm{A}(2)$ receptor in vivo. Circulation 101:2833-2840; 2000.

[171] Banerjee, M.; Kang, K. H.; Morrow, J. D.; Roberts, L. J.; Newman, J. H. Effects of a novel prostaglandin, 8-epi-PGF2 alpha, in rabbit lung in situ. Am. J. Physiol. 263: H660-H663; 1992.

[172] Sametz, W.; Grobuschek, T.; Hammer-Kogler, S.; Juan, H.; Wintersteiger, R. Influence of isoprostanes on vasoconstrictor effects of noradrenaline and angiotensin II. Eur. J. Pharmacol. 378:47-55; 1999.

[173] Mobert, J.; Becker, B. F.; Zahler, S.; Gerlach, E. Hemodynamic effects of isoprostanes (8-iso-prostaglandin F2alpha and E2) in isolated guinea pig hearts. 29:789-794; 1997.

[174] Miller, J. M.; Brown, J. N.; Schacht, J. 8-iso-prostaglandin F(2alpha), a product of noise exposure, reduces inner ear blood flow. Audiol. Neuro-otol. 8:207-221; 2003.

[175] Kromer, B. M.; Tippins, J. R. Coronary artery constriction by the isoprostane 8-epi prostaglandin F2 alpha. Br. J. Pharmacol. 119:1276-1280; 1996.

[176] Mohler, E. R.; Franklin, M. T.; Adam, L. P. Intracellular signaling by 8epi-prostaglandin F2 alpha is mediated by thromboxane A2/prostaglandin endoperoxide receptors in porcine carotid arteries. Biochem. Biophys.Res. Commun. 225:915-923; 1996.
[177] Wilson, S. H.; Best, P. J.; Lerman, L. O.; Holmes Jr., D. R.; Richardson, D. M.; Lerman, A. Enhanced coronary vasoconstriction to oxidative stress product, 8 epi-prostaglandinF2 alpha, in experimental hypercholesterolemia. Cardiovasc. Res. 44:601-607; 1999.

[178] Janssen, L. J.; Premji, M.; Netherton, S.; Coruzzi, J.; Lu-Chao, H.; Cox, P. G. Vasoconstrictor actions of isoprostanes via tyrosine kinase and Rho kinase in human and canine pulmonary vascular smooth muscles. Br. J. Pharmacol. 132 127-134; 2001.

[179] Gardan, B.; Cracowski, J. L.; Sessa, C.; Hunt, M.; Stanke-Labesque, F.; Devillier, P., et al. Vasoconstrictor effects of iso-prostaglandin F2alpha type-III (8-isoprostaglandin F2alpha) on human saphenous veins. J. Cardiovasc. Pharmacol. 35:729-734; 2000.

[180] Cracowski, J. L.; Stanke-Labesque, F.; Devillier, P.; Chavanon, O.; Hunt, M.; Souvignet, C., et al. Human internal mammary artery contraction by isoprostaglandin $\mathrm{f}$ (2alpha) type-III [8-iso-prostaglandin F(2alpha)]. Eur. J. Pharmacol. 397:161-168; 2000 .

[181] Mueed, I.; Tazzeo, T.; Liu, C.; Pertens, E.; Zhang, Y.; Cybulski, I., et al. Isoprostanes constrict human radial artery by stimulation of thromboxane receptors, Ca2+ release, and RhoA activation. J. Thorac. Cardiovasc. Surg. 135:131-138; 2008.

[182] Friel, A. M.; Hynes, P. G.; Sexton, D. J.; Smith, T. J.; Morrison, J. J. Expression levels of mRNA for Rho A/Rho kinase and its role in isoprostane-induced vasoconstriction of human placental and maternal vessels. Reprod. Sci. 15:179-188; 2008. 


\section{Chapter VI:}

Age-related differences in vasoconstrictor responses to isoprostanes in piglet pulmonary and mesenteric vascular smooth muscle.

Pediatr Res 2005; 57:845-52. 


\title{
Age-Related Differences in Vasoconstrictor Responses to Isoprostanes in Piglet Pulmonary and Mesenteric Vascular Smooth Muscle
}

\author{
GEMA GONZÁLEZ-LUIS, FRANCISCO PÉREZ-VIZCAÍNO, FERMÍN GARCÍA-MUÑOZ, \\ JO G.R. DE MEY, CARLOS E. BLANCO, AND EDUARDO VILLAMOR
}

\begin{abstract}
Department of Pediatrics, University Hospital Maastricht, Research Institute Growth and Development (GROW) [G.G.-L., C.E.B., E.V.], Department of Pharmacology and Toxicology, Cardiovascular Research Institute Maastricht (CARIM) [J.G.R.D.M.], University of Maastricht, 6202 AZ Maastricht, The Netherlands, Division of Neonatology, Department of Pediatrics [G.G.-.L., F.G.-.M.], Hospital Universitario Materno-Infantil de Canarias, 35015 Las Palmas de Gran Canaria, Spain, Department of Pharmacology [F.P.-.V.], School of Medicine, Universidad Complutense, 28040 Madrid, Spain
\end{abstract}

evoked contractions in 2-wk-old PA were reduced by inhibitors of tyrosine kinase (genistein) and Rho kinase (Y 27632 and hydroxyfasudil) but not by inhibitors of protein kinase C (chelerythrine), mitogen-activated protein kinase kinase (PD 98059) or p38-kinase (SB 203580). In conclusion, isoprostanes produced compound-, tissue-, and age-dependent constriction of neonatal porcine pulmonary and mesenteric vascular smooth muscle. Isoprostane-evoked PA vasoconstriction involved TP receptors and activation of tyrosine kinases and Rho kinases. (Pediatr Res 57: 845-852, 2005)

\section{Abbreviations}

COX, cyclooxygenase

EC50, half-maximum effective concentration

MA, mesenteric artery

PA, pulmonary artery

PG, prostaglandin

PKC, protein kinase $\mathrm{C}$

$\mathbf{P V}$, pulmonary vein

TP, thromboxane $\mathrm{A}_{2}$ receptor

TXA $_{2}$, thromboxane $\mathrm{A}_{2}$
Isoprostanes are PG-like compounds formed in vivo by the free radical-catalyzed peroxidation of arachidonic acid, a reaction independent of the COX enzyme (1-3). They are generated initially at the site of a free radical attack of esterified arachidonate in cell membranes from which they are cleaved, presumably by

Received August 2, 2004; accepted November 2, 2004

Correspondence: E. Villamor, M.D., Ph.D., Department of Pediatrics, University Hospital Maastricht. P. Debyelaan 25, PO Box 5800, 6202 AZ Maastricht, The Netherlands; e-mail: eiv@ paed.azm.nl

G.G.-L. was supported by a grant of Fundación Canaria de Investigación y Salud (FUNCIS-2/2002). F.P.-V. was supported by Comunidad Autónoma de Madrid (CAM) (08.4/0036.2001) and Comisión Interministerial de Ciencia y Technologia (CICYT) (SAF 2002/02304) grants.

DOI: 10.1203/01.PDR.0000161411.01208.83 phospholipases (2,3). Isoprostanes are used clinically and experimentally as markers for many disease states in which oxidative stress is a prominent feature, including asthma, myocardial and renal ischemia-reperfusion injury, atherosclerosis, pulmonary hypertension, and hypercholesterolemia (4-6). However, isoprostanes are much more than inert markers and have been shown to possess biologic activity in whole-animal, isolated tissue, and cell-based systems $(6,7)$. In the vascular system, isoprostanes exert important effects that range from powerful vasoconstriction to complete vasodilatation, depending on the particular isoprostane, tissue, and species studied (7).

The neonatal period appears to be particularly interesting for the study of the biologic effects of isoprostanes because the 
3 -fold increase in the arterial oxygen tension after birth renders a higher susceptibility to oxidant-mediated lipid peroxidation $(8,9)$. Moreover, isoprostanes have been proposed as markers to quantify oxidative stress in perinatal asphyxia (10), prematurity (11), periventricular leukomalacia (12), bronchopulmonary dysplasia (12), and neonatal pulmonary disease (13).

At birth, the placenta is replaced in its respiratory function by the lungs and in its nutritional function by the gastrointestinal tract. The unique hemodynamic changes that this process of transition implies for the pulmonary and mesenteric circulations have been extensively studied but remain incompletely understood. Numerous studies demonstrated ontogenic differences in contractile and relaxing responses of pulmonary and mesenteric vessels (14-19). However, despite the fast-growing body of literature addressing isoprostanes and their effects on diverse vascular smooth muscles, data regarding the development of isoprostane effects in newborn vasculature are scarce. Truog et al. (20), observed that 8-iso-PGF2 $\alpha$ induced marked pulmonary vasoconstriction in 2-wk-old piglets. In addition, Belik et al. (9) have shown that the 1-wk-old rat pulmonary vascular response to 8 -iso-PGF $2 \alpha$ is clearly distinct from the adult. This age-dependent difference in force development was similar to the pattern previously described during stimulation of rat pulmonary artery with other agonists, including the $\mathrm{TxA}_{2}$ analog $\mathrm{U} 46619$, which appears to act via the same receptor as 8 -iso-PGF $2 \alpha(9,21)$. No study has characterized the response to isoprostanes in neonatal systemic vessels.

In the present study, we hypothesized that the vascular response to isoprostanes in early postnatal life is developmentally regulated in porcine pulmonary and mesenteric vessels. Therefore, we aimed to study the effects of several E-ring (8-iso-PGE ${ }_{1}$ and 8-iso- $\mathrm{PGE}_{2}$ ) and F-ring (8-iso- $\mathrm{PGF}_{1 \alpha}, 8$-iso$\mathrm{PGF}_{1 \beta}, 8$-iso- $\mathrm{PGF}_{2 \alpha}, 8$-iso- $\mathrm{PGF}_{2 \beta}$ ) isoprostanes on contractile activity in isolated pulmonary arteries (PA), pulmonary veins $(\mathrm{PV})$, and mesenteric arteries (MA) from newborn and 2-wkold piglets.

\section{METHODS}

Tissue preparation. All experiments were carried out in accordance with the European Animals Act 1986 (Scientific Procedures) and approved by the institutional review board. Neonatal piglets aged $12-24 \mathrm{~h}(n=24)$ and $2 \mathrm{wk}$ $(n=25)$, obtained from a local farm, were killed by exsanguination after being anesthetized with sodium pentobarbitone $\left(100 \mathrm{mg} \cdot \mathrm{kg}^{-1}\right)$. The stomachs of all subjects were distended with milk curd at the time of sacrifice and their small intestine was filled with chyme, confirming that they had been fed. This observation is important, because it has been reported that the initial feedings after birth, specifically in the first $18 \mathrm{~h}$ of postnatal life, produce significant changes on vasoactive mediators within the piglet mesenteric vasculature (19). The lungs and intestines were rapidly immersed in cold $\left(4^{\circ} \mathrm{C}\right) \mathrm{Krebs}$-Ringer bicarbonate buffer (composition in $\mathrm{mmol} \mathrm{L}^{-1}: \mathrm{NaCl}, 118.5 ; \mathrm{KCl}, 4.75 ; \mathrm{MgSO}_{4}$ . $7 \mathrm{H}_{2} \mathrm{O}, 1.2 ; \mathrm{KH}_{2} \mathrm{PO}_{4}, 1.2 ; \mathrm{NaHCO}_{3}, 25.0 ; \mathrm{CaCl}_{2}, 2.5$; glucose, 5.5). PA, PV (third-fourth branch, in situ external diameter 1-2 mm), and MA with a similar in situ external diameter (distal half of the MA trunk) were carefully dissected free of surrounding tissue and cut into rings of $2-3 \mathrm{~mm}$ of length under a dissection microscope.

Isometric force measurement. After dissection, two L-shaped stainlesssteel wires were inserted into the arterial lumen and the rings were introduced in Allhin organ chambers filled with Krebs solution at $37^{\circ} \mathrm{C}$, gassed with $95 \%$ $\mathrm{O}_{2} / 5 \% \quad \mathrm{CO}_{2}$. One wire was attached to the chamber and the other to an isometric force-displacement transducer (model PRE 206-4, Cibertec, Madrid, Spain). The isometric force signal was amplified, A/D converted (PowerLab, ADInstruments Pty., Castle Hill, Australia), and recorded (Chart v3.4, ADInstruments Pty.). An optimal resting tension of $0.3 \mathrm{~g}$ (PA of 12- to $24 \mathrm{~h}$-old animals), $0.5 \mathrm{~g}$ (PA of 2-wk-old animals and PV of both groups), $1 \mathrm{~g}$ (MA of 12- to 24 h-old animals), or $2 \mathrm{~g}$ (MA of 2-wk-old animals) was applied to the vascular segments, as determined from previous experiments $(14,15)$. Tissues were allowed to equilibrate for $60-90 \mathrm{~min}$. During this period, they were restretched and washed every $30 \mathrm{~min}$ with warm Krebs solution. Before commencing the experiments, the tissues were transiently challenged with 62.5 $\mathrm{mM} \mathrm{KCl}$ to assess the functional state of each vessel and to establish a reference nonreceptor-mediated contraction for standardization of contractile responses to the isoprostanes. This method of standardization was chosen because it takes into account not only the vascular smooth muscle mass but also the functional capacity of the vascular rings to develop contraction. The contractile response to $\mathrm{KCl}$ of piglet pulmonary and mesenteric vascular rings is qualitatively similar at $12-24 \mathrm{~h}$ and $14 \mathrm{~d}$ of age, as demonstrated by preliminary (unpublished) concentration-response curves. In these curves, 62.5 $\mathrm{mM} \mathrm{KCl}$ produced $75-85 \%$ of the maximal contraction induced by $125 \mathrm{mM}$ $\mathrm{KCl}$.

Cumulative concentration $(0.1 \mathrm{nM}-10 \mu \mathrm{M})$ response curves were constructed for 8-iso-PGE 1,8 -iso-PGE 2,8 -iso-PGF $1 \alpha, 8$-iso-PGF ${ }_{1 \beta}, 8$-iso-PGF $2 \alpha$, 8-iso-PGF ${ }_{2 \beta}$, and the $\mathrm{TXA}_{2}$ mimetic U46619. In some experiments, the vascular effects of isoprostanes and U46619 were tested in endotheliumdenuded arteries or in the presence of the TXA 2 receptor (TP) antagonist SQ $29,548(10 \mathrm{nM}-0.1 \mu \mathrm{M})$, the COX inhibitor indomethacin $(10 \mu \mathrm{M})$, the tyrosine kinase inhibitor genistein $(0.1 \mathrm{mM})$, the protein PKC inhibitor chelerythrine $(10 \mu \mathrm{M})$, the Rho kinase inhibitors Y $27632(10 \mu \mathrm{M})$ and hydroxyfasudil $(10 \mu \mathrm{M})$, the mitogen-activated protein kinase kinase inhibitor PD $98059(50 \mu \mathrm{M})$, and the p38-kinase inhibitor SB $203580(30 \mu \mathrm{M})$.

Drugs. Isoprostanes and U46619 (9,11-dideoxy- $11 \alpha, 9 \alpha$-epoxymethanoprostaglandin $\mathrm{F}_{2 \alpha}$ methyl acetate solution) were purchased from Cayman Chemical (Ann Arbor, MI). Y27632 was obtained from Tocris (Ellisville, MO) and hydroxyfasudil from Asahi Chemical (Tokyo, Japan). All other chemicals were obtained from Sigma Chemical Co. (St. Louis, MO). Isoprostanes, genistein, chelerythrine, PD 98059, and SB 203580 were dissolved initially in DMSO. Indomethacin and Y 27632 were dissolved initially in ethanol. All other chemicals were dissolved initially in distilled deionized water. The maximal bath concentration of DMSO and ethanol did not exceed $0.1 \%$, which was found to have no effect on mechanical activity.

Analysis of data. Results are expressed as mean \pm SEM and $n$ reflects the number of animals. The contractile responses were expressed as absolute values ( $\mathrm{g}$ ) or were standardized relative to responses to $62.5 \mathrm{mM} \mathrm{KCl}$. The potency of each isoprostane, EC50, was interpolated from the individual concentration-effect curves. However, the EC50 value for the majority of the isoprostanes was not determined, as the responses did not appear to be maximal at the highest concentration tested $(10 \mu \mathrm{M})$. The efficacy was defined as the maximum vasoconstriction (Emax) achieved with each isoprostane. Differences between mean values were assessed by one-way ANOVA followed by Bonferroni posthoc $t$ test. Differences were considered significant at a $p<0.05$.

\section{RESULTS}

Contractile effects of isoprostanes in porcine pulmonary and mesenteric vessels. Isoprostanes produced concentrationdependent contractions of 12- to 24-old and 2-wk-old piglet $\mathrm{PA}, \mathrm{PV}$, and MA with magnitudes up to 1.5- to 2-fold greater than the responses to $62 \mathrm{mM} \mathrm{KCl}$ but they showed, in general, markedly lower potency and efficacy than the TP receptor agonist U46619 (Figs. 1-3 and Table 1).

In PA (Fig. 1), 8-iso-PGE 2 appeared to be the most potent of the isoprostanes (Fig. 1B, Table 1). When constructing the cumulative concentration-response curve, addition of the highest concentrations $(>1 \mu \mathrm{M})$ of 8 -iso-PGE ${ }_{2}$ consistently reduced the vessel tone in PA and this effect was more marked in the 2-wk-old animals (Fig. 1B). 8-iso- $\mathrm{PGF}_{2 \alpha}$ was the most efficacious of the isoprostanes (Fig. 1D). However, the responses did not appear to be maximal at the highest concentration tested $(10 \mu \mathrm{M})$ and the detectable threshold concentration for the constrictor effects of 8 -iso- $\mathrm{PGF}_{2 \alpha}$ was relatively high $(\sim 0.1 \mu \mathrm{M})$. 8-iso-PGF ${ }_{1 \alpha}$ and 8-iso-PGF $1 \beta$ had little or no contractile effect on the 2-wk-old PA but produced a potent constriction on the neonatal PA (Fig. $1 C$ and $E$ ). In addition, 


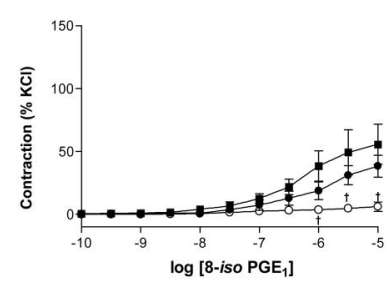

C
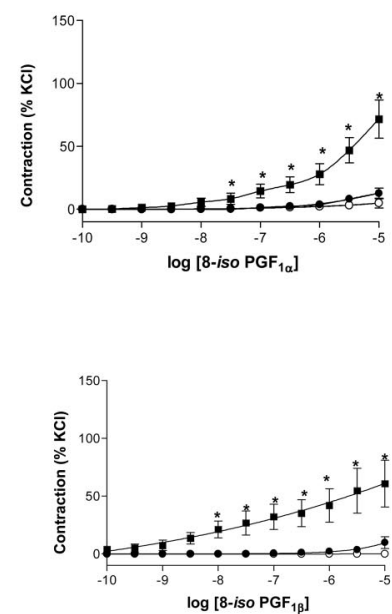

G

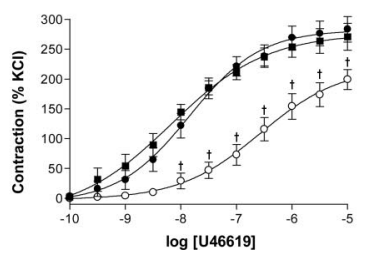

B

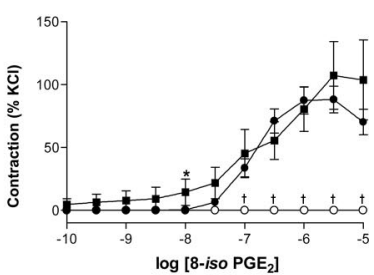

D

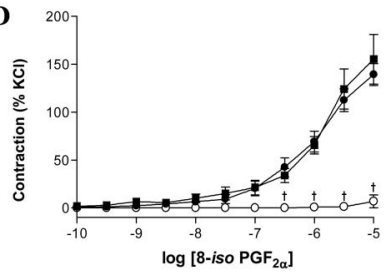

F

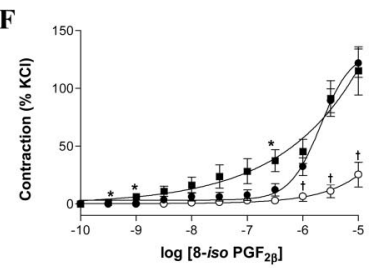

H

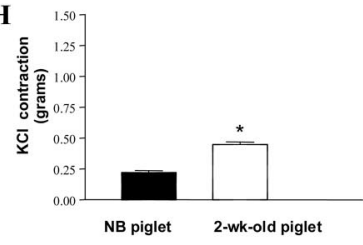

Figure 1. Isoprostane-evoked contractions in 12- to 24-h-old ( squares) and 2-wk-old (circles) piglet pulmonary arteries. Mean concentration-response relationships obtained in response to cumulative addition of 8-iso-PGE ${ }_{1}(A)$, 8-iso-PGE $2(B), 8$-iso- $\mathrm{PGF}_{1 \alpha}(C), 8$-iso- $\mathrm{PGF}_{2 \alpha}(D)$, 8-iso-PGF $1 \beta(E)$, and 8 -iso- $\mathrm{PGF}_{2 \beta}(F)$. Contractions evoked in response to the $\mathrm{TXA}_{2}$ mimetic $\mathrm{U} 46619(G)$ and $62.5 \mathrm{mM} \mathrm{KCl}(H)$ are also represented. Responses are expressed as a percentage of the response to $62.5 \mathrm{mM} \mathrm{KCl}$ evoked in each tissue at the beginning of the study. Open symbols represent isoprostaneevoked contraction in the presence of the TP receptor antagonist SQ 29,548 (10 $\mathrm{nM})$. Each point represents the mean \pm SEM of $6-24$ animals. ${ }^{*} p<0.0512-$ to 24-h-old vs 2-wk-old. $\dagger p<0.05$ vs control.

the contractions induced by 8 -iso- $\mathrm{PGE}_{2}$ (only one point) and 8 -iso- $\mathrm{PGF}_{2 \beta}$ were, at some of the concentrations tested, significantly higher in neonatal than in 2-wk-old PA (Fig. $1 B$ and $F$ ). Significant age-related changes were not observed for the PA contractions induced by 8 -iso- $\mathrm{PGE}_{1}, 8$-iso- $\mathrm{PGF}_{2 \alpha}$, and U46619 (Fig. 1, Table 1).

In PV (Fig. 2), 8-iso- $\mathrm{PGE}_{2}$ was the most potent and efficacious of the isoprostanes, being, in terms of efficacy (but not of potency), comparable with U46619 in the 12- to 24-h-old animals (Fig. 2B, Table 1). The efficacy of 8-iso$\mathrm{PGF}_{2 \alpha}$ (Fig. 2D) in neonatal PV was also comparable to U46619. When comparing isoprostane-evoked contractions in 12- to 24-h-old and 2-wk-old PV, a clear ontogenic pattern was not observed. However, for some particular concentrations, 8-iso- $\mathrm{PGE}_{2}$ and 8 -iso- $\mathrm{PGF}_{1 \alpha}$ produced a higher level of contraction in the neonatal PV (Fig. $2 B$ and

A

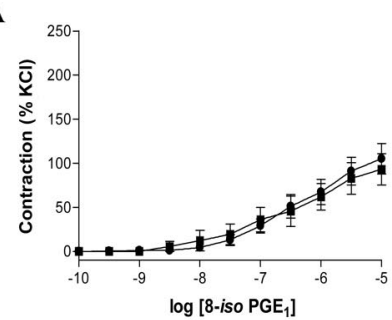

C

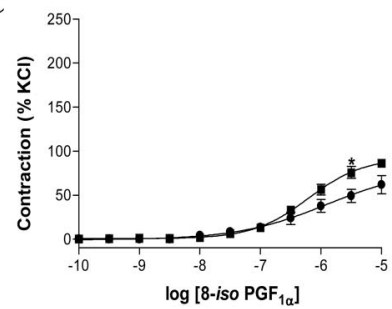

$\mathbf{E}$
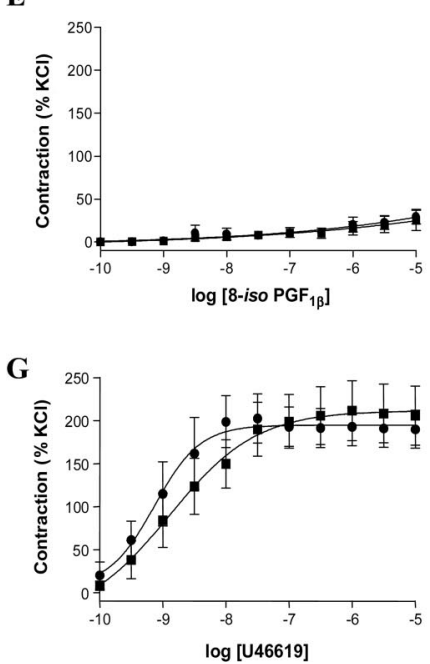

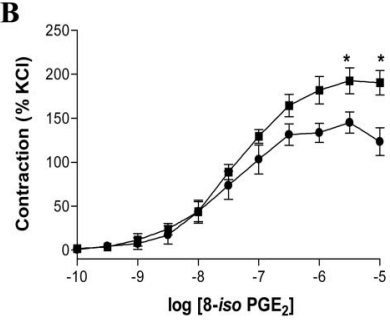

D

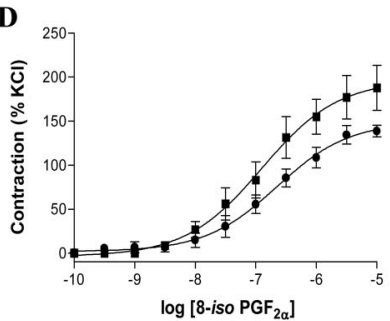

F
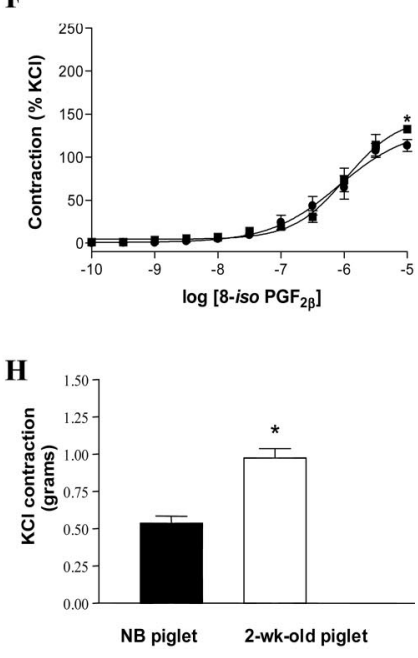

Figure 2. Isoprostane-evoked contractions in 12- to 24-h-old (squares) and 2 -wk-old (circles) piglet pulmonary veins. Mean concentration-response relationships obtained in response to cumulative addition of 8 -iso- $\mathrm{PGE}_{1}(A)$, 8-iso-PGE $2(B), 8$-iso-PGF ${ }_{1 \alpha}(C)$, 8-iso- $\mathrm{PGF}_{2 \alpha}(D)$, 8-iso-PGF $1 \beta$ (E), and 8 -iso- $\mathrm{PGF}_{2 \beta}(F)$. Contractions evoked in response to the $\mathrm{TXA}_{2}$ mimetic $\mathrm{U} 46619(G)$ and $62.5 \mathrm{mM} \mathrm{KCl}(H)$ are also represented. Responses are expressed as a percentage of the response to $62.5 \mathrm{mM} \mathrm{KCl}$ evoked in each tissue at the beginning of the study. Each point represents the mean \pm SEM of 5-8 animals. $* p<0.0512$ - to 24-h-old $v s$ 2-wk-old.

C). As occurred with the PA, addition of high concentrations $(>10 \mu \mathrm{M})$ of 8 -iso- $\mathrm{PGE}_{2}$ consistently reduced tone in PV and this effect was more marked in the 2-wk-old animals (Fig. 2B).

In MA (Fig. 3), the response to isoprostanes demonstrated a high degree of variability. In spite of that, we observed that 8-iso- $\mathrm{PGE}_{2}$ was the most potent and efficacious of the isoprostanes, being, in terms of efficacy (but not of potency), comparable with U46619 in the 12- to 24-h-old animals (Fig. 3B, Table 1). As shown in Figure 3, the relaxation induced by high doses of 8-iso-PGE 2 in PA and PV was not observed in MA (the maximal concentration tested was $10 \mu \mathrm{M}$ ). 8-iso- $\mathrm{PGE}_{2}$, 8-iso- $\mathrm{PGF}_{1 \alpha}, 8$-iso-PGF ${ }_{2 \alpha}$, and 8-iso- $\mathrm{PGF}_{2 \beta}$ produced higher contractions in neonatal MA than in the corresponding 2-wk- 
A

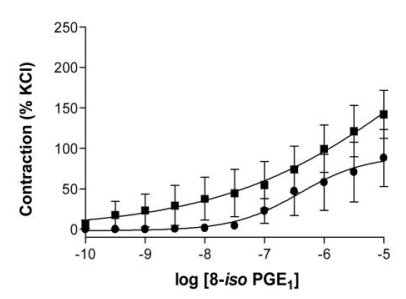

B

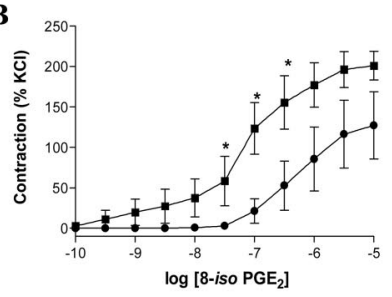

C

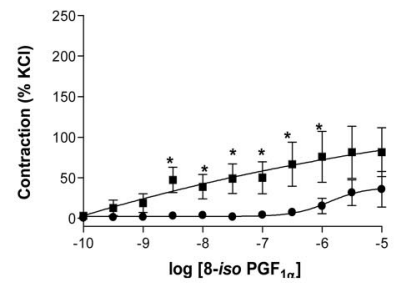

$\mathbf{E}$
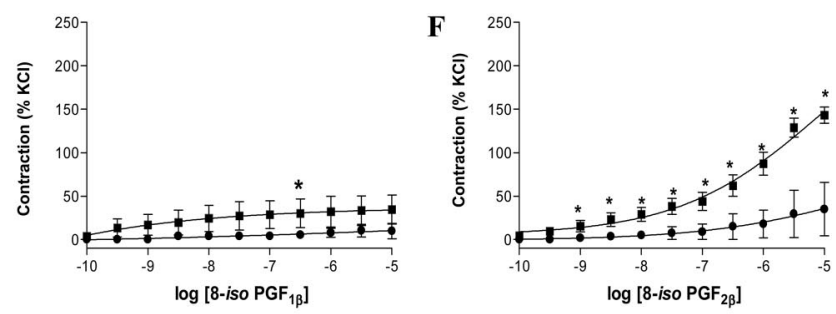

G

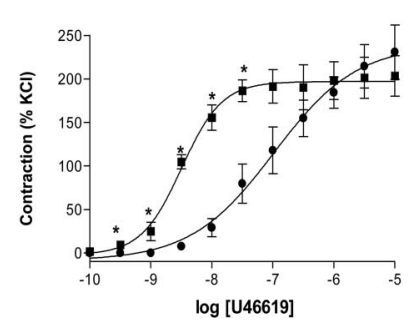

$\mathbf{H}$

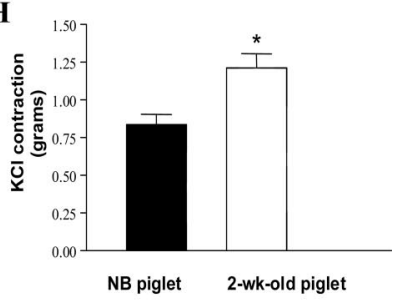

Figure 3. Isoprostane-evoked contractions in 12- to 24-h-old (squares) and 2-wk-old (circles) piglet mesenteric arteries. Mean concentration-response relationships obtained in response to cumulative addition of 8 -iso- $\mathrm{PGE}_{1}(A)$, 8-iso-PGE $2(B), 8$-iso-PGF - $_{1 \alpha}(C), 8$-iso-PGF $2 \alpha(D), 8$-iso-PGF ${ }_{1 \beta}(E)$, and 8 -iso- $\mathrm{PGF}_{2 \beta}(F)$. Contractions evoked in response to the $\mathrm{TXA}_{2}$ mimetic $\mathrm{U} 46619(G)$ and $62.5 \mathrm{mM} \mathrm{KCl}(H)$ are also represented. Responses are expressed as a percentage of the response to $62.5 \mathrm{mM} \mathrm{KCl}$ evoked in each tissue at the beginning of the study. Each point represents the mean \pm SEM of 5-9 animals. $* p<0.05$ 12- to 24-h-old vs 2-wk-old.

old vessels (Fig. 3, Table 1). Sensitivity to U46619 also decreased with postnatal age (Fig. $3 G$, Table 1).

Involvement of TP receptors in mediating isoprostane contractions. We examined the effect of the TP receptor antagonist SQ 29,548 on isoprostane- and U46619-mediated contractions in piglet pulmonary and MA and PV. When 2-wk-old PA were exposed to SQ 29,548 (10 $\mathrm{nM})$, the contractile responses to isoprostanes and U46619 were markedly reduced or even abolished (Fig. 1). In another group of experiments, tissues were first preconstricted with isoprostanes or U46619 at a concentration of $10 \mu \mathrm{M}$, then challenged with SQ 29,5480 (0.1 $\mu \mathrm{M})$. We observed that isoprostane- and U46619-induced contractions of 12- to 24-h-old and 2-wk-old PA, PV, and MA were significantly reversed or completely abolished by SQ
29,548 (not shown). In contrast, SQ 29,548 had no remarkable effect on the contractions induced by endothelin-1 $(0.1 \mu \mathrm{M})$ or $\mathrm{KCl}(62.5 \mathrm{mM})$.

Characterization of underlying signalling pathways. The contribution of various signalling pathways to 8-iso- $\mathrm{PGE}_{2}$, 8-iso- $\mathrm{PGF}_{2 \alpha^{-}}, 8$-iso- $\mathrm{PGF}_{2 \beta^{-}}$, and U46619-evoked contractions were examined pharmacologically in the 2-wk-old PA. 8-iso$\mathrm{PGE}_{2}, 8$-iso-PGF ${ }_{2 \alpha}, 8$-iso- $\mathrm{PGF}_{2 \beta}$, and $\mathrm{U} 46619$ were tested because they produced the highest level of contraction. Endothelium removal and COX inhibition did not significantly affect isoprostane- or U46619-induced contractions (Figs. 4-7). In another group of experiments, 2-wk-old PA were exposed to various kinase inhibitors for 20-30 min before the concentration-response curves to 8-iso- $\mathrm{PGE}_{2}, 8$-iso- $\mathrm{PGF}_{2 \alpha}$, 8-iso-PGF $2 \beta$, and U46619 were carried out. Contractions to isoprostanes and U46619 were unaffected by the PKC inhibitor chelerythrine, the mitogen-activated protein kinase kinase PD 98059, or the p38-kinase inhibitor SB 203580 (Figs. 4-7) but were markedly reduced or abolished by the tyrosine kinase inhibitor genistein or the Rho kinase inhibitors Y 27632 and hydroxyfasudil (Figs. 4-7).

\section{DISCUSSION}

We have examined the effects of a wide range of isoprostanes in pulmonary and mesenteric blood vessels from 12- to 24-h-old and 2-wk-old piglets. We found several E-ring (8-iso$\mathrm{PGE}_{1}$ and 8-iso- $\mathrm{PGE}_{2}$ ) and F-ring (8-iso-PGF ${ }_{1 \alpha}, 8$-iso-PGF ${ }_{1 \beta}$, 8-iso-PGF ${ }_{2 \alpha}$, and 8-iso- $\mathrm{PGF}_{2 \beta}$ ) isoprostanes to increase tone in these vascular smooth muscles to varying degrees. Interestingly, some of the isoprostanes induced higher contractile responses in neonatal than in 2-wk-old vessels. Either in PA, $\mathrm{PV}$, or MA isoprostane-induced contraction was markedly reduced in the presence of the thromboxane TP receptor antagonist SQ 29,548, indicating that isoprostane-evoked responses involve primarily these receptors. This leads to the suggestion that isoprostanes may act as an alternative ligand for TP receptors in addition to $\mathrm{TXA}_{2}$ itself. Although high concentrations of isoprostanes (in the micromolar range) were required to induce significant vascular contraction, high local concentrations of some of these compounds are found in clinical situations of oxidative injury $(22,23)$. Thus, it is likely that incidental activation of the TP receptors by isoprostanes may indeed contribute to and exacerbate the pathology associated with oxidative injury in the neonatal period.

Isoprostanes and pulmonary vessels. During the transition from fetal to postnatal life, dramatic changes in the pulmonary circulation take place, characterized by a marked decrease in pulmonary vascular resistance within minutes from birth. A second postnatal phase of pulmonary vascular resistance reduction takes place over the first weeks of extrauterine life (24). Several age-related changes on pulmonary vascular reactivity have been characterized during this second phase of pulmonary vascular resistance reduction (14-16). However, this study and another (25) showed that the responses of pulmonary vessels to U46619 did not change with postnatal age. Because U46619 is a selective agonist of TP receptors, these results suggest that there are no developmental changes 
Table 1. Parameters of the concentration-response curves reflecting the efficacy and potency (Emax and EC50, respectively) of 8-iso-PGE 2 and U46619 in pulmonary and mesenteric vasculature of 12- to 24-h-old (NB) and 2-wk-old (2 wk) piglets

\begin{tabular}{|c|c|c|c|c|c|c|c|}
\hline & & \multicolumn{3}{|c|}{ 8-iso-PGE 2} & \multicolumn{3}{|c|}{ U46619 } \\
\hline & & $\operatorname{Emax}(\% \mathrm{KCl})$ & $\log \mathrm{EC} 50$ & $n$ & $\operatorname{Emax}(\% \mathrm{KCl})$ & $\log \mathrm{EC} 50$ & $n$ \\
\hline Pulmonary artery & NB & $114.46 \pm 30.79$ & $-6.58 \pm 0.17$ & 7 & $269.42 \pm 26.09$ & $-8.06 \pm 0.13$ & 9 \\
\hline \multirow[t]{2}{*}{ Pulmonary vein } & NB & $198.77 \pm 14.40^{*}$ & $-7.44 \pm 0.12$ & 6 & $216.25 \pm 35.71$ & $-9.19 \pm 0.63$ & 6 \\
\hline & $2 \mathrm{wk}$ & $144.77 \pm 11.32$ & $-7.61 \pm 0.22$ & 8 & $193.96 \pm 22.28$ & $-8.45 \pm 0.58$ & 5 \\
\hline Mesenteric artery & NB & $211.53 \pm 22.26$ & $-7.26 \pm 0.46^{* *}$ & 6 & $203.38 \pm 13.16$ & $-8.29 \pm 0.09 * *$ & 7 \\
\hline
\end{tabular}

Contractions are expressed as the percentage of the response to $62.5 \mathrm{mM} \mathrm{KCl}$ evoked in each tissue at the beginning of the study.

$*, * * p<0.05,0.01$ 12- to 24-h-old vs 2-wk-old.
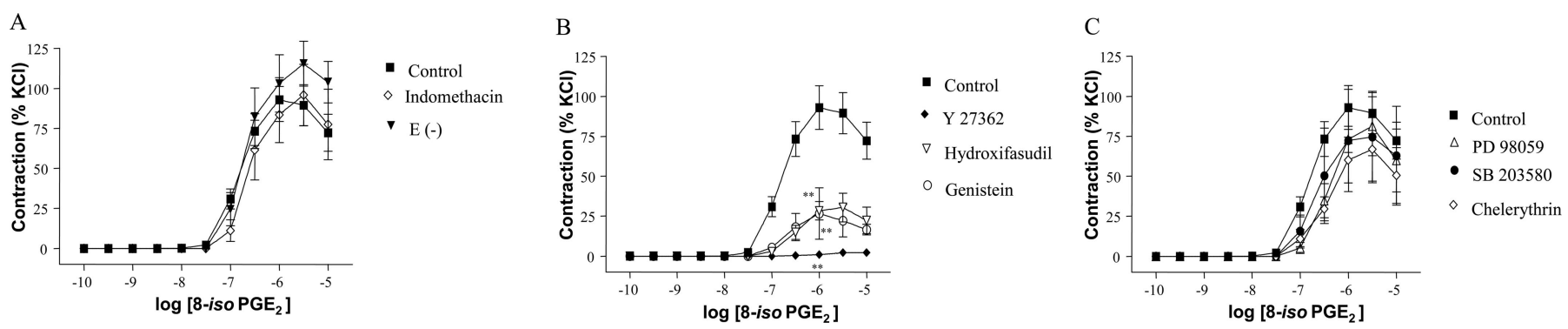

Figure 4. Mean dose-response relationship for 8 -iso- $\mathrm{PGE}_{2}$ in 2-wk-old piglet pulmonary artery, obtained in the presence and absence of the following: endothelium, the cyclooxygenase inhibitor indomethacin $(10 \mu \mathrm{M})$, the Rho kinase inhibitors Y $27632(10 \mu \mathrm{M})$ and hydroxyfasudil $(10 \mu \mathrm{M})$, the tyrosine kinase inhibitor genistein $(0.1 \mathrm{mM})$, the mitogen-activated protein kinase kinase inhibitor PD $98059(50 \mu \mathrm{M})$, the p38-kinase inhibitor SB $203580(30 \mu \mathrm{M})$, and the protein kinase $\mathrm{C}$ inhibitor chelerythrine $(10 \mu \mathrm{M})$. Each point represents the mean \pm SEM of 5-6 animals. **p $<0.01 v s$ control. Only levels of statistical significance for the highest difference are shown.
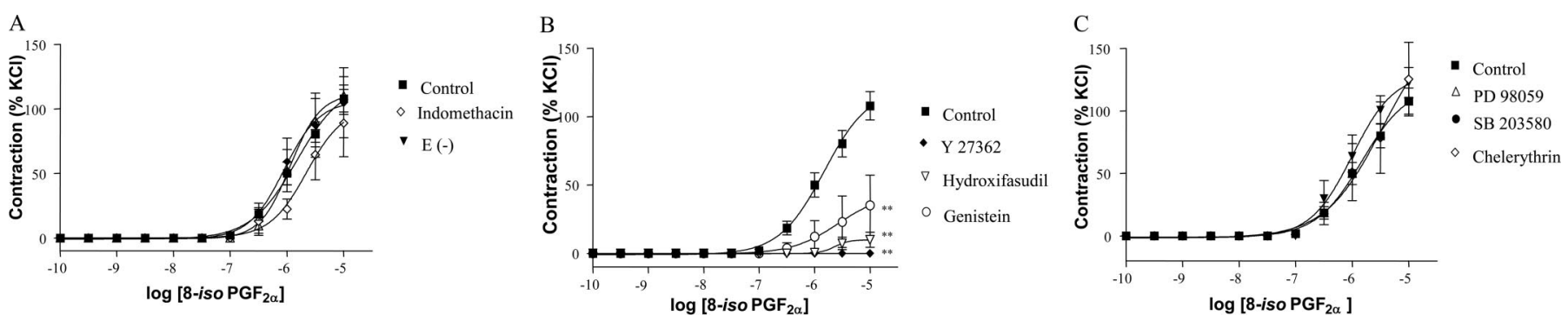

Figure 5. Mean dose-response relationship for 8 -iso- $\mathrm{PGF}_{2 \alpha}$ in 2-wk-old piglet pulmonary artery, obtained in the presence and absence of the following: endothelium, the cyclooxygenase inhibitor indomethacin $(10 \mu \mathrm{M})$, the Rho kinase inhibitors Y $27632(10 \mu \mathrm{M})$ and hydroxyfasudil (10 $\mu \mathrm{M})$, the tyrosine kinase inhibitor genistein $(0.1 \mathrm{mM})$, the mitogen-activated protein kinase kinase inhibitor PD $98059(50 \mu \mathrm{M})$, the p38-kinase inhibitor SB $203580(30 \mu \mathrm{M})$, and the protein kinase $\mathrm{C}$ inhibitor chelerythrine $(10 \mu \mathrm{M})$. Each point represents the mean \pm SEM of $5-6$ animals. $* * p<0.01 v s$ control. Only levels of statistical significance for the highest difference are shown.

in TP-receptor activity. In contrast, we found age-related differences on isoprostane-evoked responses in PA and veins, i.e. a reduction with postnatal age in the contractile responses of $\mathrm{PA}$ and/or PV to 8-iso-PGF ${ }_{1 \alpha}, 8$-iso-PGF $1 \beta, 8$-iso-PGF ${ }_{1 \beta}$, and 8 -iso-PGE ${ }_{2}$. Therefore, age-related decreases in pulmonary vascular sensitivity to isoprostanes appear to be a specific phenomenon for mild stimulation of TP receptor with these compounds more than a general reduction in the contractile response of the pulmonary vessels with age.

In a previous study in 2-wk-old piglets, Truog et al. (20) observed that 8 -iso- $\mathrm{PGF}_{2 \alpha}$ induced, in a dose-dependent manner, marked pulmonary vasoconstriction transduced through the TP receptor. However, when compared with U46619, 8 -iso-PGF ${ }_{2 \alpha}$ was less potent by approximately one order of magnitude (20). Janssen and Tazzeo (21) and Tazzeo et al. (26) examined the responses of adult porcine $\mathrm{PA}$ and veins to 8-iso-PGE 1,8 -iso-PGE 2,8 -iso-PGF ${ }_{1 \alpha}, 8$-iso-PGF ${ }_{2 \alpha}$, and 8-iso-
$\mathrm{PGF}_{2 \beta}$, finding that 8 -iso-PGE 2 was the most potent and efficacious in both PA and veins. However, isoprostanes exerted, in adult pulmonary vessels, maximal contractions that were $50-90 \%$ of the response to $60 \mathrm{mM} \mathrm{KCl}$, whereas the contractions that we describe in 12- to 24-h-old and 2-wk-old tissues were as much as $150-200 \%$ of the response to $\mathrm{KCl}$. Therefore, the age-related decrease in isoprostane-evoked contractions, which we have found by comparing neonatal and 2-wk-old animals, seems to be augmented in adult vessels. Another point of interest is that some of the F-ring isoprostanes, such as 8-iso- $\mathrm{PGF}_{2 \alpha}$ and 8-iso- $\mathrm{PGF}_{2 \beta}$, produced, in our experiments, levels of contraction that are comparable with those induced by the E-ring isoprostanes. In contrast, in the porcine adult pulmonary vessels, F-ring isoprostanes induced markedly weaker contractions than E-ring isoprostanes $(21,26)$. Finally, Janssen and Tazzeo (21) observed that, although the contractions induced in adult porcine PA and PV by 

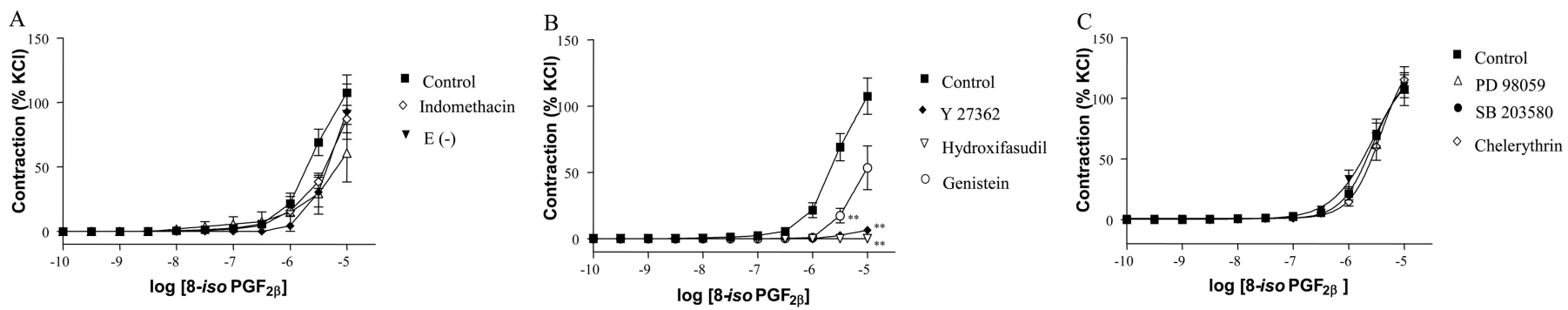

Figure 6. Mean dose-response relationship for 8 -iso- $\mathrm{PGF}_{2 \beta}$ in 2 -wk-old piglet pulmonary artery, obtained in the presence and absence of the following: endothelium, the cyclooxygenase inhibitor indomethacin $(10 \mu \mathrm{M})$, the Rho kinase inhibitors $\mathrm{Y} 27632(10 \mu \mathrm{M})$ and hydroxyfasudil $(10 \mu \mathrm{M})$, the tyrosine kinase inhibitor genistein $(0.1 \mathrm{mM})$, the mitogen-activated protein kinase kinase inhibitor PD $98059(50 \mu \mathrm{M})$, the p38-kinase inhibitor SB $203580(30 \mu \mathrm{M})$, and the protein kinase $\mathrm{C}$ inhibitor chelerythrine $(10 \mu \mathrm{M})$. Each point represents the mean \pm SEM of $5-6$ animals. $* * p<0.01 v s$ control. Only levels of statistical significance for the highest difference are shown.
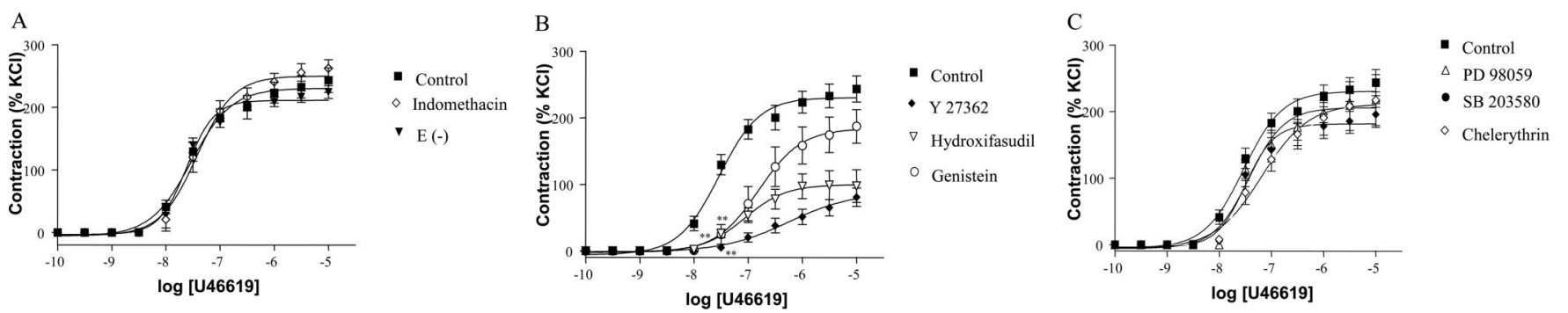

Figure 7. Mean dose-response relationship for U46619 in 2-wk-old piglet pulmonary artery, obtained in the presence and absence of the following: endothelium, the cyclooxygenase inhibitor indomethacin $(10 \mu \mathrm{M})$, the Rho kinase inhibitors $\mathrm{Y} 27632(10 \mu \mathrm{M})$ and hydroxyfasudil $(10 \mu \mathrm{M})$, the tyrosine kinase inhibitor genistein $(0.1 \mathrm{mM})$, the mitogen-activated protein kinase kinase inhibitor PD $98059(50 \mu \mathrm{M})$, the p38-kinase inhibitor SB $203580(30 \mu \mathrm{M})$, and the protein kinase $\mathrm{C}$ inhibitor chelerythrine $(10 \mu \mathrm{M})$. Each point represents the mean \pm SEM of 5-6 animals. $* * p<0.01 v s$ control. Only levels of statistical significance for the highest difference are shown.

8-iso-PGE 1,8 -iso- $\mathrm{PGF}_{1 \alpha}, 8$-iso- $\mathrm{PGF}_{2 \alpha}$, and 8-iso- $\mathrm{PGF}_{2 \beta}$ were essentially completely prevented by TP receptor blockade, 8 -iso- $\mathrm{PGE}_{2}$ was able to evoke substantial contraction of PV in the maintained presence of TP receptor blockade. Moreover, their data suggest that, in the adult porcine PV, 8-iso- $\mathrm{PGE}_{2}$ can also act upon another type of excitatory receptor, likely $\mathrm{EP}_{3}$ receptors or a unique isoprostane receptor (21). Our data do not allow us to speculate on the presence of these putative isoprostane receptors. However, we found 8-iso- $\mathrm{PGE}_{2}$ evoked contractions of PV, PA, and MA to be equally highly sensitive to the TP-receptor blocker SQ 29,548.

8 -iso- $\mathrm{PGF}_{2 \alpha}$ is the isoprostane upon which most previous studies focused. In fact, the only previous study evaluating age-related changes in the vascular actions of isoprostanes described the effects of 8-iso-PGF ${ }_{2 \alpha}$ in intralobar PA segments of 1- and 2-wk-old rats, compared with adults (9). Belik et al. (9) demonstrated that force developed by the rat PA in response to 8-iso-PGF ${ }_{2 \alpha}$ increased with postnatal age. However, the lesser force development of the newborn pulmonary arterial muscle during 8-iso- $\mathrm{PGF}_{2 \alpha}$ stimulation reflected the decreased force potential of this tissue in response to a number of stimuli, including the TxA $\mathrm{A}_{2}$ analog U46619 (9). In contrast, we have not observed developmental changes on the response to U46619 in porcine pulmonary vessels. Interestingly, when PA were stimulated with U46619, Belik et al. (9) observed an 8 -iso-PGF ${ }_{2 \alpha}$-induced relaxation in the adult and a marked dose-dependent contraction in the 1-wk-old rat. This contractile effect of 8-iso- $\mathrm{PGF}_{2 \alpha}$ was abolished by endothelium removal and NO synthase inhibition and was markedly attenu- ated by COX inhibition (9). In contrast, we did not observe any significant alteration of 8-iso-PGF $2 \alpha$-induced contraction when endothelium was removed or the COX inhibitor indomethacin was present. Moreover, during stimulation of either neonatal or 2-wk-old PA with U46619 $(0.1 \mu \mathrm{M})$, we did not observe additional contractions produced by any of the six isoprostanes tested in the present work (27). Therefore, the vascular actions of isoprostanes seem to be markedly species-dependent. This fact limits the extrapolation of our results to the human newborn. In fact, Tazzeo et al. (26) compared the responses to isoprostanes of human and porcine PA and found a higher efficacy of these compounds in the human tissues. However, the underlying signaling pathways of isoprostane-induced contraction were similar in both species.

Using pharmacological tools, we sought to characterize the signaling pathways underlying the PA vasoconstrictor responses to 8 -iso- $\mathrm{PGE}_{2}, 8$-iso- $\mathrm{PGF}_{2 \alpha}, 8$-iso- $\mathrm{PGF}_{2 \beta}$, and U46619. The PKC inhibitor chelerythrine had no effect on isoprostane- or U46619-induced contractions. In contrast, it has been recently reported that an atypical isoform of PKC (PKC $\zeta)$ plays a key role in U46619-induced contraction in rat PA (28). It might be argued that chelerythrine is a poor inhibitor of this isoform (29). However, calphostin C or the $\mathrm{PKC} \zeta$ pseudosubstrate peptide, which are effective inhibitors of $\operatorname{PKC} \zeta$, were also without effect on the vasoconstriction induced by U46619 in 2-wk-old piglet PA (unpublished experiments) indicating interspecies differences in the signal transduction pathways. 
8-iso-PGE $2^{-}$, 8-iso- $\mathrm{PGF}_{2 \alpha^{-}}$, 8-iso- $\mathrm{PGF}_{2 \beta^{-}}$, and U46619evoked pulmonary artery contractions were unaffected by inhibitors of the mitogen-activated protein kinase kinase (PD 98059) or the p38-kinase (SB 203580), but markedly reduced by the nonspecific tyrosine kinase inhibitor genistein. Tyrosine kinases are known to activate several other kinases (7). We found that two agents highly selective for Rho-kinase (Y 27632 and hydroxyfasudil) also inhibited isoprostane- and U46619mediated contractions. Therefore, the excitatory effects of 8-iso-PGE 2,8 -iso- $\mathrm{PGF}_{2 \alpha}, 8$-iso-PGF $2 \beta$, and U46619 in 2-wkold PA appear to be mediated by TP receptors and their signaling pathways involve tyrosine kinases(s) and Rhokinase. Similar signaling pathways of isoprostane-evoked constriction have been reported in human and canine pulmonary vasculature (7). Intracellular signaling via the small GTPbinding protein RhoA and its downstream effector Rho-kinase plays a role in regulating diverse cellular functions, including vascular smooth muscle contraction (30). Maturational changes in the RhoA/Rho-kinase pathway have been very recently described in piglet pulmonary arteries (30). The putative role of RhoA/Rho-kinase maturation in age-related changes in isoprostane-evoked responses remains to be investigated.

Pulmonary veins are exposed to higher oxygen concentrations than PA, but it seems that this fact does not imply a higher activity of antioxidant defenses $(15,31)$. Thus, PV are presumably exposed to higher oxidant conditions and, consequently, to higher formation of isoprostanes. In addition, PV are the major site of action of a number of vasoactive factors in different animal species and at different ages $(14,32,33)$. In the present work, we found porcine PV to exhibit a profound vasoconstrictor response to several isoprostanes. Certain isoprostanes (8-iso-PGE 1 , 8-iso-PGE ${ }_{2}$ ) were more potent vasoconstrictors in PV than in PA. Moreover, at high concentrations $(1-10 \mu \mathrm{M})$, contractions produced by 8 -iso- $\mathrm{PGE}_{2}$ and 8-iso-PGF ${ }_{2 \alpha}$ were similar in magnitude than U46619-evoked contractions. In addition, we have observed an age-related decrease of the responses induced by 8 -iso- $\mathrm{PGE}_{2}$ and 8-iso$\mathrm{PGF}_{1 \alpha}$ (only one point). Previous studies have evaluated the response to isoprostanes of adult human (7), canine (7), and porcine (21) PV. Human PV responded to E-ring and F-ring isoprostanes but to a lesser extent than human PA (7). The canine PA was essentially unresponsive to isoprostanes, whereas the PV exhibited a marked stimulatory response to both E- and F-ring compounds (7). Finally, in the adult porcine pulmonary vessels, the differences between arteries and veins concerning isoprostane-induced contractions (21) are not so marked as those presently described in neonatal vessels.

Isoprostanes and mesenteric arteries. The fetal intestine is functionally dormant and has a high vascular resistance, most likely because its oxidative demands are significantly low $(18,34)$. Vascular resistance in the intestinal bed drops dramatically at birth, when increased intestinal function demands an enhanced oxygen delivery (18). This transition is accompanied by dramatic functional changes in mesenteric vascular reactivity, as occurs in the other dormant fetal organ, the lung (18). NO, endothelin-1, and myogenic responses are the three determinant factors for vascular control in 1-d-old porcine small
MA (18,35). In older subjects, however, these vessels are primarily passive in nature and fail to demonstrate significant diameter change in response to NO synthase inhibitors, blockade of endothelin receptors, or changes of pressure or flow rate (18). In the present work, we observed a significant postnatal decrease in isoprostane-evoked contraction of rings from the distal portion of the MA trunk. However, and in contrast with the pulmonary vessels, the sensitivity of the MA to U46619 also decreased with age. Vascular reactivity data obtained in larger arteries are difficult to extrapolate to small resistance arteries. However, we speculate that this age-related reduction in the response to TP-receptor stimulation, by either isoprostanes or $\mathrm{TXA}_{2}$, may play a role in the postnatal reduction of mesenteric vascular resistance.

Conclusion. An increasing body of evidence seems to indicate that free radicals are involved in several neonatal disease processes such as chronic lung disease, retinopathy of prematurity, necrotizing enterocolitis, and periventricular leukomalacia $(12,36)$. There are also accumulating data implying the involvement of reactive oxygen species and oxidative stress in signal transduction of numerous biologic processes, including control of newborn transitional circulation $(15,16,37)$. This type of cell signalling consistently implies the additional involvement of other bioactive molecules, such as isoprostanes, that stem from reactive oxygen species reaction with cell membrane lipids. In the present work, we describe for the first time the effects of a wide range of E-ring and F-ring isoprostanes in 12- to 24-h-old and 2-wk-old porcine pulmonary and mesenteric vasculature. We found that isoprostanes evoked vasoconstriction via an action on TP receptor and that the response to some of the isoprostanes decreased with postnatal age. Although information obtained in conduit arteries should be cautiously extrapolated to resistance vessels and to in vivo situations, we speculate that age-related changes in isoprostane activity may have implications for the perinatal circulatory transition. Whether neonatal pathologic conditions with increased oxidative stress result in alterations not only in isoprostane production but also in the vascular response to these compounds, remains to be investigated.

\section{REFERENCES}

1. Roberts LJ II, Morrow JD 1997 The generation and actions of isoprostanes. Biochim Biophys Acta 1345:121-135

2. Janssen LJ 2001 Isoprostanes: an overview and putative roles in pulmonary pathophysiology. Am J Physiol Lung Cell Mol Physiol 280:L1067-L1082

3. Pratico D, Lawson JA, Rokach J, FitzGerald GA 2001 The isoprostanes in biology and medicine. Trends Endocrinol Metab 12:243-247

4. Baraldi E, Ghiro L, Piovan V, Carraro S, Ciabattoni G, Barnes PJ, Montuschi P 2003 Increased exhaled 8-isoprostane in childhood asthma. Chest 124:25-31

5. Cracowski JL, Cracowski C, Bessard G, Pepin JL, Bessard J, Schwebel C, StankeLabesque F, Pison C 2001 Increased lipid peroxidation in patients with pulmonary hypertension. Am J Respir Crit Care Med 164:1038-1042

6. Crankshaw DJ, Rangachari PK 2003 Isoprostanes: more than just mere markers. Mol Cell Biochem 253:125-130

7. Janssen LJ, Premji M, Netherton S, Coruzzi J, Lu-Chao H, Cox PG 2001 Vasoconstrictor actions of isoprostanes via tyrosine kinase and Rho kinase in human and canine pulmonary vascular smooth muscles. Br J Pharmacol 132:127-134

8. Neefjes VM, Evelo CT, Baars LG, Blanco CE 1999 Erythrocyte glutathione S transferase as a marker of oxidative stress at birth. Arch Dis Child Fetal Neonatal Ed 81:F130-F133

9. Belik J, Jankov RP, Pan J, Yi M, Pace-Asciak CR, Tanswell AK 2003 Effect of 8-isoprostaglandin F2alpha on the newborn rat pulmonary arterial muscle and endothelium. J Appl Physiol 95:1979-1985

10. Qin Y, Wang CC, Kuhn H, Rathmann J, Pang CP, Rogers MS 2000 Determinants of umbilical cord arterial 8-iso-prostaglandin F2alpha concentrations. BJOG 107:973981 
11. Stier C, Schweer H, Jelinek J, Watzer B, Seyberth HW, Leonhardt A 2001 Effect of preterm formula with and without long-chain polyunsaturated fatty acids on the urinary excretion of F2-isoprostanes and 8-epi-prostaglandin F2alpha. J Pediatr Gastroenterol Nutr 32:137-141

12. Ahola T, Fellman V, Kjellmer I, Raivio KO, Lapatto R 2004 Plasma 8-isoprostane is increased in preterm infants who develop bronchopulmonary dysplasia or periventricular leukomalacia. Pediatr Res 56:88-93

13. Goil S, Truog WE, Barnes C, Norberg M, Rezaiekhaligh M, Thibeault D 1998 Eight-epi-PGF2alpha: a possible marker of lipid peroxidation in term infants with severe pulmonary disease. J Pediatr 132:349-351

14. Villamor E, Perez-Vizcaino F, Cogolludo AL, Conde-Oviedo J, Zaragoza-Arnaez F, Lopez-Lopez JG, Tamargo J 2000 Relaxant effects of carbon monoxide compared with nitric oxide in pulmonary and systemic vessels of newborn piglets. Pediatr Res 48:546-553

15. Villamor E, Kessels CG, Fischer MA, Bast A, de Mey JG, Blanco CE 2003 Role of superoxide anion on basal and stimulated nitric oxide activity in neonatal piglet pulmonary vessels. Pediatr Res 54:372-381

16. Perez-Vizcaino F, Lopez-Lopez JG, Santiago R, Cogolludo A, Zaragoza-Arnaez F, Moreno L, Alonso MJ, Salaices M, Tamargo J 2002 Postnatal maturation in nitric oxide-induced pulmonary artery relaxation involving cyclooxygenase- 1 activity. Am J Physiol Lung Cell Mol Physiol 283:L839-L848

17. Morecroft I, MacLean MR 1998 Developmental changes in endothelium-dependen vasodilation and the influence of superoxide anions in perinatal rabbit pulmonary arteries. Br J Pharmacol 125:1585-1593

18. Nankervis CA, Dunaway DJ, Nowicki PT 2001 Determinants of terminal mesenteric artery resistance during the first postnatal month. Am J Physiol Gastrointest Liver Physiol 280:G678-G686

19. Reber KM, Su BY, Clark KR, Pohlman DL, Miller CE, Nowicki PT2002 Developmental expression of eNOS in postnatal swine mesenteric artery. Am J Physiol Gastrointest Liver Physiol 283:G1328-G1335

20. Truog WE, Norberg M, Thibeault DW 1997 Effects of 8-epi-prostaglandin F2 alph and U46,619 on pulmonary hemodynamics in piglets. Biol Neonate 71:306-316

21. Janssen LJ, Tazzeo T 2002 Involvement of TP and EP3 receptors in vasoconstricto responses to isoprostanes in pulmonary vasculature. J Pharmacol Exp Ther 301:1060-1066

22. Patrono C, FitzGerald GA 1997 Isoprostanes: potential markers of oxidant stress in atherothrombotic disease. Arterioscler Thromb Vasc Biol 17:2309-2315

23. Kinsella BT 2001 Thromboxane A2 signalling in humans: a 'tail' of two receptors Biochem Soc Trans 29:641-654
24. Haworth SG, Hislop AA 1981 Adaptation of the pulmonary circulation to extrauterine life in the pig and its relevance to the human infant. Cardiovasc Res 15:108-119

25. Arrigoni FI, Hislop AA, Haworth SG, Mitchell JA 1999 Newborn intrapulmonary veins are more reactive than arteries in normal and hypertensive piglets. Am J Physiol 277:L887-L892

26. Tazzeo T, Miller J, Janssen LJ 2003 Vasoconstrictor responses, and underlying mechanisms, to isoprostanes in human and porcine bronchial arterial smooth muscle. Br J Pharmacol 140:759-763

27. González-Luis G, García-Muñoz F, Pérez-Vizcaíno F, De Mey JG, Blanco CE Villamor E 2004 Vasorelaxant actions of isoprostanes in neonatal porcine pulmonary, mesenteric, and coronary vascular smooth muscle. Pediatr Res 55:587A

28. Cogolludo A, Moreno L, Bosca L, Tamargo J, Perez-Vizcaino F 2003 Thromboxane A2-induced inhibition of voltage-gated $\mathrm{K}+$ channels and pulmonary vasoconstriction: role of protein kinase Czeta. Circ Res 93:656-663

29. Di Mari JF, Mifflin RC, Adegboyega PA, Saada JI, Powell DW 2003 IL-1alphainduced COX-2 expression in human intestinal myofibroblasts is dependent on a PKCzeta-ROS pathway. Gastroenterology 124:1855-1865

30. Bailly K, Ridley AJ, Hall SM, Haworth SG 2004 RhoA activation by hypoxia in pulmonary arterial smooth muscle cells is age and site specific. Circ Res 94:1383-1391

31. Schmalfuss CM, Chen LY, Bott JN, Staples ED, Mehta JL 1999 Superoxide anion generation, superoxide dismutase activity, and nitric oxide release in human internal mammary artery and saphenous vein segments. J Cardiovasc Pharmacol Ther 4:249-257

32. Raj JU, Hillyard R, Kaapa P, Gropper M, Anderson J 1990 Pulmonary arterial and venous constriction during hypoxia in 3- to 5-wk-old and adult ferrets. J Appl Physiol 69:2183-2189

33. Gao Y, Tolsa JF, Botello M, Raj JU 1998 Developmental change in isoproterenolmediated relaxation of pulmonary veins of fetal and newborn lambs. J Appl Physiol 84:1535-1539

34. Edelstone DI, Holzman IR 1982 Fetal intestinal oxygen consumption at various levels of oxygenation. Am J Physiol Heart Circ Physiol 242:H50-H54

35. Su BY, Reber KM, Nankervis CA, Nowicki PT 2003 Development of the myogenic response in postnatal intestine: role of PKC. Am J Physiol Gastrointest Liver Physiol 284:G445-G452

36. Saugstad OD Update on oxygen radical disease in neonatology. Curr Opin Obstet Gynecol 13:147-153, 2001

37. Nozik-Grayck E, Dieterle CS, Piantadosi CA, Enghild JJ, Oury TD 2000 Secretion of extracellular superoxide dismutase in neonatal lungs. Am J Physiol Lung Cell Mol Physiol 279:L977-L984 


\section{Chapter VII:}

Age-related changes in isoprostanemediated relaxation of piglet vessels.

Front Biosci 2010; E2:369-379. 
Age-related changes in isoprostane-mediated relaxation of piglet blood vessels

\author{
Gema Gonzalez-Luis ${ }^{1}$, Francisco Perez-Vizcaino ${ }^{2}$. Carlos E. Blanco ${ }^{3}$, Eduardo Villamor ${ }^{3}$ \\ ${ }^{I}$ Division of Neonatology, Department of Pediatrics, Hospital Universitario Materno-Infantil de Canarias, 35016 Las Palmas de \\ Gran Canaria, Spain, ${ }^{2}$ Department of Pharmacology, School of Medicine, Complutense University, CIBER Enfermedades \\ Respiratorias (Ciberes), 28040 Madrid, Spain, ${ }^{3}$ Department of Pediatrics, Maastricht University Medical Center (MUMC+), \\ School for Oncology and Developmental Biology (GROW), 6202 AZ Maastricht, the Netherlands
}

\title{
TABLE OF CONTENTS
}

1. Abstract

2. Introduction

3. Materials and methods

3.1. Tissue preparation

3.2. Isometric force measurement

3.3. Drugs and solutions

4. Results

3.4. Analysis of data

5. Discussion

6. Acknowledgments

7. References

\section{ABSTRACT}

We studied the putative relaxant effects of several isoprostanes (8-iso- $\mathrm{PGE}_{1}$, and 8-iso- $\mathrm{PGE}_{2}, 8$-iso$\mathrm{PGF}_{1 \text { alpha, }}$ 8-iso-PGF 1beta, $_{\text {iso-iso-PGF }}$ 2alpha, and 8-iso$\mathrm{PGF}_{2 \text { beta }}$ ) on pulmonary (PA), mesenteric (MA), coronary (CA) arteries and pulmonary veins (PV), from newborn and 2-week-old piglets. Isoprostanes were compared with agonists of the EP ( $\mathrm{PGE}_{1}, \mathrm{PGE}_{2}$, and misoprostol), DP $\left(\mathrm{PGD}_{2}\right)$, and IP (iloprost) receptors. Isoprostane-induced relaxation was only observed when TP receptors were occupied (by U46619) or blocked (by SQ 29,548). Under these conditions, 8-iso- $\mathrm{PGE}_{2}$ induced a relaxation of $\mathrm{PA}$ (but not PV or MA) that increased with postnatal age. 8iso- $\mathrm{PGE}_{1}, 8$-iso- $\mathrm{PGE}_{2}$, and 8-iso- $\mathrm{PGF}_{2 \mathrm{alpha}}$ evoked modest relaxations in CA. 8-iso- $\mathrm{PGE}_{2}$-induced relaxation of $\mathrm{PA}$ was impaired by endothelium removal and by the presence of blockers of NO synthase (L-NAME), guanylate cyclase (ODQ), or EP receptor (AH6809). $\mathrm{PGE}_{1}, \mathrm{PGE}_{2}$, and misoprostol (but not $\mathrm{PGD}_{2}$ or iloprost) induced a relaxation of PA that increased with age. In conclusion, occupancy or blockade of TP receptors unmasked a relaxant effect of 8iso- $\mathrm{PGE}_{2}$ in piglet PA. This relaxation increased with postnatal age, was endothelium-dependent and involved EP receptors and $\mathrm{NO}$.

\section{INTRODUCTION}

Isoprostanes are prostaglandin (PG) isomers that are produced in vivo primarily by a free radical-catalyzed peroxidation of polyunsaturated fatty acids $(1,2)$. Initially, isoprostanes were recognized as being valuable markers of oxidative stress and numerous pathological conditions have been shown to be associated with increases in urinary, plasma, and tissue levels of isoprostanes. Moreover, few members of the isoprostane family are biologically active and could contribute to the functional consequences of oxidant injury and mediate many of the features of the disease states for which they are used as indicators $(1,2)$.

There is increasing evidence that isoprostanes exert a wide variety of actions on vascular smooth muscle and endothelial cells. Many have described contractile responses to isoprostanes in a wide variety of vascular tissues, generally via stimulation of thromboxane $\mathrm{A}_{2}$ receptors (TP receptors) (1-4) . In addition, and depending on the compound and the vascular bed, vasodilatory actions of isoprostanes have been also identified (5-7). These actions were frequently masked by the vasoconstrictive effects of isoprostanes on TP receptors and only were observed when these receptors were blocked by antagonists 
(such as SQ 29,548 or ICI 192605) or saturated by an agonist (such as U46619) (5-7).

Newborns and particularly preterm infants are very susceptible to oxidative stress $(8,9)$. A large growing body of literature is addressing the possible role of isoprostanes in the pathophysiology of several neonatal conditions, such as asphyxia, intraventricular hemorrhage, periventricular leukomalacia, bronchopulmonary dysplasia, pulmonary hypertension and retinopathy of prematurity (10-16). However, the possible contribution of isoprostanes to the normal transition to extra-uterine life remains largely unknown. In a previous study, we reported that several Eand F-ring isoprostanes induced vasoconstriction in pulmonary arteries (PA), pulmonary veins (PV), and mesenteric arteries (MA) from newborn and 2-wk-old piglets (17). This effect was mediated by stimulation of TP receptors and decreased with postnatal age. Interestingly, we observed that 8-iso- $\mathrm{PGE}_{2}$ presented a dual effect on piglet $\mathrm{PA}$, inducing contraction at low concentrations and relaxation at high concentrations. The relaxant effects of 8iso-PGE ${ }_{2}$ were more marked in the PA from 2-week-old piglets than in the newborns (17). Similarly, Belik et al. demonstrated that in PA of adult rats contracted with U46619, 8-iso-PGF ${ }_{2 \alpha}$ induced a significant dose-dependent relaxation. In contrast, no effect was observed in arteries from 2-week-old animals, and a significant contraction was noted in PA from 1-wk-old animals (18). Therefore, the relaxant effects of isoprostanes in PA appear to be agedependent. In the present study, we hypothesized that TP receptor blockade or occupancy unmasked the relaxant effects of several E-ring (8-iso-PGE ${ }_{1}$ and 8-iso- $\mathrm{PGE}_{2}$ ) and F-ring (8-iso-PGF ${ }_{1 \alpha}, 8$-iso-PGF ${ }_{1 \beta}, 8$-iso- $\mathrm{PGF}_{2 \alpha}$, and 8-iso$\mathrm{PGF}_{2 \beta}$ ) isoprostanes in neonatal and 2-week-old piglet pulmonary, mesenteric and coronary vessels.

\section{MATERIALS AND METHODS}

\subsection{Tissue preparation}

All experiments were carried out in accordance with the European Animals Act 1986 (Scientific Procedures) and approved by institutional review board. Neonatal piglets aged $12-24 \mathrm{~h}(\mathrm{n}=30)$ and 2 weeks $(\mathrm{n}=30)$, obtained from a local farm, were killed by exsanguination after being anesthetized with sodium pentobarbitone (100 $\mathrm{mg} / \mathrm{kg}$ ). The lungs, heart and intestines were rapidly immersed in cold $\left(4^{\circ} \mathrm{C}\right)$ Krebs-Ringer bicarbonate buffer (composition in mmol/L: $\mathrm{NaCl}, 118.5 ; \mathrm{KCl}, 4.75 ; \mathrm{MgSO}_{4}$. $7 \mathrm{H}_{2} \mathrm{O}, 1.2 ; \mathrm{KH}_{2} \mathrm{PO} 4,1.2 ; \mathrm{NaHCO}_{3}, 25.0 ; \mathrm{CaCl}_{2}, 2.5$; glucose, 5.5). PA, PV (third-fourth branch, in situ external diameter 1-2 mm), MA with a similar in situ external diameter (distal half of the MA trunk) and coronary artery (CA, left anterior descendent) were carefully dissected free of surrounding tissue and cut into rings of 2-3 $\mathrm{mm}$ of length under a dissection microscope. Lungs from adult pigs were obtained from a local abattoir and processed in the same way.

\subsection{Isometric force measurement}

After dissection, two L-shaped stainless steel wires were inserted into the arterial lumen and the rings were introduced in Allhin organ chambers filled with Krebs solution at $37^{\circ} \mathrm{C}$, gassed with $95 \% \mathrm{O}_{2} / 5 \% \mathrm{CO}_{2}$. One wire was attached to the chamber and the other to an isometric force-displacement transducer (model PRE 206-4, Cibertec, Madrid, Spain). The isometric force signal was amplified, A/D converted (PowerLab, ADInstruments Pty., Castle Hill, Australia), and recorded (Chart v3.4, ADInstruments Pty.). An optimal resting tension of $0.3 \mathrm{~g}$ (PA of 12 to $24 \mathrm{~h}-$ old animals), $0.5 \mathrm{~g}$ (PA of 2-week-old animals and PV of both groups), $1 \mathrm{~g}$ (MA of 12- to $24 \mathrm{~h}$-old animals and CA), or 2 g (MA of 2-week-old animals, PA of adults) was applied to the vascular segments, as determined from previous experiments (19-22). Tissues were allowed to equilibrate for $60-90 \mathrm{~min}$. During this period, they were restretched and washed every $30 \mathrm{~min}$ with warm Krebs solution.

Concentration-response curves to isoprostanes: 8 -iso-PGE 1 (15- $\mathrm{E}_{1 \mathrm{t}}$-IsoP in the nomenclature of Taber et

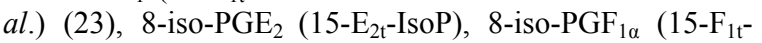
IsoP), 8-iso-PGF $1 \beta$ (9-epi-15- $\mathrm{F}_{1 \mathrm{t}}$-IsoP), 8-iso-PGF $2 \alpha$ (15$\mathrm{F}_{2 \mathrm{t}}$-IsoP), and 8-iso-PGF ${ }_{2 \beta}$ (9-epi-15- $\mathrm{F}_{2 \mathrm{t}}$-IsoP) and prostanoids (misoprostol, $\mathrm{PGE}_{1}, \mathrm{PGE}_{2}, \mathrm{PGD}_{2}$, and iloprost) were carried out in rings pre-contracted with U46619 (0.1$1 \mu \mathrm{M})$ or endothelin-1 (ET-1, 10nM). In some experiments, the vascular effects of isoprostanes were tested in endothelium-denuded arteries or in the presence of the TP receptor antagonist SQ 29,548 $(0.1 \mu \mathrm{M})$, the non-selective EP receptor antagonist AH6809 (6-isopropoxy-9oxoxanthene-2-carboxylic acid; $10 \mu \mathrm{M})$, the cyclooxygenase (COX) inhibitor indomethacin $(10 \mu \mathrm{M})$, the non-selective NO synthase inhibitor L-NAME $(0.1 \mathrm{mM})$, or the soluble guanylate cyclase inhibitor ODQ $(10 \mu \mathrm{M})$. At the end of the experiments, papaverine $(0.1 \mathrm{mM})$ was added to determine the maximum relaxation of each vessel.

\subsection{Drugs and solutions}

Isoprostanes, U46619 (9,11-dideoxy-11 $\alpha, 9 \quad \alpha^{-}$ epoxymethanoprostaglandin $\mathrm{F}_{2 \alpha}$ methyl acetate solution), misoprostol, $\mathrm{PGE}_{1}, \mathrm{PGE}_{2}, \mathrm{PGD}_{2}$, iloprost, and AH6809 were purchased from Cayman Chemical (Ann Arbor, MI, U.S.A.). All other chemicals were obtained from Sigma Chemical Co. (St. Louis, MO). Isoprostanes and ODQ were dissolved initially in DMSO. Indomethacin and prostaglandins were dissolved initially in ethanol. All other chemicals were dissolved initially in distilled deionized water. The maximal bath concentration of DMSO and ethanol did not exceed $0.1 \%$, which was found to have no effect on mechanical activity.

\subsection{Analysis of data}

Results are expressed as mean \pm SEM and $n$ reflects the number of animals from which the rings were obtained. Contractions are expressed in terms of active wall tension $(\mathrm{mN})$, while the relaxant responses are expressed as the percentage of the maximum relaxation induced by papaverine in each individual vessel. The maximal effect $\left(E_{\max }\right)$ produced with the highest concentration $(10 \mu \mathrm{M})$ of an agonist and the half-maximum effective concentration $\left(\mathrm{EC}_{50}\right)$ value were interpolated from the individual concentration-effect curves. The $\mathrm{pD}_{2}$ values were calculated as the negative $\log$ of $\mathrm{EC}_{50}$ values. Statistically significant differences between groups were calculated by 
Table 1. Contractions induced by U46619 and ET-1 in porcine pulmonary arteries

\begin{tabular}{|l|l|l|l|l|}
\hline Agonist & $\begin{array}{l}\text { Concentration } \\
(\boldsymbol{\mu M})\end{array}$ & Age & Tension $(\mathbf{m N})$ & $\boldsymbol{n}$ \\
\hline U46619 & 0.1 & NB & $4.88 \pm 0.51^{* \dagger}$ & 24 \\
\hline U46619 & 0.1 & $2 \mathrm{wk}$ & $6.85 \pm 0.64$ & 26 \\
\hline U46619 & 1 & $2 \mathrm{wk}$ & $9.16 \pm 0.88^{*}$ & 8 \\
\hline U46619 & $0.1+\mathrm{AH}$ & $2 \mathrm{wk}$ & $4.51 \pm 0.52^{*}$ & 8 \\
\hline U46619 & 0.1 & adult & $17.73 \pm 2.95^{*}$ & 12 \\
\hline ET-1 & 0.01 & NB & $6.70 \pm 0.70$ & 24 \\
\hline ET-1 & 0.01 & $2 \mathrm{wk}$ & $8.83 \pm 0.82$ & 26 \\
\hline ET-1 & $0.01+\mathrm{SQ}$ & $2 \mathrm{wk}$ & $8.47 \pm 0.94$ & 26 \\
\hline
\end{tabular}

Values are means \pm SEM of $\mathrm{n}$ animals. $\mathrm{NB}=$ newborn; $\mathrm{AH}=\mathrm{AH} 6809 ; \quad \mathrm{SQ}=\mathrm{SQ} 29,548 ; * \mathrm{P}<0.05$ vs. $\mathrm{U} 46619 / 0.1$ $\mu \mathrm{M} / 2 \mathrm{wk} ;{ }^{\dagger} \mathrm{P}<0.05$ vs. adult.

Student's test for unpaired observations or for multiple comparisons by one-way ANOVA followed by Bonferroni's test. $\mathrm{P}<0.05$ was considered statistically significant.

\section{RESULTS}

The contractions induced by U46619 and ET-1 under the different experimental conditions are summarized in Table 1. In endothelium intact PA pre-contracted with U46619 $(0.1 \mu \mathrm{M}), 8$-iso- $\mathrm{PGE}_{2}$ induced a concentrationdependent relaxation (Figures $1 \mathrm{~A}$ and $1 \mathrm{~B}$ ) with higher efficacy and potency in the 2-wk-old $\left(\mathrm{E}_{\max } 76.37 \pm 5.09 \%\right.$, $\left.\mathrm{pD}_{2} 5.95 \pm 0.13, n=8\right)$ than in the neonatal vessels $\left(\mathrm{E}_{\max }\right.$ $22.06 \pm 2.92 \%, \mathrm{pD}_{2} 5.51 \pm 0.01, n=5, \mathrm{P}<0.05$ vs. 2 -week-old) (Figures 1 and 2). No significant differences in the relaxant effects of 8-iso- $\mathrm{PGE}_{2}$ were observed when the PA were precontracted with U46619 $1 \mu \mathrm{M}$ instead of $0.1 \mu \mathrm{M}$ (Figure 2). The other isoprostanes (8-iso-PGE 1,8 -iso-PGF ${ }_{1 \alpha}$, 8-iso$\mathrm{PGF}_{1 \beta}, 8$-iso- $\mathrm{PGF}_{2 \alpha}$, and 8-iso- $\mathrm{PGF}_{2 \beta}$ ) did not induce significant relaxation of U46619-contracted PA from newborn and 2-wk-old animals (an example of 8-iso-PGF $2 \alpha$ is shown in Figure 1C), and none of the isoprostanes relaxed PV (an example is shown in Figure 1D). In adult PA, 8-iso- $\mathrm{PGE}_{1}$, and 8-iso- $\mathrm{PGF}_{2 \alpha}$ induced modest relaxations and 8 -iso- $\mathrm{PGE}_{2}$ evoked a relaxation of $56.71 \pm$ $8.91 \%\left(\mathrm{pD}_{2} 6.29 \pm 0.12, \mathrm{n}=6, \mathrm{P}<0.05\right.$ vs. newborn) (Figure 2C).

When the pulmonary vessels were pre-contracted with ET-1 $(10 \mathrm{nM})$ none of the isoprostanes induced a significant relaxation. As shown in Figure 2A, high concentrations of 8-iso- $\mathrm{PGE}_{2}$ even increased the tone induced by ET-1 and this effect was reversed by adding the TP receptor antagonist SQ 29,548 $(0.1 \mu \mathrm{M})$. As shown in Figure 2B, when SQ 29,548 was present in combination with ET-1, 8-iso-PGE 2 relaxed the PA (but not PV). The maximal relaxation induced by iso-8-iso- $\mathrm{PGE}_{2}$ in 2-wk-old PA incubated with SQ 29,548 and pre-contracted with ET1 was $35.70 \pm 12.02$ (Figure $2 \mathrm{~A}$ ). The presence of SQ 29,548 did not unmask a relaxant effect of the other isoprostanes tested in PA or veins (data not shown).

As shown in Figures $3 \mathrm{~A}$ and $3 \mathrm{~B}$, the relaxation induced by 8 -iso- $\mathrm{PGE}_{2}$ in the $\mathrm{PA}$ was impaired $(\mathrm{P}<0.05$ vs. control) by endothelium removal $\left(\mathrm{E}_{\max } 28.08 \pm 7.06 \%\right.$ ), or by the presence of NO synthase inhibitor L-NAME ( $\mathrm{E}_{\max }$ $42.79 \pm 7.06 \%$ ), the guanylate cyclase inhibitor ODQ ( $E_{\max }$
$27.72 \pm 4.65 \%$ ), or the EP receptor antagonist AH6809 $\left(\mathrm{E}_{\max } 44.50 \pm 6.04 \%\right)$ In contrast, the presence of the COX inhibitor indomethacin did not significantly affect 8-iso$\mathrm{PGE}_{2}-$ evoked relaxation of PA (Figure $3 \mathrm{~B}$ ).

In order to asses the functionality of prostanoid receptors in the 2-wk-old piglet $\mathrm{PA}$, we examined the relaxant effects of the EP receptor agonists $\mathrm{PGE}_{1}, \mathrm{PGE}_{2}$, and misoprostol, the DP-receptor agonist $\mathrm{PGD}_{2}$, and the IP receptor agonist iloprost and we observed that only the EP receptor agonists relaxed U46619-contracted arteries (Figure 4). In contrast, the IP and EP receptor agonists did not produce any relaxation under the same experimental conditions. As shown in Figure 5 and Table 2, the relaxant efficacy of $\mathrm{PGE}_{1}, \mathrm{PGE}_{2}$, and misoprostol, as well as the sensitivity of the PA to the adenylate cyclase stimulator forskolin increased with postnatal age.

None of the isoprostanes tested induced relaxation of MA pre-contracted with U46619. In contrast, 8-iso- $\mathrm{PGE}_{1}$, 8-iso- $\mathrm{PGE}_{2}$, and 8-iso-PGF $2 \alpha$ relaxed U46619-contracted $\mathrm{CA}$ in a concentrationdependent-manner (Figure 3C). The maximal relaxations obtained (with an isoprostane concentration of $10 \mu \mathrm{M}$ ) were $19.85 \pm 6.54 \%, 29.56 \pm 7.89 \%$, and $10.27 \pm 5.78 \%$ (for 8-iso-PGE 1 , 8-iso- $\mathrm{PGE}_{2}$, and 8iso-PGF ${ }_{2 \alpha}$, respectively). Endothelium removal did not affect isoprostane-induced relaxation in CA (data not shown). The other isoprostanes tested (i.e. 8-iso$\mathrm{PGF}_{1 \alpha}, 8$-iso-PGF ${ }_{1 \beta}$, and 8-iso- $\mathrm{PGF}_{2 \beta}$ ) did not induce significant relaxations in $\mathrm{CA}$.

\section{DISCUSSION}

In a previous work we demonstrated that several E- and F-ring isoprostanes induced TP receptor-mediated contraction of PA, PV, and MA form newborn and 2-weekold piglets (17). Herein, we report that occupancy (with the agonist U46619) or blockade (with the antagonist SQ 29,548 ) of TP receptors unmasked a relaxant effect of 8iso-PGE ${ }_{2}$ in the PA. This effect was not observed for the other E- or F-ring isoprostanes tested. 8-iso-PGE 2 mediated PA relaxation increased with postnatal age, was partially endothelium-dependent and appeared to involve stimulation of EP receptors and production of NO.

Several studies demonstrated that when their effects through TP receptors are blocked, certain isoprostanes can elicit a relaxant response in pulmonary vessels. However, the relaxant potency and efficacy of isoprostanes in pulmonary vascular smooth muscle is very low when compared with airway smooth muscle $(1,2,24)$. 8 -iso- $\mathrm{PGF}_{2} \alpha$ induced relaxation of rat PA by a non-TP receptor mechanism that involves the release of $\mathrm{NO}(5,18)$. 8 -iso-PGE ${ }_{1}$ evoked dose-dependent relaxations in human and canine $\mathrm{PV}$, and in canine PA, but not in the human PA (25). 8-iso- $\mathrm{PGE}_{2}$, and 8-iso-PGF $1 \alpha$ also induced modest relaxations of human PV (25). In the present study, we observed that 8-iso- $\mathrm{PGE}_{2}$ was the isoprostane with the highest relaxing efficacy in porcine PA. 8-iso-PGE ${ }_{1}$ and $\mathrm{PGF}_{2 \alpha}$ elicited modest relaxations in the adult PA, which were not found in the vessels from newborn or 2-week-old 

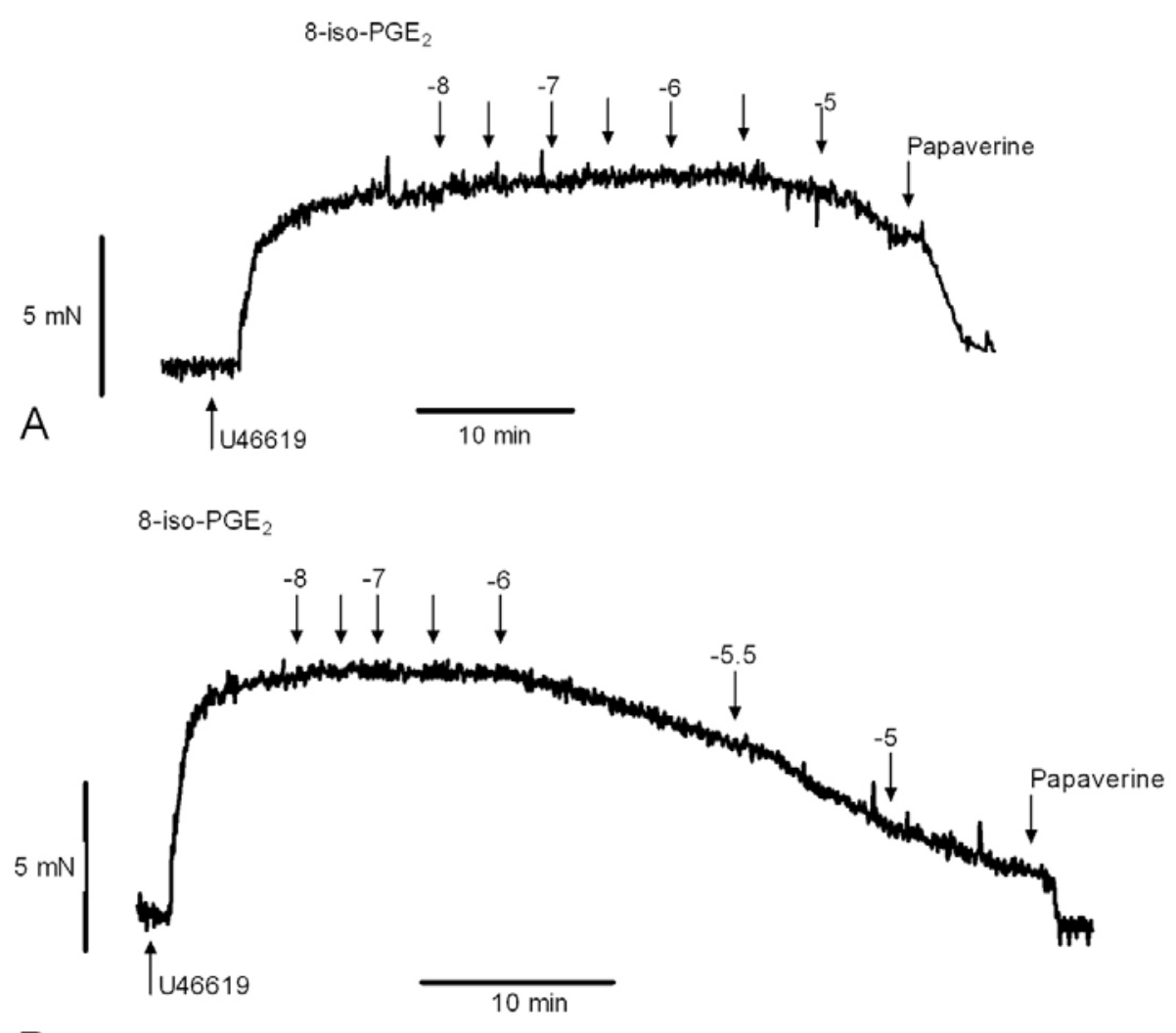

B

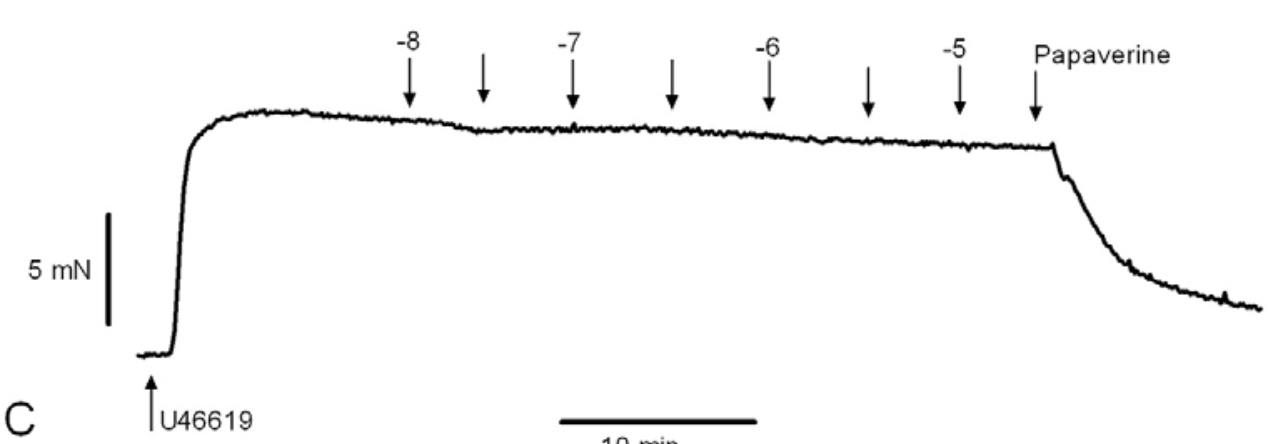

$10 \mathrm{~min}$

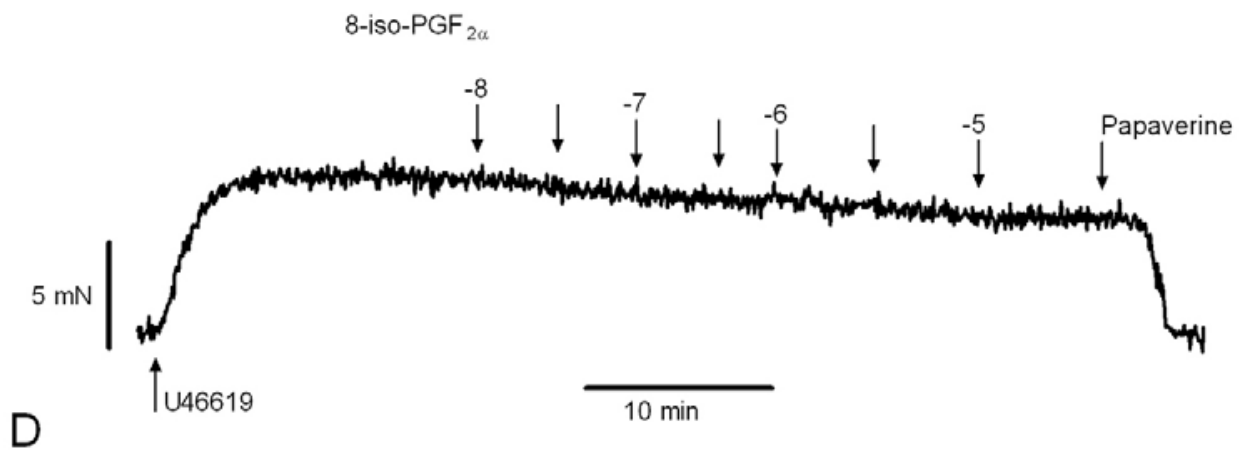

Figure 1. Relaxant effects of cumulative half-logarithmic concentrations of isoprostanes in piglet pulmonary vessels. Typical original recordings of tension development over time in pulmonary artery (A-C) and vein (D) rings from newborn (A) and 2-wkold (C-D) piglets. Vessels were pre-contracted with $\mathrm{U} 46619(0.1 \mu \mathrm{M})$ and, at the end of the experiment, papaverine $(0.1 \mathrm{mM})$ was added to determine the maximum relaxation. 

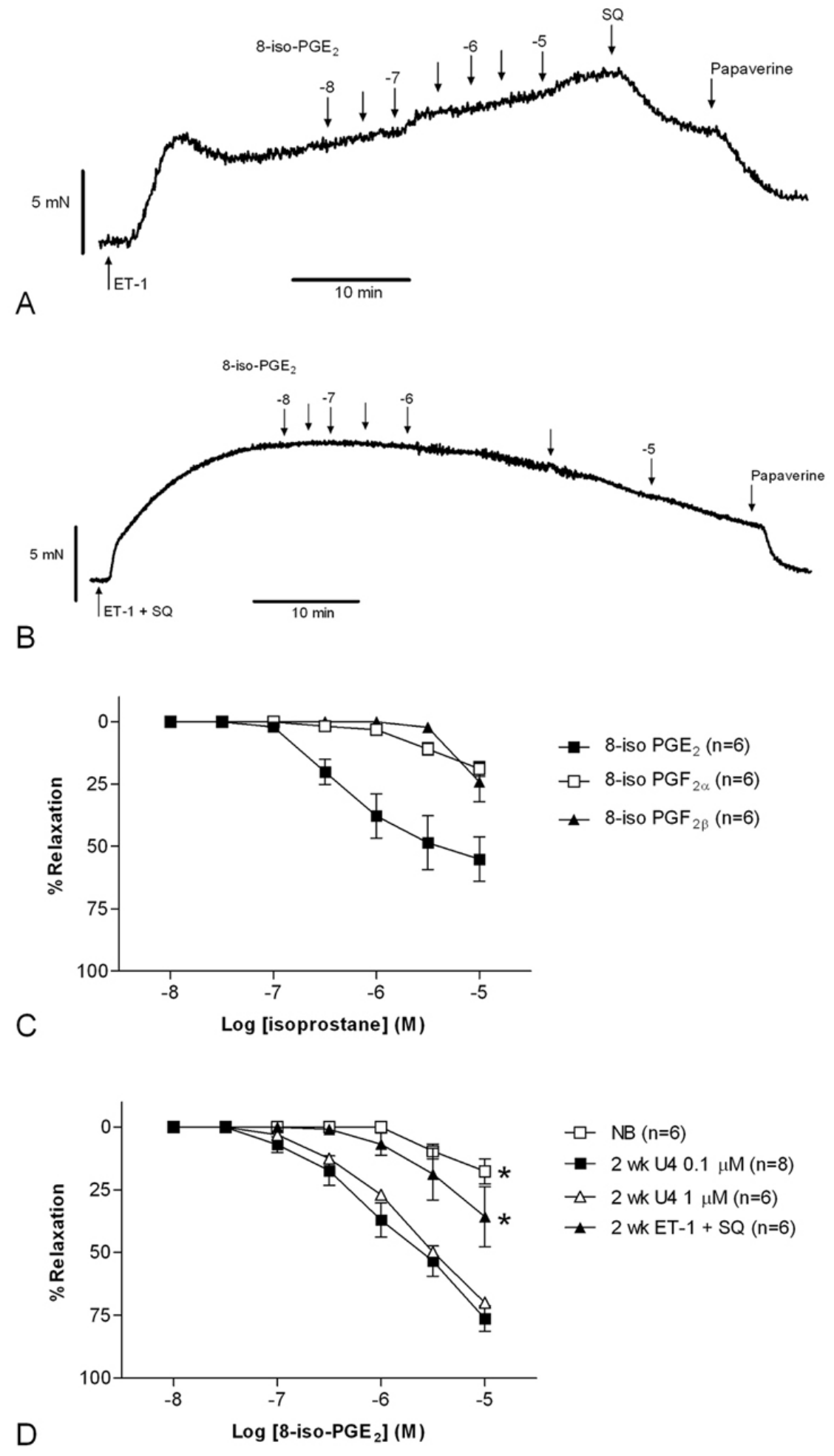

Figure 2. Relaxant effects of isoprostanes in porcine pulmonary vessels. A, B: Typical original recordings of tension development over time in pulmonary artery rings from 2-wk-old piglets pre-contracted with endothelin-1 (ET-1, $10 \mathrm{nM})$. Observe (A) that 8-iso-PGE 2 increased the tone induced by ET-1 and this effect was reversed by adding the TP receptor

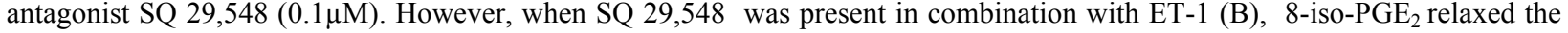
pulmonary artery. At the end of the experiment, papaverine $(0.1 \mathrm{mM})$ was added to determine the maximum relaxation. C, D: Summary of the relaxant effects of isoprostanes in PA from newborn (C), 2-wk-old, and adult pigs. 

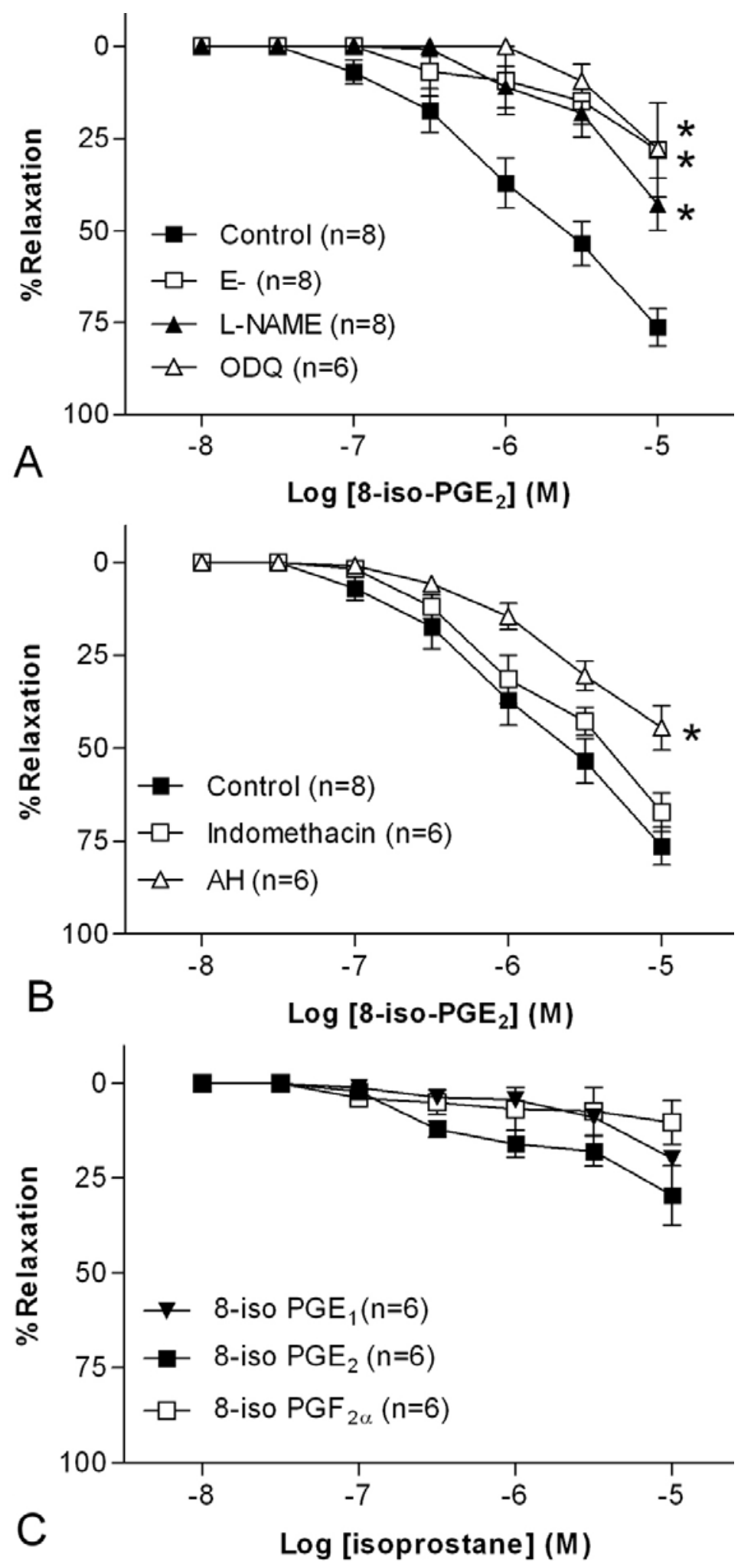

Figure 3. A, B: Effects of endothelium removal (E-), the non-selective NO synthase inhibitor L-NAME $(0.1 \mathrm{mM})$, the soluble guanylate cyclase inhibitor ODQ $(10 \mu \mathrm{M})$, the COX inhibitor indomethacin $(10 \mu \mathrm{M})$, and the non-selective EP receptor antagonist AH6809 $(10 \mu \mathrm{M})$ on the relaxations induced by 8 -iso- PGE $_{2}$ in pulmonary arteries form 2-wk-old piglets. For clarity, the control group is repeated in panels A and B. C: Relaxant effects of isoprostanes in coronary artery rings from 2-wk-old piglets. All the vessels were pre-contracted with $\mathrm{U} 46619(0.1 \mu \mathrm{M}) .{ }^{*} \mathrm{P}<0.05$ for difference in $\mathrm{E}_{\max }$ from control. 

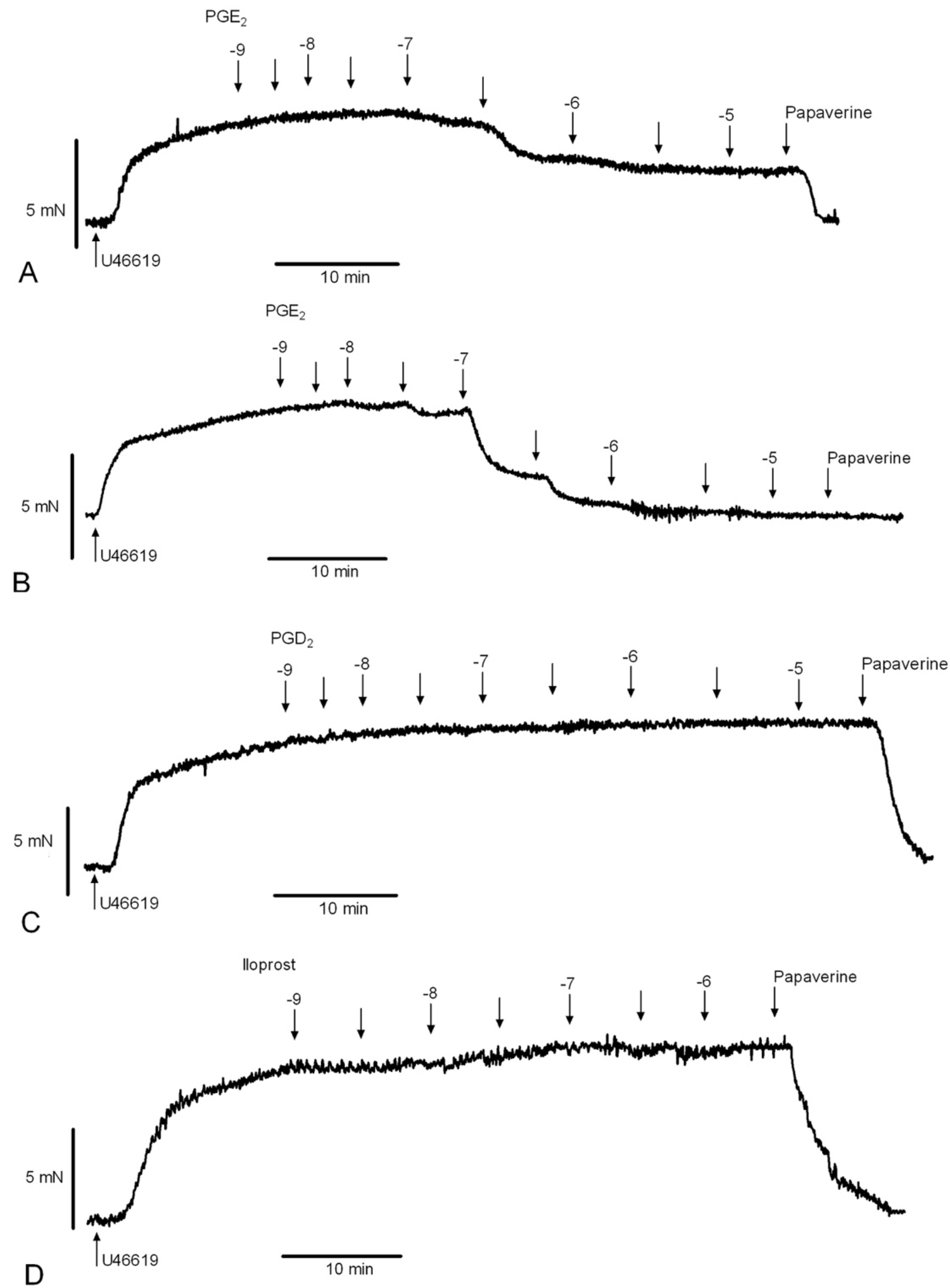

Figure 4. Relaxant effects of cumulative half-logarithmic concentrations of prostanoids in pulmonary arteries from 2-wk-old piglets. Typical original recordings of tension development over time. Vessels were pre-contracted with U46619 (0.1 $\mu \mathrm{M})$ and, at the end of the experiment, papaverine $(0.1 \mathrm{mM})$ was added to determine the maximum relaxation. 


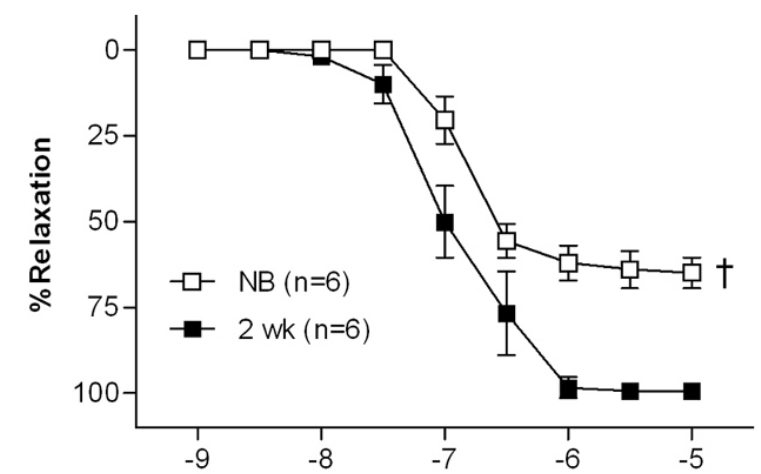

A

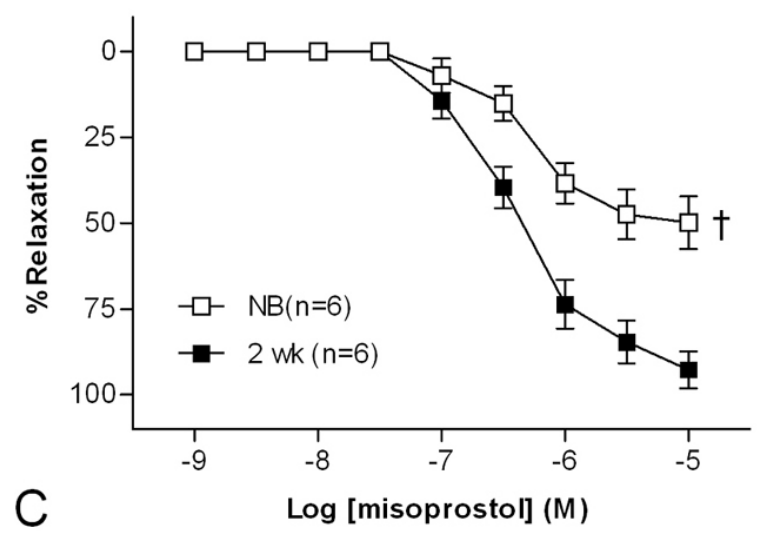

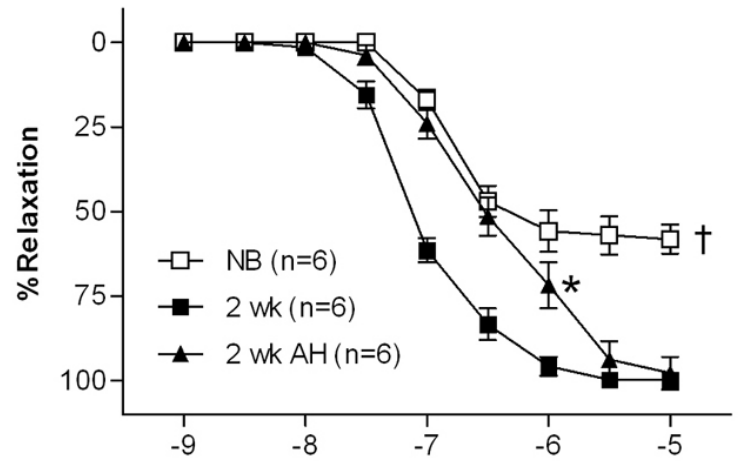

$\mathrm{B} \quad \log \left[\mathrm{PGE}_{2}\right](\mathrm{M})$

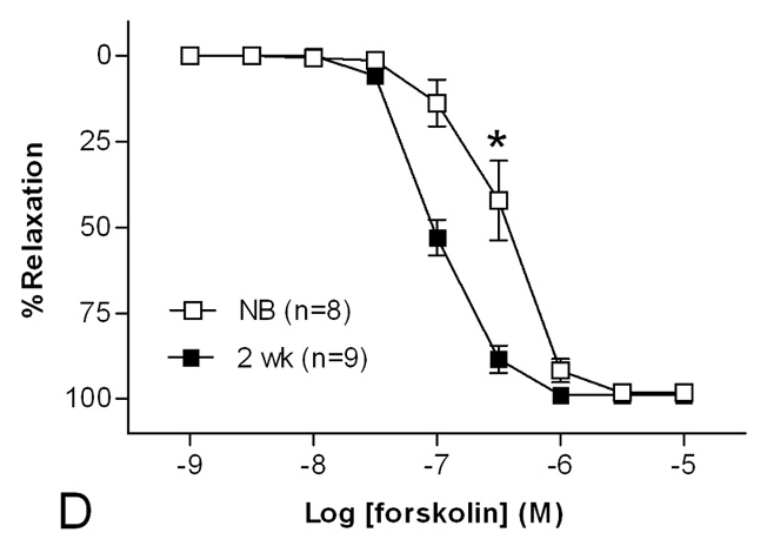

Figure 5. Relaxant effects of the EP receptor agonists prostaglandin (PG)E1 (A), PGE2 (B), and misoprostol and the adenylate cyclase stimulator forskolin (D) in pulmonary arteries form newborn (NB) and 2-wk-old piglets. Vessels were pre-contracted with U46619 $(0.1 \mu \mathrm{M})$. The effects of the non-selective EP receptor antagonist AH6809 $(10 \mu \mathrm{M})$ on the relaxation induced by $\mathrm{PGE}_{2}$ are shown in panel $\mathrm{B}$. ${ }^{*} \mathrm{P}<0.05$ for difference in $\mathrm{pD}_{2}$ from control. ${ }^{\dagger} \mathrm{P}<0.05$ for difference in $\mathrm{E}_{\max }$ from control.

animals. Therefore, the vascular relaxant effects of isoprostanes appear to be species-, tissue-, and -age dependent. Accordingly, Belik et al. found significant developmental differences in the NO-dependent, rat pulmonary arterial relaxant response to 8 -iso- $\mathrm{PGF}_{2 \alpha}(18)$.

Isoprostanes and prostanoids share a similar structure, differing only in the orientation of their aliphatic side chains $(1,2)$. Thus, it is reasonable to assume that isoprostanes are capable of forming similar binding interactions with classic prostanoid receptors $(1,2,26)$, four of which (DP, IP, $\mathrm{EP}_{2}$, and $\mathrm{EP}_{4}$ ) mediate relaxation through a cyclic AMP-dependent mechanism (27). A possible explanation for the modest isoprostane-induced relaxations that we found might be a low functionality of prostanoid receptors in our vascular preparations. However, we observed that the EP receptor agonists $\mathrm{PGE}_{1}$ (present work and 28), $\mathrm{PGE}_{2}$, and misoprostol were potent relaxants of the porcine PA. In contrast, the DP-receptor agonist $\mathrm{PGD}_{2}$, and the IP-receptor agonist iloprost did not evoke relaxation of these vessels. To the best of our knowledge, the prostanoid receptor population expressed in porcine PA has not been characterized. The main receptor responsible for $\mathrm{PGE}_{2}$-induced ductus arteriosus relaxation in fetal pigs is $\mathrm{EP}_{2}$, but the cAMP-inhibiting $\mathrm{EP}_{3}$ receptor is also present, modulating the dilating effect of $\mathrm{PGE}_{2}$ (29). E-ring isoprostanes evoke EP-mediated relaxations in porcine airway smooth muscle (26). We found that $\mathrm{PGE}_{2-}$ and 8iso- $\mathrm{PGE}_{2}$-induced relaxation of piglet $\mathrm{PA}$ was impaired by AH6809 suggesting the involvement of EP receptors. However, AH6809 is a non selective EP receptor antagonist, which does not allow us to discriminate between $\mathrm{EP}_{2}$ and $\mathrm{EP}_{4}$ receptors. Moreover, AH6809 may also block DP and TP receptors $(30,31)$. Accordingly, we observed that AH6809 impaired the contraction induced by U46619. Interestingly, a recent study in murine aorta demonstrated that $\mathrm{PGE}_{2}$ elicits relaxation through $\mathrm{EP}_{4}$ receptor-mediated formation of cAMP by the endothelium, which stimulates endothelial NOS activity (32). With our present results we can only speculate about the putative participation of this mechanism in the endotheliumdependent relaxation evoked by 8 -iso- $\mathrm{PGE}_{2}$. Future functional experiments with more selective EP antagonists (32), as well as investigations addressing the expression and binding activity of prostanoid receptors in porcine pulmonary vessels are, therefore, warranted.

Depending on the species and the vascular tissue, the relaxations evoked by isoprostanes has been reported to be endothelium-dependent $(5,18)$ or -independent (7). Isoprostanes have been shown to induce endothelial NO, $\mathrm{TxA}_{2}$, ET-1 and inositol 1,4,5-trisphosphate formation (10, 
Table 2. Concentration-response parameters for prostanoids and forskolin in piglet pulmonary arteries

\begin{tabular}{|c|c|c|c|c|c|c|}
\hline Agonist & Newborn & & & 2-wk-old & & \\
\hline & $\mathbf{E}_{\max }$ & $\mathrm{pD}_{2}$ & $n$ & $\mathbf{E}_{\max }$ & $\mathrm{pD}_{2}$ & $n$ \\
\hline $\mathrm{PGE}_{1}$ & $64.9 \pm 4.4$ & $6.82 \pm 0.23$ & 6 & $99.3 \pm 2.2^{*}$ & $6.94 \pm 0.19$ & 6 \\
\hline $\mathrm{PGE}_{2}$ & $58.2 \pm 4.2$ & $6.78 \pm 0.14$ & 6 & $99.8 \pm 0.5^{*}$ & $7.08 \pm 0.12$ & 6 \\
\hline Misoprostol & $49.8 \pm 7.1$ & $6.24 \pm 0.14$ & 6 & $92.7 \pm 5.3^{*}$ & $6.38 \pm 0.12$ & 6 \\
\hline Forskolin & $98.2 \pm 2.2$ & $6.42 \pm 0.11$ & 6 & $98.9 \pm 0.7$ & $7.0 \pm 0.11^{*}$ & 6 \\
\hline
\end{tabular}

Values are means \pm SEM of $n$ animals. $* \mathrm{P}<0.05$ vs. newborn..

$18,33)$. We observed that 8 -iso- $\mathrm{PGE}_{2}$-induced relaxation of PA (but not CA) was impaired by endothelium removal as well as by NOS and sGC inhibition, suggesting a role for endothelium-derived NO. The age-dependent increase that was observed for 8-iso- $\mathrm{PGE}_{2}$-elicited relaxation, is a common finding for other vasodilators acting through the NO-sGC-cGMP pathway in piglet PA and has been extensively discussed elsewhere (19-21, 34-37). Developmental changes in the expression and/or activity of NO synthases, sGC, phosphodiesterases, and reactive oxygen species-producing enzymes may account for this postnatal increase in responsiveness (19-21, 34-36). Herein, we found that the relaxant efficacy of $\mathrm{PGE}_{1}, \mathrm{PGE}_{2}$, and misoprostol, as well as the potency of the adenylate cyclase stimulator forskolin, also increased with age. This suggests that also the adenylate cyclase/cAMP pathway undergoes significant alterations during the first days of postnatal life. Alternatively, as discussed below, the developmental changes in relaxation might be related to alterations in the responsiveness to U46619, the TP receptor agonist used to contract the arteries in our experiments (34).

Cogolludo et al. (34) have shown that two pathways are involved in TP-receptor induced vasoconstriction in piglet PA. First, the activation of protein kinase $\mathrm{C}$ (PKC) zeta leads to voltage-gated $\mathrm{K}^{+}$ channels channel blockade, membrane depolarization, Ltype $\mathrm{Ca}^{2+}$ channel activation, and increase in $\left[\mathrm{Ca}^{2+}\right]_{\mathrm{i}}$. Second, a RhoA/Rho kinase-mediated $\mathrm{Ca}^{2+}$ sensitization pathway also mediate U46619-induced contraction. This second pathway contributes more importantly to TPmediated contraction in the 2 -week-old animals than in the newborns (34). $\mathrm{Ca}^{2+}$-desensitization is mediated by both cGMP- and cAMP-dependent protein kinases (38). Therefore, the maturational shift from PKC and voltagegated $\mathrm{K}^{+}$channels to RhoA/Rho kinase-mediated $\mathrm{Ca}^{2+}$ sensitization in TP receptor-elicited pulmonary vasoconstriction might be partially responsible for the developmental increase in cGMP- and cAMP-mediated relaxation.

In conclusion, our results contribute to reinforce the idea that isoprostanes are not only markers but also mediators of the biological effects of oxidative stress. Part of the vascular effects of isoprostanes are based on their capacity to stimulate contractile and relaxant receptors $(1$, $2,17,18,25)$ but another part is based on their stimulation of the production and release of vasoconstrictors and vasodilators $(1,2,10,18,33)$. In addition, reactive oxygen species induce the release of isoprostanes and other vasoactive mediators but can also interact with these mediators $(21,36)$ and may even be produced by them as part of their transduction mechanisms $(37,39)$. The interactions of these processes achieve a particular relevance in the perinatal period, which is characterized by abrupt changes in the oxidant status $(8,9)$.

\section{ACKNOWLEDGEMENTS}

Gema Gonzalez-Luis was supported by a Grant of Fundación Canaria de Investigación y Salud (FUNCIS).

\section{REFERENCES}

1. Janssen, L. J.: Isoprostanes and lung vascular pathology. Am J Respir Cell Mol Biol, 39, 383-9 (2008)

2. Janssen, L. J., A. Catalli \& P. Helli: The pulmonary biology of isoprostanes. Antioxid Redox Signal, 7, 244-55 (2005)

3. Mueed, I., T. Tazzeo, C. Liu, E. Pertens, Y. Zhang, I. Cybulski, L. Semelhago, J. Noora, A. Lamy, K. Teoh, V. Chu \& L. J. Janssen: Isoprostanes constrict human radial artery by stimulation of thromboxane receptors, $\mathrm{Ca} 2+$ release, and RhoA activation. J Thorac Cardiovasc Surg, 135, 131-8 (2008)

4. Oliveira, L., N. A. Stallwood \& D. J. Crankshaw: Effects of some isoprostanes on the human umbilical artery in vitro. $\mathrm{Br} J$ Pharmacol, 129, 509-14 (2000)

5. Jourdan, K. B., T. W. Evans, N. P. Curzen \& J. A. Mitchell: Evidence for a dilator function of 8-iso prostaglandin F2 alpha in rat pulmonary artery. Br J Pharmacol, 120, 1280-5 (1997)

6. Zhang, Y., E. Pertens \& L. J. Janssen: 8-isoprostaglandin $\mathrm{E}(2)$ activates $\mathrm{Ca}(2+)$-dependent $\mathrm{K}(+)$ current via cyclic AMP signaling pathway in murine renal artery. Eur J Pharmacol, $520,22-8(2005)$

7. Zhang, Y., T. Tazzeo, S. Hirota \& L. J. Janssen: Vasodilatory and electrophysiological actions of 8-isoprostaglandin E2 in porcine coronary artery. J Pharmacol Exp Ther, 305, 1054-60 (2003)

8. Saugstad, O. D.: Oxidative stress in the newborn--a 30-year perspective. Biol Neonate, 88, 228-36 (2005)

9. Buonocore, G. \& F. Groenendaal: Anti-oxidant strategies. Semin Fetal Neonatal Med, 12, 287-95 (2007)

10. Weinberger, B., S. Nisar, M. Anwar, B. Ostfeld \& T. Hegyi: Lipid peroxidation in cord blood and neonatal outcome. Pediatr Int, 48, 479-83 (2006)

11. Hardy, P., I. Dumont, M. Bhattacharya, X. Hou, P. Lachapelle, D. R. Varma \& S. Chemtob: Oxidants, nitric oxide and prostanoids in the developing ocular vasculature: 
a basis for ischemic retinopathy. Cardiovasc Res, 47, 489509 (2000)

12. Ahola, T., V. Fellman, I. Kjellmer, K. O. Raivio \& R. Lapatto: Plasma 8-isoprostane is increased in preterm infants who develop bronchopulmonary dysplasia or periventricular leukomalacia. Pediatr Res, 56, 88-93 (2004)

13. Comporti, M., C. Signorini, S. Leoncini, G. Buonocore, V. Rossi \& L. Ciccoli: Plasma F2-isoprostanes are elevated in newborns and inversely correlated to gestational age. Free Radic Biol Med, 37, 724-32 (2004)

14. Longini, M., S. Perrone, A. Kenanidis, P. Vezzosi, B. Marzocchi, F. Petraglia, G. Centini \& G. Buonocore: Isoprostanes in amniotic fluid: a predictive marker for fetal growth restriction in pregnancy. Free Radic Biol Med, 38, 1537-41 (2005)

15. Signorini, C., L. Ciccoli, S. Leoncini, S. Carloni, S. Perrone, M. Comporti, W. Balduini \& G. Buonocore: Free iron, total F-isoprostanes and total F-neuroprostanes in a model of neonatal hypoxic-ischemic encephalopathy: neuroprotective effect of melatonin. J Pineal Res, 46, 14854 (2009)

16. Signorini, C., S. Perrone, C. Sgherri, L. Ciccoli, G. Buonocore, S. Leoncini, V. Rossi, D. Vecchio \& M. Comporti: Plasma esterified F2-isoprostanes and oxidative stress in newborns: role of nonprotein-bound iron. Pediatr Res, 63, 287-91 (2008)

17. Gonzalez-Luis, G., F. Perez-Vizcaino, F. GarciaMunoz, J. G. de Mey, C. E. Blanco \& E. Villamor: Agerelated differences in vasoconstrictor responses to isoprostanes in piglet pulmonary and mesenteric vascular smooth muscle. Pediatr Res, 57, 845-52 (2005)

18. Belik, J., R. P. Jankov, J. Pan, M. Yi, C. R. Pace-Asciak \& A. K. Tanswell: Effect of 8-isoprostaglandin F2alpha on the newborn rat pulmonary arterial muscle and endothelium. J Appl Physiol, 95, 1979-85 (2003)

19. Gonzalez-Luis, G., A. Cogolludo, L. Moreno, F. Lodi, J. Tamargo, F. Perez-Vizcaino \& E. Villamor: Relaxant effects of the soluble guanylate cyclase activator and NO sensitizer YC-1 in piglet pulmonary arteries. Biol Neonate, 90, 66-72 (2006)

20. Gonzales-Luis, G., A. J. Fletcher, L. Moreno, F. PerezVizcaino, C. E. Blanco \& E. Villamor: Nitric oxidemediated nonadrenergic noncholinergic relaxation of piglet pulmonary arteries decreases with postnatal age. J Physiol Pharmacol, 58, 45-56 (2007)

21. Villamor, E., C. G. Kessels, M. A. Fischer, A. Bast, J. G. de Mey \& C. E. Blanco: Role of superoxide anion on basal and stimulated nitric oxide activity in neonatal piglet pulmonary vessels. Pediatr Res, 54, 372-81 (2003)

22. Villamor, E., T. Ruiz, F. Perez-Vizcaino, J. Tamargo \& M. Moro: Endothelium-derived nitric oxide-dependent response to hypoxia in piglet intrapulmonary arteries. Biol Neonate, 72, 62-70 (1997)

23. Taber, D. F., J. D. Morrow \& L. J. Roberts, 2nd: A nomenclature system for the isoprostanes. Prostaglandins, 53, 63-7 (1997)

24. Janssen, L. J., M. Premji, S. Netherton, A. Catalli, G. Cox, S. Keshavjee \& D. J. Crankshaw: Excitatory and inhibitory actions of isoprostanes in human and canine airway smooth muscle. J Pharmacol Exp Ther, 295, 506-11 (2000)

25. Janssen, L. J., M. Premji, S. Netherton, J. Coruzzi, H. Lu-Chao \& P. G. Cox: Vasoconstrictor actions of isoprostanes via tyrosine kinase and Rho kinase in human and canine pulmonary vascular smooth muscles. $\mathrm{Br} J$ Pharmacol, 132, 127-34 (2001)

26. Catalli, A., D. Zhang \& L. J. Janssen: Receptors and signaling pathway underlying relaxations to isoprostanes in canine and porcine airway smooth muscle. Am J Physiol Lung Cell Mol Physiol, 283, L1151-9 (2002)

27. Narumiya, S. \& G. A. FitzGerald: Genetic and pharmacological analysis of prostanoid receptor function. $J$ Clin Invest, 108, 25-30 (2001)

28. Perez-Vizcaino, F., E. Villamor, M. Moro \& J. Tamargo: Pulmonary versus systemic effects of vasodilator drugs: an in vitro study in isolated intrapulmonary and mesenteric arteries of neonatal piglets. Eur J Pharmacol, 314, 91-8 (1996)

29. Bhattacharya, M., P. Asselin, P. Hardy, A. M. Guerguerian, H. Shichi, X. Hou, D. R. Varma, A. Bouayad, J. C. Fouron, R. I. Clyman \& S. Chemtob: Developmental changes in prostaglandin $\mathrm{E}(2)$ receptor subtypes in porcine ductus arteriosus. Possible contribution in altered responsiveness to prostaglandin E(2). Circulation, 100, 1751-6 (1999)

30. Tang, E. H., B. L. Jensen, O. Skott, G. P. Leung, M. Feletou, R. Y. Man \& P. M. Vanhoutte: The role of prostaglandin $\mathrm{E}$ and thromboxane-prostanoid receptors in the response to prostaglandin E2 in the aorta of Wistar Kyoto rats and spontaneously hypertensive rats. Cardiovasc Res, 78, 1308 (2008)

31. Agren, P., S. van der Sterren, A. L. Cogolludo, C. E. Blanco \& E. Villamor: Developmental changes in the effects of prostaglandin $\mathrm{E}(2)$ in the chicken ductus arteriosus. J Comp Physiol [B], 179, 133-143 (2009)

32. Hristovska, A. M., L. E. Rasmussen, P. B. Hansen, S. S. Nielsen, R. M. Nusing, S. Narumiya, P. Vanhoutte, O. Skott \& B. L. Jensen: Prostaglandin E2 induces vascular relaxation by E-prostanoid 4 receptor-mediated activation of endothelial nitric oxide synthase. Hypertension, 50, 525-30 (2007)

33. Yura, T., M. Fukunaga, R. Khan, G. N. Nassar, K. F. Badr \& A. Montero: Free-radical-generated F2-isoprostane 


\section{Isoprostanes and vascular relaxation}

stimulates cell proliferation and endothelin-1 expression on endothelial cells. Kidney Int, 56, 471-8 (1999)

34. Cogolludo, A., L. Moreno, F. Lodi, J. Tamargo \& F. Perez-Vizcaino: Postnatal maturational shift from PKCzeta and voltage-gated $\mathrm{K}+$ channels to $\mathrm{RhoA} / \mathrm{Rho}$ kinase in pulmonary vasoconstriction. Cardiovasc Res, 66, 84-93 (2005)

35. Moreno, L., B. Losada, A. Cogolludo, F. Lodi, C. Lugnier, E. Villamor, M. Moro, J. Tamargo \& F. PerezVizcaino: Postnatal maturation of phosphodiesterase 5 (PDE5) in piglet pulmonary arteries: activity, expression, effects of PDE5 inhibitors, and role of the nitric oxide/cyclic GMP pathway. Pediatr Res, 56, 563-70 (2004)

36. Villamor, E., F. Perez-Vizcaino, A. L. Cogolludo, J. Conde-Oviedo, F. Zaragoza-Arnaez, J. G. Lopez-Lopez \& J. Tamargo: Relaxant effects of carbon monoxide compared with nitric oxide in pulmonary and systemic vessels of newborn piglets. Pediatr Res, 48, 546-53 (2000)

37. Cogolludo, A., L. Moreno \& E. Villamor: Mechanisms controlling vascular tone in pulmonary arterial hypertension: implications for vasodilator therapy. Pharmacology, 79, 65-75 (2007)

38. Somlyo, A. P. \& A. V. Somlyo: $\mathrm{Ca} 2+$ sensitivity of smooth muscle and nonmuscle myosin II: modulated by G proteins, kinases, and myosin phosphatase. Physiol Rev, 83, 1325-58 (2003)

39. Cogolludo, A., G. Frazziano, L. Cobeno, L. Moreno, F. Lodi, E. Villamor, J. Tamargo \& F. Perez-Vizcaino: Role of reactive oxygen species in $\mathrm{Kv}$ channel inhibition and vasoconstriction induced by TP receptor activation in rat pulmonary arteries. Ann N Y Acad Sci, 1091, 41-51 (2006)

Abbreviations: PG: prostaglandin, PA: pulmonary arteries, PV: pulmonary veins, MA: mesenteric arteries, CA: coronary arteries, NO: nitric oxide, NOS: NO synthase, COX: cyclooxygenase, Tx: thromboxane, sGC: soluble guanylate cyclase, $\mathrm{PKC}$ : protein kinase $\mathrm{C}$

Key Words: Isoprostanes, Prostaglandin, Pulmonary Artery, Newborn, Oxidative Stress

Send correspondence to: Eduardo Villamor, Department of Pediatrics, Maastricht University Medical Center, P. Debyelaan 25. P.O. Box 58006202 AZ Maastricht, The Netherlands, Tel: 31-43-3877246, Fax: 31-43-3875246, Email: E.Villamor@mumc.nl

http://www.bioscience.org/current/vol2E.htm 


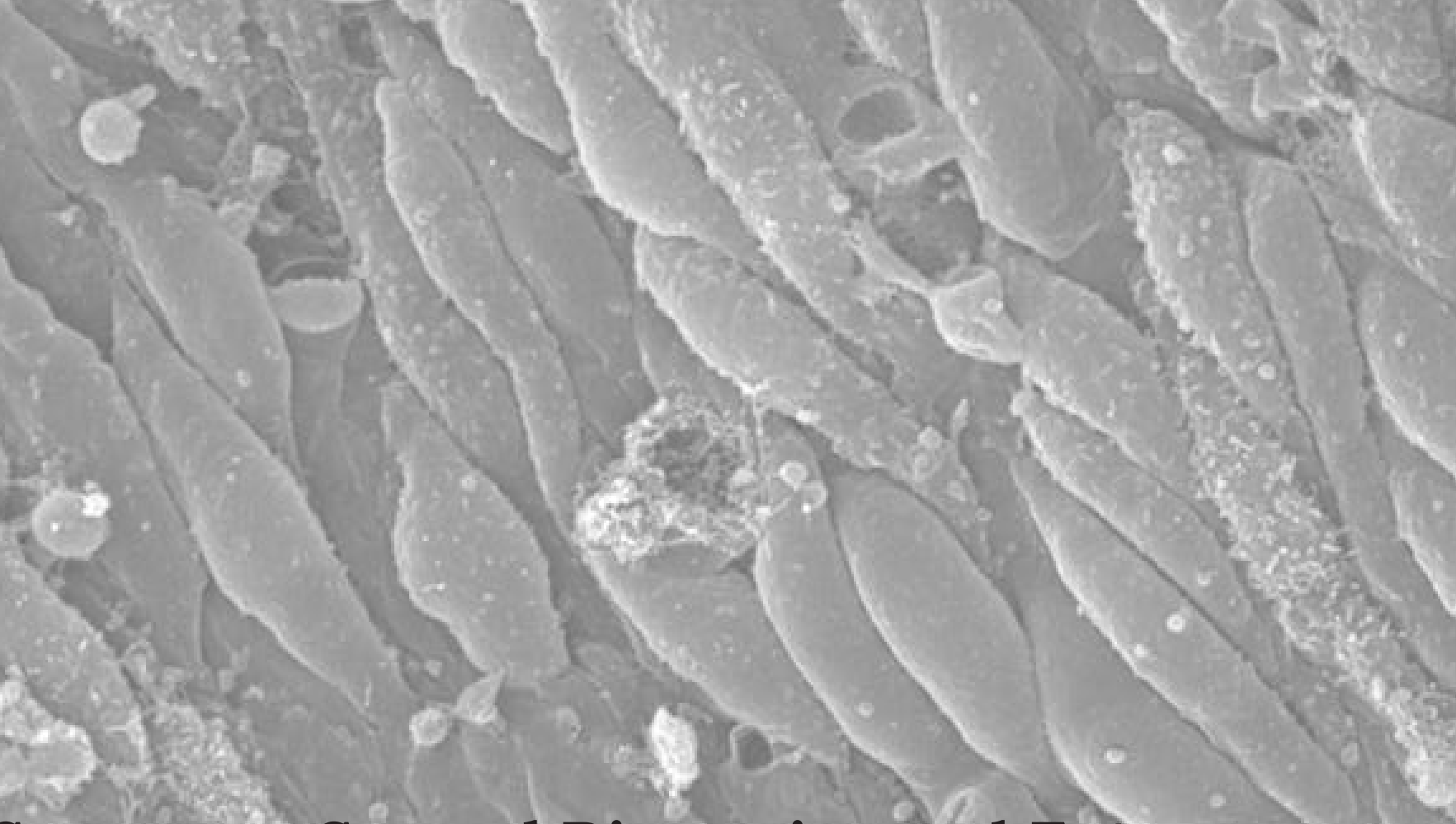

Summary, General Discussion and Future

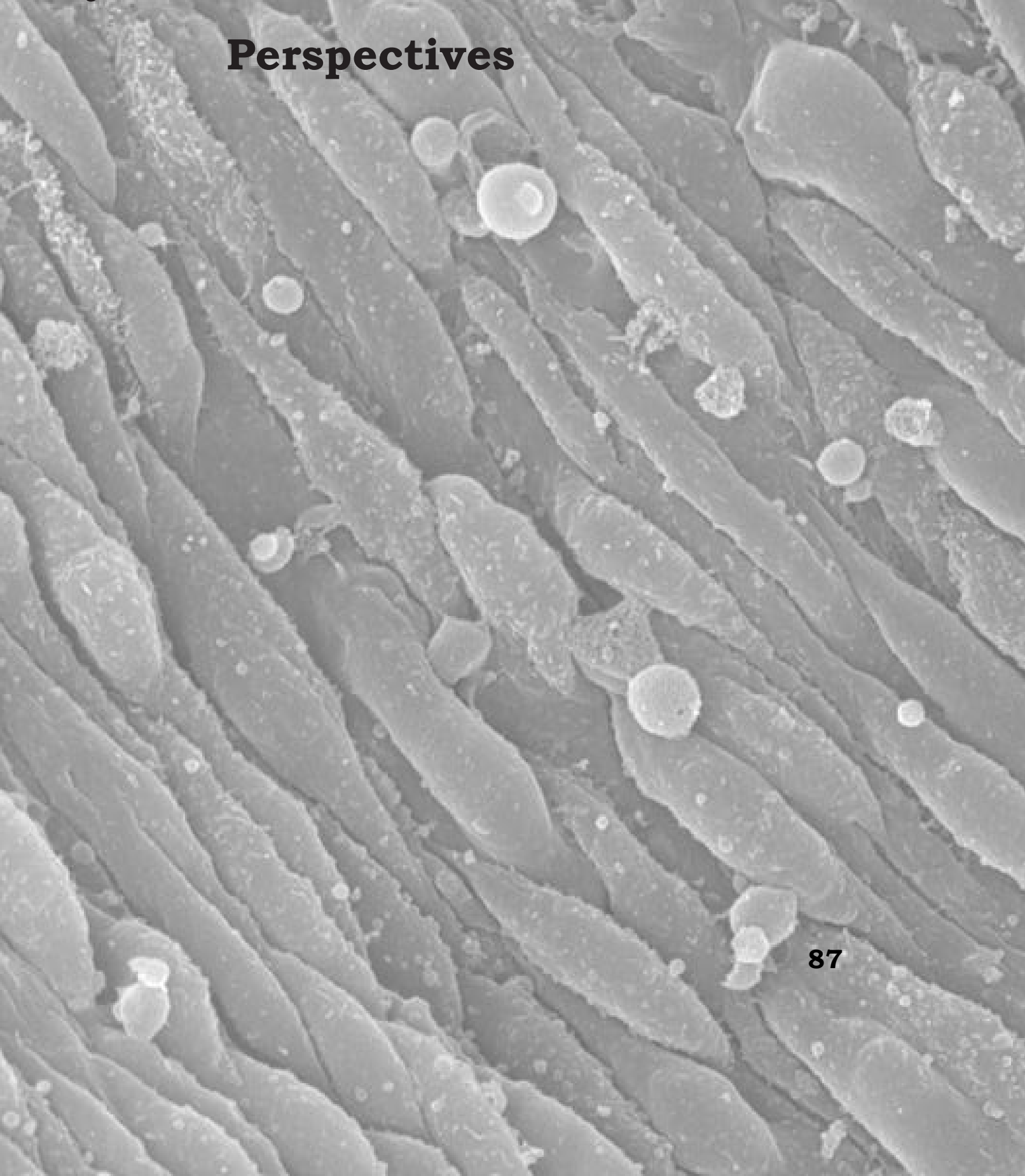

$3 \times 18$ 


\section{Summary, General Discussion and Future Perspectives}

\section{The NO/sGC/cGMP pathway}

At birth, as the lung becomes responsible for blood oxygenation, there is an 8- to 10fold increase in pulmonary blood flow, and pulmonary arterial pressure falls from suprasystemic levels in the fetus to about half of systemic values $(2,5,25)$. A second gradual phase of reduction in pulmonary vascular resistance occurs over the first weeks of postnatal life in order to reach the low pulmonary arterial pressure characteristic of the adult (37-39). Although the NO/sGC/cGMP pathway is critically involved in the transition of pulmonary circulation at birth, neonatal pulmonary arteries from several species show an impairment in endothelium-dependent relaxation $(4,8,37,91)$. More specifically, neonatal pulmonary arteries fail to relax to acetylcholine and the response gradually matures during the first 2 weeks of life. Muscarinic receptor density increases rapidly immediately after birth and the subtypes change (40) but the relatively poor newborn relaxant response is not restricted to receptor-dependent mechanisms (37). Endothelium removal or NOS inhibitors abolished the relaxant response to acetylcholine, indicating the prominent role of endothelium-derived NO in the phenomenon $(37,91)$. The poor vasodilatory response to acetylcholine of neonatal pulmonary arteries is not due to the arterial smooth muscle cells being incapable of relaxation. The neonatal pulmonary arteries relax in response to exogenous NO $(37,51,72,93)$ and to NO-independent sGC stimulators (chapters II and III) although the response does improve significantly during the first 2 weeks of life.

Ideally, eNOS is sufficiently expressed, produces NO sufficiently and the NO is not scavenged by ROS. The NO produced by the endothelial cells diffuses to the adjacent smooth muscle cells reaches its signaling target, mainly sGC, and elicits an increase in cGMP (18). In the present Thesis, and in the work of other investigators, the NO/sGC/cGMP pathway has been dissected in an attempt to explain the relatively poor NO bioactivity of neonatal pulmonary arteries. The expression of eNOS did not change in the pulmonary arteries after birth (8, 41 and chapter IV). In contrast, cytosolic SOD expression and activity are higher in neonatal than in 2-wk-old pulmonary arteries $(72,91)$. Herein (chapter II), we found an age-dependent increase in the $\beta_{1}$ subunit of sGC protein expression which correlates with the increased vasorelaxant response to the sGC stimulators NO and YC-1 (chapters II and III). The sGC increase was also observed at the level of mRNA, indicating that the agedependent change does not require post-transductional mechanisms. Finally, PDE5 activity and expression increased with postnatal age (61). Taken together, all these 
results suggest that the age-related changes in the efficacy of NO/cGMP to induce pulmonary relaxation and its contribution to reduce pulmonary vascular resistance are due to alterations in multiple steps in the signalling pathway (Figure 1). First, the bioavalability of NO during the first hours of life may be reduced due to an enhanced metabolism of NO by superoxide anion. In pulmonary arteries, superoxide levels depend on the balance of its synthesis, mainly contributed by the membrane NADPH oxidase, and its metabolism, mainly contributed by cytosolic SOD (72). However, as mentioned above, the expression (72) or activity (91) of SOD was not reduced in newborns. A potential additional vascular source of superoxide is COX-1. Interestingly, COX-1 inhibitors increased the NO-induced relaxation in newborns but not in 2 week-old piglets which suggested that COX-1 was contributing to an increased metabolism of NO in newborn pulmonary arteries (72). Second, a reduced expression of sGC in newborns as described herein is consistent with a lower response to NO. Third, a reduced expression and activity of PDE5, and thus, a reduced cGMP metabolism, in newborns piglets may partly counteract the above mechanisms (61). Finally, an increased responsiveness to cGMP cannot be excluded.

In contrast to the relaxations induced by $\mathrm{ACh}$, NO gas, NO donors and $\mathrm{YC}-1$, NOmediated NANC relaxation of piglet pulmonary arteries decreased with postnatal age and is almost absent in the 2-week-old pulmonary arteries (chapter IV). Paradoxically, whereas NANC relaxation decreased with advancing age, a marked increase in nNOS expression was observed. These data reflect how during the early stages of life, where marked physiological changes take place, changes in the expression of a single protein often do not correlate with a complex functional response which involves the integrated activity of large number of proteins. NO production is regulated by NOS transcription, post-transcriptional modification, intracellular localization, substrate and co-factor availability, and superoxide production (37). Alterations in these regulatory mechanisms, and structural or metabolic factors which might interfere with the NO diffusion from the nerve terminal to the smooth muscle cell and its oxidative breakdown within the adventitial layer of the vessel $(49,51,56,91)$ might explain the developmental changes in NO-mediated NANC relaxation of pulmonary arteries. Other potential mechanism which might account for changes in NANC relaxation include developmental changes in other vasoactive mediators released by NANC stimulation. 


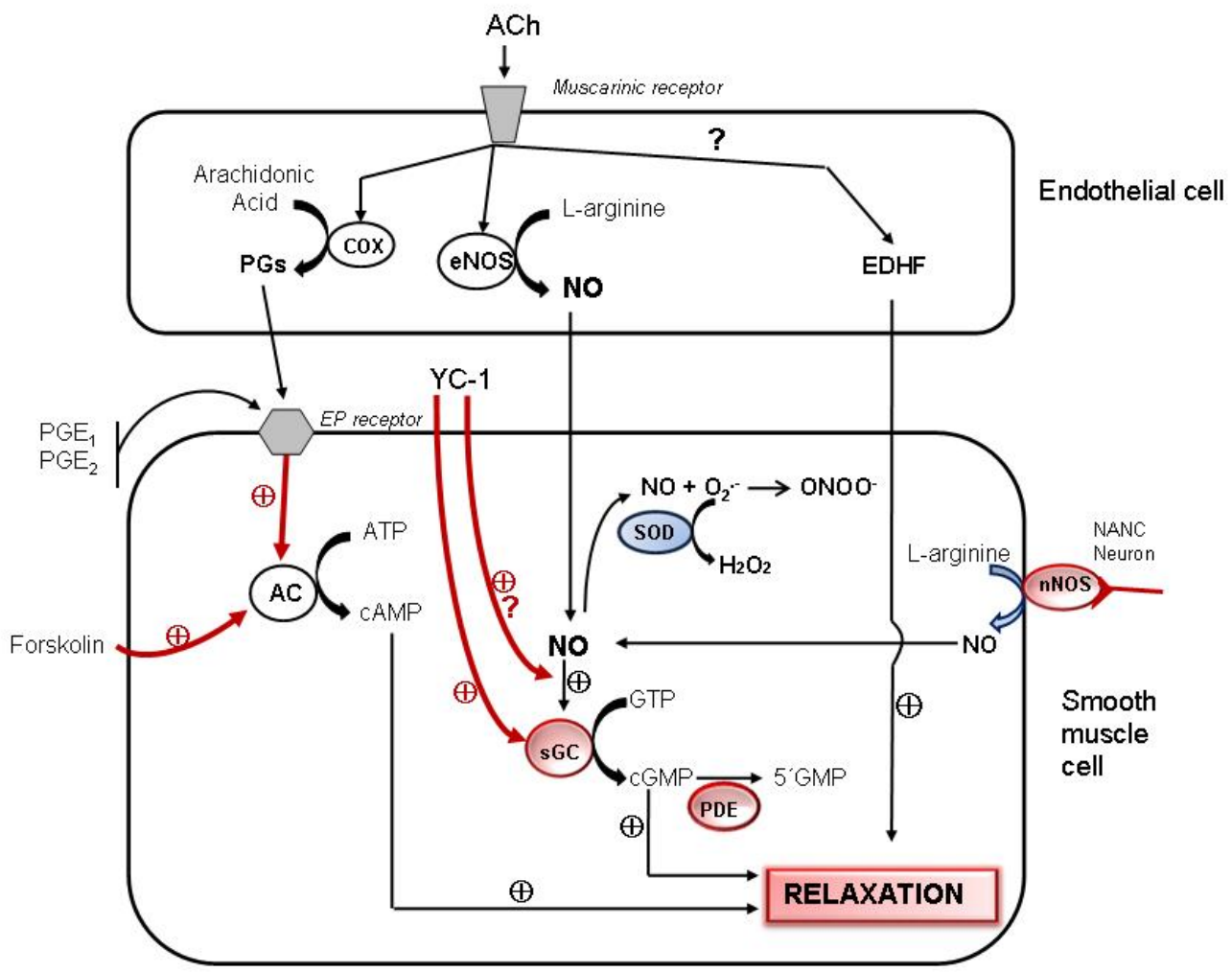

Figure 1. Age related changes in the relaxation mediated by the NO/sGC/cGMP and the AC/cAMP pathways in piglet pulmonary arteries during the first two weeks of postnatal life. The signalling steps which increase with age are depicted in red and the steps which decrease with age are depicted in blue.

\section{The Isoprostane pathway}

Isoprostanes are nonenzymatic, free radical-catalyzed isomers of COX-derived enzymatic products of arachidonic acid (62-64). Isoprostane body fluid levels have been extensively used as clinical markers of oxidative stress in many disease states $(44,46,59,60,62)$. Yet, members of the isoprostane family are also biologically active and likely contribute to the pathogenesis of oxidant-induced injury and may mediate clinical features of diseases for which they are used as indicators. There is increasing evidence that isoprostanes exert a wide variety of actions on vascular smooth muscle and endothelial cells. Many have described contractile responses to isoprostanes in a wide variety of vascular tissues, generally via stimulation of thromboxane $\mathrm{A}_{2}$ receptors (TP receptors) $(46,47,65,67)$. In addition, and depending on the compound and the vascular bed, vasodilatory actions of isoprostanes have been also identified $(48,103$, 104). These actions were frequently masked by the vasoconstrictive effects of isoprostanes on TP receptors and only were observed when these receptors were 
blocked by antagonists (such as SQ 29,548 or ICI 192605), or saturated by an agonist (such as U46619) $(48,103,104)$.

The pulmonary vascular responses to isoprostanes have been studied in the newborn rat (12) and pig (chapters VI and VII) and the available data suggest that these compounds play an important role in the transitional circulation. Belik et al. analyzed the effects of $15-\mathrm{F}_{2 \mathrm{t}}$-IsoP in intralobar pulmonary arteries of 1- and 2-week-old rats, as compared with adults (12). 15- $\mathrm{F}_{2 \mathrm{t}}$-IsoP evoked a TP-receptor-mediated contraction that increased with postnatal age in a similar pattern as previously reported with the TP receptor agonist U46619 $(12,14)$. In U46619-precontracted pulmonary arterial muscle, $15-\mathrm{F}_{2 \mathrm{t}}$-IsoP induced a relaxant effect in the adult and further contraction in the newborn rat. This pulmonary vasoconstrictor effect of $15-\mathrm{F}_{2 \mathrm{t}}$-IsoP was abolished by endothelium removal and NO synthase inhibition, and was markedly attenuated by COX blockade (12). Truog et al. observed that $15-\mathrm{F}_{2 \mathrm{t}}-\mathrm{IsoP}$ induced marked pulmonary vasoconstriction in 2-week-old piglets (88). We evaluated the response to several Fand E-ring IsoPs in pulmonary arteries and veins from newborn and 2-week-old piglets (Chapters VI and VII). A postnatal age-dependent reduction in the contractile responses to $15-\mathrm{F}_{1 \mathrm{t}}$-IsoP (8-iso-PGF ${ }_{1 \mathrm{a}}$ ), 9-epi-15- $\mathrm{F}_{1 \mathrm{t}}$-IsoP (8-iso- $\mathrm{PGF}_{1 \beta}$ ), 15- $\mathrm{F}_{2 \mathrm{t}}$-IsoP (8iso-PGF $2 \mathrm{a}$ ), and $15-\mathrm{E}_{2 \mathrm{t}}-\mathrm{IsoP}$ (8-iso-PGE $\mathrm{E}_{2}$ ) was documented in these vessels. Isoprostane contraction was mediated through TP receptors and the signaling pathways involved tyrosine kinases(s) and Rho kinase. Interestingly, no developmental changes on the pulmonary vascular responsiveness to the TP-receptor agonist U46619 were observed. Therefore, age-related decreases in pulmonary vascular sensitivity appear to be unique for isoprostanes. The E- and the F-ring isoprostanes also induced TP-mediated contraction of neonatal and 2-week-old piglet mesenteric arteries that decreased with postnatal age.

Occupancy (with the agonist U46619) or blockade (with the antagonist SQ 29,548) of TP receptors unmasked a relaxant effect of $15-\mathrm{E}_{2 \mathrm{t}}$-IsoP (8-iso-PGE $\mathrm{E}_{2}$ ) in the PA (chapter VII). This effect was not observed for the other E- or F-ring isoprostanes tested. 15- $\mathrm{E}_{2 \mathrm{t}^{-}}$ IsoP-mediated PA relaxation increased with postnatal age, was partially endotheliumdependent and appeared to involve stimulation of EP receptors and production of NO. The age-dependent increase that was observed for $15-\mathrm{E}_{2 \mathrm{t}}-\mathrm{IsoP}-\mathrm{elicited}$ relaxation is, as discussed above, a common finding for vasodilators acting through the NO-sGC-cGMP pathway. However, we found that the relaxant efficacy of $\mathrm{PGE}_{1}, \mathrm{PGE}_{2}$, and misoprostol, as well as the potency of the adenylate cyclase stimulator forskolin, also increased with age. This suggests that also the adenylate cyclase/cAMP pathway undergoes significant alterations during the first days of postnatal life. Alternatively the developmental changes in relaxation might be related to alterations in the 
responsiveness to U46619, the TP receptor agonist used to contract the arteries in our experiments. Cogolludo et al. (21) have shown that two pathways are involved in TPreceptor induced vasoconstriction in piglet PA. First, the activation of protein kinase $\mathrm{C}$ (PKC) zeta leads to $\mathrm{K}_{\mathrm{V}}$ channel blockade, membrane depolarization, L-type $\mathrm{Ca}^{2+}$ channel activation, and increase in $\left[\mathrm{Ca}^{2+}\right]_{i}$. Second, a RhoA/Rho kinase-mediated $\mathrm{Ca}^{2+}$ sensitization pathway. This second pathway contributes more importantly to TPmediated contraction in the 2-wk-old animals than in the newborns (21). $\mathrm{Ca}^{2+}$ desensitization is mediated by both cGMP- and cAMP-dependent protein kinases (85). Therefore, the maturational shift from $\mathrm{PKC}$ and voltage-gated $\mathrm{K}^{+}$channels to RhoA/Rho kinase in TP receptor-mediated pulmonary vasoconstriction might be partially responsible for the developmental increase in cGMP- and cAMP-mediated relaxation.

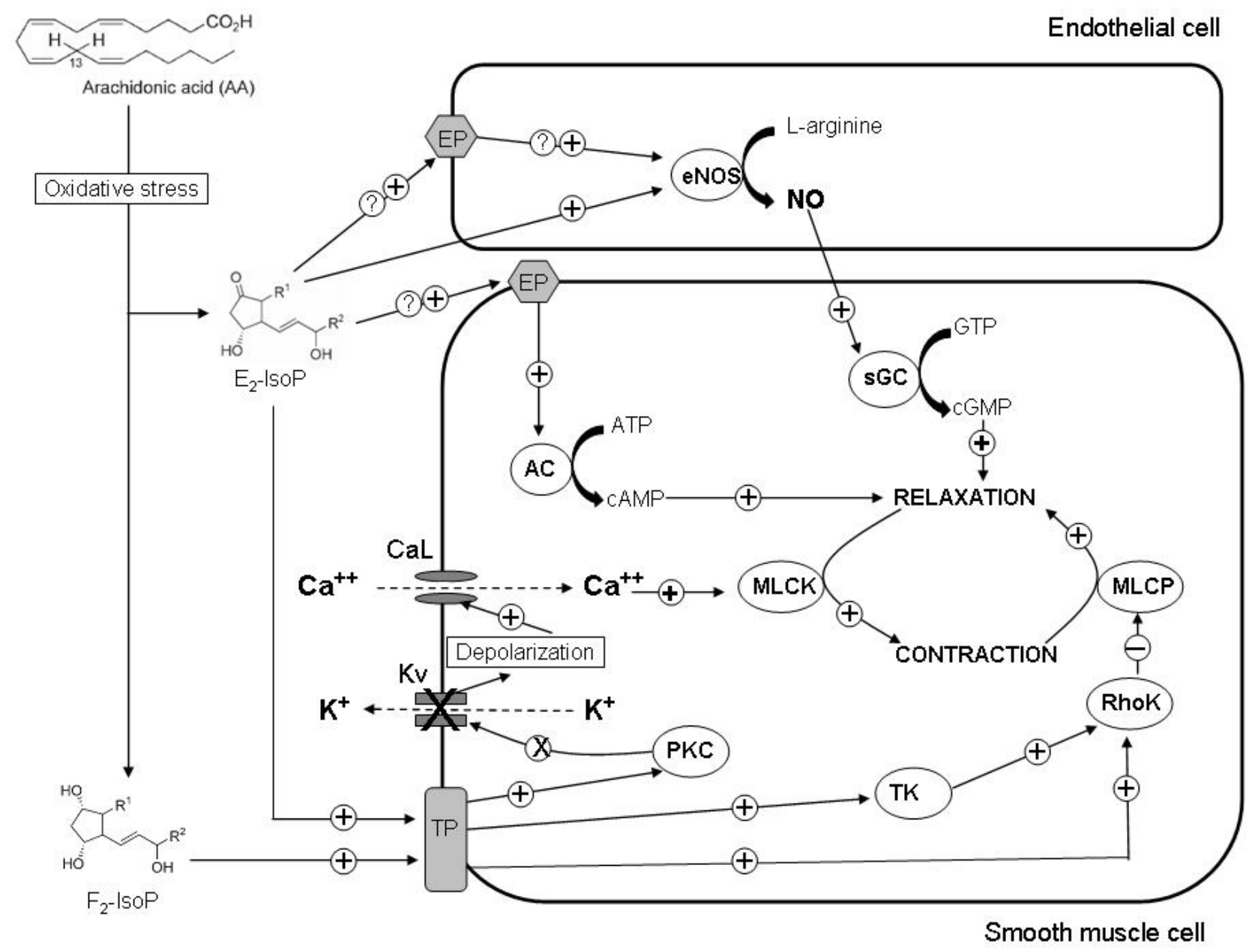

Figure 2. Mechanisms of action of isoprostanes in piglet pulmonary arteries. 


\section{Future Perspectives}

\subsection{Other causes of disminished NO bioactity: eNOS uncoupling and naturally ocurring NOS inhibitors}

There are four principle causes of diminished NO bioactivity: decreased expression and/or activity of the eNOS enzyme, eNOS uncoupling, enhanced breakdown or scavenging of $\mathrm{NO}$ and impaired transmission of NO-mediated signaling events (failure of the effector mechanisms) (18). As discussed above, the role of some of these factors on the neonatal impairment of NO bioactivity in pulmonary arteries has been extensively analyzed. However, the information about other putative factors (such as eNOS uncoupling or naturally occurring NOS inhibitors) is more limited.

The activity of eNOS might be affected at multiple levels, including subcellular localization, interaction with substrate and co-factors, posttranslational modifications, and interaction with several regulatory proteins (34). Reduced availability of the substrate L-arginine, or the cofactor $\mathrm{BH}_{4}$ ), as well as changes in HSP90-eNOS interactions or Thr495 dephosphorylation can uncouple eNOS and result in the production of superoxide instead of NO $(13,34)$. Uncoupling transforms eNOS from a protective enzyme to a oxidative stress contributor and appears to play an important role in the pathogenesis of various cardiovascular diseases (35). Interestingly, upon stimulation of eNOS, fetal pulmonary artery endothelial cells produced only NO but eNOS becomes uncoupled after birth, leading to production of both NO and superoxide (55). This suggests that eNOS uncoupling might participate in the developmental adaptation of the pulmonary vascular system.

Asymmetric dimethylarginine (ADMA) and $N^{\mathrm{G}}$-monomethyl- L-arginine (L-NMMA) are naturally occurring inhibitors of NOS which compete with the NO substrate L-arginine $(77,90)$. The concentration of ADMA in the human circulation is approximately 10 times greater than that of L-NMMA. ADMA has emerged as an early marker and/or mediator of endothelial dysfunction and it has been proved to be a novel, independent risk factor of cardiovascular and metabolic diseases (26). ADMA is present in the urine of healthy newborn infants, and gradually declines to become undetectable by five days of age (73). ADMA is metabolised to citrulline by the dimethylarginine dimethylaminohydrolase enzymes (DDAH I and II) both of which are highly expressed in the fetal lung. Each isoform is developmentally regulated and DDAH II activity increases rapidly immediately after birth $(9,52)$. Therefore, it has been suggested that ADMA and DDAH could play a significant role in the regulation of the fetal and newborn pulmonary vasculature (37). 


\subsection{New therapeutic agents for PPHN: sGC stimulators/activators and Rho-kinase inhibitors}

Recent studies indicate that NO-independent sGC stimulators/activators and Rhokinase inhibitors can cause pulmonary vasodilation and augment responsiveness to inhaled NO in the laboratory, suggesting a future role for these strategies in neonates with PPHN who fail to respond to other therapies $(3,27-29,71)$

NO-independent but heme-dependent stimulators of sGC, as well as NO- and hemeindependent sGC activators, are emerging as valuable tools that could help to elucidate the physiology and pathophysiology of the NO-sGC-cGMP pathway in more detail $(19,31,86)$. The first group of these compounds comprises the heme-dependent sGC stimulators including YC-1, BAY 41-2272, BAY 41-8543, A-350619 and CFM1571. These compounds show a strong synergy with NO and a loss of activation after oxidation or removal of the prosthetic heme moiety of $\operatorname{sGC}(19,31,86)$. However, more recent studies reveal that $\mathrm{YC}-1$ can activate $\mathrm{sGC}$ with both heme-dependent and heme-independent mechanisms (54). The second group comprises the sGC activators, including BAY 58-2667, HMR-1766 and S-3448, which have been found to require neither NO nor heme, and demonstrate even more pronounced action on the oxidized form of $\operatorname{sGC}(31,86)$. This unique characteristic can be explained by a mechanistic model in which the sGC prosthetic heme is replaced by the sGC activator (31). These compounds therefore represents an entirely new pharmacological principle and are now entering clinical development.

Activation of the RhoA/Rho-kinase pathway can induce $\mathrm{Ca}^{2+}$ sensitization, a phenomenon in which sustained vasoconstriction occurs, independent of ongoing increases in cytosolic $\mathrm{Ca}^{2+}$ smooth muscle $(22,85,98)$. Studies on the role of Rho kinase in the regulation of vascular tone and structure have been aided by the development of selective Rho kinase inhibitors. Results with the prototypical inhibitors, fasudil, and Y-27632, have provided support for the concept that Rho kinase plays an important role in the regulation of baseline tone and vasoconstrictor responses in the pulmonary vascular bed $(3,66)$. In the present Thesis we demonstrated that the RhoA/Rho-kinase pathway is involved in isoprostane-mediated contraction of the pulmonary arteries (chapter VI). Rho-kinase inhibitors cause potent and sustained pulmonary vasodilation in fetal sheep, suggesting that high Rho-kinase activity maintains elevated PVR in utero $(3,71)$. Maturational changes in the RhoA/Rho-kinase pathway have been also described in newborn piglet pulmonary arteries and postnatal exposure to hypoxia induced actin cytoskeleton remodelling associated with Rho activation in PASMCs from these animals (10). A Rho-kinase inhibitor prevented the increase in PVR associated with the exposure to acute or 
chronic hypoxia in neonatal rats (57). Therefore, Rho kinase inhibitors appear as promising therapeutic agents for neonatal and postnatal pulmonary hypertension (3).

\subsection{The cross-talk between cGMP- and cAMP-mediated relaxation}

Cyclic cGMP and cAMP are major second messengers that play a key role in eliciting vascular relaxation after stimulation of the corresponding upstream receptors. A cross-talk between the cGMP and cAMP pathways has been proposed to exist. This can involve activation of eNOS by cAMP, cross-activation of PKG by cAMP and of cAMP-dependent protein kinase (PKA) by cGMP as well as actions of the nucleotides or the kinases on PDEs (17). PDE2 and PDE3 are both cAMP-selective, but they have significant relevance to the NO/cGMP transduction system since the rate of cAMP hydrolysis by PDE2 and PDE3 is stimulated and inhibited, respectively, by cGMP (42). In the present Thesis we demonstrated an age-related increase in the pulmonary relaxation evoked by either the NO/sGC/cGMP (chapters II and III) and the adenylate cyclase/cAMP (chapter VII) pathways. The putative cross-talk between the two pathways of relaxation during the first days of postnatal life remains to be investigated.

\subsection{Developmental trajectory of pulmonary vascular reactivity under oxygen stress}

Prenatal and postnatal exposure to chronic hypoxia compromises the development of pulmonary vasculature and impairs adaptation to extrauterine life $(39,92)$. Permanent, irreversible hypoxic damage to vasculature can occur, particularly in the immature lungs of preterm infants (39). As extensively discussed above, endotheliumdependent relaxation via the NO pathway is normally absent or poor at birth and the response increases during the first days of postnatal life. Chronic postnatal hypoxia abolishes this developmental increase in NO-mediated relaxation $(33,39)$ but the mechanisms underlying this impairment remain to be investigated.

It has been shown that hyperoxia, even for short periods and particularly following a previous hypoxic insult, contributes to the development of several neonatal morbidities $(15,30,81-83)$. In this regard, oxygen administration in the delivery room has become a matter of discussion in the last years $(30,82,83,89)$. Supplemental $\mathrm{O}_{2}$ is detrimental to the development of both airways and pulmonary vasculature. Our present understanding of cellular mechanisms by which NO and isoprostanes participate in the manifestations of oxygen toxicity, or in the countervailing processes 
that defend against it, is incomplete (6). A significant increase in pulmonary arterial muscle force generation and a reduced endothelium-dependent relaxation has been documented in the $60 \% \mathrm{O}_{2}$ chronically-exposed newborn rat (11). Isoprostanes have been directly implicated in this model of hyperoxia-induced pulmonary hypertension. The mechanism by which this occurs involves lipid peroxidation-dependent isoprostane release that induces endothelin-1 generation (45). Chronic $\mathrm{O}_{2}$ exposure in the presence of an isoprostane scavenger abrogates the pulmonary hypertension, but not the lung parenchymal changes in this experimental model (51). In addition, the pulmonary vascular response to $15-\mathrm{F}_{2 \mathrm{t}}$-IsoP is altered following chronic $\mathrm{O}_{2}$ exposure. Thus, not only a hyperoxia regimen, similar to what is used clinically, induces isoprostane release, but it also potentiates the pulmonary vasoconstrictive effects of these metabolites accounting for the maintenance of a high pulmonary vascular resistance (11). Whether neonatal pathological conditions with increased oxidative stress result in alterations not only in the production of isoprostanes but also in the vascular response to these compounds in other species, remains to be studied.

\subsection{Postnatal changes in hypoxic pulmonary vasoconstriction}

Hypoxic pulmonary vasoconstriction (HPV) is a highly conserved adaptive physiological mechanism that optimizes $\mathrm{O}_{2}$ saturation of pulmonary venous blood by increasing PVR in poorly aerated regions of the lung, thereby diverting pulmonary blood flow to the better ventilated ones $(1,80,95-97,100,101)$. HPV reflects an intrinsic property of the pulmonary artery smooth muscle cells. However, despite intensive research, the molecular basis of HPV remains one of the most enduring mysteries of cell physiology and several, sometimes contradictory, hypotheses have emerged to explain it $(1,95$, 97). Nevertheless, there is consensus about the involvement of a putative redox-based $\mathrm{O}_{2}$ sensor, i.e. the mitochondrial electron transport chain (mETC) $(50,58,70,95,97)$ and/or the membrane NADPH oxidase $(95,101)$, regulating the activity of effector proteins and there is a large body of evidence indicating a role of reactive $\mathrm{O}_{2}$ species (ROS) as signalling intermediates $(96,97,100,101)$. Voltage-gated $\mathrm{K}^{+}\left(\mathrm{K}_{\mathrm{V}}\right)$ channels are known effector proteins which are inhibited by hypoxia, leading to cell membrane depolarization and opening of L-type voltage-operated $\mathrm{Ca}^{2+}$ channels (VOCC) $(7,16$, 23, 43, 53, 75). Additional effectors include store-operated $\mathrm{Ca}^{2+}$ channels (SOCC) leading to increased capacitative $\mathrm{Ca}^{2+}$ entry and Rho kinase, which is involved in $\mathrm{Ca}^{2+}$ sensitization $(78,79,87,94,99,102)$

The developmental aspects of HPV have been studied using a variety of species, ages and methods $(23,24,32,36,69,74,76)$. These studies have yielded variable results and describe developmental increases $(23,24,32,36,69)$, decreases (76), or no changes (74) in the pulmonary vascular response to acute hypoxia. The specific 
postnatal developmental trajectories of the different mediators involved in HPV sensing/signalling remains to be investigated. In addition, new HPV sensors/transducers such as hydrogen sulfide (68), or ceramide (20) have recently been proposed and the study of their putative role in neonatal pulmonary arteries is warranted.

\subsection{Isoprostanes and ductus arteriosus}

COX-mediated metabolites of arachidonic acid, and more particularly E-series PGs, have a profound relaxant effect in the DA. Accordingly, they are used as standard therapy to treat some forms of congenital heart disease in which survival of the newborn is dependent on persistent patency of the DA. On the other hand, patent DA is a major indication for use of COX inhibitors in preterm infants (84). As discussed elsewhere, isoprostanes are PG-like bioactive molecules generated via nonenzymatic peroxidation of arachidonic acid by free radicals and reactive oxygen species. Surprisingly, the vascular actions of isoprostanes in the DA have not been studied so far. Therefore, further investigation of the role of IsoPs in the regulation of ductus arteriosus patency during fetal life, and its closure immediately after birth is warranted. It would be also of interest to analyze whether COX inhibition for the treatment of patent DA alters isoprostane production by increasing substrate availability.

\subsection{Inhibition of isoprostane production. Other metabolites from polyunsaturated fatty acids.}

Given the potential role of isoprostanes in multiple diseases, the development of tools directed to inhibit their synthesis or their biological effects is an appealing therapeutic strategy. Part of their biological effects can be prevented by TP-receptor antagonists. However, the nonenzymatic nature of their synthetic process is a challenge to achieve synthesis inhibition in a targeted manner. Finally, the biological significance of other metabolites formed by free-radical pathways from polyunsaturated fatty acids, such as isothromboxanes, isoketals, isofurans, neuroprostanes, or non-arachidonic acidderived isoprostanes requires further investigation (44).

\section{References}

1. Aaronson PI, Robertson TP, Knock GA, Becker S, Lewis TH, Snetkov V, and Ward JP. Hypoxic pulmonary vasoconstriction: mechanisms and controversies. J Physiol 570: 53-58, 2006. 
2. Abman SH. Abnormal vasoreactivity in the pathophysiology of persistent pulmonary hypertension of the newborn. Pediatr Rev 20: e103-109, 1999.

3. Abman SH. Recent advances in the pathogenesis and treatment of persistent pulmonary hypertension of the newborn. Neonatology 91: 283-290, 2007.

4. Abman SH, Chatfield BA, Rodman DM, Hall SL, and McMurtry IF. Maturational changes in endothelium-derived relaxing factor activity of ovine pulmonary arteries in vitro. Am $J$ Physiol 260: L280-285, 1991.

5. Abman SH and Stevens T. Perinatal pulmonary vasoregulation: implications for the pathophysiology and treatment of neonatal pulmonary hypertension. In: Tissue Oxygen Deprivation: Developmental, Molecular and Integrative Function, edited by Haddad G and Lister G. New York: Marcel Dekker, 1996, p. 367-432.

6. Allen BW, Demchenko IT, and Piantadosi CA. Two faces of nitric oxide: implications for cellular mechanisms of oxygen toxicity. J Appl Physiol 106: 662-667, 2009.

7. Archer SL, Wu XC, Thebaud B, Nsair A, Bonnet S, Tyrrell B, McMurtry MS, Hashimoto K, Harry G, and Michelakis ED. Preferential expression and function of voltagegated, $\mathrm{O} 2$-sensitive $\mathrm{K}+$ channels in resistance pulmonary arteries explains regional heterogeneity in hypoxic pulmonary vasoconstriction: ionic diversity in smooth muscle cells. Circ Res 95: 308-318, 2004.

8. Arrigoni FI, Hislop AA, Pollock JS, Haworth SG, and Mitchell JA. Birth upregulates nitric oxide synthase activity in the porcine lung. Life Sci 70: 1609-1620, 2002.

9. Arrigoni FI, Vallance P, Haworth SG, and Leiper JM. Metabolism of asymmetric dimethylarginines is regulated in the lung developmentally and with pulmonary hypertension induced by hypobaric hypoxia. Circulation 107: 1195-1201, 2003.

10. Bailly $\mathbf{K}$, Ridley AJ, Hall SM, and Haworth SG. RhoA activation by hypoxia in pulmonary arterial smooth muscle cells is age and site specific. Circ Res 94: 1383-1391, 2004.

11. Belik J, Jankov RP, Pan J, Yi M, Chaudhry I, and Tanswell AK. Chronic O2 exposure in the newborn rat results in decreased pulmonary arterial nitric oxide release and altered smooth muscle response to isoprostane. J Appl Physiol 96: 725-730, 2004.

12. Belik J, Jankov RP, Pan J, Yi M, Pace-Asciak CR, and Tanswell AK. Effect of 8isoprostaglandin F2alpha on the newborn rat pulmonary arterial muscle and endothelium. $J$ Appl Physiol 95: 1979-1985, 2003.

13. Belik J, Jerkic M, McIntyre BA, Pan J, Leen J, Yu LX, Henkelman RM, Toporsian $\mathbf{M}$, and Letarte $\mathbf{M}$. Age-dependent endothelial nitric oxide synthase uncoupling in pulmonary arteries of endoglin heterozygous mice. Am J Physiol 297: L1170-1178, 2009.

14. Belik J, Kerc E, and Pato MD. Rat pulmonary arterial smooth muscle myosin light chain kinase and phosphatase activities decrease with age. Am J Physiol 290: L509-516, 2006.

15. Bland RD. Neonatal chronic lung disease in the post-surfactant era. Biol Neonate 88: 181-191, 2005.

16. Bonnet $\mathbf{P}$, Vandier $\mathbf{C}$, Cheliakine C, and Garnier D. Hypoxia activates a potassium current in isolated smooth muscle cells from large pulmonary arteries of the rabbit. Exp Physiol 79: 597-600, 1994.

17. Bonnevier J, Fassler R, Somlyo AP, Somlyo AV, and Arner A. Modulation of Ca2+ sensitivity by cyclic nucleotides in smooth muscle from protein kinase G-deficient mice. $J$ Biol Chem 279: 5146-5151, 2004.

18. Braam B and Verhaar MC. Understanding eNOS for pharmacological modulation of endothelial function: a translational view. Curr Pharm Design 13: 1727-1740, 2007.

19. Bryan NS, Bian K, and Murad F. Discovery of the nitric oxide signaling pathway and targets for drug development. Front Biosci 14: 1-18, 2009.

20. Cogolludo A, Moreno L, Frazziano G, Moral-Sanz J, Menendez C, Castaneda J, Gonzalez C, Villamor E, and Perez-Vizcaino F. Activation of neutral sphingomyelinase is involved in acute hypoxic pulmonary vasoconstriction. Cardiovasc Res 82: 296-302, 2009.

21. Cogolludo A, Moreno L, Lodi F, Tamargo J, and Perez-Vizcaino F. Postnatal maturational shift from PKCzeta and voltage-gated $\mathrm{K}+$ channels to RhoA/Rho kinase in pulmonary vasoconstriction. Cardiovasc Res 66: 84-93, 2005.

22. Cogolludo A, Moreno L, and Villamor E. Mechanisms controlling vascular tone in pulmonary arterial hypertension: implications for vasodilator therapy. Pharmacology 79: 65-75, 2007.

23. Cornfield DN, Saqueton CB, Porter VA, Herron J, Resnik E, Haddad IY, and Reeve HL. Voltage-gated $\mathrm{K}(+)$-channel activity in ovine pulmonary vasculature is developmentally regulated. Am J Physiol 278: L1297-1304, 2000.

24. Custer JR and Hales CA. Influence of alveolar oxygen on pulmonary vasoconstriction in newborn lambs versus sheep. Am Rev Respir Dis 132: 326-331, 1985.

25. Dawes GS and Mott JC. The vascular tone of the foetal lung. $J$ Physiol 164: 465-477, 1962.

26. De Gennaro Colonna V, Bianchi M, Pascale V, Ferrario P, Morelli F, Pascale W, Tomasoni L, and Turiel M. Asymmetric dimethylarginine (ADMA): an endogenous inhibitor of 
nitric oxide synthase and a novel cardiovascular risk molecule. Med Sci Monit 15: RA91-101, 2009.

27. Deruelle P, Balasubramaniam V, Kunig AM, Seedorf GJ, Markham NE, and Abman SH. BAY 41-2272, a direct activator of soluble guanylate cyclase, reduces right ventricular hypertrophy and prevents pulmonary vascular remodeling during chronic hypoxia in neonatal rats. Biol Neonate 90: 135-144, 2006.

28. Deruelle P, Grover TR, and Abman SH. Pulmonary vascular effects of nitric oxidecGMP augmentation in a model of chronic pulmonary hypertension in fetal and neonatal sheep. Am J Physiol 289: L798-806, 2005.

29. Deruelle P, Grover TR, Storme L, and Abman SH. Effects of BAY 41-2272, a soluble guanylate cyclase activator, on pulmonary vascular reactivity in the ovine fetus. Am $J$ Physiol 288: L727-733, 2005.

30. Escrig R, Arruza L, Izquierdo I, Villar G, Saenz P, Gimeno A, Moro M, and Vento M. Achievement of targeted saturation values in extremely low gestational age neonates resuscitated with low or high oxygen concentrations: a prospective, randomized trial. Pediatrics 121: 875-881, 2008.

31. Evgenov OV, Pacher P, Schmidt PM, Hasko G, Schmidt HH, and Stasch JP. NOindependent stimulators and activators of soluble guanylate cyclase: discovery and therapeutic potential. Nat Rev Drug Discov 5: 755-768, 2006.

32. Fike CD and Hansen TN. Hypoxic vasoconstriction increases with postnatal age in lungs from newborn rabbits. Circ Res 60: 297-303, 1987.

33. Fike CD, Pfister SL, Kaplowitz MR, and Madden JA. Cyclooxygenase contracting factors and altered pulmonary vascular responses in chronically hypoxic newborn pigs. $J$ Appl Physiol 92: 67-74, 2002.

34. Fleming I. Molecular mechanisms underlying the activation of eNOS. Pflügers Arch, 2009.

35. Forstermann $\mathbf{U}$ and Munzel T. Endothelial nitric oxide synthase in vascular disease: from marvel to menace. Circulation 113: 1708-1714, 2006.

36. Gordon JB, Tod ML, Wetzel RC, McGeady ML, Adkinson NF, Jr., and Sylvester JT. Age-dependent effects of indomethacin on hypoxic vasoconstriction in neonatal lamb lungs. Pediatr Res 23: 580-584, 1988.

37. Haworth SG. Pulmonary endothelium in the perinatal period. Pharmacol Rep 58 Suppl: 153-164, 2006.

38. Haworth SG and Hislop AA. Adaptation of the pulmonary circulation to extra-uterine life in the pig and its relevance to the human infant. Cardiovasc Res 15: 108-119, 1981.

39. Haworth SG and Hislop AA. Lung development-the effects of chronic hypoxia. Semin Neonatol 8: 1-8, 2003.

40. Hislop AA, Mak JC, Reader JA, Barnes PJ, and Haworth SG. Muscarinic receptor subtypes in the porcine lung during postnatal development. Eur J Pharmacol 359: 211-221, 1998.

41. Hislop AA, Springall DR, Buttery LD, Pollock JS, and Haworth SG. Abundance of endothelial nitric oxide synthase in newborn intrapulmonary arteries. Arch Dis Child Fetal Neonatal 73: F17-21, 1995.

42. Hobbs AJ and Ignarro LJ. Nitric oxide-cyclic GMP signal transduction system. Methods Enzymol 269: 134-148, 1996.

43. Hong Z, Weir EK, Varghese A, and Olschewski A. Effect of normoxia and hypoxia on $\mathrm{K}(+)$ current and resting membrane potential of fetal rabbit pulmonary artery smooth muscle. Physiol Res 54: 175-184, 2005.

44. Jahn U, Galano JM, and Durand T. Beyond prostaglandins--chemistry and biology of cyclic oxygenated metabolites formed by free-radical pathways from polyunsaturated fatty acids. Angew Chem Int Ed Engl 47: 5894-5955, 2008.

45. Jankov RP, Luo X, Cabacungan J, Belcastro $\mathbf{R}$, Frndova $\mathbf{H}$, Lye SJ, and Tanswell AK. Endothelin-1 and O2-mediated pulmonary hypertension in neonatal rats: a role for products of lipid peroxidation. Pediatr Res 48: 289-298, 2000.

46. Janssen LJ. Isoprostanes and lung vascular pathology. Am J Respir Cell Mol Biol 39: 383-389, 2008.

47. Janssen LJ, Catalli A, and Helli P. The pulmonary biology of isoprostanes. Antioxid Redox Signal 7: 244-255, 2005.

48. Jourdan KB, Evans TW, Curzen NP, and Mitchell JA. Evidence for a dilator function of 8-iso prostaglandin F2 alpha in rat pulmonary artery. Brit J Pharmacol 120: 1280-1285, 1997.

49. Kamada Y, Jenkins GJ, Lau M, Dunbar AY, Lowe ER, and Osawa Y. Tetrahydrobiopterin depletion and ubiquitylation of neuronal nitric oxide synthase. Brain Res Mol Brain Res 142: 19-27, 2005. 
50. Leach RM, Hill HM, Snetkov VA, Robertson TP, and Ward JP. Divergent roles of glycolysis and the mitochondrial electron transport chain in hypoxic pulmonary vasoconstriction of the rat: identity of the hypoxic sensor. $J$ Physiol 536: 211-224, 2001.

51. Lopez-Lopez JG, Perez-Vizcaino F, Cogolludo AL, Ibarra M, Zaragoza-Arnaez F, and Tamargo J. Nitric oxide- and nitric oxide donors-induced relaxation and its modulation by oxidative stress in piglet pulmonary arteries. Brit J Pharmacol 133: 615-624, 2001.

52. MacAllister RJ, Parry H, Kimoto M, Ogawa T, Russell RJ, Hodson H, Whitley GS, and Vallance $\mathbf{P}$. Regulation of nitric oxide synthesis by dimethylarginine dimethylaminohydrolase. Brit J Pharmacol 119: 1533-1540, 1996.

53. MacLean MR, McCulloch KM, and Baird M. Effects of pulmonary hypertension on vasoconstrictor responses to endothelin-1 and sarafotoxin S6C and on inherent tone in rat pulmonary arteries. J Cardiovasc Pharmacol 26: 822-830, 1995.

54. Martin E, Lee YC, and Murad F. YC-1 activation of human soluble guanylyl cyclase has both heme-dependent and heme-independent components. Proc Natl Acad Sci USA 98: 12938-12942, 2001.

55. Mata-Greenwood E, Jenkins C, Farrow KN, Konduri GG, Russell JA, Lakshminrusimha S, Black SM, and Steinhorn RH. eNOS function is developmentally regulated: uncoupling of eNOS occurs postnatally. Am J Physiol 290: L232-241, 2006.

56. McCormack DG, Salonen RO, and Barnes PJ. Effect of sensory neuropeptides on canine bronchial and pulmonary vessels in vitro. Life Sci 45: 2405-2412, 1989.

57. McNamara PJ, Murthy P, Kantores C, Teixeira L, Engelberts D, van Vliet T, Kavanagh BP, and Jankov RP. Acute vasodilator effects of Rho-kinase inhibitors in neonatal rats with pulmonary hypertension unresponsive to nitric oxide. Am J Physiol 294: L205-213, 2008.

58. Michelakis ED, Hampl V, Nsair A, Wu X, Harry G, Haromy A, Gurtu R, and Archer SL. Diversity in mitochondrial function explains differences in vascular oxygen sensing. Circ Res 90: 1307-1315, 2002 .

59. Milne GL and Morrow JD. Isoprostanes and related compounds: update 2006. Antioxid Redox Signal 8: 1379-1384, 2006.

60. Milne GL, Yin H, and Morrow JD. Human biochemistry of the isoprostane pathway. $J$ Biol Chem 283: 15533-15537, 2008.

61. Moreno L, Losada B, Cogolludo A, Lodi F, Lugnier C, Villamor E, Moro M, Tamargo $\mathbf{J}$, and Perez-Vizcaino F. Postnatal maturation of phosphodiesterase 5 (PDE5) in piglet pulmonary arteries: activity, expression, effects of PDE5 inhibitors, and role of the nitric oxide/cyclic GMP pathway. Pediatr Res 56: 563-570, 2004

62. Morrow JD. The isoprostanes - unique products of arachidonate peroxidation: their role as mediators of oxidant stress. Curr Pharm Des 12: 895-902, 2006.

63. Morrow JD, Harris TM, and Roberts LJ, 2nd. Noncyclooxygenase oxidative formation of a series of novel prostaglandins: analytical ramifications for measurement of eicosanoids. Anal Biochem 184: 1-10, 1990.

64. Morrow JD, Hill KE, Burk RF, Nammour TM, Badr KF, and Roberts LJ, 2nd. A series of prostaglandin F2-like compounds are produced in vivo in humans by a noncyclooxygenase, free radical-catalyzed mechanism. Proc Natl Acad Sci USA 87: 9383-9387, 1990. 65. Mueed I, Tazzeo T, Liu C, Pertens E, Zhang Y, Cybulski I, Semelhago L, Noora J, Lamy A, Teoh $\mathbf{K}$, Chu $\mathbf{V}$, and Janssen $\mathbf{L}$. Isoprostanes constrict human radial artery by stimulation of thromboxane receptors, $\mathrm{Ca} 2+$ release, and RhoA activation. J Tthorac Cardiovasc Surg 135: 131-138, 2008.

66. Murthy SN, Nossaman BD, and Kadowitz PJ. New Approaches to the Treatment of Pulmonary Hypertension: From Bench to Bedside. Cardiol Rev 18: 76-84, 2010.

67. Oliveira L, Stallwood NA, and Crankshaw DJ. Effects of some isoprostanes on the human umbilical artery in vitro. Brit J Pharmacol 129: 509-514, 2000.

68. Olson KR, Dombkowski RA, Russell MJ, Doellman MM, Head SK, Whitfield NL, and Madden JA. Hydrogen sulfide as an oxygen sensor/transducer in vertebrate hypoxic vasoconstriction and hypoxic vasodilation. J Exp Biol, 209: 4011-4023, 2006.

69. Owen-Thomas JB and Reeves JT. Hypoxia and pulmonary arterial pressure in the rabbit. J Physiol 201: 665-672, 1969.

70. Paddenberg $\mathbf{R}$, Ishaq B, Goldenberg A, Faulhammer P, Rose F, Weissmann N, Braun-Dullaeus RC, and Kummer W. Essential role of complex II of the respiratory chain in hypoxia-induced ROS generation in the pulmonary vasculature. Am J Physiol Lung Cell Mol Physiol 284: L710-719, 2003.

71. Parker TA, Roe G, Grover TR, and Abman SH. Rho kinase activation maintains high pulmonary vascular resistance in the ovine fetal lung. Am J Physiol 291: L976-982, 2006.

72. Perez-Vizcaino F, Lopez-Lopez JG, Santiago R, Cogolludo A, Zaragoza-Arnaez F, Moreno L, Alonso MJ, Salaices $\mathbf{M}$, and Tamargo J. Postnatal maturation in nitric oxideinduced pulmonary artery relaxation involving cyclooxygenase-1 activity. Am J Physiol Lung Cell Mol Physiol 283: L839-848, 2002. 
73. Pierce CM, Krywawych S, and Petros AJ. Asymmetric dimethyl arginine and symmetric dimethyl arginine levels in infants with persistent pulmonary hypertension of the newborn. Pediatr Crit Care Med 5: 517-520, 2004.

74. Redding GJ, McMurtry I, and Reeves JT. Effects of meclofenamate on pulmonary vascular resistance correlate with postnatal age in young piglets. Pediatr Res 18: 579-583, 1984.

75. Reeve HL, Weir EK, Archer SL, and Cornfield DN. A maturational shift in pulmonary $\mathrm{K}+$ channels, from Ca2+ sensitive to voltage dependent. Am J Physiol 275: L1019-1025, 1998.

76. Reeves JT and Leathers JE. Circulatory Changes Following Birth of the Calf and the Effect of Hypoxia. Circ Res 15: 343-354, 1964.

77. Richir MC, Siroen MP, van Elburg RM, Fetter WP, Quik F, Nijveldt RJ, Heij HA, Smit BJ, Teerlink T, and van Leeuwen PA. Low plasma concentrations of arginine and asymmetric dimethylarginine in premature infants with necrotizing enterocolitis. $\mathrm{Br} J \mathrm{Nutr}$ 97: 906-911, 2007.

78. Robertson TP, Dipp M, Ward JP, Aaronson PI, and Evans AM. Inhibition of sustained hypoxic vasoconstriction by Y-27632 in isolated intrapulmonary arteries and perfused lung of the rat. Brit J Pharmacol 131: 5-9, 2000.

79. Robertson TP, Hague D, Aaronson PI, and Ward JP. Voltage-independent calcium entry in hypoxic pulmonary vasoconstriction of intrapulmonary arteries of the rat. $J$ Physiol 525 Pt 3: 669-680, 2000.

80. Russell MJ, Dombkowski RA, and Olson KR. Effects of hypoxia on vertebrate blood vessels. J Exp Zool Part A Ecol Genet Physiol 309: 55-63, 2008.

81. Saugstad OD. Bronchopulmonary dysplasia-oxidative stress and antioxidants. Semin Neonatol 8: 39-49, 2003.

82. Saugstad OD. Optimal oxygenation at birth and in the neonatal period. Neonatology 91: 319-322, 2007.

83. Saugstad OD, Ramji S, and Vento M. Oxygen for newborn resuscitation: how much is enough? Pediatrics 118: 789-792, 2006.

84. Smith GC. The pharmacology of the ductus arteriosus. Pharmacol Rev 50: 35-58, 1998.

85. Somlyo AP and Somlyo AV. Ca2+ sensitivity of smooth muscle and nonmuscle myosin II: modulated by G proteins, kinases, and myosin phosphatase. Physiol Rev 83: 1325-1358, 2003.

86. Stasch JP and Hobbs AJ. NO-independent, haem-dependent soluble guanylate cyclase stimulators. Handb Exp Pharmacol: 277-308, 2009.

87. Stenmark KR, Fagan KA, and Frid MG. Hypoxia-induced pulmonary vascular remodeling: cellular and molecular mechanisms. Circ Res 99: 675-691, 2006.

88. Truog WE, Norberg $\mathbf{M}$, and Thibeault DW. Effects of 8-epi-prostaglandin F2 alpha and U46,619 on pulmonary hemodynamics in piglets. Biol Neonate 71: 306-316, 1997.

89. Vento M, Asensi M, Sastre J, Garcia-Sala F, Pallardo FV, and Vina J. Resuscitation with room air instead of $100 \%$ oxygen prevents oxidative stress in moderately asphyxiated term neonates. Pediatrics 107: 642-647, 2001.

90. Vida G, Sulyok E, Ertl T, Martens-Lobenhoffer J, and Bode-Boger SM. Plasma asymmetric dimethylarginine concentration during the perinatal period. Neonatology 92: 8-13, 2007.

91. Villamor E, Kessels CG, Fischer MA, Bast A, de Mey JG, and Blanco CE. Role of superoxide anion on basal and stimulated nitric oxide activity in neonatal piglet pulmonary vessels. Pediatr Res 54: 372-381, 2003.

92. Villamor E, Kessels CG, Ruijtenbeek K, van Suylen RJ, Belik J, de Mey JG, and Blanco CE. Chronic in ovo hypoxia decreases pulmonary arterial contractile reactivity and induces biventricular cardiac enlargement in the chicken embryo. Am J Physiol Regul Integr Comp Physiol 287: R642-651, 2004.

93. Villamor E, Perez-Vizcaino F, Cogolludo AL, Conde-Oviedo J, Zaragoza-Arnaez F, Lopez-Lopez JG, and Tamargo J. Relaxant effects of carbon monoxide compared with nitric oxide in pulmonary and systemic vessels of newborn piglets. Pediatr Res 48: 546-553, 2000.

94. Wang Z, Jin N, Ganguli S, Swartz DR, Li L, and Rhoades RA. Rho-kinase activation is involved in hypoxia-induced pulmonary vasoconstriction. Am J Respir Cell Mol Biol 25: 628-635, 2001.

95. Ward JPT. Oxygen sensors in context. Biochim Biophys Acta 1777: 1-14, 2008.

96. Wardle RL, Gu M, Ishida Y, and Paul RJ. Rho kinase is an effector underlying Ca2+desensitizing hypoxic relaxation in porcine coronary artery. Am J Physiol Heart Circ Physiol 293: H23-29, 2007.

97. Waypa GB and Schumacker PT. Hypoxic pulmonary vasoconstriction: redox events in oxygen sensing. J Appl Physiol 98: 404-414, 2005.

98. Webb RC. Smooth muscle contraction and relaxation. Adv Physiol Educ 27: 201-206, 2003. 
99. Weigand L, Foxson J, Wang J, Shimoda LA, and Sylvester JT. Inhibition of hypoxic pulmonary vasoconstriction by antagonists of store-operated $\mathrm{Ca} 2+$ and nonselective cation channels. Am J Physiol 289: L5-L13, 2005.

100. Weir EK, Obreztchikova M, Vargese A, Cabrera JA, Peterson DA, and Hong $Z$. Mechanisms of oxygen sensing: a key to therapy of pulmonary hypertension and patent ductus arteriosus. Brit J Pharmacol 155: 300-307, 2008.

101. Wolin MS. Reactive oxygen species and the control of vascular function. Am J Physiol Heart Circ Physiol 296: H539-549, 2009.

102. Young S, Evans K, and Eu J. Nitric oxide modulates branching morphogenesis in fetal rat lung explants. Am J Physiol Lung Cell Mol Physiol 282: L379-L385, 2002.

103. Zhang Y, Pertens E, and Janssen LJ. 8-isoprostaglandin E(2) activates $\mathrm{Ca}(2+)$ dependent $\mathrm{K}(+)$ current via cyclic AMP signaling pathway in murine renal artery. Eu $J$ Pharmacol 520: 22-28, 2005.

104. Zhang Y, Tazzeo T, Hirota S, and Janssen LJ. Vasodilatory and electrophysiological actions of 8-iso-prostaglandin E2 in porcine coronary artery. J Pharmacol Exp Ther 305: 10541060, 2003. 


\section{Abbreviations}

$\mathrm{AC}$, adenylate cyclase

$\mathrm{ACh}$, acetylcholine

ADMA, asymmetric dimethylarginine

ANP, atrial natriuretic peptide

$\mathrm{BH}_{4}$, tetrahydrobiopterin

BPD, broncopulmonary displasia.

cAMP, cyclic adenosine-3', 5'-monophosphate

cAK, cAMP-dependent kinase

cGK, cGMP-dependent kinase

cGMP, cyclic guanosine-3', 5'-monophosphate

CLD, chronic lung disease

CNG, cyclic-nucleotide-gated channels

$\mathrm{CO}$, carbon monoxide

COX, cyclooxygenase

DA, ductus arteriosus

DDAH, dimethylarginine dimethylaminohydrolase

EDHF, endothelium-derived hyperpolarizing factor

EDNO, endothelium-derived nitric oxide

EDRF, endothelium-derived relaxing factor

eNOS, endothelial nitric oxide synthase

ET, endothelin

GTP, guanosine-5'-triphosphate

HIF, hypoxia inducible factor

HO, heme oxygenase

HPV, hypoxic pulmonary vasoconstriction

HSP90, heat shock protein 90

iNOS, inducible nitric oxide synthase

$\mathrm{IP}_{3}$, inositol 1,4,5-triphosphate 
IsoP, isoprostane

L-NAME, NG-Nitro-L-arginine methyl ester

L-NMMA, $N^{\mathrm{G}}$-monomethyl- L-arginine

MLCK, myosin light chain kinase

MLCP, myosin light chain phosphatase

NANC, nonadrenergic noncholinergic

nNOS, neuronal nitric oxide synthase

NO, nitric oxide

$\mathrm{NO}_{2}$, nitrogen dioxide

NOS, nitric oxide synthase

ODQ, 1H-[1,2,4]oxadiazolo[4,3-a]quinoxalin-1-one (sGC inhibitor)

$\mathrm{ONOO}^{-}$, peroxynitrite

PAF, platelet-activating factor

PAP, pulmonary artery pressure

PDE, phosphodiesterase

PG prostaglandin

pGS, particulate guanylate cyclase

$\mathrm{PGI}_{2}$, prostacyclin

$\mathrm{PKC}$, protein kinase $\mathrm{C}$

PPHN, persistent pulmonary hypertension of the newborn

PVR, pulmonary vascular resistance

RhoK, Rho kinase

sGC, soluble guanylate cyclase

SNP, sodium nitroprusside

SOCC, store-operated $\mathrm{Ca}^{2+}$ channels

SOD, superoxide dismutase

SVR, systemic vascular resistance

TK, tyrosine kinase

TX, thromboxane

VEGF, vascular endothelial growth factor 
VOCC, voltage-operated $\mathrm{Ca}^{2+}$ channels

VSM, vascular smooth muscle

VSMC, vascular smooth muscle cell 


\section{Samenvatting}

Succesvolle aanpassing van de pasgeborene aan postnatale omstandigheden vereist een dramatische overgang van de pulmonale circulatie van een conditie met hoge weerstand in utero naar een toestand van lage weerstand binnen enkele minuten na de geboorte. Wanneer de pulmonale circulatie niet in staat is deze normale transitie te ondergaan of te behouden, resulteert dit in persisterende pulmonale hypertensie van de neonaat (PPHN), een klinisch syndroom bestaande uit verscheidene neonatale cardiopulmonale afwijkingen die gekenmerkt worden door een aanhoudende verhoging van pulmonale vasculaire weerstand na de geboorte, leidend tot een rechts-links shunt van bloed door de ductus arteriosus of het foramen ovale en ernstige hypoxemie. Oorzaken van PPHN zijn onder meer afwijkingen betreffende de pulmonale vasculaire tonus, reactiviteit, groei en structuur. De aard van de onderliggende defecten is echter onzeker, niet verrassend aangezien de mechanismen die verantwoordelijk zijn voor het bereiken van de normale daling van pulmonale vasculaire weerstand bij de geboorte nog altijd slecht begrepen zijn.

Gedurende het foetale en neonatale leven, is de reactie op verschillende vasoactieve stimuli waarschijnlijk afhankelijk van de mate van structurele ontwikkeling van de pulmonale circulatie en, misschien meer specifiek, van de mate van structurele en functionele maturatie van specifieke receptoren. Daarbij variëren zowel het rijpingstempo alsook de kwetsbaarheid voor insulten, zoals hypoxie, voor verschillende vasoactieve mechanismen. In de afgelopen jaren richtten talrijke studies zich op de veranderingen die optreden gedurende de foetale/neonatale ontwikkeling in verscheidene zoogdiersoorten betreffende de pulmonale vasculaire reactiviteit door foetale, neonatale en volwassen vaten te vergelijken.

Bij de regulatie van de tonus van de pulmonale circulatie is een groot aantal factoren betrokken die hun invloed uitoefenen via een breed scala aan signaleringsroutes en het is niet mogelijke deze allemaal in één onderzoek te overzien. Het belangrijkste doel van deze Thesis is daarom het verschaffen van inzicht in twee van deze zogenoemde pathways (de $\mathrm{NO} / \mathrm{cGMP} / \mathrm{sGC}$ en de isoprostanen pathway) en het analyseren van de veranderingen die deze pathways ondergaan tijdens de ontwikkeling gedurende de eerste dagen post partum in pulmonale en systemische vaten. Deze veranderingen werden bestudeerd in bloedvaten van pasgeboren en 2 weken oude biggetjes. 


\section{Curriculum vitae}

The author of this thesis was born in Tenerife, Spain on July $10^{\text {th }}$, 1972. After finishing her basic education in 1991, she started her medicine study at the "Universidad de La Laguna", Tenerife -Spain-. The fifth year of study was spent at the "Universite de Rennes" -France-, as part of the Erasmus student exchange program. She prepared her exam for the "MIR: Médico Interno Residente" in Oviedo -Spain-, during nine months in 1996. After that, she did her specialization in Paediatrics at "Hospital Sant Joan de Déu, Barcelona" -Spain-, from 1997 to 2001. At the end of this period, she obtained a one-year grant for research related to quality of life of children with cancer. Since 2002 she has been working as Neonatologist at the "Complejo Universitario Hospitalario Insular Materno-Infantil", in Las Palmas de Gran Canaria -Spain-. She performed a research fellowship at the University of Maastricht-The Nederland- at the Research Institute Growth and Development (GROW) during 2003. The extensive amount of experimental work during that period laid the basis for the present Thesis. Since her research fellowship, she continued her collaboration with Dr. Villamor research team at Maastricht University in basic and clinical research projects.

\section{List of publications}

\section{Included in this Thesis:}

Gonzalez-Luis G, Perez-Vizcaino F, Blanco CE, Villamor E. Age-related changes in isoprostane-mediated relaxation of piglet blood vessels. Front Biosci (Elite Ed). 2010; 2:36979.

Belik J, González-Luis GE, Perez-Vizcaino F, Villamor E. Isoprostanes in fetal and neonatal health and disease. Free Radic Biol Med. 2010; 48:177-88.

González-Luis G, Fletcher AJ, Moreno L, Pérez-Vizcaíno F, Blanco CE, Villamor E. Nitric oxide-mediated nonadrenergic noncholinergic relaxation of piglet pulmonary arteries decreases with postnatal age. J Physiol Pharmacol. 2007;58:45-56.

González-Luis G, Cogolludo A, Moreno L, Lodi F, Tamargo J, Pérez-Vizcaíno F, Villamor E. Relaxant effects of the soluble guanylate cyclase activator and NO sensitizer YC-1 in piglet pulmonary arteries. Biol Neonate. 2006; 90:66-72.

González-Luis G, Pérez-Vizcaíno F, García-Muñoz F, de Mey JG, Blanco CE, Villamor E. Agerelated differences in vasoconstrictor responses to isoprostanes in piglet pulmonary and mesenteric vascular smooth muscle. Pediatr Res. 2005; 57:845-52. 
Moreno L, Gonzalez-Luis G, Cogolludo A, Lodi F, Lopez-Farre A, Tamargo J, Villamor E, Perez-Vizcaino F. Soluble guanylyl cyclase during postnatal porcine pulmonary maturation. Am J Physiol Lung Cell Mol Physiol. 2005; 288:L125-30.

\section{Not included in this Thesis:}

Moonen RM, Reyes I, Cavallaro G, González-Luis G, Bakker JA, Villamor E. The T1405N carbamoyl phosphate synthetase polymorphism does not affect plasma arginine concentrations in preterm infants. PLoS One. 2010 May 25;5(5):e10792.

Guzmán Cabañas JM, Párraga Quiles MJ, del Prado N, Ruíz MD, García Del Río M, Benito Zaballo F, Fernández C, Figueras Aloy J; Red Neonatal Española SEN 1500.[Usefulness of Clinical Risk Index for Babies based on birth weight in predicting hospital death and severe intraventicular hemorrhage in the SEN 1500 Spanish neonatal network]. An Pediatr (Barc). 2009; 71:117-27. Spanish.

Trujillo C, González-Luis G, Avila-Suárez R, Santana-Reyes C,

González-González R, García-Muñoz F. [Vein of Galen arteriovenous malformations and neonatal convulsions]. Rev Neurol. 2005; 40:664-7. Spanish.

González-Luis G, Jordán García I, Rodríguez-Miguélez J, Botet Mussons F, Figueras Aloy J. [Neonatal morbidity and mortality in very low birth weight infants according to exposure to chorioamnionitis]. An Esp Pediatr. 2002; 56:551-5. Spanish.

Gonzalez-Luis G, Pons M, Cambra FJ, Martin JM, Palomeque A. Use of the Pediatric Risk of Mortality Score as predictor of death and serious neurologic damage in children after submersion. Pediatr Emerg Care. 2001;17:405-9.

Carbonell Estrany X, Figueras Aloy J, Pérez Fernández JM, Fernández López A, González Luis G, Salvia Roiges MD. [Usefulness of erythropoietin in the treatment of anemia of prematurity. Influence of birth weight]. An Esp Pediatr. 1999; 51: 281-6. Spanish.

Jorán García I, González Luis G, May Llanas E, Bosch JC, Cambra Lasaosa JF, Vicente Vila A. [Congenital neonatal varicella with systemic involvement]. An Esp Pediatr. 1999; 51:1979.

Jordán García I, Quintillà Martínez JM, Alcover Bloch E, González Luis G, RodríguezMiguélez JM, Figueras Aloy J. [Morbidity of the newborn infant born to a diabetic mother in relation to macrosomia]. An Esp Pediatr. 1999; 50:275-8. Spanish. 


\section{Acknowledgments}

- To the memory of Andy Fletcher, talented investigator and great human being.

-To Eduardo Villamor, without whom this Thesis would never have seen the light. His enthusiasm and persistence serve as an inspiration for me and others.

-To Prof. Blanco and Prof. De Mey and the rest of the laboratory team. They made me feel one of them during my unforgettable period at their place.

-To Prof. Pérez Vizcaíno and his research group in Madrid. They trusted me to be included in their projects.

-To my colleagues of the Department of Neonatology of "Hospital Materno-Infantil de Canarias", because they supported me from distance.

-To my parents and brothers, who are always unconditionally present, whatever I am doing and wherever I am.

-To Remko and Niko for their enormous patience. 
